Universidade de São Paulo

Instituto de Física

\title{
Dissociação da molécula de água em superfícies de silício: um estudo teórico
}

Regina Lélis de Sousa

Orientadora: Prof. Dra. Marília Junqueira Caldas

Tese apresentada ao Instituto
de Física para a obtenção do
título de Doutor em Ciências

Comissão Examinadora:

Profa. Dra. Marília Junqueira Caldas (IF-USP)

Prof. Dr. Antônio José Roque da Silva (IF-USP)

Prof. Dr. Luiz Guimarães Ferreira (IF-USP)

Prof. Dr. Osvaldo Novaes de Oliveira Junior (IFSC-USP)

Prof. Dr. Helio Chacham (UFMG)

São Paulo 

"O que conhecemos faz parte da totalidade do que é, da qual ignoramos a maior parte".

\section{Michel Paty}





\section{Agradecimentos}

Gostaria de agradecer a todos que contribuíram de maneira relevante para a minha formação e, particularmente, com o trabalho aqui apresentado. Em especial À Professora Marília Caldas pela atenção, paciência, dedicação e inestimável contribuição para minha formação acadêmica. Foi maravilhoso conviver com uma excelente profissional, cuja competência, a seriedade e a paixão pela Física são características notáveis. Agradeço ainda por respeitar minhas iniciativas e por apresentar-me, de maneira única, o maravilhoso mundo da Física. Certamente foram anos divertidos.

Aos amigos do grupo Nanomol, pelos ótimos momentos que passamos juntos. Faço minhas as palavras de Henry Ford: "Reunir-se é um começo. Manter-se unido é um progresso. Trabalhar unido é um sucesso".

Aos bons amigos de São Paulo, que eu nunca esperei encontrar: Marcelo Santos, Marcelo Garcia, Cedric Rocha Leão, Rodrigo Amorim, Joelson Cott Garcia, Járlesson Amazonas, Leonardo Mateus Marion Jorge, Sandra Regina Rodrigues Ribeiro, Rodrigo Ramos, Marcos Brown e Eliane Braga. Por causa de vocês, São Paulo é um bom lugar para se estar.

Aos funcionários Sandra Regina Rodrigues Ribeiro e Francisco Ribacionka que tornaram a minha vida acadêmica muito mais fácil. Minha admiração pelo exemplo de competência e seriedade.

Ao Arrigo Calzolari e Andrea Ferretti pela contribuição para a minha formação acadêmica.

À todas as pessoas da minha família que souberam compreender que minha ausência 
teve por objetivo a realização de um sonho. Aos que sempre tiveram ao meu lado sem nunca questionar minhas razões. Em especial minha Mãe, minhas irmãs e ao Isi que soube bravamente suportar os meus momentos de fúria.

Ao LCCA-USP (Laboratório de Computação Científica Avançada) e ao CENPADSP (Centro Nacional de Processamento de Alto Desempenho em São Paulo) pelo tempo computacional e auxílio técnico.

À CAPES pela concessão da minha bolsa de estudo. Em última instância, ao bravo povo brasileiro, que financiou a realização desta pesquisa.

Ao CNPQ, FAPESP e aos Institutos do Milênio de Nanotecnologia (IN) e de Materiais Poliméricos (INEO), pelo apoio financeiro para estágios e participação em eventos científicos.

Ao Departamento de Física dos Materiais e Mecânica (DFMT) do Instituto de Física da Universidade de São Paulo pelo suporte técnico em nossa jornada diária. 


\section{Resumo}

O silício é o material-base para a indústria de microeletrônica e tem acompanhado a evolução para a nanoeletrônica. Em várias aplicações é importante o processo de química molhada, ou seja, na presença de moléculas de água na superfície do semicondutor. Entretanto, os mecanismos e as estruturas resultantes da reação da molécula de $\mathrm{H}_{2} \mathrm{O}$ sobre $\mathrm{Si}$ ainda são objetos de debate, tanto do ponto de vista teórico quanto experimental, e são muito importantes pois determinam os estágios iniciais de oxidação. Neste trabalho, apresentamos um estudo detalhado da dissociação de uma molécula de água sobre as superfícies $\operatorname{Si}(100)(2 \times 1)$ (superfície limpa) e $\operatorname{Si}(100)(2 x 1): H$ (superfície monohidrogenada), cobrindo desde a evolução da reação em si, até a caracterização da superfície oxidada. Utilizamos para tal metodologia baseada na Teoria do Funcional da Densidade, para a reação a CI-NEB (Climbing Image - Nudging Elastic Band), e o modelo de Tersoff-Haman para a caracterização superficial.

Nossos resultados mostram que a dissociação da molécula de água sobre a superfície limpa é independente do "sítio de ataque"; o produto $\mathrm{H}-\mathrm{Si}-\mathrm{Si}-\mathrm{OH}$ desta reação é estável, e a posterior decomposição ocorre por energia térmica. Neste caso, a transferência do átomo de oxigênio para o dímero de Si para a superfície é energética e cineticamente favorável em relação à oxidação de sítios subsuperficiais.

Os processos de passivação são eficientes, uma vez que a superfície monohidrogenada é mais resistente ao ataque do oxigênio. Nossos resultados indicam que alguns processos oxidativos têm dependência com o "sítio de ataque", enquanto em outros a interação ocorre igualmente em regiões de vale ou sobre a fileira de dímeros. Análise 
de barreiras de ativação sugerem que a rota de ataque sugerida por trabalhos experimentais anteriores não deve ser eficiente para inserção de oxigênio em estágios iniciais de oxidação. Propomos que a oxidação do dímero e de sítio de subsuperfície, concomitante com a liberação de uma molécula de $\mathrm{H}_{2}$, são cinética e energeticamente viáveis. Finalmente, apresentamos uma análise das modificações do perfil de corrente de tunelamento (STM - Scanning Tunneling Microscopy) provocadas por estes defeitos. Deste modo, esperamos ter contribuído para o entendimento dos processos de oxidação, e ao mesmo tempo motivar investigações experimentais. 


\section{Abstract}

Silicon is the basic material for microelectronics industry, and for the recent developments in nanoelectronics. In many applications, wet chemistry processing is important that is, with the presence of water molecules on the semiconductor surface. However, the reaction mechanisms for the $\mathrm{H}_{2} \mathrm{O}$ molecule with $\mathrm{Si}$, and the resulting structures, are still object of debate, from both theoretical and experimental points of view. Here, we present a detailed study of the dissociation of one water molecule on the surfaces $\operatorname{Si}(100)(2 \times 1)$ (clean surface) and $\operatorname{Si}(100)(2 \times 1): H$ (monohydride), covering from the reaction evolution, to the characterization of the final surface. To do that, we use methodologies based on Density Functional Theory; the reaction pathways for decomposition of the water molecule on the surface have been carried out with CI-NEB (Climbing Image - Nudging Elastic Band), and we used the Tersoff-Hamann model for surface characterization. Our results show that the water molecule dissociation on the clean surface is independent of the "site of attack". The product of this reaction, $\mathrm{H}-\mathrm{Si}-\mathrm{Si}-\mathrm{OH}$ unit, is stable and its subsequent decomposition occurs through thermal energy. We also find that the insertion of the

oxygen atom a Si surface dimer is energetically and kinetically favorable compared to absorption in the back-bond (subsurface) sites.

Although hydrogenation cannot prevent oxidation of the surface, we can say that the passivation processes are efficient, since the monohydride surface is more resistant to attack by oxygen. In contrast with the clean surface, for this case, some oxidative process have dependency on the site of attack, while others are indifferent whether the interaction occurs in the valley or over the dimer rows. Our results indi- 
cate that the oxidation route suggested by earlier experimental works is not favored. In this way, we propose two new oxidation routes, one related to chemisorption of the oxygen atom on the $\mathrm{Si}-\mathrm{Si}$ dimer bond, and another related to the absorption on the back-bond, with simultaneous ejection of one $\mathrm{H}_{2}$ molecule. Analysis of energy barriers showed that these two new possibilities are both kinetically and energetically viable. We finally present analyses of the profiles of tunneling current, predicted by STM (Scanning Tunneling Microscopy) for oxygen incorporation in all studied structures. We hope to have contribuited to the understanding of the oxidation processes, and at the same time to motivate new experimental investigations. 


\section{Conteúdo}

Resumo $\quad$ iii

Abstract $\quad$ v

1 Introdução 1

2 Métodos Teóricos 6

2.1 Aproximação de Born-Oppenheimer . . . . . . . . . . . . . . . 7

2.2 Teoria do Funcional da Densidade - DFT . . . . . . . . . . . . . 9

2.3 Métodos DFT . . . . . . . . . . . . . . . . . . . . 14

2.3.1 Base de Ondas Planas ................ 15

2.3.2 Pseudopotenciais . . . . . . . . . . . . . . 16

2.4 Método para Cálculos de Caminhos de Reação . . . . . . . . . . . . 18

2.4.1 Método NEB ..................... 19

2.4.2 Método CI-NEB .................. 23

2.5 Microscopia de Tunelamento: Aproximação de Tersoff-Hamman . . . 25

3 Propriedades Estruturais das Superfícies Si(100) Limpa e Hidroge$\begin{array}{ll}\text { nada } & 28\end{array}$

3.1 Revisão de Dados Experimentais e Teóricos . . . . . . . . . . . . . . . 29

3.2 Nossos Resultados . . . . . . . . . . . . . . . . 38

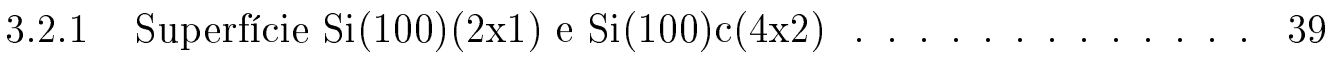

3.2.2 Superfície $\operatorname{Si}(100)(2 \mathrm{x} 1): \mathrm{H}$. . . . . . . . . . . . . . 42 
3.2.3 Superfície $\operatorname{Si}(100)(3 \mathrm{x} 1): \mathrm{H}$ e $\mathrm{Si}(100)(1 \mathrm{x} 1): 2 \mathrm{H} \quad \ldots . . . . . . .444$

3.3 Conclusões Parciais . . . . . . . . . . . . . . . . . 45

4 Reação entre a molécula de $\mathrm{H}_{2} \mathrm{O}$ isolada e a superfície limpa $\begin{array}{ll}\mathrm{H}_{2} \mathrm{O} / \mathrm{Si}(100)(2 \times 1) & 47\end{array}$

4.1 Revisão de Dados Experimentais e Teóricos . . . . . . . . . . . . . . 48

4.2 Nossos Resultados . . . . . . . . . . . . . . . . . . 54

4.2.1 Dissociação da Molécula de Água em $\operatorname{Si}(100)(2 \times 1)$. . . . . . . 55

4.2.2 Decomposição das unidades $\mathrm{H}-\mathrm{Si}-\mathrm{Si}-\mathrm{OH}$. . . . . . . . . . . . 62

4.3 Conclusões Parciais . . . . . . . . . . . . . . . . . . . 73

5 Reação entre a molécula de $\mathrm{H}_{2} \mathrm{O}$ e a Superfície Monohidrogenada - $\mathrm{H}_{2} \mathrm{O} / \mathrm{Si}(100)(2 \times 1): \mathrm{H} \quad 75$

5.1 Revisão de Dados Experimentais e Teóricos . . . . . . . . . . . . . . 76

5.2 Nossos Resultados . . . . . . . . . . . . . . . . . . . . 81

5.2.1 Deposição de moléculas de água sobre Si(100)(2x1):H por Dinâmica Molecular Clássica . . . . . . . . . . . . . . . . . 82

5.2.2 Configurações iniciais e finais: Cálculos de Primeiros Princípios 83

5.2.3 Caminhos de reação: cálculos quânticos . . . . . . . . . . . . 87

5.3 Conclusões Parciais . . . . . . . . . . . . . . . . . . 110

6 Imagens Teóricas de STM: Identificação Direta dos Sítios de Oxidação nas Superfícies Si(100)(2x1) Limpas ou Hidrogenadas 113

6.1 Revisão de Dados Experimentais e Teóricos . . . . . . . . . . . . . . 114

6.2 Nossos Resultados . . . . . . . . . . . . . . . . . . . . 115

6.2.1 Superfícies $\operatorname{Si}(100) c(4 \times 2), \operatorname{Si}(100)(2 \times 1)$ e $\operatorname{Si}(100)(2 \times 1): H$. . . 116

6.2.2 $\mathrm{H}_{2} \mathrm{O} / \mathrm{Si}(100) \mathrm{c}(4 \mathrm{x} 2)$ e $\mathrm{H}_{2} \mathrm{O} / \mathrm{Si}(100)(2 \mathrm{x} 1)$. . . . . . . . . . 120

6.2.3 $\mathrm{H}_{2} \mathrm{O} / \mathrm{Si}(100)(2 \mathrm{x} 1): \mathrm{H}$. . . . . . . . . . . . . . . . 131

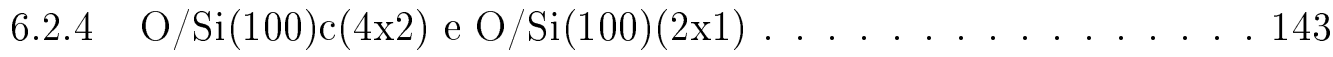

6.3 Conclusões Parciais . . . . . . . . . . . . . . . . . . 155 
$\begin{array}{llr}7 & \text { Conclusões } & 157\end{array}$

A Taxas de reação e Lei de Arrhenius $\quad 161$

Referências Bibliográficas $\quad 163$ 


\section{Capítulo 1}

\section{Introdução}

Nos últimos anos observamos avanços tanto tecnológicos quanto científicos para o desenvolvimento de nanodispositivos. As pesquisas são guiadas por dois objetivos: a transição da microeletrônica para a nanoeletrônica e o desenvolvimento de novas aplicações, se possível utilizando os sólidos conhecimentos já adquiridos com a tecnologia baseada no silício [1,2]. Como colocado por Aswal e colaboradores [3], o desafio vindo dos processos de miniaturização é a produção de dispositivos cada vez menores, mais rápidos e sem acréscimo de preços, impulsionando a busca por uma nova classe de materiais que atenda a tais requisitos $[2,4]$. Uma estratégia muito interessante tem sido a construção de materiais híbridos, através do ancoramento de moléculas orgânicas em substratos semicondutores limpos, hidrogenados ou oxidados [2,5-20], constituindo o advento da eletrônica molecular $[1,3,4,21]$. O caráter direcional e localizado da absorção de orgânicos em semicondutores aliada à tecnologia bem consolidada baseada em superfícies de semicondutoras, torna este substrato uma boa opção em relação às superfícies metálicas [22], foi já demonstrada a possibilidade de se produzir SAMs (SAM - self-assembled monolayers) via processos de microfabricação [23-25]. Assim, a deposição de SAMs de orgânicos sobre superfícies de Si une a riqueza da química orgânica com a bem estabelecida tecnologia de dispositivos convencionais [3,21,26]. A flexibilidade e variedade de compostos orgânicos permite criar novos dispositivos híbridos com características 
óticas, elétricas e mecânicas que apresentem diferentes atividades químicas e biológicas. Assim, a funcionalização de superfícies de Si por moléculas orgânicas tem se tornado uma área de pesquisa muito ativa, e encontramos trabalhos recentes que relatam a produção de dispositivos eletrônicos [27-37], biosensores [38-43], entre outras aplicações.

Atenção especial tem sido dada às SAMs obtidas a partir da formação de ligações Si-C ou Si-O em superfícies de Si passivadas [6,9-11,13,14,19,20,23,27-29,36,37,39], mais estáveis e homogêneas que as limpas, sem a presença da camada isolante de óxido de Si, inclusive por métodos de química molhada [3,21,26]. Estas interfaces híbridas têm como característica especial a comunicação eletrônica entre o substrato semicondutor e a molécula orgânica.

Atualmente, o grande desafio é a obtenção de monocamadas orgânicas ordenadas, puras, termicamente estáveis, com a funcionalidade desejada, que apresentem alto grau de cobertura das superfícies de Si. A solução de tais problemas está vinculada ao melhor entendimento dos processos termodinâmicos e cinéticos envolvidos na produção destas interfaces [15], porém é preciso considerar a formação de defeitos, como por exemplo, aqueles produzidos pela reação com oxigênio e água.

De fato, um ponto importante para funcionalização das superfícies de Si com orgânicos são os processos que culminam com a inserção de oxigênio na rede cristalina da superfície. Estudos apontam que a presença de agentes oxidantes tem como consequência o desordenamento das SAMs, e devemos ainda considerar que os processos de oxidação também afetam as superfícies originais de Si, mesmo que passivada.

As reações de oxidação são por sua vez necessárias no crescimento das interfaces $\mathrm{Si} / \mathrm{SiO}_{2}$. Estas estruturas híbridas semicondutor/óxido semicondutor têm função crucial em dispositivos eletrônicos onde haja necessidade de uma interface com algumas camadas atômicas de espessura, porém que possa impedir passagem de corrente elétrica. O crescimento do filme de óxido pode ser feito através do ataque oxidativo por moléculas de $\mathrm{O}_{2}$ ou $\mathrm{H}_{2} \mathrm{O}$. Resultados experimentais apontam que, nestes casos, a reação com $\mathrm{O}_{2}$ pode provocar a dessorção (etching) de átomos de Si. Assim, a 
reação com o $\mathrm{H}_{2} \mathrm{O}$ tem sido preferida e dados mostram que o crescimento de filme é mais rápido que aquele obtido na presença de oxigênio molecular. Este processo tem sido exaustivamente repetido nas últimas décadas mas, os anos de estudos ainda não foram suficientes para se ter entendimento atomístico dos filmes obtidos. Também não há modelos estabelecidos sobre as características cinéticas da formação do filme de óxido. Há controvérsias relacionadas inclusive aos sítios de oxidação.

Após um curto período de exposição (aproximadamente 10 minutos) das superfícies passivadas a ambientes contendo água ou oxigênio, estas sofrem degradação estrutural devido ao ataque oxidativo $[44,45]$. Neste momento a principal lacuna está no entendimento dos mecanismos pelos quais estes eventos oxidativos ocorrem e quais os produtos resultantes desta interação. O número de trabalhos teóricos e experimentais dedicados à elucidação destes processos, sejam estes desencadeados por água ou oxigênio, é ainda insuficiente; e os resultados experimentais mais frequentes são obtidos através de técnicas indiretas, como espectro vibracional, por exemplo. Desta forma, seja para a superfície limpa ou para a passivada, estamos distantes de modelos microscópicos do ataque oxidativo. Porém, como visto acima, o entendimento e controle de tais reações são fundamentais não somente do ponto de vista de física básica, mas também para aplicações tecnológicas em eletrônica molecular. Assim sendo, a interação teoria $\leftrightarrow$ experimento torna-se essencial para investigar com maior precisão tais eventos. Seria desejável maior frequência de resultados experimentais obtidos de forma direta, por exemplo, através de imagens de microscopia de tunelamento (STM - Scanning Tunneling Microscopy), técnica adequada para estudo de interação entre o $\mathrm{O}$ e a superfície em baixos regimes de fluxo.

Antes do advento da nanoeletrônica os processos de oxidação eram normalmente investigados por físicos, mas agora notamos o surgimento de um maior número de trabalhos na área da química, marcando a transição entre processos de crescimento de semicondutores para aqueles relativos a compostos orgânicos (resultados relevantes deste esforço científico que datam da década de 80 até o presente serão 
comentados durante a apresentação dos nossos resultados).

Ainda assim, o campo é extremamente amplo e fértil, e depende do intercâmbio de informações teórica-experimental, sobre superfícies em diversos estágios de oxidação ou funcionalização. O objetivo deste trabalho em particular é o estudo teórico dos caminhos de reação para a dissociação da molécula de água quando interagindo com as superfícies de $\operatorname{Si}(100)(2 \times 1)$ e $\operatorname{Si}(100)(2 \times 1): H$. Para tal, utilizamos métodos $a b$ initio baseados na Teoria do Funcional da Densidade (DFT - Density Functional Theory). Nosso próposito é obter o caminho de menor energia (MEP - Minimum Energy Path) para as reações de oxidação, e empregamos para tal o método denominado CI-NEB (Climbing Image - Nudging Elastic Band). Este método nos permite acessar o MEP e a geometria do estado de transição, refletindo o estado da arte em estudos ab initio de caminhos de reação. A superfície é representada pelo modelo de fatias, com o qual podemos descrever adequadamente a periodicidade bidimensional destes sistemas e erradicar os efeitos artificiais produzidos por bordas quando utilizando aglomerados moleculares. Esperamos que este modelo nos possibilite descrição detalhada e confiável do processo de oxidação. Simulamos ainda o perfil de corrente de tunelamento associado às regiões onde há a formação de ligações Si-O, o que esperamos forneça subsídios para a interpretação de resultados experimentais.

A metodologia empregada neste trabalho é descrita no capítulo 2. No capítulo 3 apresentamos, resumidamente, resultados para as propriedades estruturais das superfícies $\mathrm{Si}(100)$ e $\mathrm{Si}(100): \mathrm{H}$. Os resultados são comparados com dados experimentais e teóricos. A inclusão deste capítulo tem como objetivo facilitar a posterior discussão sobre a oxidação. Os principais resultados relacionados à reação entre a molécula de água e a superfície $\operatorname{Si}(100)(2 x 1)$ bem como $\operatorname{Si}(100)(2 \times 1): H$ são discutidos nos capítulos 4 e 5 , respectivamente. No capítulo 6 , discutimos as alterações de perfil de corrente de tunelamento em consequência da inserção de oxigênio, proveniente de fenômenos de oxidação molhada, no perfil de sinal das superfícies limpa e monohidrogenada. Apresentamos detalhadamente as características que tornam possível o reconhecimento dos sítios de oxidação, empregando esta técnica experi- 
mental. Nosssas principais conclusões são resumidas no capítulo 7 . 


\section{Capítulo 2}

\section{Métodos Teóricos}

Neste capítulo apresentamos brevemente os métodos teóricos, no formalismo da Teoria do Funcional da Densidade (DFT - Density Functional Theory), que empregamos para estudos das propriedades estruturais, eletrônicas e caminhos de reação para a dissociação da molécula de água sobre as superfícies de silício.

Partimos sempre da resolução da equação de Schrödinger independente do tempo

$$
\widehat{H}^{T} \Psi\left(\mathbf{R}_{\mu}, \mathbf{r}_{i}\right)=E \Psi\left(\mathbf{R}_{\mu}, \mathbf{r}_{i}\right)
$$

onde $\widehat{H}^{T}$ é o operador hamiltoniano total não relativístico, $\Psi\left(\mathbf{R}_{\mu}, \mathbf{r}_{i}\right)$ é a função de estado do sistema com autovalor de energia $\mathrm{E}, \mathbf{R}=\left\{\mathbf{R}_{\mu}, \mu=1,2, \cdots, \mathbf{R}_{M}\right\}$ e $\mathbf{r}=\left\{\mathbf{r}_{i}\right.$, $\left.i=1,2, \cdots, \mathbf{r}_{n}\right\}$ são, respectivamente, um conjunto de $\mathrm{M}$ coordenadas nucleares e $\mathrm{n}$ coordenadas eletrônicas. Aqui, o operador hamiltoniano, $\widehat{H}^{T}$, é escrito como

$$
\begin{array}{r}
\widehat{H}^{T}=-\sum_{\mu=1}^{N} \frac{\hbar^{2}}{2 M_{\mu}} \nabla_{\mu}^{2}+\frac{e^{2}}{2} \sum_{\mu \neq \nu} \frac{Z_{\mu} Z \nu}{\left|\mathbf{R}_{\mu}-\mathbf{R}_{\nu}\right|}-e^{2} \sum_{\mu=1}^{M} \sum_{i=1}^{n} \frac{Z_{\mu}}{\left|\mathbf{R}_{\mu}-\mathbf{r}_{i}\right|}-\sum_{\mu=1}^{n} \frac{\hbar^{2}}{2 m} \nabla_{i}^{2}+ \\
+\frac{e^{2}}{2} \sum_{i \neq j} \frac{1}{\left|\mathbf{r}_{i}-\mathbf{r}_{j}\right|}=\widehat{T}_{I}+\widehat{V}_{I I}+\widehat{V}_{e I}+\widehat{T}_{e}+\widehat{V}_{e e} .
\end{array}
$$

O operador $\widehat{T}_{I}$ representa a energia cinética nuclear, $\widehat{V}_{I I}$ a energia potencial coulombiana de repulsão entre os núcleos, $\widehat{V}_{e I}$ a energia coulombiana de atração entre elétron e núcleo, $\widehat{T}_{e}$ a energia cinética eletrônica e $\widehat{V}_{e e}$ energia potencial coulombiana de repulsão entre os elétrons. A carga nuclear é representada pelo símbolo $Z_{\mu}$. A 
resolução da equação 2.1, uma equação de muitos corpos e com $3(\mathrm{M}+\mathrm{n})$ graus de liberdade acoplados, é quase impossível de ser realizada sem o uso de aproximações. Invariavelmente, um dos primeiros passos em cálculos quânticos de propriedades de moléculas e sólidos é o uso da aproximação e separação de Born-Oppenheimer [46].

\subsection{Aproximação de Born-Oppenheimer}

Born e Oppenheimer [46] propuseram o desacoplamento completo entre os graus de liberdade dos núcleos e elétrons, de forma que, devido à grande diferença entre as massas dos núcleos e dos elétrons, os últimos seguem o movimento nuclear, enquanto os núcleos "enxergam" um potencial efetivo que é gerado pelos elétrons. Assim, podemos reescrever a equação 2.1 como

$$
\left(\widehat{T}_{I}+\widehat{V}_{I I}+\widehat{V}_{e I}+\widehat{T}_{e}+\widehat{V}_{e e}\right) \Phi\left(\mathbf{R}_{\mu}\right) \psi_{\mathbf{R}}^{(l)}=E \Phi\left(\mathbf{R}_{\mu}\right) \psi_{\mathbf{R}}^{(l)}
$$

sendo que

$$
\underbrace{\left(\widehat{T}_{e}+\widehat{V}_{e e}+\widehat{V}_{e I}\right)}_{\widehat{H}_{e l e}} \psi_{\mathbf{R}}^{(l)}=E_{\mathbf{R}}^{(l)} \psi_{\mathbf{R}}^{(l)}
$$

O operador $\widehat{H}_{\text {ele }}$ é denominado de hamiltoniano eletrônico e $\left[\widehat{H}_{\text {ele }}, \mathbf{R}\right]=0$. Na equação 2.4, o índice (l) numera os estados eletrônicos, e a etiqueta $\mathbf{R}$ lembra-nos que a função de onda bem como o autovalor de energia dependem parametricamente das coordenadas eletrônicas. Considerando que o operador $\widehat{T}_{e}$ não tem efeito sobre as coordenadas nucleares, a equação 2.3 torna-se

$$
\left(\widehat{T}_{I}+\widehat{V}_{I I}+E_{\mathbf{R}}^{(l)}\right) \Phi\left(\mathbf{R}_{\mu}\right) \psi_{\mathbf{R}}^{(l)}=E \Phi\left(\mathbf{R}_{\mu}\right) \psi_{\mathbf{R}}^{(l)}
$$

Como passo sucessivo, admitimos que

$$
\begin{array}{r}
\widehat{T}_{I}\left(\Phi\left(\mathbf{R}_{\mu}\right) \psi_{\mathbf{R}}^{(l)}\right)=\psi_{\mathbf{R}}^{(l)}\left(\sum_{\mu} \frac{\hbar^{2}}{2 M_{\mu}} \nabla_{\mu}^{2} \Phi\left(\mathbf{R}_{\mu}\right)\right)+2\left(\sum_{\mu} \frac{\hbar^{2}}{2 M_{\mu}}\left(\nabla_{\mu} \Phi\left(\mathbf{R}_{\mu}\right)\right)\left(\nabla_{\mu} \psi_{\mathbf{R}}^{(l)}\right)\right)+ \\
+\Phi\left(\mathbf{R}_{\mu}\right)\left(\sum_{\mu} \frac{\hbar^{2}}{2 M_{\mu}} \nabla_{\mu}^{2} \psi_{\mathbf{R}}^{(l)}\right) \simeq \psi_{\mathbf{R}}^{(l)}\left(\widehat{T}_{I} \Phi\left(\mathbf{R}_{\mu}\right)\right)
\end{array}
$$


Em que desprezarmos o segundo e o terceiro termos da operação. Desprezamos o terceiro termo da equação 2.6, isto é, não são feitas correções na função de onda eletrônica devido ao movimento dos núcleos. De fato, usualmente o terceiro termo da equação 2.6 introduziria correções muito pequenas [47]. Ao fazermos o segundo termo nulo, admitimos que os movimento dos núcleos não causam transições eletrônicas.

Após a aproximação de Born-Oppenheimer, obtemos que

$$
\left(\widehat{T}_{I}+\widehat{V}_{I I}+E_{\mathbf{R}}^{(l)}\right) \Phi\left(\mathbf{R}_{\mu}\right)=E \Phi\left(\mathbf{R}_{\mu}\right)
$$

onde a dependência eletrônica está embutida em $\mathrm{E}_{\mathbf{R}}^{(l)}$. Os termos $\widehat{V}_{I I}+E_{\mathbf{R}}^{(l)}$ definem o potencial efetivo de interação entre os núcleos.

Para cada configuração nuclear fixa, a resolução da equação 2.4 fornece um autovalor de energia e assim, para sistemas poliatômicos, obtemos a hipersuperfície de energia potencial (PES - potential energy surface). Mesmo com a aproximação de Born-Oppenheimer, resolver esta equação ainda é lidar com um problema de muitos corpos interagentes com 3n graus de liberdade acoplados.

A configuração nuclear de mínima energia, para qual a força entre os núcleos é nula, é obtida através do teorema de Hellmann-Feynman. Hellmann [48] e Feynman [49] mostraram que, para um hamiltoniano $\widehat{H}(\lambda)$, como na equação 2.4 , onde $\lambda$ são as coordenadas nucleares $\mathbf{R}_{\mu}$, temos a dependência

$$
\frac{\partial E(\lambda)}{\partial \lambda}=\left\langle\Psi(\lambda)\left|\frac{\partial \widehat{H}(\lambda)}{\partial \lambda}\right| \Psi(\lambda)\right\rangle
$$

com $\mathrm{E}(\lambda)$ representando o autovalor associado ao autoestado $\Psi(\lambda)$, ambos dependendo parametricamente de $\lambda$. Assim, a energia é obtida a partir do valor médio da hamiltoniana e sua derivada é obtida através do valor médio da derivada da hamiltoniana. Especificamente para o hamiltoniano eletrônico, a força atuando sobre o íon $\mu$ é dada por

$$
F=\nabla_{R_{\mu}} E=\left\langle\Psi(\lambda)\left|\frac{\partial \widehat{H}(\lambda)}{\partial \mathbf{R}_{\mu}}\right| \Psi(\lambda)\right\rangle .
$$


Este teorema é amplamente empregado para cálculos de otimização estrutural e é o método que utilizamos para obtenção das estruturas minimizadas.

\subsection{Teoria do Funcional da Densidade - DFT}

Atualmente duas aproximações têm sido amplamente utilizadas para cálculos de primeiros princípios de materiais: aproximações para as quais a função de onda (aproximação de Hartree-Fock) ou a densidade eletrônica são as variáveis fundamentais. Aqui, utilizamos a Teoria do Funcional da Densidade (DFT - Density Functional Theory). Esta teoria tem se tornado popular em diferentes comunidades devido à maior simplicidade computacional quando comparada a métodos como o de Hartree-Fock, produzindo resultados com a mesma precisão.

As origens da DFT remontam aos trabalhos de Thomas [50] e Fermi [51] (TF), que independemente propuseram que o estado fundamental de um sistema de $n$ elétrons (equação 2.4) descrito pela função de onda de 3n variáveis (desconsiderando o grau de liberdade de spin), $\psi$, pode ser obtido utilizando a densidade eletrônica, $n(\mathbf{r}) \equiv n(x, y, z)$, com somente 3 variáveis. Nesta aproximação a energia do estado fundamental de um sistema de muitos corpos, a menos de uma constante, fica dada por

$$
\begin{aligned}
E[n(\mathbf{r})]=\left\langle\psi\left|\widehat{T}_{e}+\widehat{V}_{e e}+\widehat{V}_{e I}\right| \psi\right\rangle & =\left\langle\psi\left|\widehat{T}_{e}+\widehat{V}_{e e}\right| \psi\right\rangle+\left\langle\psi\left|\widehat{V}_{e I}\right| \psi\right\rangle= \\
& =F[n(\mathbf{r})]+\int n(\mathbf{r}) V_{e I}(\mathbf{r}) d(\mathbf{r}) .
\end{aligned}
$$

O termo $F[n(\mathbf{r})]$ (equação 2.10) é denominado de funcional universal, introduz o efeito de muitos corpos, e é válido para qualquer sistema de $n$ elétrons; entretanto, sua forma funcional em termos da densidade não é conhecida. A demonstração matemática das idéias de $\mathrm{TF}[47,52]$ de que $n(\mathbf{r})$ poderia ser utilizada como variável básica foi realizada em 1964 através de dois teoremas formulados por Hohenberg e Kohn (HK) [53] e que constituem o que hoje denominamos DFT. Os teoremas mostram que, dado um potencial externo arbitrário, $\mathrm{V}(\mathbf{r})$, 
Teorema 1 - Para qualquer sistema de particulas interagentes, em um potencial externo $V(\boldsymbol{r})$, a densidade eletrônica do estado fundamental, $n_{0}(\boldsymbol{r})$, determina univocamente o potencial $V(\boldsymbol{r})$ a menos de uma constante aditiva.

Teorema 2 - A energia do estado fundamental $E\left[n_{0}(\boldsymbol{r})\right]$ é minima para a densidade $n(\boldsymbol{r})$ exata. Neste caso, $E\left[n_{0}(\boldsymbol{r})\right]<E_{v}[\tilde{n}(\boldsymbol{r})]$, para qualquer $\tilde{n}(\boldsymbol{r}) \neq n_{0}(\boldsymbol{r})$.

Os teoremas de HK asseguram que o conhecimento de $n_{0}(\mathbf{r})$ nos permite obter todas as propriedades do estado fundamental deste sistema.

\section{Equações de Kohn-Sham}

Aplicações práticas da DFT, como a que utilizamos neste trabalho, se tornaram factíveis com a reformulação do problema de muitos corpos realizada por Kohn e Sham (KS) [54] em 1965. A idéia em KS foi mapear o sistema de elétrons interagentes em um sistema não interagente, denominado auxiliar ou de referência, cuja densidade do estado fundamental, $n(\mathbf{r})$, é a mesma obtida para o sistema de muitos corpos. Com esta aproximação, a solução numérica exata do problema de $n$ elétrons não interagentes poderia ser obtida exatamente a partir de um determinante de Slater, construído com orbitais de um elétron. Neste caso, a densidade de estado fundamental do sistema auxiliar é dada por

$$
n(\mathbf{r})=\sum_{i=1}^{n}\left|\psi_{i}(\mathbf{r})\right|^{2}
$$

e $\psi_{i}(\mathbf{r})$ são os orbitais de um elétron de KS, solução da equação

$$
\widehat{H}_{K S} \psi_{i} \mathbf{r}=\epsilon_{i} \psi_{i} \mathbf{r} \Longrightarrow-\left(\frac{\hbar^{2}}{2 m} \nabla^{2}+V_{K S}(\mathbf{r})\right) \psi_{i} \mathbf{r}=\epsilon_{i} \psi_{i} \mathbf{r}
$$

onde $\epsilon_{i}$ são os autovalores de energia e $m$ é a massa do elétron. Os orbitais de KS formam um conjunto completo e ortonormal, $\left\langle\psi_{i} \mid \psi_{j}\right\rangle=\delta_{i j}$ e os teoremas de HK garantem que, para a densidade de estado fundamental, o potencial $\mathrm{V}_{K S}(\mathbf{r})$ é 
univocamente determinado. A equação 2.10, na formulação de KS, é reescrita como

$$
E_{K S}[n(\mathbf{r})]=E[n(\mathbf{r})]=\underbrace{T_{a}[n(\mathbf{r})]+\underbrace{E_{H}[n(\mathbf{r})]+E_{x c}[n(\mathbf{r})]}_{V_{e e}}}_{F[n(\mathbf{r})]}+\int n(\mathbf{r}) V_{e x t}(\mathbf{r}) d(\mathbf{r}) .
$$

O primeiro termo representa a energia cinética do sistema de elétron não interagentes de KS, funcional direto dos orbitais de um elétron e funcional implícito da densidade eletrônica:

$$
T_{a}[n(\mathbf{r})]=T_{a}\left[\psi_{i}[n]\right]=-\frac{\hbar^{2}}{2 m} \sum_{i=1}^{n} \int \psi_{i} \nabla^{2} \psi_{i} d(\mathbf{r}) .
$$

A energia de interação entre os elétrons foi dividida em duas partes distintas: $\mathrm{E}_{H} \mathrm{e}$ $\mathrm{E}_{x c} \cdot \mathrm{E}_{H}$ está relacionada à interação coulombiana clássica da densidade de cargas $n(\mathbf{r})$ e (denominada potencial de Hartree)

$$
E_{H}[n(\mathbf{r})]=\frac{e^{2}}{2} \int \frac{n(\mathbf{r}) n\left(\mathbf{r}^{\prime}\right)}{\left|\mathbf{r}-\mathbf{r}^{\prime}\right|} d \mathbf{r} d \mathbf{r}^{\prime}
$$

O teceiro termo, $\mathrm{E}_{x c}$, encerra toda a nossa ignorância acerca do problema de muitos corpos e contém as diferenças $\left(\mathrm{T}-\mathrm{T}_{a}\right)$ e $\left(\mathrm{V}_{e e}-\mathrm{V}_{H}\right)$. Isto é, a correlação cinética (ignorada na equação 2.14) e a contribuição da troca e da correlação eletrônica que deve ser adicionada ao potencial de Hartree para levar em conta o fato de que a presença de um elétron em $\mathbf{r}$ reduz a probabilidade de encontrarmos um segundo elétron na posição r' nas vizinhanças de r. A energia de troca, relacionada ao princípio de Pauli, poderia ser calculada exatamente, mas a correlação não. Se $\mathrm{E}_{x c}$ fosse conhecida, a solução das equações de $\mathrm{KS}$ nos forneceriam a energia e a densidade exata do estado fundamental. Por fim, $\mathrm{V}_{\text {ext }}(\mathbf{r})$ é resultado da soma de $\mathrm{V}_{I I} \mathrm{e} \mathrm{V}_{e I}$.

Até este ponto sabemos que o potencial de $\mathrm{KS}, \mathrm{V}_{K S}(\mathbf{r})$, é o potencial que assegura que a densidade de estado fundamental do sistema auxiliar coincide com a densidade de estado fundamental do sistema real. Assim, podemos determinar este pontencial através da minimização do funcional de $\mathrm{KS}\left(E_{K S}[n(\mathbf{r})]\right.$, equação 2.13) com respeito à densidade, com o vínculo de que a integral desta densidade seja igual ao número 
total de partículas. Usando o princípio variacional $[47,52,55]$ e os resultados da equação 2.13, encontramos que

$$
V_{K S}(\mathbf{r})=V_{H}(\mathbf{r})+V_{x c}[n(\mathbf{r})]+V_{e x t}(\mathbf{r}),
$$

sendo que

$$
V_{H}(\mathbf{r})=e^{2} \int \frac{n\left(\mathbf{r}^{\prime}\right)}{\left|\mathbf{r}-\mathbf{r}^{\prime}\right|} d \mathbf{r}^{\prime}
$$

e

$$
V_{x c}[n(\mathbf{r})]=\frac{\delta E_{x c}}{\delta n(\mathbf{r})}
$$

Notamos que o $\mathrm{V}_{K S}(\mathbf{r})$ (equação 2.16), que depende de $n(\mathbf{r})$, deve ser introduzido na equação 2.12, para que possamos obter a densidade de estado fundamental do sistema de muitos corpos. Assim, a solução da equação 2.12 deve ser feita através de um cálculo autoconsistente. Ainda necessitamos de uma aproximação para o termo de troca e correlação a fim de que possamos resolver a equação de KS, sendo o termo de correlação totalmente desconhecido.

\section{Aproximações para $\mathrm{E}_{x c}$}

A aproximação mais simples e amplamente utilizada nas implementações da DFT é a Aproximação da Densidade Local (LDA - Local Density Approximation). Esta aproximação consiste em admitir que a densidade varia lentamente nas proximidades de $\mathbf{r}$ e tratar o gás de elétrons não homogêneo como localmente homogêneo. Assim, temos que

$$
E_{x c}^{L D A}[n(\mathbf{r})]=\int n(\mathbf{r}) \epsilon_{x c}^{L D A}(n(\mathbf{r})) d \mathbf{r}=\int n(\mathbf{r})\left(\epsilon_{x}^{L D A}(n(\mathbf{r}))+\epsilon_{c}^{L D A}(n(\mathbf{r}))\right) d \mathbf{r} .
$$

onde $\epsilon_{x c}^{L D A}[n(\mathbf{r})]$ é a energia de troca e correlação por elétron de um gás de elétron homogêneo. O termo $\epsilon_{x}^{L D A}[n(\mathbf{r})]$ é conhecido exatamente e é dado pela equação de Dirac

$$
\epsilon_{x}^{L D A}[n(\mathbf{r})]=-\frac{3}{4}\left(\frac{3}{\pi}\right)^{1 / 3} n^{1 / 3}=\frac{0,458}{r_{s}} a . u .
$$


com a distância média entre os elétrons dada por $\mathrm{r}_{s}=(3 / 4 \pi n)^{1 / 3}$, em unidades atômicas. O termo $\epsilon_{c}^{L D A}[n(\mathbf{r})]$ não é conhecido exatamente, mas é obtido com precisão dos cálculos de Monte Carlo Quântico de Ceperley e Alder (CP) [56] para um sistema interagente homogêneo, com densidade $\tilde{n}(\mathbf{r})=n(\mathbf{r})$ igual à densidade local no ponto $\mathbf{r}$ do sistema inomogêneo. Aqui, usaremos o termos de correlação como parametrizados por Perdew e Zunger (PZ) [57] a partir dos dados obtidos por CP:

$$
\epsilon_{c}^{P Z}[n(\mathbf{r})]= \begin{cases}A l n r_{s}+B+C r_{s} \ln r_{s}+D r_{s} & r_{s} \leqslant 1, \\ \gamma /\left(1+\beta_{1} \sqrt{r_{s}}+\beta_{2} r_{s}\right) & r_{s} \geq 1 .\end{cases}
$$

Para sistemas de camada fechada, temos que $\mathrm{A}=0,0311 ; \mathrm{B}=-0,048 ; \mathrm{C}=0,002$; $\mathrm{D}=-0,0116 ; \gamma=-0,1423 ; \beta_{1}=1,0529$ e $\beta_{2}=0,3334$.

O uso da LDA tem tido sucesso em prever propriedades de sistemas onde a densidade não é homogênea por princípio, como, por exemplo, átomos e moléculas. Além disso, esta aproximação descreve muito bem as propriedades estruturais e vibracionais de sólidos. Uma parte deste sucesso pode ser atribuída a um cancelamento de erros entre as partes de energia de troca e correlação. A LDA tem também algumas falhas conhecidas, como as listadas na referência [47], e métodos diversos para melhorar as aproximações para o termo $\mathrm{E}_{x c}$ têm sido propostos. Mencionamos aqui somente aqueles baseados na correção de efeitos de não homogeneidade através da inclusão de termos do gradiente e de derivadas de mais alta ordem da densidade, que foram utilizados por neste trabalho. Esta aproximação é conhecida como espansão generalizada em termos de gradientes (GGA - Generalized Gradient Approximation). A equação 2.19 pode ser reescrita como:

$$
E_{x c}^{G G A}[n(\mathbf{r})]=\int n(\mathbf{r}) \epsilon_{x c}(n(\mathbf{r})) F_{x c}(n(\mathbf{r}),|\nabla n(\mathbf{r})|) d \mathbf{r}
$$

onde a função $\mathrm{F}_{x c}(n(\mathbf{r}),|\nabla n(\mathbf{r})|)$ (denominado "enhancement factor") modifica a expressão LDA de acordo com a variação da densidade nas vizinhanças de um dado ponto $\mathbf{r}$. 
A expansão em série de potências da densidade (conhecida como GEA - Gradient Expantion Approximation) quase nunca melhora os resultados LDA e, em alguns casos, pode até piorá-los. O que se faz então é expandir a densidade em série de potências, mas não necessariamente ordem a ordem, procedimento adotado na aproximação GGA. Existem diferentes implementações de funcionais GGAs, que diferem na escolha da função $\mathrm{F}_{x c}(n(\mathbf{r}),|\nabla n(\mathbf{r})|)$. Podemos separá-los em duas categorias distintas: (I) os que utilizam ajustes de parâmetros e os que (II) empregam espressões de $\mathrm{F}_{x c}$ resultantes de métodos teóricos. Das implementações mais populares e teoricamente bem sucedidas de GGAs pertencentes à categoria (II), podemos citar a PBE [58] (funcional proposto por Perdew, Burke e Ernzerhorf) e a PW-91 [59] (funcional proposto por Perdew e Wang). Ambos fornecem resultados semelhantes e utilizamos a aproximação GGA-PW-91.

Comparativamente à LDA, podemos afirmar que os funcionais GGA fornecem maior precisão nos valores de energias atômicas e energias de ligação. Em particular, destacamos a melhora na descrição das ligações de hidrogênio (que são preditas serem "mais ligadas" pelo funcional local). Este aperfeiçoamento abre caminhos para investigações de sistemas tais como água. Todavia, com excessão das energias de ligação, a LDA ainda é o funcional mais bem sucedido na descrição das propriedades de semicondutores. Tanto os funcionais LDA quanto GGA falham na descrição das interações de caráter "não local", como, por exemplo, as de van der Waals, e ainda a energia de estados intermediários ou "de transição " em reações químicas podem apresentar problemas. Nossa estratégia é de, muitas vezes, realizar o mesmo cálculo utilizando um e outro procedimento (LDA e GGA) para comparação de resultados.

\subsection{Métodos DFT}

Neste ponto, a resolução do problema de muitos corpos de $n$ elétrons interagentes sob a ação de um potencial criado por $M$ núcleos, depende ainda da escolha de como trataremos o potencial de interação entre elétron e núcleo, $\widehat{V}_{e I}$, e a forma matemática 
de representação dos orbitais de um elétron de KS, $\psi_{i}(\mathbf{r})$.

\subsubsection{Base de Ondas Planas}

Em sistemas periódicos, o teorema de Bloch garante que a função de onda do sistema pode ser escrita como o produto de uma fase imaginária e uma função com periodicidade do cristal, de forma que o uso de funções de base tipo ondas planas (PW plane waves) torna a representação dos orbitais de KS mais simples. Além disso, ondas planas são já soluções da equação de Schrödinger para um gás de elétrons não interagentes sob a ação de um potencial constante, sendo que a solução desta equação para potenciais variáveis pode ser escrita como uma combinação de PWs. Podemos ainda citar outras características que tornam as funções de base PW interessantes e convenientes: • os elementos de matriz da hamiltoniana assumem uma forma particularmente simples; • as PWs são ortonormais por construção; • a expansão depende somente do cristal e da energia de truncamento, providenciando uma aplicação direta do teorema de HF para cálculo das forças interatômicas; todas as regiões do espaço são igualmente descritas; entre outras.

A expansão dos orbitais de KS em termos de uma combinação de PWs, em termos de vetores da rede recíproca $\mathbf{G}$ e vetores de onda da primeira zona de Brillouin (ZB) k, é dada por:

$$
\psi_{i}(\mathbf{r})=\frac{e^{i \mathbf{k} \cdot \mathbf{r}}}{\sqrt{\Omega}} \sum_{\mathbf{G}=0}^{\infty} C_{i \mathbf{k}}(\mathbf{G}) e^{i \mathbf{G} \cdot \mathbf{r}}=\sum_{\mathbf{G}=0}^{\infty} C_{i \mathbf{k}}(\mathbf{G}) \frac{1}{\sqrt{\Omega}} e^{i(\mathbf{k}+\mathbf{G}) \cdot \mathbf{r}}=\sum_{\mathbf{G}=0}^{\infty} C_{i \mathbf{k}}(\mathbf{G}) \phi_{\mathbf{G}}^{\mathbf{k}}(\mathbf{r}),
$$

onde $\Omega$ é o volume do cristal e a energia cinética máxima destas PW pode ser escrita como:

$$
\frac{\hbar^{2}}{2 m}|\mathbf{k}+\mathbf{G}|^{2} \leq E_{\text {cut }}
$$

O termo $\mathrm{E}_{\text {cut }}$ é o valor de energia onde truncamos a expansão 2.23. Na prática, os coeficientes de Fourier $\mathrm{C}_{\mathbf{k}}(\mathbf{G})$ decrescem rapidamente com o aumento da energia de corte das ondas PW. Ou seja, a verificação da convergência das propriedades físicas em função do tamanho da função de base é muito simples. A densidade eletrônica 
(equação 2.11) torna-se

$$
n(\mathbf{r})=\frac{2}{\Omega N_{k p t}} \sum_{\mathbf{k}} f_{\mathbf{k} i} \sum_{\mathbf{G}, \mathbf{G}^{\prime}} C_{i \mathbf{k}}^{*}\left(\mathbf{G}^{\prime}\right) C_{i \mathbf{k}}(\mathbf{G}) e^{-i\left(\mathbf{k}+\mathbf{G}^{\prime}\right) \cdot \mathbf{r}} e^{i(\mathbf{k}+\mathbf{G}) \cdot \mathbf{r}}
$$

sendo que a ocupação ou não do orbital é dada por $f_{\mathbf{k} i}$ e $\mathrm{N}_{k p t}$ define o número de pontos $\mathbf{k}$ da grade numérica do espaço recíproco na qual avaliamos a densidade eletrônica. Isto é, a soma infinita sobre a ZB é substituída por uma soma discretizada em $\mathrm{N}_{k p t}$ pontos. Existem alguns esquemas para construir a grade de pontos $\mathbf{k}$ e neste trabalho utilizamos o esquema proposto por Monkhorst e Pack [60].

O uso das funções de base tipo PW é computacionalmente inviável para descrição de funções com muitas oscilações, como é o caso nas regiões próximas aos núcleos atômicos. Uma forma de contornar tal problema é utilizando a aproximação bem sucedida do pseudopotencial.

\subsubsection{Pseudopotenciais}

A aproximação do pseudopotencial (PP) é baseada na observação de que os elétrons mais externos (elétrons de valência) são importantes para a descrição das ligações químicas e propriedades de sólidos, enquanto aqueles mais internos (elétrons de caroço - core electrons) não contribuem significativamente para estas propriedades. Além disso, não é estritamente necessária uma boa descrição da função de onda dos elétrons de valência nas regiões de caroço, de forma que não deixaremos de descrever propriedades relevantes do sistema se substituirmos a função de onda, na região de caroço, por uma pseudofunção de onda sem nós de ortogonalidade ao caroço, que não é solução do problema atômico original, enquanto nas regiões mais externas se aproxima rapidamente à solução exata. As vantagens imediatas do uso de PP é que o número de orbitais de KS a serem avaliados é reduzido, e principalemente o uso de PW torna-se factível. Tomemos por exemplo o átomo de Si, cuja distribuição eletrônica é dada por: $1 s^{2}, 2 s^{2}, 2 p^{6}, 3 s^{2}, 3 p^{2}$. O pseudo-átomo fica dado por: $3 s^{2}, 3 p^{2}$. 


\section{Pseudopotenciais de Norma Conservada}

Os PPs modernos são construídos a partir da resolução numérica da equação de Schrödinger para o átomo, substituindo o potencial de KS dentro de uma esfera de raio $R_{\text {cut }}$ por um pseudopotencial suave. Ou seja, substituimos a função de onda original, $\Phi_{l}^{A E}$, no interior da esfera de raio $\mathrm{R}_{c u t}$ por uma pseudofunção de onda sem nós, $\Phi_{l}^{P P}$, com a derivada logarítimica, em $\mathrm{R}_{c u t}$, idêntica àquela obtida para a função de onda original. $R_{c u t}$ é o raio de corte que delimita a região a partir da qual a pseudofunção de onda do sistema deve coincidir com $\Phi_{l}^{A E} . \Phi_{l}^{P P}$ é construída de forma tal

que seus autovalores, $\varepsilon_{l}^{P P}$, coincidem $\operatorname{com} \varepsilon_{l}^{A E}$. Por construção, também devemos garantir a reprodução da derivada logarítima de $\Phi_{l}^{A E}$ para todo o espectro de autovalores de energia. Em outras palavras, pseudopotenciais úteis devem ser capazes de descrever o átomo em diferentes ambiente químicos (isto é, devem ser transferíveis). Outra propriedade importante é que a integral da densidade de carga no interior de $\mathrm{R}_{c u t}$ seja idêntica àquela obtida para $\Phi_{l}^{A E}$. Os PP que respeitam tal condição são denominados de PP de norma conservada, o que garante boa transferibilidade dos pseudopotenciais.

Atualmente, o estado da arte na construção de PPs são as "receitas" desenvolvidas por Troullier-Martins (TM) [61] e a proposta alternativa de Rappé e colaboradores (RRKJ) [62]. Ambas "receitas" são capazes de gerar PPs ditos suaves, ou seja, PPs para os quais a expansão em PWs (equação 2.23) converge rapidamente. Tanto a suavidade quanto a transferibilidade estão diretamente relacionadas aos valores de $\mathrm{R}_{c u t}$, sendo que o aumento do raio de corte aumenta a suavidade, mas prejudica a transferibilidade.

\section{Pseudopotenciais "Ultrasuaves"}

O objetivo da utilização da aproximação do pseudopotencial é criar pseudofunções de onda suaves e com a maior precisão possível. A conservação da norma garante a precisão, mas é o principal fator responsável pela diminuição da suavidade de 
pseudopotenciais, especialmente PPs obtidos para estados $p$ e $d$ dos elementos da segunda linha da tabela periódica. Como exemplo, podemos citar o átomo de oxigênio, para o qual resultados razoáveis só são obtidos para altos valores de $\mathrm{E}_{\text {cut }}$, uma vez que $\Phi_{l}^{A E}$ e $\Phi_{l}^{P P}$ são quase idênticas. Este problema pode ser contornado utilizando os pseudopotenciais denominados "ultrasuaves", gerados segundo o esquema proposto por Vanderbilt [63]. Neste caso, a condição de conservação da norma não é garantida por construção, permitindo o aumento dos valores de $\mathrm{R}_{c u t}$, mas ainda sim, a transferibilidade é mantida. A utilização da receita de Vanderbilt faz com que, durante a minimização do funcional de KS, a densidade eletrônica do sistema deva ser acrescida de um termo que garanta que $n^{P P}$ seja igual a $n^{A E}$. O custo computacional para avaliar a correção da densidade é baixo, e os PPs "ultrasuaves" têm sido amplamente utilizados, especialmente quando os orbitais de KS são expandidos em PWs [47].

De posse da representação matemática dos orbitais de KS e de $\widehat{V}_{e I}$, estamos em condições de obter a solução da equação de KS para o sistema de muitos corpos. A metodologia que empregamos para tal é aquela implementada no código computacional de domínio público ESPRESSO [64] que permite também o cálculo de forças sobre os núcleos, e "otimização de geometria" através do teorema de HellmannFeynman.

\subsection{Método para Cálculos de Caminhos de Reação}

O mapeamento dos caminhos de reação e a definição dos estados de transição para a dissociação da molécula de água sobre a superfície $\operatorname{Si}(100)(2 \times 1)$ ou $\operatorname{Si}(100)(2 \times 1): H$ são grandes desafios em física da matéria condensada. Não é suficiente obtermos as energias totais desses sistemas na situação inicial - sistemas isolados - superfície e molécula - e final - molécula fisissorvida na superfície, ou molécula quimissorvida e resíduos da reação; devemos ainda conhecer as barreiras, se existirem, para tal reação. 
Sejam duas configurações estáveis I e $\mathbf{P}$ de um sistema. Para um dado valor de energia térmica, este sistema pode estar nas configurações de mínimo local I, $\mathbf{P}$ ou ainda pode migrar entre elas. Em ambas as configurações de baixa energia, há movimento vibracional. Se queremos estudar eventos relacionados às transições entre $\mathbf{I}$ e $\mathbf{P}$, poderíamos fazê-lo utilizando dinâmica molecular (DM). Todavia, se

$$
\frac{k_{B} T}{E_{T S}} \ll 1
$$

onde $\mathrm{E}_{T S}$ é a barreira de energia entre $\mathbf{I}$ e $\mathbf{P}$, o sistema executa muitos períodos vibracionais para cada transição entre entre os mínimos locais, de forma que o uso de dinâmica molecular não é adequado para estudar estes eventos raros. Tomemos por exemplo, $\mathrm{E}_{T S}=0,6 \mathrm{eV}$. Segundo as estimativas Henkelman [65], o sistema executará cerca de $10^{10}$ períodos vibracionais para cada transição $\mathbf{I} \rightarrow \mathbf{P}$. Isto implica que, utilizando os computadores atuais, gastaríamos cerca de $10^{5}$ anos para observamos a ocorrência de um único evento raro. Assim, o estudos cinéticos destes eventos são realizados por outros métodos que não DM. Nós empregamos um método de primeiros princípios, baseado em DFT-KS, que nos permite obter o caminho e a barreira de reação, denominado de CI-NEB (Climbing Image - Nudged Elastic Band method).

\subsubsection{Método NEB}

O caminho de mais baixa energia para o qual o rearranjo de um grupo de átomos leva o sistema de uma configuração inicial I a uma configuração final $\mathbf{P}$ é denominado de caminho de menor energia (MEP - Minimum Energy Path). Em qualquer ponto ao longo do MEP, a força agindo nos átomos aponta na direção da tangente ao caminho, sendo que a energia é estacionária para qualquer grau de liberdade perpendicular ao mesmo [65-67]. Cada ponto $\mathbf{R}$ ao longo do MEP corresponde a uma configuração nuclear $\left\{\mathbf{R}_{N}\right\}$ de todos os átomos do sistema, sendo que as distância relativas entre estes pontos definem a coordenada de reação para os estados de transição. Ao analisarmos o gráfico da variação de energia em função das coordenadas de reação, 
o ponto de energia mais alta (não necessariamente o único) ao longo do caminho é a energia do ponto de sela, que fornece a barreira de reação. Assim, um método de cálculos de MEP tem que ser capaz de (i) encontrar os pontos de sela ao longo do caminho de reação; (ii) identificar o mais alto ponto de sela ao longo do MEP e (iii) ser computacionalmente viável. Considerando a discussão da seção 2.1, isto é uma tarefa formidável, uma vez que a hipersuperfície de energia não é conhecida.

Diferentes métodos têm sido propostos para encontrar caminhos e barreiras de reação, sendo que os baseados em cálculos de segunda derivada de matrizes são computacionalmente inviáveis. Dentre os métodos que requerem a avaliação de derivada da energia potencial, podemos citar o método de "arraste" (Drag method), o NEB (Nudged Elastic Band method), o CI-NEB (Climbing Image - Nudged Elastic Band method), o CPR (Conjugated Peak Refinement method), o DHS (método proposto por Dewar, Healy e Stewart) e o método do "dimero" (Dimer method) entre os mais populares [65]. Dentre estes, o método de "arraste" (ou método da coordenada de reação ) é o mais simples, intuitivo e frequentemente utilizado. Este método consiste em escolhermos uma coordenada de reação (por exemplo, a distância entre dois átomos) que é fixada enquanto todos os outros graus de liberdade do sistema (num total de (3N-1) para $\mathrm{N}$ átomos em 3 dimensões) são minimizados. Com pequenos incrementos da coordenada de reação, o sistema é "arrastado" do estado inicial até o final. Este método entretanto falha em muitos casos, uma vez que uma boa coordenada de reação deve seguir o modo normal instável no ponto de sela e, em geral, não pode ser aproximada por uma simples distância interatômica, por exemplo.

O método NEB, desenvolvido por Henkelman $[65,67,68]$ e colaboradores, constitui uma evolução dos métodos denominados "chain-of-states" (COS) e reflete o estado da arte em estudos ab initio de caminhos de reação, satisfazendo os prérequisitos (i) a (iii). No método COS, o caminho de reação entre um estado inicial $\mathbf{I}$ e um estado final $\mathbf{P}$ (ambos, I e $\mathbf{P}$ conhecidos) é discretizado com um conjunto de imagens (ou réplicas) conectadas entre si por uma mola de constante k. O "cordão" de imagens, $\left[\mathbf{R}_{0}=\mathbf{I}, \mathbf{R}_{1}, \mathbf{R}_{2}, \ldots, \mathbf{R}_{N}=\mathbf{P}\right]$, que "imita" uma fita elástica formada por 
N-1 configurações intermediárias, é então minimizada a fim de que possa convergir para o MEP. A força agindo em uma imagem $i$ é dada por:

$$
\mathbf{F}_{i}^{C O S}=-\nabla E\left(\mathbf{R}_{i}\right)+\mathbf{F}_{i}^{s}=-\nabla E\left(\mathbf{R}_{i}\right)+\underbrace{k\left(\left(\mathbf{R}_{i+1}-\mathbf{R}_{i}\right)-\left(\mathbf{R}_{i}-\mathbf{R}_{i-1}\right)\right)}_{\mathbf{F}_{i}^{s}} .
$$

Na figura 2.1(a) [66] apresentamos o MEP (linha + círculos) obtido após a convergência utilizando a equação 2.27. Dois problemas são observados: as imagens na fita elástica (linha + círculos) são "empurradas" para fora da região curva do MEP ("corner-cutting") e também tendem a "deslizar" na direção das configurações I ou $\mathbf{P}$ ("down-sliding"). De forma que, as imagens da fita estão concentradas nas regiões mais próximas aos mínimos de energia $\mathbf{I}$ ou $\mathbf{P}$, prejudicando a resolução do caminho na região do estado de transição. O primeiro efeito é causado pela interferência da componente perpendicular da força da mola $\mathbf{F}_{i}^{s}$, enquanto o segundo surge devido à componente paralela da força $\nabla E\left(\mathbf{R}_{i}\right)$, resultante da interação entre os átomos.

Estes problemas são solucionados se a força agindo em uma imagem $i$ for reescrita como:

$$
\begin{array}{r}
\mathbf{F}_{i}^{N E B}=-\left.\nabla E\left(\mathbf{R}_{i}\right)\right|_{\perp}+\left.\mathbf{F}_{i}^{s}\right|_{\|}= \\
=-\left(\nabla E\left(\mathbf{R}_{i}\right)-\nabla E\left(\mathbf{R}_{i}\right) \cdot \widehat{\tau}_{i}\right)+k\left(\left(\mathbf{R}_{i+1}-\mathbf{R}_{i}\right)-\left(\mathbf{R}_{i}-\mathbf{R}_{i-1}\right)\right) \cdot \widehat{\tau}_{i} \widehat{\tau}_{i},
\end{array}
$$

onde $\left.F_{i}^{s}\right|_{\|}$é a componente paralela da força da "mola", $\left.\nabla E\left(\mathbf{R}_{i}\right)\right|_{\perp}$ a componente perpendicular da força e $\widehat{\tau}_{i}$ é a tangente local ao MEP [69],

$$
\widehat{\tau}_{i}=\frac{\mathbf{R}_{i+1}-\mathbf{R}_{i-1}}{\left|\mathbf{R}_{i+1}-\mathbf{R}_{i-1}\right|}=\frac{\mathbf{R}_{i}-\mathbf{R}_{i-1}}{\left|\mathbf{R}_{i+}-\mathbf{R}_{i-1}\right|}+\frac{\mathbf{R}_{i+1}-\mathbf{R}_{i}}{\left|\mathbf{R}_{i+1}-\mathbf{R}_{i}\right|} .
$$

Este esquema de projeção recebe o nome de "nudging" e desacopla a ação entre as diferentes forças na fita elástica, de forma que os problemas de "corner-cutting" e "down-sliding" desaparecem (figura 2.1(a) [66], MEP representado por linha). Quanto ao desacoplamento entre a convergência e a discretização do caminho, este procedimento torna o NEB um método robusto, uma vez que a escolha da constante de mola não interfere na componente $\left.\nabla E\left(\mathbf{R}_{i}\right)\right|_{\perp}$. Alguns testes [66] para diferentes 


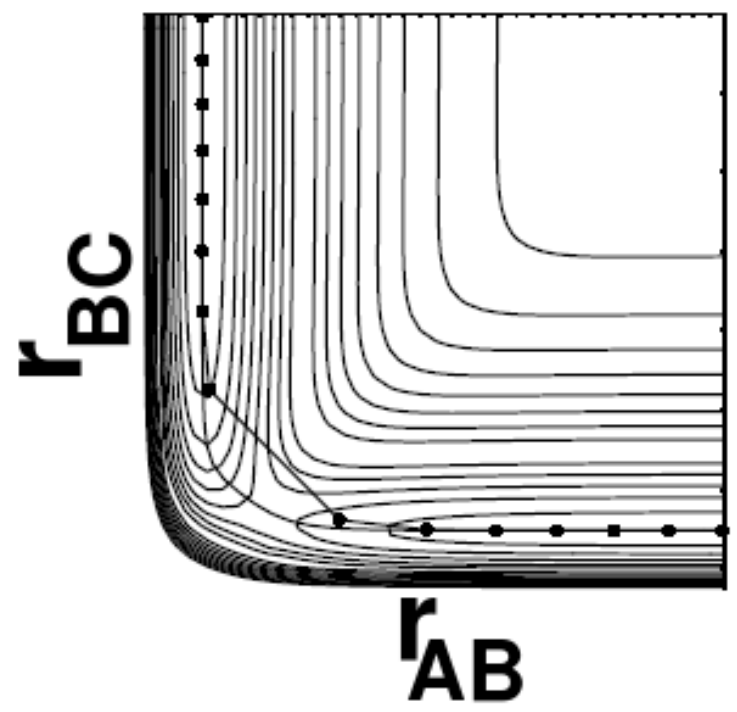

(a) MEP

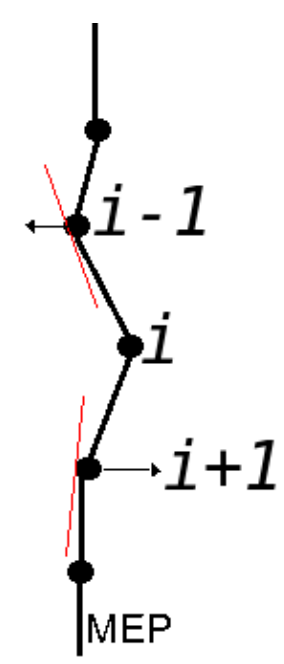

(b) Cúspides

Figura 2.1: Em (a), comparação entre MEPs obtidos a partir da minimização da fita elástica utilizando as equações 2.27 (linha + círculos) e 2.28 (linha). A imagem foi retirada da referência [66]. A isosuperfície de energia potencial foi obtida para um sistema composto por 3 átomos: $A, B$ e $C$. Os átomos $A$ e $C$ estão livres para se mover, enquanto o átomo $B$ pode se ligar a $A$ ou $C$. No eixo das ordenadas, temos valores para a distância $\mathrm{r}_{B C}$ e no eixo das abcissas $\mathrm{r}_{A B}$. Em (b), mostramos um exemplo da presença de cúspide na fita elástica na imagem $i$, afetando a tangente nas imagens adjacentes: $i-1$ e $i+1$.

valores de $\mathrm{k}$ mostram que valores da barreira de energia de reação varia de $\approx 0,02$ $\mathrm{eV}$ devido a uma variação de k no intervalo entre 0,2 e 2,0 eVA $\AA^{-1}$.

A presença de cúspides na fita elástica (figura 2.1(b)), provocados, por exemplo, por quebra e formação de ligações covalentes, torna a convergência do MEP bastante difícil, uma vez que acrescenta instabilidades numéricas. Como estas situações são comuns, Henkelman e Jónsson [69] desenvolveram um método eficiente de avaliação de $\widehat{\tau}_{i}$, que assegura que as imagens adjacentes a um cúspide não executem movimentos oscilatórios perpendiculares à fita elástica. A "receita" é detalhadamente descrita nas referências [69] e [65] e assegura a convergência rigorosa do MEP. 


\subsubsection{Método CI-NEB}

Após a convergência do MEP, nenhuma imagem está posicionada sobre o ponto de mais alta energia. Assim, a barreira de energia e a configuração atômica do estado de transição têm que ser aproximadas pelas imagens imediatamente vizinhas ao ponto de sela, o que dificulta o cálculo da barreira energética de transição. Estes problemas podem ser resolvidos com uma pequena modificação do método NEB, denominada CI-NEB [67]. Quando o cálculo ordinário de NEB é iniciado, após algumas poucas iterações, a imagem de mais alta energia da fita elástica (CI - Climbing Image) é identificada. O procedimento CI-NEB consiste em substituir a espressão de cálculo da força nesta imagem (equação 2.28) por:

$$
\mathbf{F}_{i_{\max }^{C I-N E B}}^{C I}=-\nabla E\left(\mathbf{R}_{i_{\max }}\right)+\left.2 \nabla E\left(\mathbf{R}_{i_{\max }}\right)\right|_{\|} .
$$

Como a força da mola sobre a $i_{\max }$ é zerada, esta imagem não está conectada às demais imagens da fita elástica e o método de "arraste" é utilizado para mover $i_{\text {max }}$ para baixo e para cima na PES, contra o gradiente de energia. Mas, neste caso, a direção de "arraste" é determinada pela localização das imagens adjacentes da fita elástica e não pelas configurações inicial I e final P. Com isto, quando a convergência da fita elástica é alcançada, obtemos um MEP para o qual há uma imagem exatamente sobre o ponto de sela e obtemos um valor para a barreira de reação e também a configuração atômica do estado de transição. Um ponto importante é que o custo computacional deste procedimento não é muito diferente do cálculo NEB e dados compilados por Henkelman [65] demonstram que, comparativamente a outros métodos de derivada primeira, o NEB e o CI-NEB são computacionalmente mais baratos.

\section{Barreiras de Reação e Diferentes Aproximações para $\mathbf{E}_{x c}$}

Atualmente, a metodologia CI-NEB têm sido amplamente empregada para estudos de MEPs, mas não encontramos na literatura nenhuma discussão sobre a influência 
de diferentes aproximações da energia de troca e correlação, $\mathrm{E}_{x c}$, nos caminhos de reação. Empregamos aqui as aproximações LDA-PZ e GGA-PW91 para este termo e a influência do funcional local e semi-local sobre o MEP é avaliada no capítulo 5. Dos diferentes resultados analisados, antecipamos que o MEP seguido pelo sistema é o mesmo tanto para o funcional LDA-PZ quanto para o GGA-PW91, mas os valores para as barreiras de energia de reação são diferentes e as divergências estão entre 30 e $40 \%$, nos piores cenários. Sabemos que em ambos os casos, existem limitações em nossas aproximações de $\mathrm{E}_{x c}$, e além disso apesar da descrição de ligações de hidrogênio ser obtida com maior precisão com o GGA-PW91, o problema não é totalmente solucionado, uma vez que as interações não-locais continuam a ser negligenciadas. Recentemente, Santra e colaboradores [70] detectaram que os funcionais de troca e correlação mais populares não são capazes de descrever adequadamente o ordenamento energético de vários clusters de água, ainda que outras propriedades sejam corretamente preditas. De qualquer forma, como será visto na discussão de resultados, existem diferenças substanciais nas alturas de barreira em diferentes caminhos que nos permitem chegar a conclusões confiáveis.

\section{Detalhes Técnicos}

Conforme comentamos anteriormente, utilizamos o método CI-NEB para cálculo de MEPs para a oxidação molhada das superfícies de Si. Apesar da metologia robusta, a convergência da fita elástica é sempre difícil, devido à complexidade inerente a esta reação. De forma que os MEPs são obtidos com critérios de convergência para a força e número de imagens na fita elástica que mantêm um compromisso entre a precisão dos resultados e a factibilidade. Nós realizamos alguns testes e, para os sistemas investigados aqui, o critério de convergência da força na fita elástica é de $0,09 \mathrm{eV}^{-1}$, enquanto o "espaçamento" médio entre as imagens da fita elástica são mantidas no intervalo entre 1,8 a $2,2 \AA$. Averiguamos que para um mesmo MEP, a variação da distância entre as imagens no intervalo entre 0,4 e 1,7 $\AA$ produz barreiras 
de energia com diferença de 0,001 eV. Endurecimento no critério de convergência na força do caminho levam a mudanças abaixo de $0,01 \mathrm{eV}$ na barreira de energia. Assim, consideramos os parâmetros anteriores adequados.

Os valores de energia de ligação, $\mathrm{E}_{b}$, para os estados inicial I ou final $\mathbf{P}$ dos MEPs são calculados pela diferença de energias totais do subsistemas isolados (molécula de água e superfície) e após a oxidação (molécula quimissorvida + resíduo), dada por:

$$
E_{b}=E(Q+R)-\left(E\left(H_{2} O\right)+E(S u p .)\right)
$$

\subsection{Microscopia de Tunelamento: Aproximação de Tersoff-Hamman}

O primeiro experimento de sucesso que possibilitou a implementação da técnica de microscopia de tunelamento (STM - Scanning Tunneling Microscopy) como a utilizamos atualmente, foi realizado por Binnig e colaboradores [71-73]. Esta técnica não destrutiva permite a determinação direta e no espaço real da estrutura atômica da superfície, revolucionando a física de superfícies [74]. O funcionamento do microscópio é simples e é baseado no fenômeno de tunelamento quântico observado para um elétron confinado em um poço de potencial criado pela interação entre dois sólidos vizinhos, neste caso a ponta metálica e a superfície. Quando se estabelece uma diferença de potencial entre a ponta e a superfície os elétrons podem tunelar da ponta para a amostra ou da amostra para a ponta metálica, desde que haja disponibilidade de um nível de mesma energia. Em geral, a distância entre a ponta e a superfície é da ordem de alguns Å. Durante o experimento, a varredura da superfície é feita para um dado valor de $\mathrm{V}$, aproximando e afastando a ponta metálica a fim de manter a corrente de tunelamento constante. Como resultado, temos um mapeamento topográfico da superfície em regime de sobreposição contante da função de onda, fornecendo informações locais sobre a densidade eletrônica da amostra. 
A simulação computacional deste experimento é difícil, uma vez que envolve o cálculo do transporte eletrônico entre a ponta e a superfície. Entretanto, Tersoff e Hamann (TH) [75] propuseram uma aproximação de implementação computacional simples, que nos permite obter imagens que podem ser comparadas com os resultados experimentais de STM. A proposta de TH consiste em um tratamento "exato" (o termo "exato" se refere no nosso caso, ao uso do método DFT-KS) da superfície, enquanto a ponta é aproximada por um poço de potencial localmente esférico. $\mathrm{O}$ ponto de partida é o uso do formalismo de Bardeen [76] para a descrição da corrente de tunelamento em um sistema de muitos corpos (equação 2.32), que em primeira ordem fica dado por:

$$
I=\frac{2 \pi e}{\hbar} \sum_{\mu, \nu} f\left(E_{\mu}\right)\left[1-f\left(E_{\nu}+e V\right)\right]\left|M_{\mu \nu}\right|^{2} \delta\left(E_{\mu}-E_{\nu}\right),
$$

onde $f(\mathrm{E})$ é a função de Fermi, $V$ a voltagem aplicada, $M_{\mu \nu}$ é o elemento de matriz de tunelamento entre os estados $\psi_{\mu}$ da ponta e $\psi_{\nu}$ da superfície. E $E_{\mu}$ representa a energia do estado $\psi_{\mu}$ na ausência de corrente de tunelamento.

A corrente de tunelamento, em regimes de baixa voltagem e temperatura, pode ser reescrita como:

$$
I=\frac{2 \pi}{\hbar} e^{2} V \sum_{\mu, \nu}\left|M_{\mu \nu}\right|^{2} \delta\left(E_{\mu}-E_{F}\right) \delta\left(E_{\nu}-E_{F}\right) .
$$

Tersoff e Hamann [75] mostraram que a substituição da ponta por um poço de potencial esférico nas proximidades da superfície (ponto de prova localmente esférico) com funções de onda arbitrariamente localizadas permite reescrever a equação 2.33 como:

$$
I \propto \sum_{\nu}\left|\psi_{\nu}\left(r_{0}\right)\right|^{2} \delta\left(E_{\mu}-E_{F}\right) \delta\left(E_{\nu}-E_{F}\right)=\rho\left(r_{0}, E_{F}\right)
$$

O elemento de matriz é proporcional à amplitude de $\psi_{\nu}$ na posição $\mathbf{r}_{0}$ da ponta e a corrente de tunelamento é proporcional à Densidade Local de Estados (Local Density Of States) da superfície na posição da ponta, $\operatorname{LDOS}\left(\mathbf{r}, \mathrm{E}_{F}\right)$, no nível de Fermi ou, equivalentemente, à densidade de carga por unidade de energia dos estados de 
superfície em $\mathrm{E}_{F}, \rho\left(\mathbf{r}, \mathrm{E}_{F}\right)$. Isto implica que as características dos estados ocupados são obtidas quando somamos a contribuição para a LDOS dos níveis eletrônicos situados entre $\mathrm{E}_{F}$ e $\mathrm{E}_{F}-\mathrm{V}$ (onde $\mathrm{V}$ é a diferença de potencial aplicada entre a ponta e a amostra). O mapa de STM dos estados desocupados pode ser obtido de maneira análoga para voltagem positiva. 


\section{Capítulo 3}

\section{Propriedades Estruturais das}

\section{Superfícies $\operatorname{Si}(100)$ Limpa e}

\section{Hidrogenada}

Atualmente, é possível produzir superfícies semicondutoras com homogeneidade atômica em escala industrial. Procedimentos de crescimento e reações destes substratos com agentes passivantes e oxidantes são de prática constante para produção de dispositivos. Entretanto, algumas questões ainda permanecem sem resposta, sendo objetos de investigação, tanto teórico como experimental. A passivação das superfícies Si por adsorção de hidrogênio e os processos pelos quais a reação com $\mathrm{H}_{2} \mathrm{O}$ leva à oxidação destes substratos é uma questão em aberto.

Neste capítulo, faremos uma breve revisão bibliográfica das propriedades estruturais das reconstruções de superfícies de Si crescidas na direção cristalográfica (100). As superfícies de Si com maiores relevâncias tecnológicas são aquelas obtidas a partir da clivagem das direções cristalogáficas (111) e (100) [21]. Ambas exibem reconstruções consideráveis, porém aquela crescida na direção (100) tem estrutura mais simples quando comparada a $\mathrm{Si}(111)$, sendo portanto mais utilizada em aplicações tecnológicas. Isto nos motivou a estudar os processos de oxidação molhada 
nas superfícies $\mathrm{Si}(100)$.

Discutiremos os métodos empregados para passivação destas estruturas via adsorção de hidrogênio atômico, bem como as reconstruções a que este fenômeno conduz. As estruturas destas superfícies (na ausência de oxidação ) têm sido extensivamente investigadas tanto experimental quanto teoricamente, e podemos afirmar que são conhecidas com detalhes. De forma que, a maioria dos resultados que descreveremos já foi relatada. Contudo, esta repetição dos cálculos para as superfície $\mathrm{Si}(100)$ e $\mathrm{Si}(100): H$ é importante para seguir melhor as discussões na próxima etapa do nosso trabalho, quando estudaremos os processos de oxidação.

\subsection{Revisão de Dados Experimentais e Teóricos}

O silício é um semicondutor que cristaliza em uma estrutrura tipo diamante, com ligações tetraédricas. Cada Si se liga a quatro outros vizinhos na rede cristalina, através dos orbitais híbridos $\mathrm{sp}^{3}$, com comprimento de ligação de 2,35 A. Quando a superfície (100) é criada, o número de vizinhos de cada átomo de Si de superfície fica reduzido pela metade, dando origem a duas dangling bonds por átomo os quais distam de aproximadamente $3.8 \AA$ (figura 3.1(a)). O sistema torna-se energeticamente instável fazendo com que os átomos das primeiras camadas sofram mudanças significativas nas suas posições atômicas para minizar a energia livre do sistema. Para a direção (100) o rearranjo atômico conduz à formação de ligações entre pares de átomos de superfície, diferentes daquelas existentes no cristal e conhecidas como dimerizações. Pares de átomos de Si formam "dímeros" através de uma ligação covalente permitindo que cada um deles tenha uma dangling bond saturada (figura 3.1(b)). A estabilização final, referente à ligação não saturada remanescente, se dá através de uma nova distorção estrutural, com transferência de carga entre os átomos do dímero: um dos átomos torna-se negativamente carregado (denominado up) e se desloca ligeiramente para fora da superfície, enquanto o Si positivamente carregado (denominado down) se desloca em direção ao bulk. Formam-se os "dímeros 


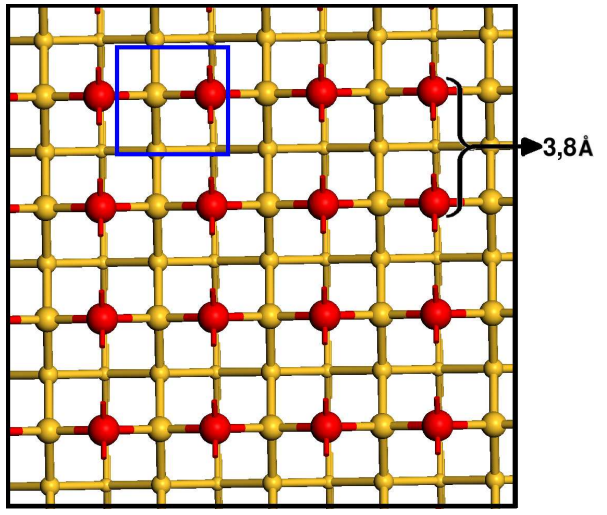

(a) $\operatorname{Si}(100)(1 \times 1)$

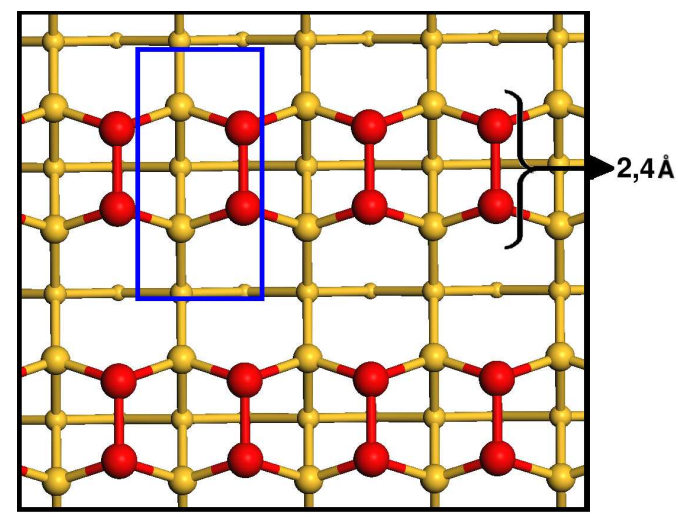

(b) $\operatorname{Si}(100)(2 \times 1)$

Figura 3.1: Vista de topo da célula unitária primitiva para a superfície (a) $\operatorname{Si}(100)(1 \times 1)$ e (b) $\operatorname{Si}(100)(2 x 1)$. Os átomos de superfície são representados por esferas vermelhas.

assimétricos“, como mostrado na figura 3.2. A transferência de cargas, responsável pela assimetria entre os átomos de Si up e down foi uma previsão teórica [77,78], mas amplamente comprovada por resultados experimentais [79,80], especialmente pela técnica de microscopia de tunelamento $(S T M)$. Esta distorção estrutural abaixa a simetria da superfície num efeito tipo Jahn-Teller [78]. Atualmente observamos que diferentes técnicas experimetais [79-89] e resultados teóricos [90-93] corroboram o modelo de reconstrução com dímeros assimétricos para a superfície $\operatorname{Si}(100)$. As consequências desta deformação afetam profundamente não somente as propriedades estruturais bem como as propriedades eletrônicas da superfície. Resultados de cálculos de primeiros princípios [78] demonstram que a presença de dímeros simétricos faria com que a superfície $\operatorname{Si}(100)$ reconstruída fosse metálica, enquanto a formação de dímeros assimétricos conduz a um sistema semicondutor. Todavia, a presença de uma ligação não saturada em um dos átomos do dímero faz com que os níveis de energia situados nos átomos up e down localizem-se no gap. Experimentos de LEED [77] obtêm a distância de ligação Si-Si entre 2,20 e 2,47 A, enquanto a inclinação do dímero varia de 15 a $20^{\circ}$ ( ângulo $\theta$ na figura 3.2 ).

A assimetria ou não dos dímeros assim como o arranjo espacial dos átomos de 

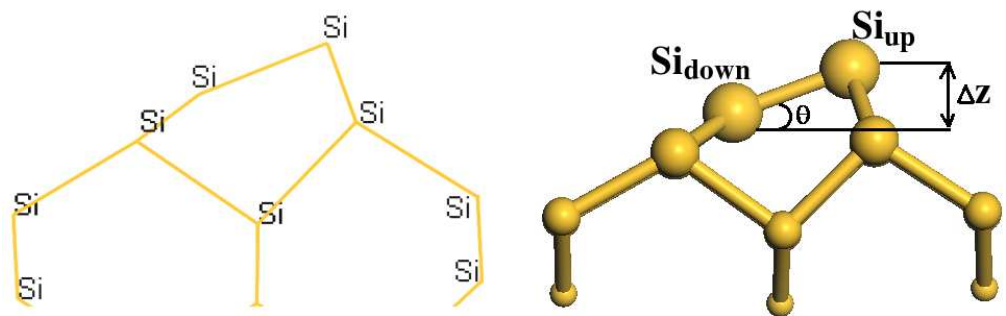

Figura 3.2: Reconstrução com dímero assimétrico para a superfície de Si(100). Para a representação mostrada à direita, o tamanho das esferas relaciona-se com a "camada" em relação à superfície livre.

superfície foi tema de debate da comunidade científica por décadas. Imagens de STM obtidas em temperatura ambiente mostravam a reconstrução (2x1) com dímeros simétricos enquanto medidas de difração de elétrons de baixa energia (Low Energy Electron Diffraction - LEED) sugeriam um modelo de dímeros assimétricos, mas com comportamento dinâmico a 300 K. A aparente contradição com as imagens de STM se deve ao fato de não haver resolução do movimento de oscilação dos átomos de superfície entre as posições up e down [85]. Para experimentos de correntes de tunelamento realizados em baixas temperaturas, quando o movimento de oscilação não está termicamente ativado, os dímeros assimétricos [79] são visualizados e estão ordenados em uma estrutura denominada c(4x2) (figuras 3.3 e 3.4), em um arranjo tipo zig-zag antiparalelo [79,85,94,95]. Se a fileira de dímeros da esquerda tem um átomo de Si negativamente carregado próximo à região de vale isto também se verifica para a fileira de dímeros imediatamente adjacente e posicionada à direita. Há alguns relatos experimentais $[81,88]$ da existência de uma outra possível reconstrução para a superfície limpa a baixas temperaturas. Esta reconstrução é conhecida como $\mathrm{p}(2 \times 2)$ e também apresenta o padrão tipo zig-zag, mas paralelo. Neste caso, se uma fileira de dímeros tem um átomo de $\mathrm{Si}_{\text {down }}$ na região de vale, isto implica que a fileira adjacente terá um átomo $\mathrm{Si}_{u p}$. As características que nos permitem reconhecer cada uma das reconstruções são mostradas na figura 3.4, retirada da referência [88]. Dados obtidos com a técnica de microscopia de força atômica em 
modo de não contato e em baixas temperaturas (LT-NC-AFM - Low-Temperature NonContact Atomic Force Microscope) $(\approx 5 \mathrm{~K})$ mostram que a fase c $(4 \times 2)$ é sempre dominante nas amostras [88], sendo que a ausência do padrão tipo zig-zag (figura 3.3) não é favorecido. Em temperaturas mais altas, o arranjo de dímeros assimétricos é aleatório devido à oscilação térmica.

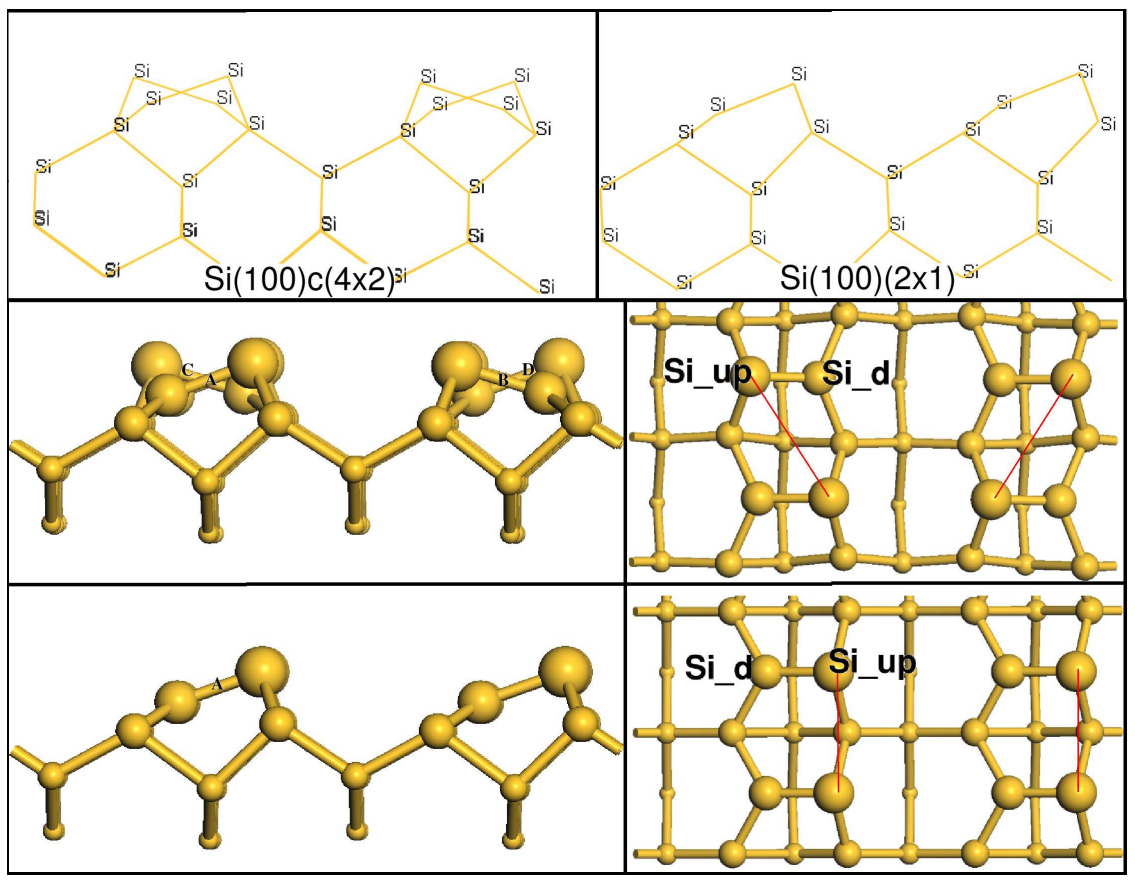

Figura 3.3: Visão lateral e de topo das configurações otimizadas das reconstruções $\operatorname{Si}(100) c(4 \times 2)$ (acima) e $\operatorname{Si}(100)(2 \times 1)$ (abaixo). Os átomos de Si são representados em amarelo e o tamanho das esferas está relacionado com a posição dos átomos de Si em relação à superfície livre.

Simulações de dinâmica molecular de Car-Parrinello [93], mostram que a ausência de padrão tipo zig-zag (linhas vermelhas na figura 3.3) não é a reconstrução mais estável para a superfície $\mathrm{Si}(100)(2 \times 1)$, em acordo com as previsões teóricas.

Ao ser retirada do ambiente de vácuo, a superfície $\operatorname{Si}(100)$ (que daqui em diante chamaremos de superfície limpa), é imediatamente coberta por óxido nativo e vários outros contaminantes, tendo suas propriedades completamente alteradas. A reatividade dos dímeros limita as aplicações tecnológicas deste material. A passivação da 


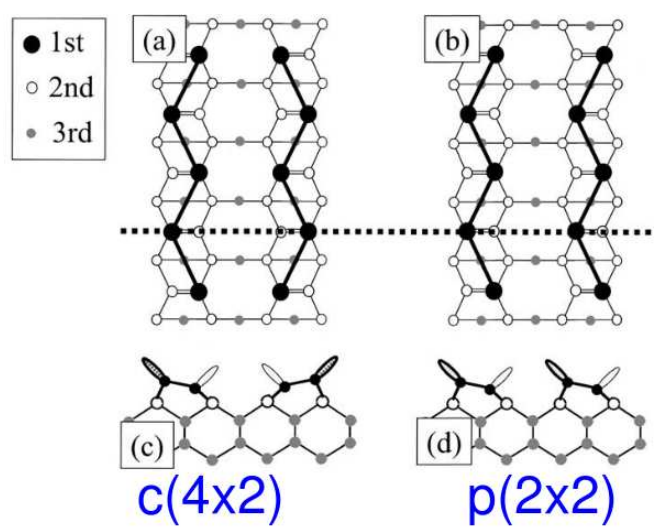

Figura 3.4: Visão de topo (a e b) e lateral (c e d) das reconstruções $\operatorname{Si}(100)$ c(4x2) e $\operatorname{Si}(100) \mathrm{p}(2 \mathrm{x} 2)$. Figura retirada da referência [88].

superfície limpa por adsorção de hidrogênio atômico, dando origem às superfícies hidrogenadas - $\mathrm{Si}(100): \mathrm{H}$, tem sido a forma mais comum de diminuição da reatividade destes sistemas. Os processos de hidrogenação promovem a remoção dos níveis de dangling bonds presentes no gap da superfície limpa, com consequente mudança nas propriedades físicas e químicas, permitindo que as superfícies hidrogenadas possam ser manipuladas fora do vácuo: em geral, as superfícies passivadas apresentam melhor homogeneidade química e menor densidade de defeitos eletrônicos, tornandose robustas para aplicações em dispositivos microeletrônicos [26,96], onde a ausência de rugosidade é requerida. Somado a isto, as superfícies hidrogenadas têm potencial para aplicações vastas em sensores biológicos, nanotecnologia, eletrônica molecular e em áreas onde contato com ambientes líquidos ou gasosos seja necessário.

Nos últimos 15 anos, foram publicados vários trabalhos experimentais dedicados ao estudo da passivação das superfícies de Si por hidrogênio, dada a complexidade do sistema em questão. A estrutura atômica resultante da hidrogenação difere muito em consequência do processo de passivação. A técnica experimental de espectroscopia no infravermelho (FTIR - Fourier Transform InfraRed) é muito uitilizada para verificar a homogeneidade destes sistemas, devido à presença de um sinal nítido da vibração $\mathrm{Si}-\mathrm{H} \mathrm{em} \approx 2100 \mathrm{~cm}^{-1}$. O foco das investigações foi inicial- 
mente voltado aos métodos de preparação e caracterização [19,97-105] destas superfícies, com o objetivo de se alcançar controle, em nível atômico, sobre as estruturas crescidas. Na década de 90, com o surgimento de algumas "receitas" bem sucedidas para a obtenção das superfícies $\operatorname{Si}(100): H$, a conjunção teoria-experimento [106] possibilitou um avanço considerável no entendimento dos processos de reconstrução induzidos pelo H na superfície limpa. Hoje, sabe-se que três fases hidrogenadas distintas, $(2 \mathrm{x} 1): \mathrm{H},(3 \mathrm{x} 1): \mathrm{H}$ e $(1 \mathrm{x} 1): 2 \mathrm{H}$ (figuras $3.5(\mathrm{a}), 3.5(\mathrm{c})$ e $3.5(\mathrm{~b}))$, podem ser obtidas dependendo das condições experimentais sobre as quais a hidrogenação foi realizada. Procedimentos tanto em ultra alto vácuo (UHV - ultra-high vacuum) quanto por métodos químicos constituem formas muito utilizadas para passivação das superfície $\mathrm{Si}(100)$. As três reconstruções passivadas diferem pela quantidade de átomos de H adsorvidos no dímero. A superfície $\operatorname{Si}(100)(2 \times 1): H$ também denominada "monohidrogenada" mantem o padrão de fileiras de dímeros, separadas por uma região de vale que muito se assemelha à superfície $\operatorname{Si}(100)(2 x 1)$. Neste caso, devido à ausência de dangling bonds, os dímeros são simétricos. A reconstrução $\operatorname{Si}(100)(3 \times 1): H$ é constituída pela alternância de unidades $\mathrm{H}-\mathrm{Si}-\mathrm{Si}-\mathrm{H}$ e H-Si-H. A superfície $\operatorname{Si}(100)(1 x 1): 2 H$ é a única que não tem presença de dímeros hidrogenados, ao contrário, sua estrutura é formada somente por grupos $\mathrm{H}-\mathrm{Si}-\mathrm{H}$, e é comumente denominada di-hidrogenada.

\section{Hidrogenação em UHV}

Este é, provavelmente, o método mais utilizado quando o objetivo é o estudo das propriedades das superfícies $\mathrm{Si}(100): H$, devido ao alto grau de pureza das amostras obtidas. O procedimento experimental constitui-se em posicionar um filamento quente $\left(1500-2000{ }^{0} \mathrm{C}\right)$ de tungstênio em frente à superfície limpa, enquanto introduz-se $\mathrm{H}_{2}$ na câmara de vácuo. $\mathrm{O}$ calor do filamento metálico promove a quebra desta molécula, fornecendo hidrogênio atômico que reagirá com a superfície limpa. A técnica é conceitualmente simples, porém há vários parâmetros a serem controlados 


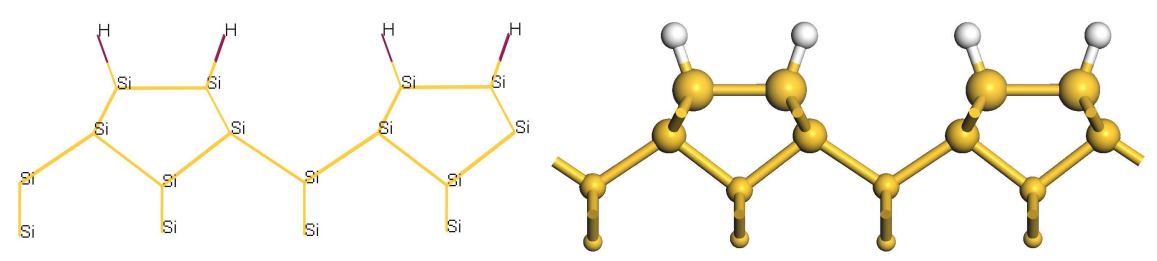

(a) $\operatorname{Si}(100)(2 \times 1): H$

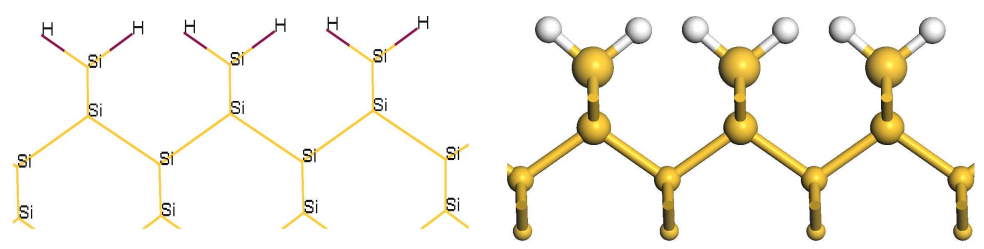

(b) $\operatorname{Si}(100)(1 \times 1): 2 \mathrm{H}$

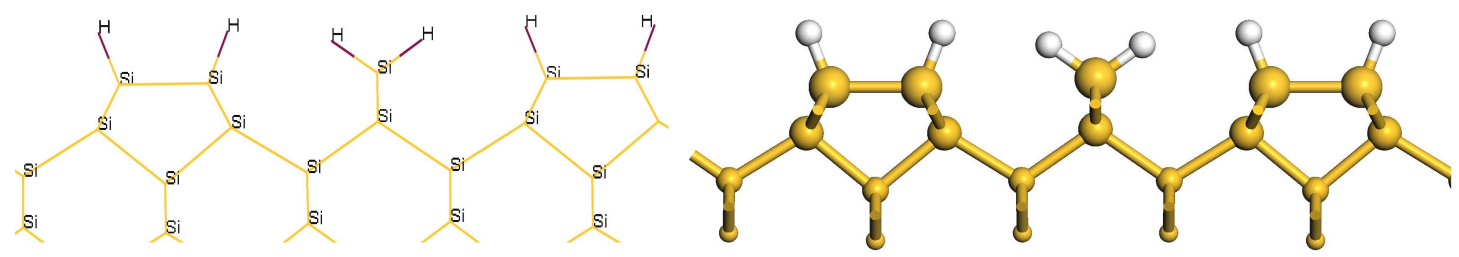

(c) $\operatorname{Si}(100)(3 \times 1): H$

Figura 3.5: Vista lateral das superfícies (a) $\operatorname{Si}(100)(2 \mathrm{x} 1): H$, (b) $\operatorname{Si}(100)(1 \times 1): 2 \mathrm{H}$ e (c) $\operatorname{Si}(100)(3 \times 1): H$. O tamanho das esferas relaciona-se com a "camada" em relação à superfície livre.

durante o processo de hidrogenação: temperatura do filamento metálico, pressão do $\mathrm{H}_{2}$, duração da exposição do substrato ao H, distância entre o filamento e a amostra, temperatura da superfície e o fluxo de H. Em geral, não é possível medir com precisão a quantidade de $\mathrm{H}$ à qual a amostra foi exposta. Uma estimativa do fluxo pode ser obtida através do produto da pressão da câmara de vácuo pelo tempo e é espressa em unidades de Langmuir $\left(1 \mathrm{~L}=1 \times 10^{-6}\right.$ Torr $\left.\mathrm{x} 1 \mathrm{~s}\right)$. Durante anos, procurou-se encontrar a melhor combinação destes parâmetros que fornecesse controle sobre a reação entre H e as superfícies de $\operatorname{Si}(100)$, no entanto as primeiras receitas de sucesso só apareceram no início da década de 90 com os trabalhos pioneiros de Boland e Wang [98-102, 107].

A hidrogenação da superfície limpa em $\approx 600 \mathrm{~K}$ mantém a periodicidade do sub- 
strato, resultando na reconstrução denominada $\mathrm{Si}(100)(2 \mathrm{x} 1): \mathrm{H}$ (ou superfície monohidrogenda). Nesta estrutura cada átomo de Si se liga a um átomo de hidrogênio, saturando todas as ligações pendentes, resultando na formação de um dímero simétrico, cujo arranjo atômico é mostrado na figura 3.5(a). Como todos os sítios disponíveis na superfície estão ocupados, temos uma cobertura de 1 Monolayer (1 ML), com um átomo de H quimiossorvido sobre um átomo de Si. Se o fluxo de H não é interrompido, mas a temperatura da superfície monohidrogenada for abaixada para $295 \mathrm{~K}$, os dímeros são quebrados e cada átomo de Si se liga a dois átomos de H (cobertura de $2 \mathrm{ML}$ ), formando a fase $\operatorname{Si}(100)(1 \times 1): 2 \mathrm{H}$, figura 3.5(b). A obtenção, em UHV, desta reconstrução é difícil, uma vez que a presença do filamento metálico aquece o substrato e induz à formação de vários defeitos. Se durante a passivação, a temperatura da amostra estiver entre 370 - $400 \mathrm{~K}$, observaremos a formação de unidades $\mathrm{H}-\mathrm{Si}-\mathrm{Si}-\mathrm{H}+\mathrm{SiH}_{2}$, originando uma fase para a qual temos uma cobertura de saturação de 1,33 ML (4 átomos de H adsorvidos sobre 3 átomos de Si). Esta reconstrução foi observada pela primeira vez em 1985 [97] e é conhecida como (3x1):H (veja figura $3.5(\mathrm{c})$ ).

Além dos parâmetros mencionados anteriormente, existem outros detalhes que influenciam diretamente a produção de uma superfície passivada com a reconstrução desejada. Tomemos, por exemplo, a superfície $\mathrm{Si}(100)(2 \mathrm{x} 1)$ :H: sabe-se que a amostra deve ser resfriada antes do filamento de tungstênio e posteriormente deve haver o interrupção do fluxo de hidrogênio na câmara de vácuo, uma vez que a interrupção simultânea destes parâmetros provocará a dessorção térmica de até $50 \%$ do H do substrato. Entretanto, a experiência mostra que, se o intervalo de tempo entre o resfriamento da amostra e do filamento metálico for superior a 30 segundos, a fase obtida será a $\operatorname{Si}(100)(3 \times 1): H$ e não a monohidorgenada. Parece-nos então compreensível, o extenso número de metodologias relatadas para os procedimentos de hidrogenação em UHV. 


\section{Hidrogenação por Métodos Químicos}

O uso de métodos de química molhada (wet chemistry - termo utilizado para se referir aos procedimentos químicos realizados em fase líquida) para hidrogenação de superfícies $\operatorname{Si}(100)$ constitui uma estratégia eficiente para formação de interfaces, deposição de moléculas orgânicas sobre o semicondutor, experimentos onde a amostra fique em contato com ambientes líquidos ou gasosos, além de possibilitar o estudo da superfície por técnicas incompatíveis com o ambiente de UHV. A única reconstrução possível para o substrato, quando este método de passivação é empregado, é a superfície $\operatorname{Si}(100)(1 \times 1): 2 H$. As etapas geralmente envolvidas no processo são:

1. oxidação térmica (reação do $\mathrm{Si}$ com $\mathrm{O}_{2}$ ou $\mathrm{H}_{2} \mathrm{O}$ em altas temperaturas (1000 $1200{ }^{0} \mathrm{C}$ ) formando um filme homogêneo de $\mathrm{SiO}_{2}$ ) de lâminas de Si monocristalino orientado na direção (100) em atmosfera contendo apenas $\mathrm{O}_{2}$ ou $\mathrm{H}_{2} \mathrm{O}$;

2. lavagem do substrato com tricloroetileno quente e acetona + álcool etílico em temperatura ambiente para remoção de possíveis contaminantes orgânicos;

3. limpeza do substrato e formação de uma camada de óxido químico, a partir da reação com solução de $\mathrm{NH}_{4} \mathrm{OH}: \mathrm{H}_{2} \mathrm{O}_{2}: \mathrm{H}_{2} \mathrm{O}$ com temperatura de $80{ }^{0} \mathrm{C}$ e

4. eliminação da camada de óxido químico e hidrogenação por imersão da amostra em solução de HF.

Entre as etapas 3 e 4, as superfícies são enxaguadas com água deionizada. Semelhante ao discutido na seção 3.1, fazendo uma breve revisão da literatura constatamos uma vasta quantidade de receitas para a preparação de superfícies dihidrogenadas por métodos químicos. A formação de defeitos tipo oxo (-O-) e estruturas trihidrogenadas $\left(\mathrm{SiH}_{3}\right)$ têm sido um dos grandes problemas associados às amostras crescidas por estas técnicas. Durante anos o grupo do pesquisador Chabal [97,102-105] investigou quais os parâmetros experimentais deveriam ser otimizados para crescimento de amostras estrutural e quimicamente homogêneas. Chegou-se a conclusão que a 
temperatura das soluções de limpeza, o tempo de lavagem em água e o pH da solução de hidrogenação são os parâmetros que influenciam de forma decisiva a qualidade das superfícies obtidas.

Apesar da passivação com hidrogênio, as superfícies $\operatorname{Si}(100): H$ são susceptíveis ao ataque de agentes oxidantes, tais como $\mathrm{O}_{2}$ e $\mathrm{H}_{2} \mathrm{O}$. Existem evidências experimentais [26] que demonstram degradação estrutural destas superfícies após $\approx 10$ minutos de exposição em ar. Focalizaremos nosso estudo sobre oxidação nas superfícies limpa e hidrogenada, $\operatorname{Si}(100)(2 \times 1): H$.

\subsection{Nossos Resultados}

\section{Sumário}

Neste capítulo apresentaremos brevemente as propriedades estruturais das superfícies limpas $\operatorname{Si}(100)(2 \times 1), \operatorname{Si}(100) c(4 x 2)$, da superfície $\operatorname{Si}(100)(2 \times 1): H$ e ainda das superfícies $\operatorname{Si}(100)(3 x 1): H$ e $\operatorname{Si}(100)(1 \times 1): 2 H$. Uma análise mais detalhada sobre as propriedades eletrônicas será realizada no capítulo 6. Ressaltamos que os resultados apresentados aqui já são conhecidos, e nosso objetivo é apenas caracterizar estas superfícies com a mesma metodologia empregada na sequência nos cálculos de caminhos de reação. Somado a isto, a vasta quantidade de resultados bem estabelecidos para estes sistemas pode ser um campo de prova para o nosso modelo. Esta revisão bibliográfica foi também importante na escolha dos sistemas a serem investigados. Nossos cálculos foram realizados dentro da aproximação da DFT, com funcional de troca e correlação LDA-PZ [57] ou GGA-PW91 [59, 108]. Devido ao elevado custo computacional envolvido nos cálculos de caminhos de reação, sempre iniciamos nossos estudos com LDA-PZ e, posteriormente repetimos os cálculos com GGA-PW91. Isto implica que, em alguns casos, só apresentaremos os resultados obtidos com o funcional local. A superfície é descrita utilizando o modelo de "fatias" (figura 3.6) e condições periódicas de contorno. Este modelo consiste em se extrair uma fatia 
do cristal infinito cujo número de camadas seja o suficiente para descrever a superfície e a região de bulk. Na direção paralela às fatias, a periodicidade bidimensional inerente à superfície é adequadamente representada. Para evitar a interação entre a fatia e sua imagem periódica na direção perpendicular (artificialmente periódica), introduzimos uma camada de vácuo, como mostrado na figura 3.6. O parâmetro de rede lateral primitivo empregado na construção das "fatias" foi obtido a partir de cálculos de otimização realizados no cristal de Si (com o termo de troca e correlação correspondente), sendo a dimensão lateral escolhida de acordo com a superfície. Para aquela denominada $(2 \mathrm{x} 1)$, teremos, nas direções cartesianas designadas por

$\mathbf{x}$ e $\mathbf{y}$ (figura 3.6), parâmetros de rede da fatia dados por $\sqrt{2} a \times \frac{\sqrt{2}}{2} a$, onde $a$ é o parâmetro de rede do Si em sua forma bulk. Para a direção cartesiana $\mathbf{z}$, o valor do parâmetro de rede tem valor adequado para que tenhamos uma camada de vácuo de $\approx 19 \AA$ entre as imagens periódicas.

\subsubsection{Superfície $\operatorname{Si}(100)(2 \times 1)$ e $\operatorname{Si}(100) c(4 \times 2)$}

Para estas superfícies, utilizamos modelos com, respectivamente, parâmetros laterais mínimos $(2 \times 1)$ e $(4 \times 2)$, e "fatias" com 8 camadas de Si reconstruídas de forma simétrica nos dois lados, e separadas por $\approx 19 \AA$. Todos os resultados foram calculados com energia de corte de ondas planas de $25 \mathrm{Ry}$ e corte da densidade de carga de 250 Ry, empregando pseudopotencial de norma conservada [61]. A variação da energia de corte para 40 Ry não produz variação nos valores dos parâmetros estruturais ou nas propriedades eletrônicas do sistema. Utilizamos 18 pontos k especiais, gerados através do esquema de Monkhorst-Pack [60], para a integração das equações de Kohn-Sham, quando a fatia era a (2x1). Neste caso, os dados analisados foram calculados com o funcional LDA-PZ. Nossos resultados mostram que a reconstrução $\operatorname{Si}(100) c(4 \times 2)$ é energeticamente favorecida por $\approx 0,8 \mathrm{eV}$ em relação à estrutura $\operatorname{Si}(100)(2 \times 1)$. Listamos na tabela 3.1 valores de distâncias e ângulos de ligação otimizados para ambas as estruturas. Para fim de comparação, tam- 

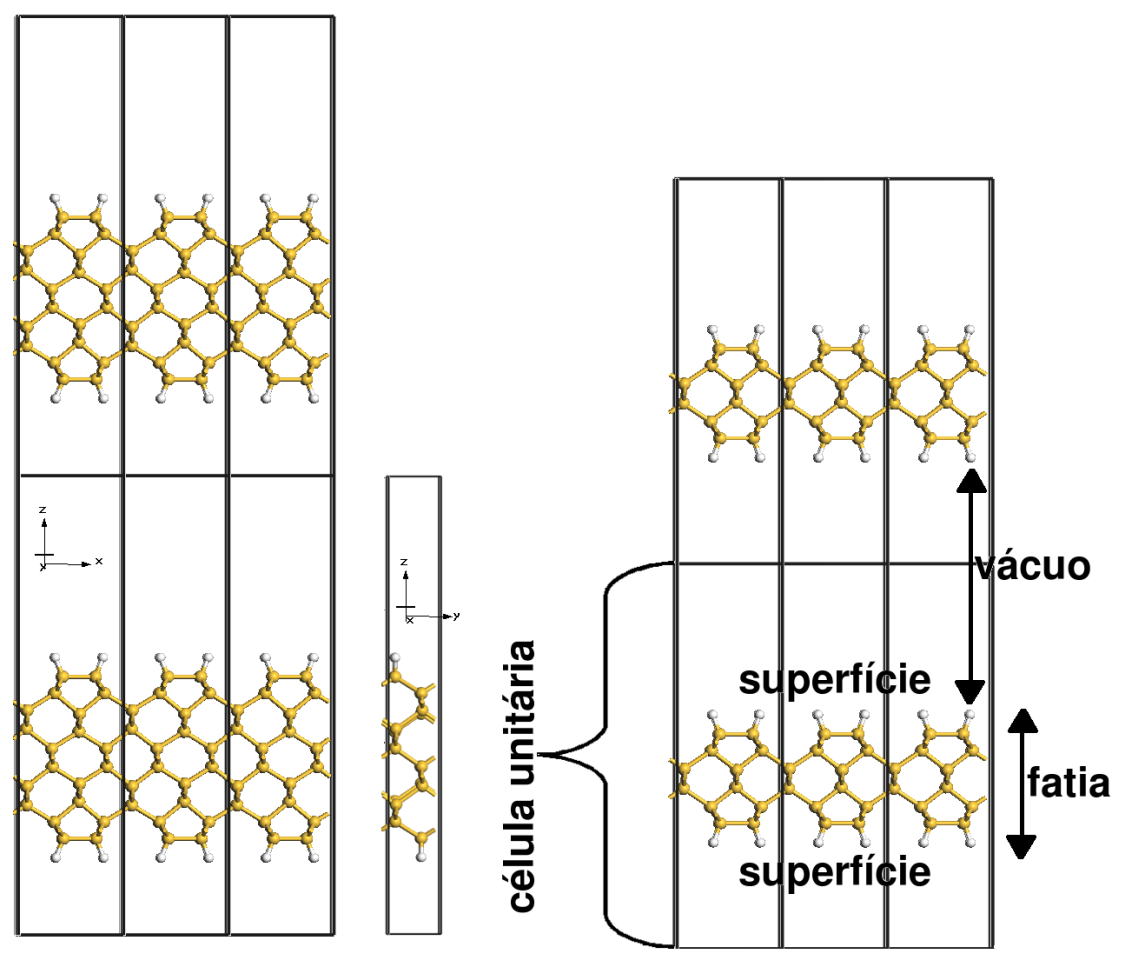

Figura 3.6: Visão lateral das células unitárias utilizadas para representar a superfície infinita, utilizando o modelo de "fatias". Da esquerda para a direita: $\operatorname{Si}(100)(2 \times 1): H$ com 10 e 6 camadas de Si. Para a fatia com 10 camadas, apresentamos a visão lateral no eixo onde temos os dímeros e também a região da fileira de dímeros. Os átomos de Si são representados em amarelo e os átomos de H por esferas brancas.

bém mostramos alguns resultados experimentais e teóricos. Os valores são idênticos aos obtidos com uma fatia $(4 \times 6)$ e com um único ponto $\mathrm{k}$ (ponto $\Gamma$ ). Os dados experimentais foram obtidos por difração de raios-X [109] e fotoemissão (surface core-level shift-SCLS) [110]. Os resultados teóricos [78,111,112] se referem à reconstrução $(2 \mathrm{x} 1)$ e foram calculados utilizando DFT-LDA, pseudopotencial de norma conservada e funções de base tipo gaussianas ou ondas planas. Para a superfície c(4x2), simulações de dinâmica molecular Car-Parrinello [93] predizem distância $\mathrm{Si}-\mathrm{Si} \approx 2,38 \AA$, e $\theta \simeq 17^{\circ}$. Para a reconstrução $\mathrm{p}(2 \mathrm{x} 2)$, Uchiyama e Tsukada [113] relatam valores $2,32 \AA$ e $17,7^{\circ}$ para o comprimento do dímero e o ângulo $\theta$.

Nossos resultados mostram que a distância de ligação do dímero na estrutura 
$\operatorname{Si}(100)(2 x 1)$ é 3,4 \% menor que o valor observado para a ligação normal Si-Si no Si cristal (bulk), 2,35 ̊. Na superfíce $\mathrm{c}(4 \mathrm{x} 2)$ esta diferença é de apenas 1,4\%. A formação de dímeros assimétricos, em ambas as reconstruções, provoca grandes distorções da configuração tetraédrica (valores de $\Delta$ z na tabela 3.1). Constatamos ainda que os átomos de Si up e down estão alinhados na fileira de dímeros, isto é, valores de $\Delta$ y são menores que $0,0001 \AA$.

Tabela 3.1: Parâmetros estruturais obtidos para a superfície Si(100)(2x1), comparados com resultados teóricos [78,111] e experimentais [109,110,112]. Os símbolos estão definidos nas figuras 3.2 e 3.3 .

\begin{tabular}{lcc|ccc}
\hline \hline & $(2 \mathrm{x} 1)$ & $\mathrm{c}(4 \mathrm{x} 2)$ & {$[78,111]$} & {$[112]$} & {$[109,110]$} \\
& LDA-PZ & LDA-PZ & LDA & LDA & \\
\hline Distâncias $(\AA)$ & & & & & \\
$(\mathrm{Si}-\mathrm{Si})_{A}$ & 2,27 & 2,32 & 2,25 & 2,29 & $2,20-2,47$ \\
$(\mathrm{Si}-\mathrm{Si})_{B}$ & 2,27 & 2,32 & & 2,29 & \\
$(\mathrm{Si}-\mathrm{Si})_{C}$ & 2,27 & 2,32 & & 2,29 & \\
$(\mathrm{Si}-\mathrm{Si})_{D}$ & 2,27 & 2,32 & & 2,29 & \\
$(\Delta \mathrm{z})_{A}$ & 0,76 & 0,81 & 0,62 & & - \\
$(\Delta \mathrm{z})_{B}$ & 0,76 & 0,67 & 0,62 & & - \\
$(\Delta \mathrm{z})_{C}$ & 0,76 & 0,67 & 0,62 & & - \\
$(\Delta \mathrm{z})_{D}$ & 0,76 & 0,81 & 0,62 & & - \\
\hline ângulos $\left(^{\circ}\right)$ & & & & & \\
$(\theta)_{A}$ & 19,6 & 20,4 & 16,$1 ; 17$ & 19,0 & $15-20$ \\
$(\theta)_{B}$ & 19,6 & 16,8 & 16,$1 ; 17$ & 19,0 & $15-20$ \\
$(\theta)_{C}$ & 19,6 & 16,8 & 16,$1 ; 17$ & 19,0 & $15-20$ \\
$(\theta)_{D}$ & 19,6 & 20,4 & 16,$1 ; 17$ & 19,0 & $15-20$ \\
\hline \hline
\end{tabular}




\subsubsection{Superfície $\operatorname{Si}(100)(2 \times 1): H$}

Como etapa inicial do nosso estudo de oxidação molhada de superfícies hidrogenadas, examinamos as propriedades estruturais e eletrônicas para a superfície $\mathrm{Si}(100)(2 \mathrm{x} 1): \mathrm{H}$. Os resultados foram obtidos através do modelo de "fatias", com 6 e 10 camadas de Si (figura 3.6) reconstruídas de forma simétrica nos dois lados. Em todos os cálculos, empregamos valores de energia de corte e número de pontos k já utilizados no estudo da superfície $\operatorname{Si}(100)(2 x 1)$. Os átomos de Si são representados por pseudopotenciais de norma conservada e os de $\mathrm{H}$ por ultrasuaves.

Na tabela 3.2 listamos valores de ângulos e distâncias de ligação, obtidos com os funcionais LDA-PZ e GGA-PW91, comparados a dados de difração de raios X [114, 115] e cálculos de primeiros princípios, baseado em DFT [114]. Na figura 3.7, mostramos a estrutura relaxada para esta superfície e definimos os símbolos utilizados na tabela 3.2 .

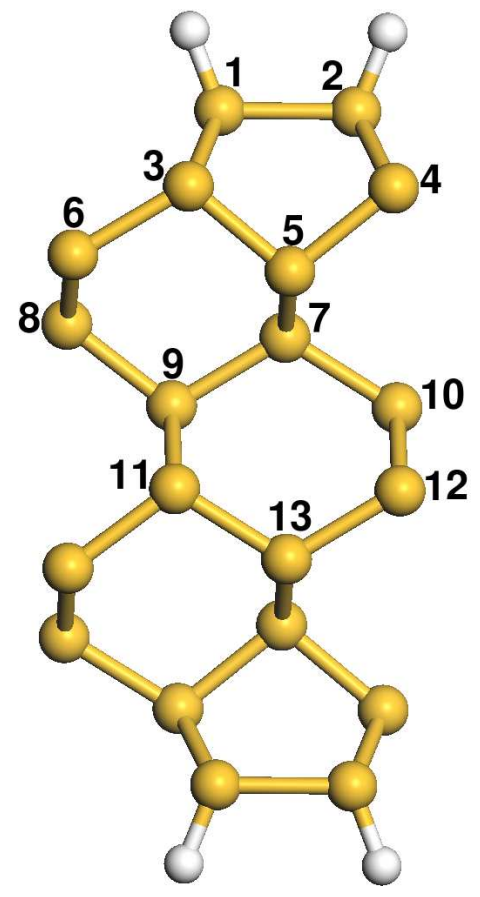

Figura 3.7: Visão da superfície $\operatorname{Si}(100)(2 \times 1): H$ com 10 camadas atômicas e monohidrogenada no lado "superior" e "inferior", e numeração utilizada na tabela 3.2. 
Tabela 3.2: Parâmetros estruturais obtidos para a superfície $\operatorname{Si}(100)(2 x 1): H$, comparados com resultados teóricos [114] e experimentais [114,115]. Os símbolos estão definidos na figura 3.7.

\begin{tabular}{|c|c|c|c|c|c|}
\hline & $\begin{array}{c}6 \text { camadas } \\
\text { LDA-PZ }\end{array}$ & $\begin{array}{c}6 \text { camadas } \\
\text { GGA-PW91 }\end{array}$ & $\begin{array}{c}10 \text { camadas } \\
\text { LDA-PZ }\end{array}$ & {$[114]$} & {$[114,115]$} \\
\hline \multicolumn{6}{|c|}{ Distâncias $(\AA)$} \\
\hline H-Si1 & 1,50 & 1,50 & 1,50 & 1,49 & 1,51 \\
\hline $\mathrm{Si} 1-\mathrm{Si} 2$ & 2,41 & 2,44 & 2,38 & 2,42 & 2,$45 ; 2,47$ \\
\hline Si1-Si3 & 2,35 & 2,37 & 2,34 & 2,36 & 2,36 \\
\hline $\mathrm{Si} 2-\mathrm{Si} 4$ & 2,35 & 2,37 & 2,34 & 2,36 & 2,36 \\
\hline $\mathrm{Si} 3-\mathrm{Si} 5$ & 2,32 & 2,34 & 2,34 & 2,34 & 2,36 \\
\hline Si3-Si6 & 2,39 & 2,43 & 2,36 & 2,39 & 2,40 \\
\hline $\mathrm{Si} 4-\mathrm{Si} 5$ & 2,32 & 2,34 & 2,34 & 2,34 & 2,36 \\
\hline $\mathrm{Si} 5-\mathrm{Si} 7$ & 2,29 & 2,32 & 2,33 & 2,34 & 2,33 \\
\hline Si6-Si8 & 2,39 & 2,42 & 2,36 & 2,38 & 2,34 \\
\hline Si7-Si9 & - & - & 2,34 & 2,34 & 2,34 \\
\hline Si8-Si9 & - & - & 2,35 & 2,38 & 2,37 \\
\hline Si7-Si10 & - & - & 2,34 & 2,35 & 2,34 \\
\hline \multicolumn{6}{|l|}{ ângulos $\left(^{\circ}\right)$} \\
\hline H-Si1-Si2 & 109,9 & 109,4 & 111,0 & - & - \\
\hline Si1-Si3-Si5 & 95,5 & 95,3 & 97,7 & - & - \\
\hline $\mathrm{Si3}-\mathrm{Si} 5-\mathrm{Si} 4$ & 105,2 & 105,1 & 99,9 & - & - \\
\hline $\mathrm{Si} 4-\mathrm{Si} 2-\mathrm{Si} 1$ & 105,7 & 105,6 & 104,9 & - & - \\
\hline $\mathrm{Si3}-\mathrm{Si} 6-\mathrm{Si} 8$ & 109,4 & 109,3 & 107,0 & - & - \\
\hline Si6-Si3-Si5 & 109,0 & 109,2 & 109,7 & - & - \\
\hline
\end{tabular}


Observamos bom acordo com os resultados experimentais e teóricos anteriores. Em consequência da absorção de H sobre a superfície limpa, os átomos Si do dímero permanecem ligados através de uma ligação $\sigma$, adquirindo configuração simétrica. A distância $\mathrm{Si}-\mathrm{Si}$ sofre um acréscimo de 4,8\% (6,2\% para a fatia de 6 camadas) em relação à superfície $\operatorname{Si}(100)(2 \times 1)$ (tabela 3.1). Este efeito de distensão na distância interatômica dos átomos dimerizados é maior nas superfícies do diamante (a ligação $\mathrm{C}-\mathrm{C}$ se alonga em $\approx 17 \%$ na presença de $\mathrm{H}[116])$, uma vez que os orbitais $2 p$ apresentam sobreposição lateral efetiva, formando uma ligação $\pi$. No Si, os orbitais $3 p$, responsáveis pelo que se convencionou chamar relação de transferência de carga

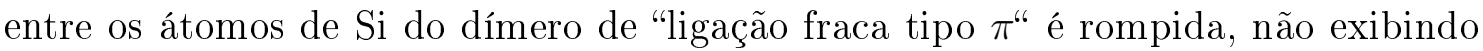
uma sobreposição lateral efetiva, o que pode ser visto pela menor diferença no comprimento de ligação dos dímeros após a hidrogenação. Para o Ge, que tem número atômico 32, este efeito é praticamente desprezível (somente há a simetrização do dímero, sem alteração na distância $\mathrm{Ge}-\mathrm{Ge}$ ) [117].

Os dados compilados na tabela 3.2, calculados para a superfície sendo representada por "fatias" contendo 6 e 10 camadas de Si, mostram que somos capazes de descrever adequadamente a reconstrução $\operatorname{Si}(100)(2 \mathrm{x} 1): \mathrm{H}$ utilizando a fatia com menor número de camadas atômicas. O fato de podermos utilizar uma fatia menor será importante nos cálculos de caminhos de reação, uma vez que a obtenção das energias de ativação é um procedimento computacional muito custoso.

\subsubsection{Superfície $\operatorname{Si}(100)(3 \times 1): H$ e $\operatorname{Si}(100)(1 \times 1): 2 H$}

As superfícies $\operatorname{Si}(100)(3 x 1): H$ e $\operatorname{Si}(100)(1 \times 1): 2 H$ são, como já mencionado, outras duas possíveis reconstruções para o substrato $\operatorname{Si}(100)$ na presença de H. Na superfície $\mathrm{Si}(100)(3 \mathrm{x} 1): \mathrm{H}$ temos uma mistura de subunidades $(2 \mathrm{x} 1): \mathrm{H}$ e (1x1):H, cuja estrutura otimizada pode ser vista na figura 3.8(a). O comprimento de ligação do dímero é muito próximo ao observado na superfície $\operatorname{Si}(100)(2 \times 1): H$ (variação percentual de 0,4 \%) e a distância entre os átomos de $\mathrm{H}$ adjacentes é $23 \%$ maior que o valor calculado 
para a superfície dihidrogenada, sendo grande o suficiente para evitar a repulsão eletrostática H-H. Assim, a fase $(3 \times 1): H$ torna-se energeticamente favorecida. Para a superfície 1x1, a repulsão eletrostática entre os átomos de hidrogênio adjacentes é responsável pela formação de estruturas dihidrogenadas denominadas canted (veja figura 3.8(b)) e não simétricas, como mostramos na figura 3.5(b) da seção 3.2.2. Para minimizar as forças repulsivas, o grupo $\mathrm{SiH}_{2}$ gira $11,4^{0}$ em relação aos átomos de $\mathrm{Si}$ da segunda camada atômica, fazendo com que a distância H...H contíguos aumente em $40.3 \%$. Com este arranjo atômico, a distância $\mathrm{Si}_{\text {superf }}-\mathrm{Si}_{\text {backbond }}$ e o ângulo

$\mathrm{Si}_{\text {superf }}-\mathrm{Si}_{\text {camada-2 }}-\mathrm{Si}_{\text {camada-3 }}$ aproxima-se do valor observado no cristal $(2,35 \AA \mathrm{e}$ $\left.109,9^{0}\right)$. Nota-se ainda o aumento de $11,8^{0}$ no valor do ângulo de ligação no grupo $\mathrm{SiH}_{2}$, contribuindo para a diminuição das interações repulsivas entre os átomos de H ligados ao mesmo átomo de superfície. Com a diminuição das tensões estruturais, a energia total decresce, em concordância com os resultados de cálculos de primeiros princípios de Northrup [106]. As variações dos parâmetros estruturais para os dois casos são mostradas na figura 3.8(b).

\subsection{Conclusões Parciais}

A descrição dos parâmetros estruturais para as superfícies ideais de Si limpas e hidrogenadas encontram-se em bom acordo com os dados teóricos e experimentais para ambos os sistemas. Para as superfícies passivadas, temos interesse especial na reconstrução $(2 \times 1): H$, visto que há indícios experimentais irrefutáveis de que esta é a superfície mais susceptível ao ataque de água [118-121] quando comparada às reconstruções (3x1):H e (1x1):H somado ao fato de que as amostras para a estrutura monohidrogenada são ordenadas, sendo muito interessante para aplicações em sistemas híbridos. As propriedades estruturais destes sistemas, obtidas aqui com as aproximações LDA-PZ e GGA-PW91 para a energia de troca e correlação, estão em acordo com dados experimentais e com resultados teóricos anteriores. Certificamos ainda que o uso de uma fatia constituída por 6 camadas atômicas de Si é suficiente 


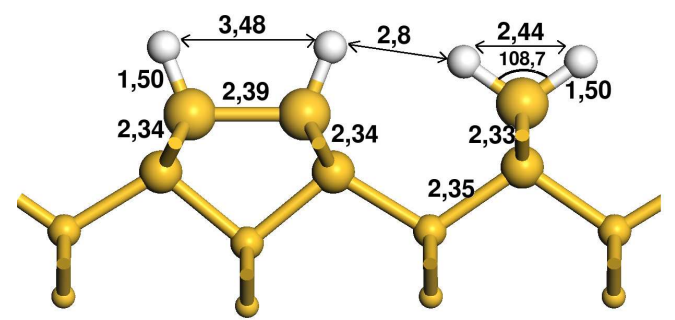

(a) $\operatorname{Si}(100)(3 \times 1): H$

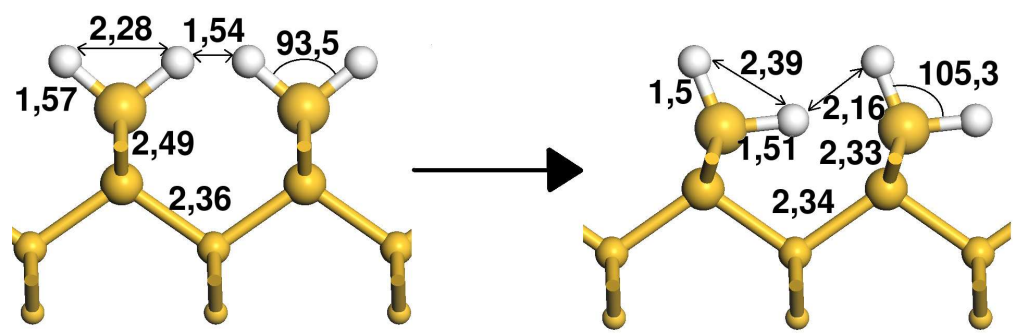

(b) $\operatorname{Si}(100)(1 \times 1): 2 \mathrm{H}$

Figura 3.8: Estruturas otimizadas para as superfície $\mathrm{Si}(100)(3 \mathrm{x} 1): \mathrm{H}$ e (1x1):H e valores de parâmetros estruturais otimizados utilizando LDA-PZ. Distâncias de ligação entre átomos indicados por setas, em $\AA$, e ângulos de ligação em graus.

para uma boa descrição da superfície monohidrogenada. Esta foi uma constatação importante para prosseguirmos com os estudos de caminhos de oxidação molhada nesta superfície. Análise detalhada das propriedades eletrônicas dos sistemas estudados anteriormente será realizada no capítulo 6 . 


\section{Capítulo 4}

\section{Reação entre a molécula de $\mathrm{H}_{2} \mathrm{O}$}

isolada e a superfície limpa $\mathrm{H}_{2} \mathrm{O} / \mathrm{Si}(100)(2 \times 1)$

Os processos de adsorção de $\mathrm{H}_{2} \mathrm{O}$ sobre superfícies de Si constitui uma área importante e ativa em pesquisa relacionada a semicondutores. Esta reação é importante não somente devido a aspectos físicos e químicos fundamentais relacionados à interação de moléculas com substratos semicondutores, mas também devido à sua relevância tecnólogica [77]. $\mathrm{O}_{2}$ e $\mathrm{H}_{2} \mathrm{O}$ (em fase gasosa) são agentes oxidantes amplamente empregados pela indústria de eletrônica para produzir interfaces $\mathrm{Si} / \mathrm{SiO}_{2}$.

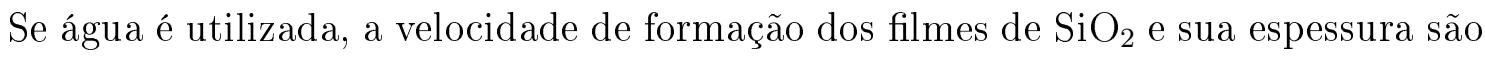
maiores quando comparadas ao resultado obtido com a reação com oxigênio [122]. Apesar do amplo uso destas interfaces na produção de dispositivos eletrônicos, um modelo microscópico claro destes sistemas ainda não existe [123]. Assim, há um esforço conjunto de teóricos e experimentais dedicados à caracterização estrutural, cinética e energética destas interfaces. Neste capítulo, dedicaremos ao estudo da cinética da reação que conduz à decomposição de uma molécula de água sobre a superfície $\operatorname{Si}(100)(2 \times 1)$. 


\subsection{Revisão de Dados Experimentais e Teóricos}

A oxidação das superfícies $\operatorname{Si}(100)(2 x 1)$ por água é amplamente estudada e tem sido objeto de investigações durante décadas. Deste modo, faremos uma breve revisão sobre os resultados teóricos e experimentais relevantes obtidas até então, e posteriormente apresentaremos nossos resultados.

Dados experimentais [84,85,95,118,119,121,124-133] e teóricos [90,91,112,134138] evidenciam que a interação entre $\mathrm{H}_{2} \mathrm{O}$, em fase gasosa, e a superfície limpa é dissociativa. A molécula se decompõe em unidades $\mathrm{H}+\mathrm{OH}$, ao reagir com o dímero na superfície, dando origem à reação descrita pela equação 4.1:

$$
\mathrm{H}_{2} \mathrm{O}+\mathrm{Si}-\mathrm{Si} \longrightarrow \mathrm{H}-\mathrm{Si}-\mathrm{Si}-\mathrm{OH}
$$

Neste caso, a dimerização do substrato é mantida [128,130] e a cobertura de saturação é de 0,5 ML (monolayer), uma vez que cada molécula de água reage com dois átomos de Si. A equação 4.1 contempla apenas uma das possibilidades para a quimissorção da água sobre a superfície $\operatorname{Si}(100)(2 \times 1)$. Experimentos sofisticados de STM, possibilitaram que Andersohn e Kohler [95] realizassem estudos detalhados sobre a cinética desta reação e concluíssem que a molécula de água pode se decompor em um único dímero (equação 4.1) ou em 2 ligações não saturadas de dois dímeros adjacentes. Isto significa que, para a dissociação da molécula sobre a superfície são necessárias 2 dangling bonds disponíveis, que podem estar localizadas sobre um mesmo dímero ou dispostas em átomos de Si pertencentes a dímeros adjacentes. Como resultado da dissociação da molécula de água em dímeros distintos restam ainda na superfície ligações não saturadas, e assim um sítio de "defeito". Estas estruturas são conhecidas como defeitos tipo C [85,132,139,140] e têm sido objeto de extensa investigação. Para a superfície Si(100), a distância entre dímeros adjacentes é de aproximadamente $3,83 \AA$ enquanto os átomos de Si de um mesmo dímero

distam apenas 2,41 $\AA$, o que favorece o primeiro processo [95]. Assim sendo, a dissociação em dímeros adjacentes deve ocorrer com probabilidade mais baixa nos 
estágios iniciais de oxidação e, hoje, sabe-se tratar de uma situação metaestável para a oxidação molhada nestas superfícies. A constatação de que a reação só ocorre na presença de 2 dangling bonds é compatível com uma adsorção mediada por um "precursor molecular". Este resultado sugere que a molécula de água interage com a superfície antes da dissociação em unidades independentes $\mathrm{H}$ e OH. Se assim não fosse, cada fragmento reagiria com uma dangling bond, independentemente da presença ou não de um segundo sítio de adsorção disponível. Não é este o caso. Outra prova de que a adsorção ocorre via o precursor molecular é a ausência de sinal STM de dangling bonds isoladas. Adicionalmente, Andersohn e Kohler [95] discutem um aspecto interessante sobre a dinâmica da quimissorção de água nesta superfície: os autores mostraram que a dissociação ocorre com da formação de ilhas, e que a mobilidade dos grupos $\mathrm{Si}-\mathrm{H}$ e $\mathrm{Si}-\mathrm{OH}$ é baixa [95], o que também é sugerido através de cálculos de primeiros princípios [112].

Experimentalmente, a formação das ligações $\mathrm{Si}-\mathrm{H}$ e Si-OH é comprovada por diversas técnicas [133] além do STM, como por exemplo, através de espectroscopia de infravermelho (IR), cujo o espectro pode ser visto na figura 4.1 [118]. Os dados mostram que a exposição superfície limpa a um fluxo de 1 Languimir $(1 \mathrm{~L})$ de $\mathrm{H}_{2} \mathrm{O}$ faz com que surjam duas bandas vibracionais nítidas, em 821 e $2081 \mathrm{~cm}^{-1}$, devido ao modo de estiramento das espécies $\mathrm{Si}-\mathrm{OH}$ e $\mathrm{Si}-\mathrm{H}$ [118-121, 124, 126, 129, 130].

Chabal [124] observou que a água adsorve dissociativamente sobre a superfície $\mathrm{Si}(100)$ no intervalo de temperatura entre 80 - $420 \mathrm{~K}$, sendo que em temperatura ambiente a razão entre o número de moléculas incidentes e o número de moléculas que efetivamente reagem (sticking coefficient) aproxima-se da unidade [84,124]. Isto sugere que não existe barreira de energia para tal reação.

A dissociação de $\mathrm{H}_{2} \mathrm{O}$ sobre a superfície limpa também tem sido discutida do ponto de vista teórico [90-92,125,137], empregando diferentes metodologias. Nesses trabalhos a superfície é modelada utilizando ou a aproximação de aglomerado molecular (comumente denominado cluster) ou o modelo de fatias, e o objetivo é investigar qual o caminho que conduz à dissociação da molécula de água sobre os dímeros, 


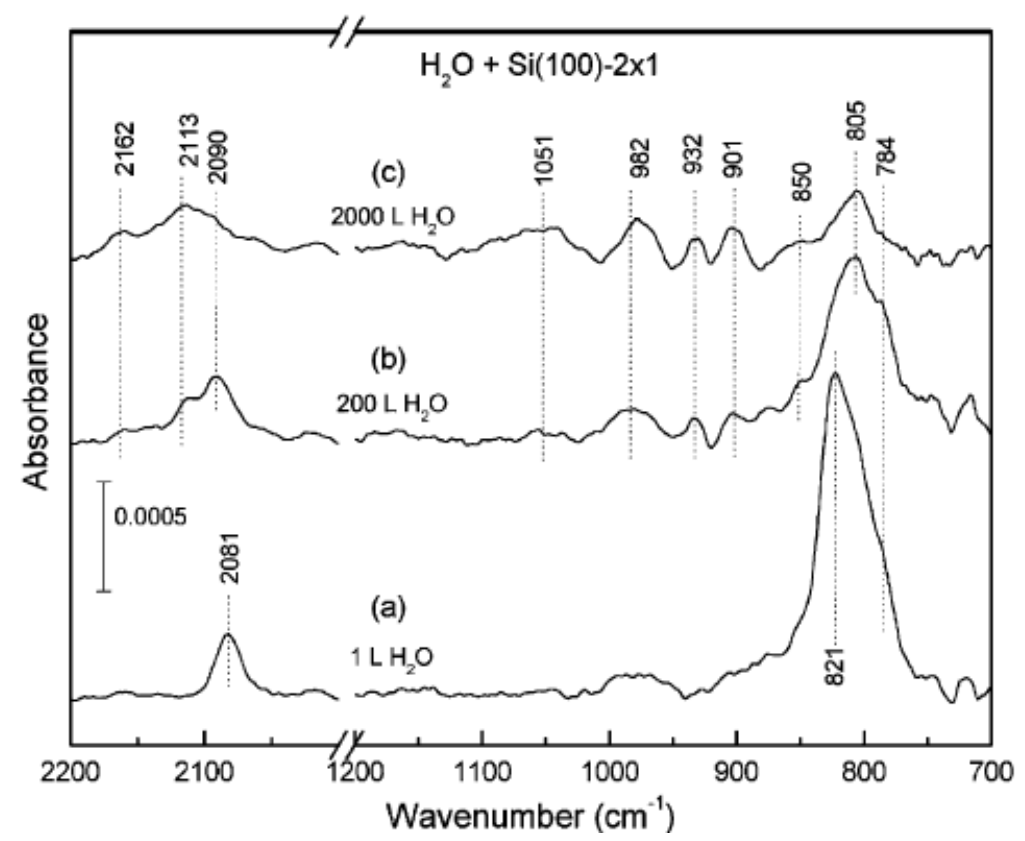

Figura 4.1: Espectro BML-IRRAS (retirado da referência [118]) para a reação entre $\operatorname{Si}(100)(2 x 1)$ e (a) $1 \mathrm{~L}$, (b) $200 \mathrm{~L}$ e (c) $2000 \mathrm{~L}$ de $\mathrm{H}_{2} \mathrm{O}$ em $373 \mathrm{~K}$.

utilizando a técnica de arraste. Contudo, desconhecemos qualquer estudo no qual se tenha realizado o cálculo do caminho de reação com um método flexível, um dos objeto de discussão deste capítulo.

Outro ponto ainda controverso refere-se à decomposição dos grupos Si-OH quando na presença de calor, ou devido ao aumento intensivo do fluxo de água (como evidenciado na figura 4.1). Há uma vasta literatura dedicada ao estudo desta questão [84, 95, 118, 119, 121, 127-135, 140], inclusive com trabalhos recentes [140], demonstrando o quão complexo pode ser o mecanismo de inserção de oxigênio nestas estruturas. Espectros de absorção no infravermelho e imagens de STM associados à calculos de primeiros princípios [127-130, 134, 135, 140], mostram que a superfície oxidada é composta majoritariamente por grupos $\mathrm{H}-\mathrm{Si}-\mathrm{Si}-\mathrm{OH}$ até a temperatura de $575 \mathrm{~K}$, sendo que mudanças importantes iniciam para valores superiores de T [127-129, 134, 135, 138]. Na referência [138] encontramos estimativas interessantes sobre a composição da superfície à medida que as espécies $\mathrm{H}-\mathrm{Si}-\mathrm{Si}-\mathrm{OH}$ são 
decompostas. Avalia-se que para $\mathrm{T}=648 \mathrm{~K}$ a superfície contenha $33 \%$ de grupos OH, $23 \%$ de espécies com 1 O, $17 \%$ com 2 átomos de O, $3 \%$ de grupos contendo 3 O e 25 - $40 \%$ de grupos $\mathrm{H}-\mathrm{Si}-\mathrm{Si}-\mathrm{H}$. Entretanto, trata-se de uma estimativa, visto que alguns modos vibracionais de espécies distintas podem ocorrer em regiões semelhantes. Embora não se possa quantificar exatamente o número de espécies oxidadas, dado que a medida do espectro de absorção é uma técnica indireta, pode-se estimar quais os grupos que estão ou não presentes após a decomposição das unidades $\mathrm{OH}$. Análises das propriedades espectrais da superfície $\operatorname{Si}(100)(2 \times 1)$ oxidada e para $\mathrm{T}=$ $650 \mathrm{~K}$, mostram que as amostras são formadas por uma combinação de $\mathrm{H}-\mathrm{Si}-\mathrm{Si}-\mathrm{H}$ (sítios não oxidados, mas hidrogenados), H-Si-O-Si-H (inserção no dímero) e H$\mathrm{Si}-\mathrm{O}-\mathrm{Si}(\mathrm{O})-\mathrm{H}$ (inserção adicional em uma ligação sub-superficial). Estas estruturas são mostradas na figura 4.2. Dois pontos a notar são que a inserção do $\mathrm{O}$ ocorre preferencialmente no dímero e não em sítios sub-superficiais (back-bonds) [128] e que os processos de dessorção de H não são observados [138]. Recentemente surgiram dados de STM, os quais mostram que a decomposição das espécies $\mathrm{Si}-\mathrm{OH}$ associadas aos defeitos tipo C podem se iniciar para temperaturas próximas a $450 \mathrm{~K}$ [140], mas, ainda sim, os processos de oxidação observados entre 575 e $675 \mathrm{~K}$ são associados à formação de $\mathrm{H}-\mathrm{Si}-\mathrm{O}-\mathrm{Si}-\mathrm{H}$. Nesse trabalho, não encontramos menção à presença de defeitos produzidos pela inserção de O sub-superficial.

As características descritas previamente são similares a àquelas encontradas na figura 4.1, visto que o efeito do aumento do fluxo de água sobre a superfície oxidada é similar ao aumento da temperatura. Neste caso, os picos de frequências 784, 805 e $854 \mathrm{~cm}^{-1}$ surgem devido a modos vibracionais associados a grupos $\mathrm{H}-\mathrm{Si}-\mathrm{Si}-$ $\mathrm{OH}$ e movimentos de torção de espécies $\mathrm{H}-\mathrm{Si}(\mathrm{O})_{x}-\mathrm{O}-\mathrm{Si}-\mathrm{H}(\mathrm{x}=0-2), \mathrm{H}-\mathrm{Si}(\mathrm{O})_{x}-\mathrm{Si}-\mathrm{H}$ $(\mathrm{x}=1-2), \mathrm{H}-\mathrm{Si}(\mathrm{O})_{2}-\mathrm{O}-\mathrm{Si}-(\mathrm{O})-\mathrm{H}$ e $\mathrm{SiH}_{3}$ (figura 4.3). O aparecimento de uma banda de absorção pouco nítida entre 1000 - $1150 \mathrm{~cm}^{-1}$ no espectro 4.1 (c) origina-se de movimentos de estiramento de unidades $\mathrm{Si}-\mathrm{O}$ e podem ser atribuídas a inúmeras espécies oxidadas, caracterizando um estágio de mudanças estruturais significativas devido à oxidação. O pico de absorção em $2090 \mathrm{~cm}^{-1}$ se relaciona a modos vibra- 


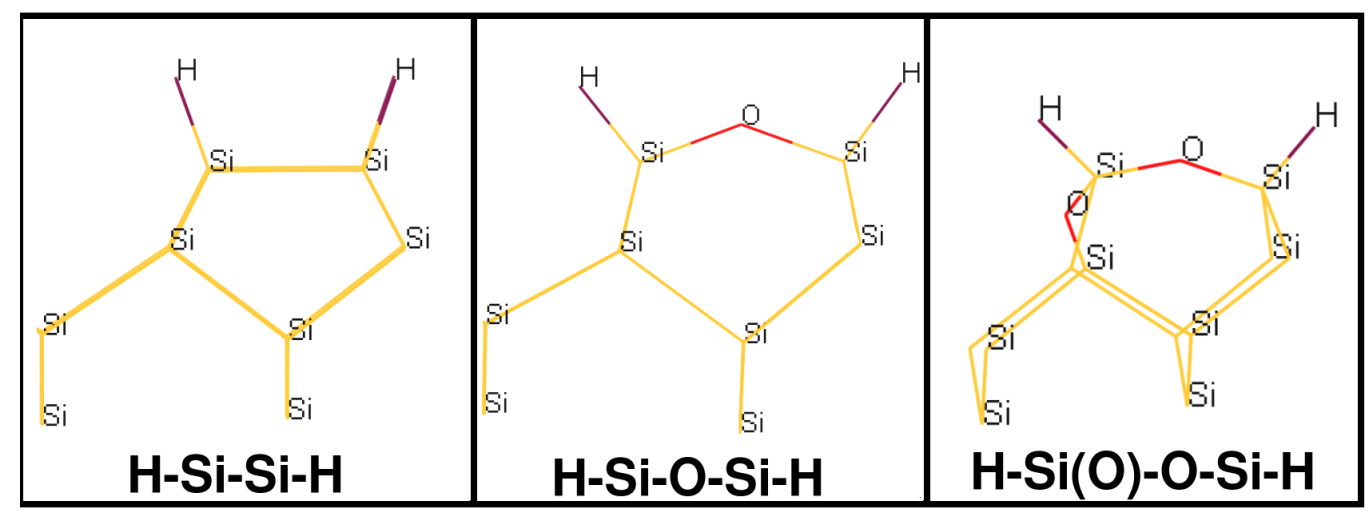

Figura 4.2: Vista lateral para as estruturas $\mathrm{H}-\mathrm{Si}-\mathrm{Si}-\mathrm{H}$ (sítios não oxidados, mas hidrogenados), H-Si-O-Si-H (inserção de oxigênio no dímero) e H-Si-O-Si(O)-H (inserção de oxigênio adicional em uma ligação sub-superficial).

cionais de estiramento $\mathrm{Si}-\mathrm{H}$ na ausência de $\mathrm{O}$, ao passo que as bandas situadas em 2113 e $2162 \mathrm{~cm}^{-1}$, também se devem ao movimento de estiramento destas espécies (figura 4.3), porém oxidadas $\left(\mathrm{H}_{2} \mathrm{Si}(\mathrm{O})_{x} \ldots \mathrm{H}_{2} \mathrm{Si}(\mathrm{O})_{x}, \mathrm{H}-\mathrm{Si}(\mathrm{O})_{x}-\mathrm{Si}(\mathrm{O})_{x}-\mathrm{H}, \mathrm{H}-\mathrm{Si}(\mathrm{O})_{x}-\right.$ $\left.\mathrm{H}, \mathrm{H}-\mathrm{Si}(\mathrm{O})_{x}-\mathrm{O}-\mathrm{Si}-\mathrm{H}\right)$. Comparando a intensidade relativa dos picos $2090 \mathrm{~cm}^{-1} \mathrm{e}$ $2113 \mathrm{~cm}^{-1}$, em 4.1 (b) e (c), nota-se a evolução da degradação estrutural promovida pela inserção de $\mathrm{O}$ na estrutura do Si. Um ponto que nos pareceu controverso aos trabalhos anteriores foi a atribuição dos picos vibracionais localizados em 901, 932 e $982 \mathrm{~cm}^{-1}$ à movimentos tipo tesoura de unidades $\mathrm{SiH}_{2}$ e $\mathrm{H}_{2} \mathrm{Si}(\mathrm{O})_{x}$ (figura 4.3) isoladas e adjacentes $\left(\mathrm{SiH}_{2} \ldots \mathrm{SiH}_{2}, \mathrm{H}_{2} \mathrm{Si}(\mathrm{O})_{x} \ldots \mathrm{H}_{2} \mathrm{Si}(\mathrm{O})_{x}\right)$. Aparentemente unidades dihidrogenadas não foram identificadas nos trabalhos anteriores de Weldon [128] e colaboradores. Contudo, os dados obtidos na referência [128] referem-se à decomposição térmica dos grupos OH. Em 2006 foi publicado um estudo de primeiros princípios [137], no qual a superfície é modelada através de aglomerados moleculares e alguns caminhos de reação são estudados de forma estática. Duas conclusões desse trabalho chamam a atenção. A diferença de energia entre os defeitos causados pela inserção de $\mathrm{O}$ no dímero ou sub-superficial é da ordem de meV, enquanto estudos teóricos anteriores predizem que a oxidação do dímero é $\approx 0,3 \mathrm{eV}$ mais estável que o defeito produzido por inserção subsuperficial [135,137,140]. Quanto às barreiras 
de reação, interpretação de resultados experimentais [128] de infravermelho sugerem que a oxidação de sítios de superfície seja associada a energia de ativação menor que aquela calculada para a quimissorção de oxigênio em sítios sub-superficiais. O resultado teórico de Watanabe e colaboradores [137] mostra que as barreiras de reação para o primeiro caso é maior que aquela associada a produção do segundo tipo de defeito, em aparente contradição com os resultados experimentais [128].

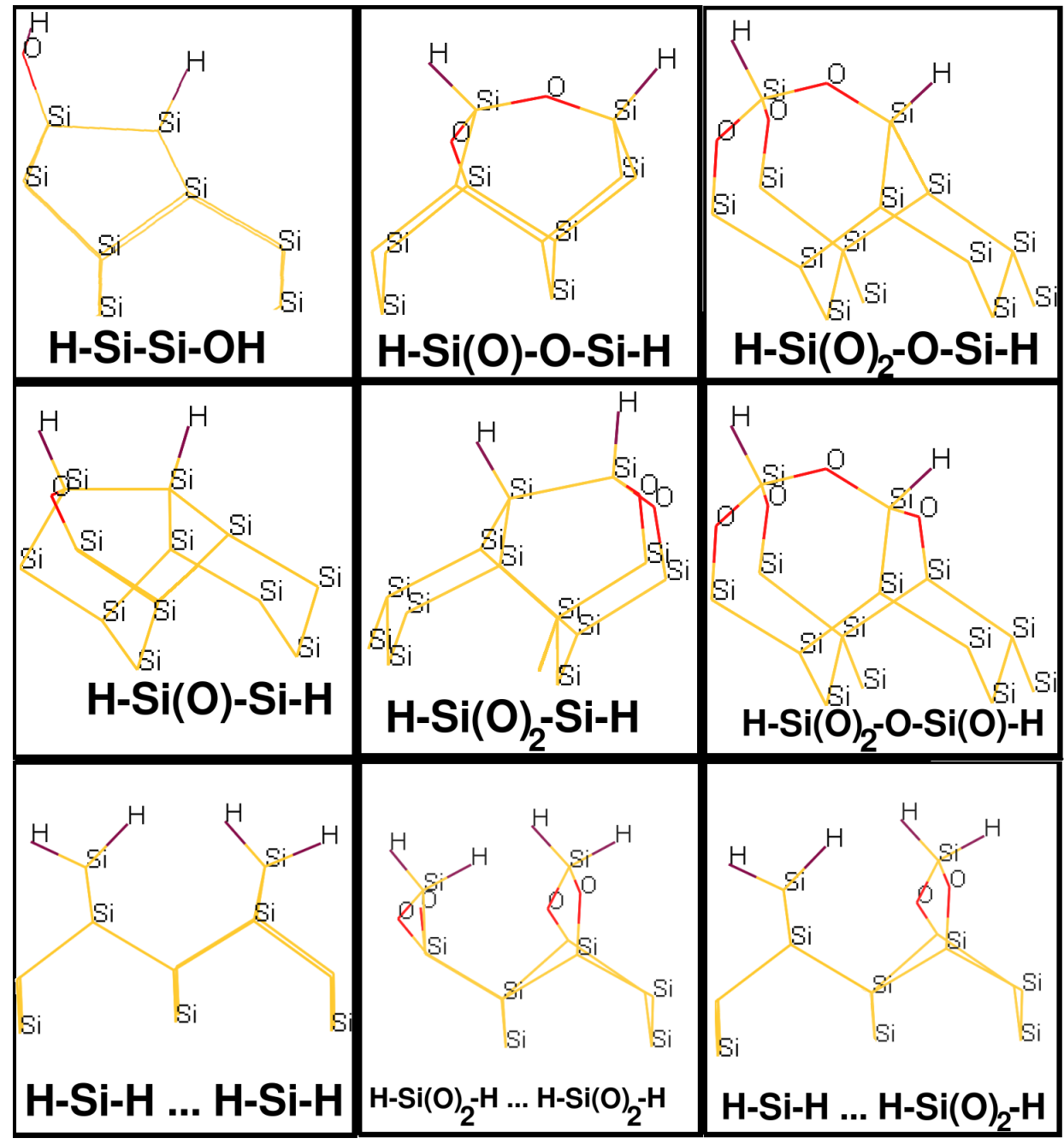

Figura 4.3: Vista lateral para as estruturas oxidadas $\mathrm{H}-\mathrm{Si}-\mathrm{Si}-\mathrm{OH}, \mathrm{H}-\mathrm{Si}(\mathrm{O})_{x}-\mathrm{O}-\mathrm{Si}-$ $\mathrm{H}(\mathrm{x}=0-2), \mathrm{H}-\mathrm{Si}(\mathrm{O})_{x}-\mathrm{Si}-\mathrm{H}(\mathrm{x}=1-2), \mathrm{H}-\mathrm{Si}(\mathrm{O})_{2}-\mathrm{O}-\mathrm{Si}-(\mathrm{O})-\mathrm{H}, \mathrm{H}_{2} \mathrm{Si}(\mathrm{O})_{x} \ldots \mathrm{H}_{2} \mathrm{Si}(\mathrm{O})_{x}$ $(\mathrm{x}=0-2)$. 


\subsection{Nossos Resultados}

\section{Sumário}

A interação entre a molécula de água e a superfície $\operatorname{Si}(100)(2 x 1)$ é dissociativa, com barreira líquida nula e, provavelmente, ocorre via precursor molecular. O produto mais estável é aquele descrito pela equação 4.1 e a dimerização do substrato é mantida após a quimissorção. Estudos teóricos, nos quais a superfície é modelada utilizando a aproximação de aglomerado molecular ou mesmo o modelo de fatias, são realizados com o intuito de investigar este processo de quimissorção. Desconhecemos qualquer estudo no qual tenha-se realizado o cálculo do caminho de reação flexíveis para a dissociação da molécula de água sobre a superfície $\mathrm{Si}(100)$, objeto de discussão desta seção.

Quanto à dissociação das unidades $\mathrm{H}-\mathrm{Si}-\mathrm{Si}-\mathrm{OH}$, este é ainda um problema em aberto e carece de investigações experimentais e teóricas. Resultados experimentais sugerem que o átomo de O migra para o dímero ou para sítios sub-superficiais. Análise do espectro de absorção no infravermelho evidenciam que oxidação em sítios localizados na superfície como sendo os mais prováveis para a quimissorção [128]. Contudo, aparentemente, resultados teóricos [137] apontam que estes dois defeitos são energeticamente degenerados e as barreiras de energia para a formação de ambos têm valores próximos. Tendo em mente esta divergência, decidimos investigar os possíveis caminhos de reação que culminam com a inserção de Oxigênio, provenientes de grupos $\mathrm{Si}-\mathrm{OH}$ no dímero $(\mathrm{H}-\mathrm{Si}-\mathrm{O}-\mathrm{Si}-\mathrm{H})$ e sub-superficial (back-bond - $\mathrm{H}-\mathrm{Si}-$ $\mathrm{Si}(\mathrm{O})-\mathrm{H})$ da superfície $\mathrm{Si}(100)(2 \times 1)$.

A estratégia utilizada consistiu em empregar métodos de primeiros príncipios para obter o caminho de menor energia através do CI-NEB [67], descrito no capítulo 2, para a formação dos defeitos $\mathrm{H}-\mathrm{Si}-\mathrm{Si}-\mathrm{OH}, \mathrm{H}-\mathrm{Si}-\mathrm{O}-\mathrm{Si}-\mathrm{H}$ e H-Si-Si(O)-H (figura 4.4). A superfície $\operatorname{Si}(100)(2 \times 1)$ foi descrita utilizando uma fatia com parâmetro lateral mínimo (2x2) e composta por 8 camadas de Si reconstruídas de forma simétrica nos dois lados, e separadas por $\approx 19 \AA$. A interação elétron-íon foi representada 
através de um pseudopotencial de norma conservada para os átomos de Si [61], enquanto para os átomos de $\mathrm{O}$ e $\mathrm{H}$ utilizamos pseudopotenciais suaves [63]. Todos os resultados foram calculados com energia de corte de ondas planas de 25 Ry e corte da densidade de carga de 250 Ry. Asseguramos que este valor de energia de corte descreve adequadamente as propriedades estruturais e eletrônicas da molécula de água e da superfície. Utilizamos sempre o funcional LDA-PZ e a integração no espaço recíproco foi realizada para em 10 pontos especiais.

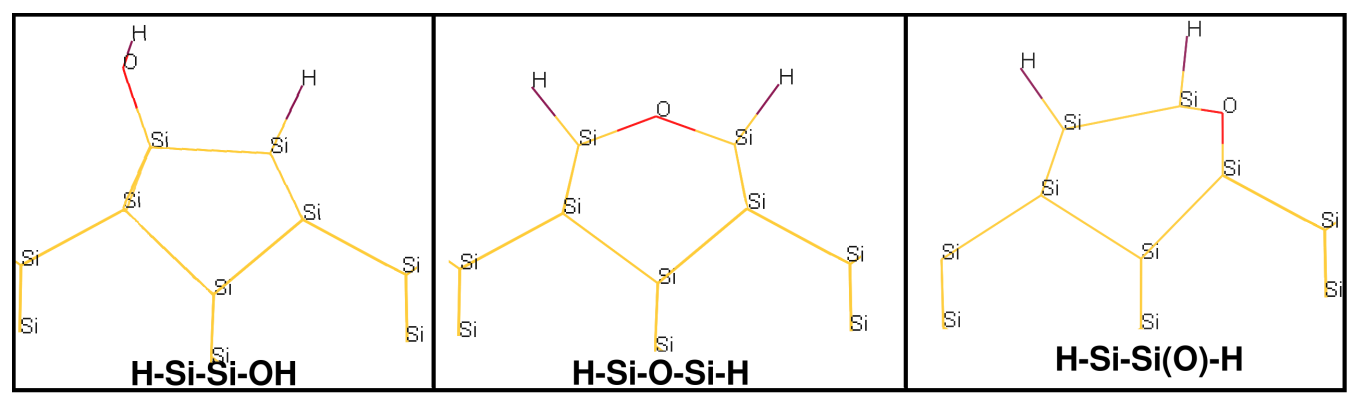

Figura 4.4: Vista lateral para as estruturas quimissorvidas investigadas neste trabalho: $\mathrm{H}-\mathrm{Si}-\mathrm{Si}-\mathrm{OH}, \mathrm{H}-\mathrm{Si}-\mathrm{O}-\mathrm{Si}-\mathrm{H}$ e H-Si-Si(O)-H.

\subsubsection{Dissociação da Molécula de Água em $\operatorname{Si}(100)(2 \times 1)$}

Discutiremos inicialmente o caminho de reação para a quimissorção de uma molécula de água sobre a superfície $\operatorname{Si}(100)(2 \times 1)$, conforme descrito na equação 4.1. Normalmente, as unidades $\equiv \mathrm{Si}-\mathrm{OH}$ são denominadas silanol, assim não deveríamos nos referir ao grupo H-Si-Si-OH (equação 4.1) como sendo um "grupo silanol". Mas, por conveniência e clareza, utilizaremos a nomenclatura $\mathrm{C}_{C-S i l}$, onde o prefixo $S i l$ faz menção à presença da unidade $\mathrm{Si}-\mathrm{OH}$ enquanto a letra $C$ indica que estamos nos referindo à superfície limpa. Nosso resultado [141] para o MEP pode ser visto na figura 4.5. O zero de energia do gráfico corresponde à soma das energias totais (em eV) para os subsistemas isolados (molécula de água isolada e superfície de $\operatorname{Si}(100)(2 \mathrm{x} 1))$. As mudanças relevantes para distâncias internucleares e ângulos de ligação (definidos na figura 4.5) durante a dissociação da molécula são sumarizadas 
na tabela 4.1 e energias e alturas de barreiras relevantes são resumidas na tabela 4.2, comparadas a dados teóricos de literatura quando disponíveis. Valores para a distância entre os átomos $\mathrm{Si}_{n 1}$ e $\mathrm{Si}_{n 2}$ mostram que o processo de quimissorção está confinado ao dímero $\mathrm{Si}_{1}-\mathrm{Si}_{2}$. Na figura 4.6, pode-se analisar o mesmo resultado mostrado anteriormente (fig. 4.5), mas graficado em função da distância $\mathrm{Si}_{1}-\mathrm{O}$. Isto permite uma melhor visualização de como a energia varia devido à interação atrativa entre a molécula de água e a superfície $\operatorname{Si}(100)(2 \mathrm{x} 1)$.

Há consenso que o átomo de oxigênio da molécula de água reage com o átomo de $\mathrm{Si}$ positivamente carregado, no nosso caso, $\mathrm{Si}_{2}$ (nomenclatura na figura 4.5). Iniciamos os cálculos a partir de uma configuração, designada por I, cuja aproximação entre a molécula e a superfície se dá através da interação entre o oxigênio e o átomo de Si negativamente carregado. A energia de ligação para o sistema na configuração inicial é positiva e está $\Delta \mathrm{E} \approx+0,01 \mathrm{eV}$ acima da soma das energias para os subsistemas isolados. Entretanto, já para a segunda imagem da "fita elástica" observamos a inversão de posição entre os átomos de $\mathrm{Si}_{1}$ e $\mathrm{Si}_{2}$, com ganho de energia de $\Delta \mathrm{E}=0,069 \mathrm{eV}$. O átomo $\mathrm{Si}_{1}$, inicialmente rico em elétrons, torna-se positivamente carregado, enquanto o átomo o $\mathrm{Si}_{2}$ assume a posição up, recebendo carga negativa. O ângulo $\theta\left(\mathrm{Si}_{1}-\mathrm{Si}_{2}\right)$, inicialmente igual a $19,97^{\circ}$, assume valor de $-6.48^{\circ}$ (imagem inserida no gráfico da figura 4.5). Assim, podemos afirmar que a reação entre a água e a superfície ocorre mesmo que a aproximação seja feita através do átomo de Si negativamente carregado e não há custo energético líquido para inverter a posição atômica de up para down. A reação procede via um estado fisissorvido, $\mathrm{P}$, com ganho de energia de $\Delta \mathrm{E}=0,39 \mathrm{eV}$ e para o qual há adsorção molecular sobre a superfície (figura 4.5). Neste ponto, identificamos a redução de 34,5 \% no valor do ângulo $\theta\left(\mathrm{Si}_{1}-\mathrm{Si}_{2}\right)$ comparado com o resultado que encontramos para a superfície não oxidada e também aumento da carga positivia sobre o átomo $\mathrm{Si}_{1}$. Este é um resultado interessante: conforme discutimos na seção 4.1, a existência desta "interação correlacionada" da molécula com a superfície havia sido prevista nos estudos de STM realizados por Andersohn e Kohler [95] e denominada de precursor molecular. 

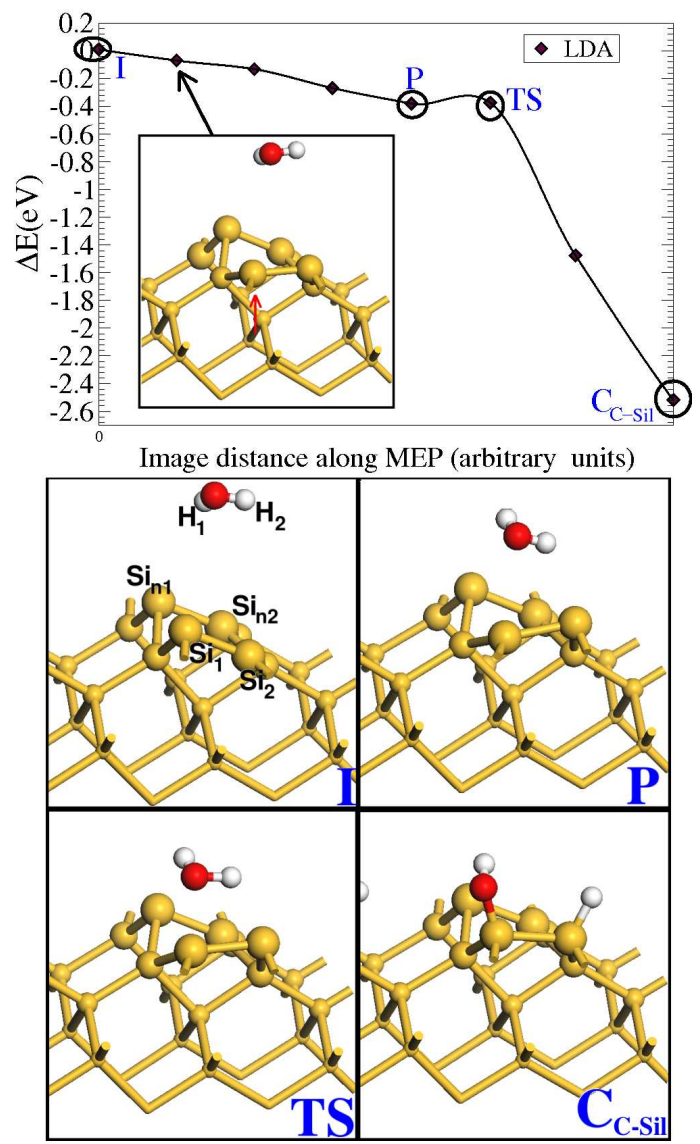

Figura 4.5: Caminho de menor energia, MEP, para a dissociação da molécula de $\mathrm{H}_{2} \mathrm{O}$ sobre a superfíce de $\mathrm{Si}(100)(2 \times 1)$ com formação de $\mathrm{C}_{C-\text { Sil }}$ (a linha no gráfico é apenas um guia para os olhos). No eixo das ordenadas, temos a energia (eV), onde o zero de energia corresponde à soma das energias totais $(\mathrm{em} \mathrm{eV})$ para os subsistemas isolados (molécula de água isolada e superfície de $\operatorname{Si}(100)(2 \times 1))$. Ilustramos ainda as configurações atômicas para alguns pontos especiais ao longo do MEP: a imagem inicial (I), a segunda imagem, a configuração fisissorvida (P), o estado de transição (TS) e a configuração final quimissorvida $\left(\mathrm{C}_{C-\text { Sil }}\right)$.

Esta configuração também foi investigada por diferentes pesquisadores [91,92, 132], mas utilizando funcional de troca e correlação GGA, enquanto aqui empregamos LDA, o que justifica em parte as diferenças de energias listadas na tabela 4.2. Mas, segundo nossos cálculos, a interação $\mathrm{O}-\mathrm{Si}_{1}$ inicia-se em uma distância razoavelmente 


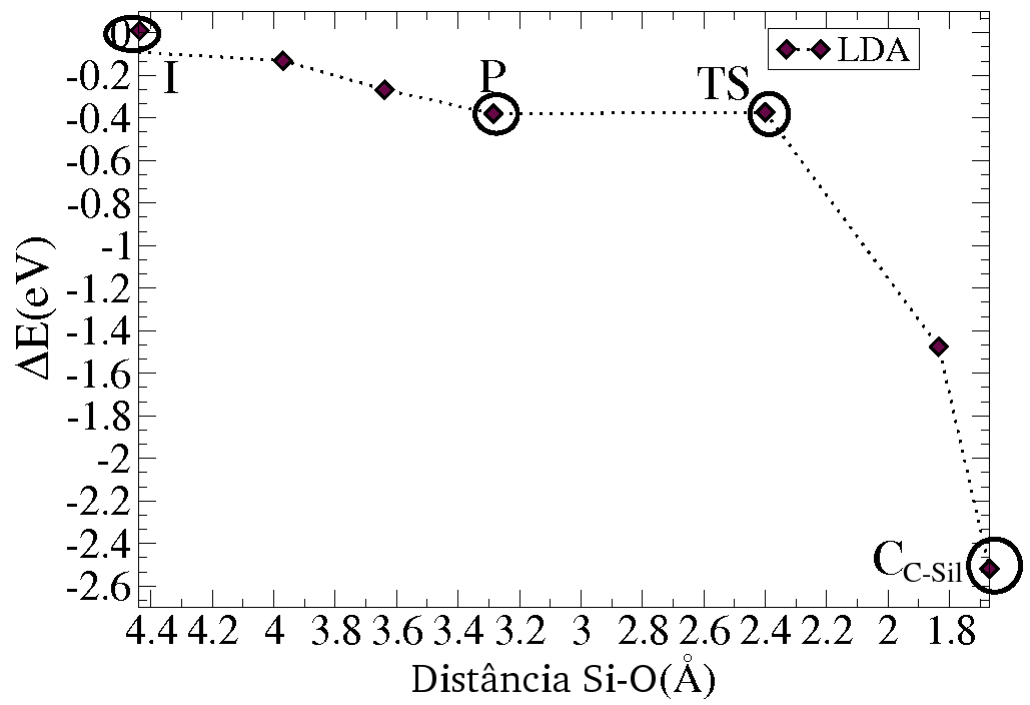

Figura 4.6: Caminho de menor energia (figura 4.5), MEP, para a dissociação da molécula de $\mathrm{H}_{2} \mathrm{O}$ sobre a superfíce de $\mathrm{Si}(100)(2 \mathrm{x} 1)$ com formação de $\mathrm{C}_{C-\text { Sil }}$, mas graficado em função da distância $\mathrm{Si}_{1}-\mathrm{O}(\AA)$. No eixo das ordenadas, temos a energia $(\mathrm{eV})$, onde o zero de energia corresponde à soma das energias totais (em eV) para os subsistemas isolados (molécula de água isolada e superfície de $\mathrm{Si}(100)(2 \mathrm{x} 1)$ ).

maior do que aquela prevista anteriormente (tabela 4.1). 
Tabela 4.1: Parâmetros estruturais calculados para a imagem inicial (I), a segunda imagem no MEP (inserido no gráfico), a configuração fisissorvida (P), o estado de transição (TS) e a configuração final quimissorvida $\left(\mathrm{C}_{C-S i l}\right)$. Os símbolos utilizados na tabela estão definidos na figura 4.5. Distâncias de ligação são dadas em $\AA$ e os ângulos em graus $\left(^{\circ}\right)$. Nossos resultados comparados a resultados das referências indicadas.

\begin{tabular}{|c|c|c|c|c|c|c|c|c|c|}
\hline Dist. $(\AA)$ & $\begin{array}{c}\text { I } \\
\text { Este trabalho }\end{array}$ & $\begin{array}{c}\mathrm{P} \\
\text { Este trabalho }\end{array}$ & $\begin{array}{c}\text { TS } \\
\text { Este trabalho }\end{array}$ & $\begin{array}{c}\mathrm{C}_{C-S i l} \\
\text { Este trabalho }\end{array}$ & $\begin{array}{c}\mathrm{P} \\
{[90]} \\
\end{array}$ & $\begin{array}{c}\mathrm{P} \\
{[91]} \\
\end{array}$ & $\begin{array}{l}\text { TS } \\
{[90]} \\
\end{array}$ & $\begin{array}{c}\mathrm{C}_{C-S i l} \\
{[90]} \\
\end{array}$ & $\begin{array}{c}\mathrm{C}_{C-S i l} \\
{[91]} \\
\end{array}$ \\
\hline $\mathrm{Si}_{1}-\mathrm{Si}_{2}$ & 2,27 & 2,33 & 2,34 & 2,40 & 2,40 & 2,33 & 2,41 & 2,46 & 2,43 \\
\hline $\mathrm{Si}_{n 1}-\mathrm{Si}_{n 2}$ & 2,27 & 2,32 & 2,31 & 2,28 & - & - & - & - & - \\
\hline $\mathrm{H}_{1}-\mathrm{O}$ & 0,98 & 1,00 & 0,97 & 0,98 & 0,99 & 1,02 & 1,24 & 0,97 & 0,98 \\
\hline $\mathrm{H}_{2}-\mathrm{O}$ & 0,98 & 0,95 & 1,17 & 3,61 & 0,98 & 0,99 & 0,98 & - & - \\
\hline $\mathrm{O}-\mathrm{Si}_{1}$ & 4,44 & 3,29 & 2,40 & 1,67 & 2,23 & 2,12 & 1,94 & 1,76 & 1,69 \\
\hline $\mathrm{O}-\mathrm{Si}_{2}$ & 5,30 & 3,43 & 3,13 & 3,40 & - & - & - & - & - \\
\hline $\mathrm{H}_{2}-\mathrm{Si}_{2}$ & 5,05 & 2,80 & 2,40 & 1,50 & - & - & 1,95 & 1,50 & 1,51 \\
\hline \multicolumn{10}{|l|}{ Âng. $\left({ }^{\circ}\right)$} \\
\hline$\theta\left(\mathrm{Si}_{1}-\mathrm{Si}_{2}\right)$ & 19,97 & $-13,1$ & $-7,9$ & $-1,5$ & 16,4 & 12,0 & 10,2 & 0,0 & 0,0 \\
\hline $\mathrm{H}_{1}-\mathrm{O}-\mathrm{H}_{2}$ & 105,5 & 106,5 & 103,7 & - & - & 107,0 & - & - & - \\
\hline $\mathrm{Si}_{1}-\mathrm{O}-\mathrm{H}_{1}$ & 75,7 & 114,3 & 120,7 & 117,8 & 117,7 & - & 118,1 & 116,4 & 115,0 \\
\hline $\mathrm{Si}_{2}-\mathrm{Si}_{1}-\mathrm{O}$ & 99,2 & 73,2 & 82,5 & 112,0 & 94,7 & - & 82,6 & 116,7 & 110,0 \\
\hline $\mathrm{Si}_{2}-\mathrm{Si}_{1}-\mathrm{O}-\mathrm{H}_{1}$ & 88,4 & 104,0 & 103,9 & 67,2 & 60,1 & - & 59,0 & 62,2 & 83,0 \\
\hline
\end{tabular}


Tabela 4.2: Diferenças de energias relativas à energia total dos subsistemas isolados (molécula de água isolada e superfície de $\operatorname{Si}(100)(2 \mathrm{x} 1)$ ) para alguns pontos da barreira de reação mostrada na figura 4.5. Comparamos nossos resultados com os dados teóricos obtidos a partir de cálculos de energia total utilizando aglomerados moleculares (clusters) [90,140] ou fatias [91,92,132] para modelar a superfície.

\begin{tabular}{ccccccc}
\hline \hline & Este trabalho & {$[90]$} & {$[140]$} & {$[91]$} & {$[92]$} & {$[132]$} \\
& fatia & cluster & cluster & fatia & fatia & fatia \\
& LDA & BP e & B3LYP & GGA & GGA & GGA \\
& PZ & B3LYP & B3LYP & PBE & PBE & PW-II \\
\hline I & 0,01 & - & - & - & - & - \\
I2 & $-0,07$ & - & - & - & - & - \\
P & $-0,39$ & $-0,24--0,61$ & $-0,51$ & $-0,57$ & $-0,231$ & $-0,74$ \\
TS & $+0,01$ & $+0,16-+0,12$ & $+0,28$ & $+0,15$ & $+0,23$ & - \\
C & $-2,52$ & $-2,13--2,67$ & $-2,58$ & $-2,37$ & $-2,37$ & $-2,38$ \\
\hline \hline
\end{tabular}

Indícios da interação eletrônica entre molécula e superfície são obtidos ao se comparar as isosuperfícies de densidade eletrônica para os orbitais de fronteira (HOMO e LUMO) calculados para as imagens I e P e mostradas na figura 4.7. Em I, o HOMO e o LUMO não têm contribuição do oxigênio todas as características descritas para estes orbitais são indistinguíveis daquelas obtidas para a superfície limpa. Já no estado fisissorvido, tanto o HOMO quanto o LUMO, têm participação do oxigênio, o qual pode interagir, via nuvem eletrônica, com o Si postivamente carregado, em semelhança aos resultados obtidos por Konecny e Doren [90].

São muitas as evidências experimentais de que não há barreira líquida para a reação entre a água e a superfície $\operatorname{Si}(100)(2 \times 1)$, conforme sugere o MEP mostrado nas figuras 4.5 e / ou 4.6. Mas, notamos que a molécula de água só se dissociará ao ultrapassar uma pequena barreira de energia de $\Delta \mathrm{E}=+0,01 \mathrm{eV}$, valor uma ordem de 


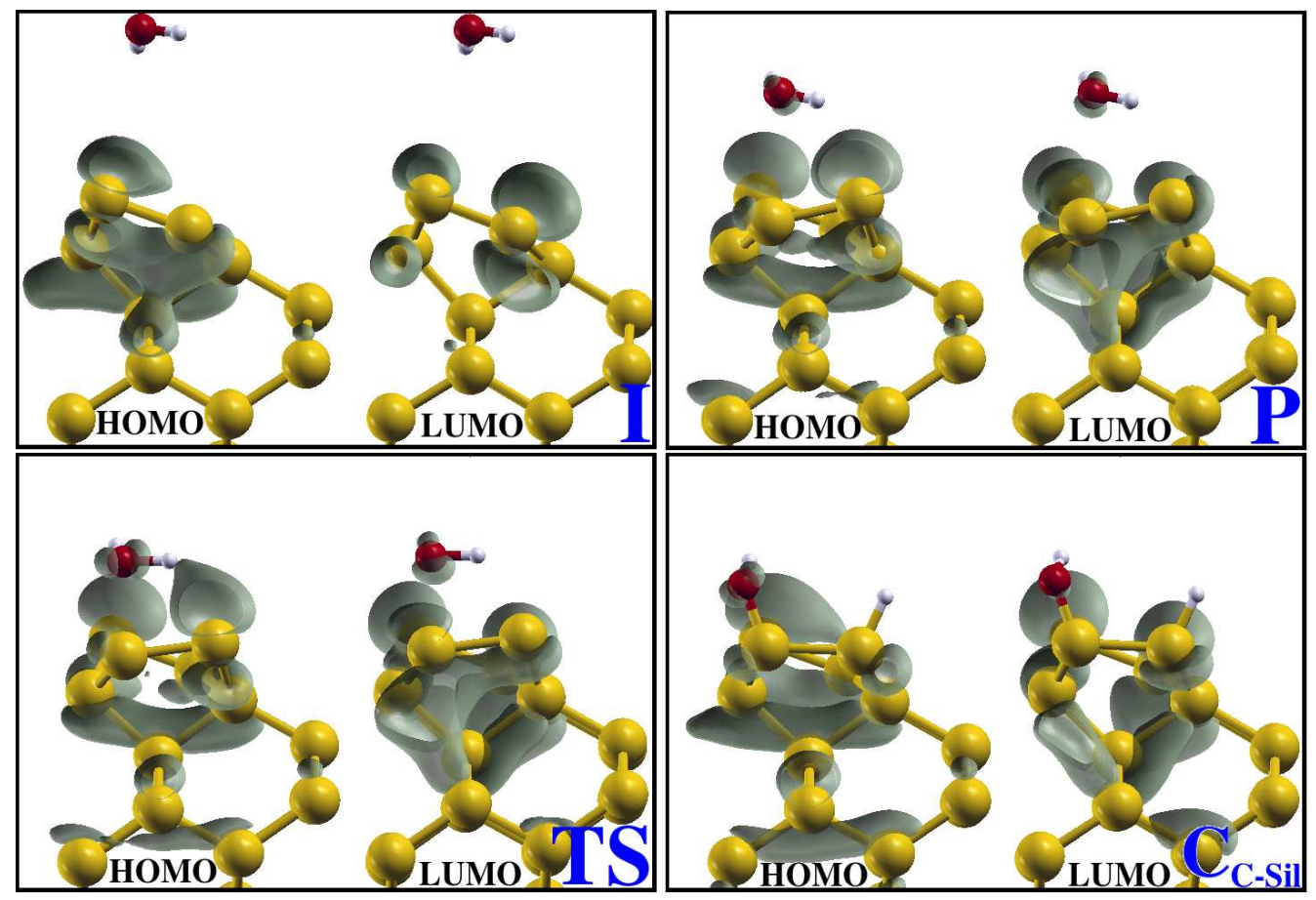

Figura 4.7: Isosuperfícies de densidade eletrônica associada ao mais alto orbital ocupado - HOMO (à esquerda) e ao mais baixo orbital desocupado - LUMO (à direita) para alguns pontos especiais ao longo do MEP mostrado na figura 4.5: a imagem inicial (I), a configuração fisissorvida (P), o estado de transição (TS) e a configuração final quimissorvida $\left(\mathrm{C}_{C-S i l}\right)$.

grandeza menor do que aquele obtido em outros trabalhos (veja tabela 4.2) empregando funcional GGA e em acordo com os experimentos, os quais predizem que a dissociação da água pode ser observada em temperaturas extremamente baixas [124]. Apesar dos valores de energia de ativação comparados a outros resultados teóricos sugerirem inadequação de cálculo simples de energia total para a descrição de caminhos de reação, devemos ser cautelosos, uma vez que esperamos um aumento desta barreira de reação ao repetirmos os cálculos, mas utilizando um funcional tipo GGA para descrição da energia de troca e correlação. Além disso, o valor da barreira de energia está dentro da nossa precisão numérica.

A geometria do estado de transição, TS, também pode ser vista na figura 4.5. 
$\mathrm{O}$ comprimento da ligação $\mathrm{H}_{1}-\mathrm{O}$ não sofre qualquer dilatação ou contração. Este resultado discorda daqueles obtidos por Konecny e Doren [90] que predizem que neste ponto da reação há afastamento (de $0,26 \AA$ ) entre os átomos $\mathrm{H}_{1}$ e O. Conforme comentamos anteriormente, também aqui a distância O-Si é maior $(\approx 19 \%)$ que aquela prevista na referência [90]. A densidade eletrônica para o HOMO (figura 4.7) permite-nos visualizar a interação eletrônica entre $\mathrm{H}_{2}$ e o $\mathrm{Si}_{2}$ e também entre o $\mathrm{O}$ e o $\mathrm{Si}_{1}$.

A dissociação completa da molécula de água em unidades $\mathrm{OH}$ e $\mathrm{H}$ sobre a superfície ocorre quando o sistema alcança a configuração $\mathrm{C}_{C-S i l}$, o que corresponde a ganho de energia de $\Delta \mathrm{E}=2,14 \mathrm{eV}$ e, tendo em conta a estabilidade de $\mathrm{C}_{C-\text { Sil }}$, praticamente não existe probabilidade de dessorção.

\subsubsection{Decomposição das unidades $\mathrm{H}-\mathrm{Si}-\mathrm{Si}-\mathrm{OH}$}

Tendo estabelecido o caminho de reação pelo qual a molécula de água se dissocia sobre a superfície $\operatorname{Si}(100)(2 \times 1)$, discutiremos, nesta seção, duas possíveis rotas para a decomposição das unidades $\mathrm{H}-\mathrm{Si}-\mathrm{Si}-\mathrm{OH}$ na presença de calor ou aumento intensivo do fluxo de água (figura 4.1). Analisaremos somente a situação na qual o O se insere em um sítio da superfície $\left(\mathrm{C}_{C-O D}\right)$ ou na back-bond $\left(\mathrm{C}_{C-B B}\right)$.

O MEP obtido para a inserção de $\mathrm{O}$ no dímero pode ser visto na figura 4.8. Neste caso, temos três dímeros desocupados dentro da célula unitária, em regime de cobertura de $25 \%$.

As tabelas 4.3 e 4.4 trazem, respectivamente, um resumo das energias associadas ao MEP para a conversão de $\mathrm{H}-\mathrm{Si}-\mathrm{Si}-\mathrm{OH}$ em $\mathrm{H}-\mathrm{Si}-\mathrm{O}-\mathrm{Si}-\mathrm{H}$ e a variação de alguns parâmetros estruturais relevantes para esta reação. Resultados teóricos disponíveis na literatura também estão incluídos nestas tabelas [92, 134, 135,137]. Verificamos que o processo de inserção do O no dímero (figura 4.8) está confinado em uma única fileira de dímeros e não afeta as fileiras vizinhas: as distâncias interatômicas $\mathrm{Si}_{n 1}-\mathrm{Si}_{n 2}$ variam entre 0,001 a $0,01 \AA$ durante todo o MEP. 

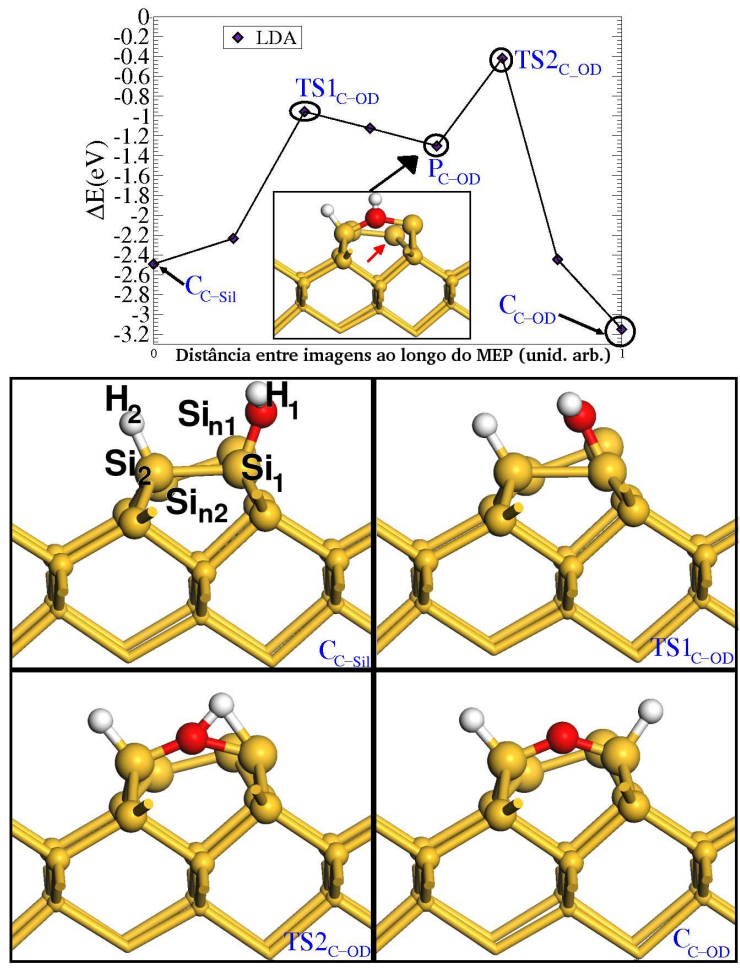

Figura 4.8: Caminho de menor energia, MEP, para a dissociação de $\mathrm{H}-\mathrm{Si}-\mathrm{Si}-\mathrm{OH}$ (configuração $\mathrm{C}_{C-S i l}$, figura 4.5) em H-Si-O-Si-H, sobre a superfíce de $\mathrm{Si}(100)(2 \times 1)$ (a linha no gráfico é apenas um guia para os olhos). No eixo das ordenadas, temos a energia $(\mathrm{eV})$, onde o zero de energia corresponde à soma das energias totais (em eV) para os subsistemas isolados (molécula de água isolada e superfície de $\operatorname{Si}(100)(2 \times 1)$ ). Ilustramos ainda as configurações atômicas para alguns pontos especiais ao longo do MEP: a imagem inicial $\left(\mathrm{C}_{C-S i l}\right)$, o primeiro estado de transição $\left(\mathrm{TS}_{C-O D}\right)$, a configuração fisissorvida ( $\mathrm{P}_{C-O D}$, inserida no gráfico), o segundo estado de transição $\left(\mathrm{TS} 2_{C-O D}\right)$ e a configuração final com o $\mathrm{O}$ quimissorvido no dímero $\left(\mathrm{C}_{C-O D}\right)$.

Para a inserção do $\mathrm{O}$ no dímero, a primeira barreira de energia $\left(\mathrm{TS} 1_{C-O D}\right)$, que também é aquela determinante da taxa de reação, está associada ao estiramento $(\approx$ $7 \%$ da ligação $\mathrm{Si}_{1}-\mathrm{Si}_{2}$ e a deformações angulares da ordem de $7 \%$ nos ângulos de ligação formado entre os átomos do dímero afetado e aqueles pertencentes à segunda camada atômica da superfície, produzindo mudanças nas isosuperfícies das 
densidades eletrônicas associadas ao HOMO e ao LUMO do sistema na região do

Tabela 4.3: Diferenças de energias relativas à energia total dos subsistemas isolados (molécula de água isolada e superfície de $\operatorname{Si}(100)(2 \times 1)$ ) para alguns pontos das barreiras de reação mostradas nas figuras 4.8, 4.10 e 4.11. Comparamos nossos resultados com os dados teóricos obtidos a partir de cálculos de energia total (HF, MP2 e DFT/B3LYP) utilizando aglomerados moleculares (clusters) [135,137] para modelar a superfície.

\begin{tabular}{|c|c|c|c|c|}
\hline \multicolumn{5}{|c|}{$\mathrm{C}_{C-S i l} \rightarrow \mathrm{C}_{C-O D}$} \\
\hline & & $(4 \times 2)$ & {$[135]$} & B3LYP/B3LYP [137] \\
\hline $\mathrm{C}_{C-S i l}$ & & $-2,49$ & - & $-2,45$ \\
\hline $\mathrm{TS} 1_{C-O D}$ & & 1,54 & $3,7-2,4$ & 2,71 \\
\hline $\mathrm{P}_{C-O D}$ & & $-0,34$ & $-2,9--1,4$ & $-1,37$ \\
\hline $\mathrm{TS} 2_{C-O D}$ & & 0,89 & $1,6--0,9$ & 0,86 \\
\hline $\mathrm{C}_{C-O D}$ & & $-3,15$ & - & $-3,37$ \\
\hline Dessorção $(\leftarrow)$ & & $+2,73$ & - & - \\
\hline Exotermicidade & & $+0,66$ & $+1,6-+1,3$ & $+0,92$ \\
\hline \multicolumn{5}{|c|}{$\mathrm{C}_{C-S i l} \rightarrow \mathrm{C}_{C-B B}$} \\
\hline & $\mathrm{C} 1_{C 1-B B}$ & $\mathrm{C} 22_{C 1-B B}$ & MP2/B3LYP [137] & B3LYP/B3LYP [137] \\
\hline $\mathrm{C}$ & $-2,52$ & $-2,52$ & $-2,45$ & $-2,70$ \\
\hline $\mathrm{TS}_{C 1-B B}$ & 2,10 & - & 2,36 & 2,42 \\
\hline $\mathrm{TS}_{C 2-B B}$ & - & 2,40 & - & - \\
\hline $\mathrm{C}_{C-B B}$ & $-2,69$ & $-2,69$ & $-3,37$ & $-3,69$ \\
\hline TS2 & - & - & 0,85 & 0,82 \\
\hline Dessorção $(\longleftarrow)$ & $+2,26$ & $+2,71$ & - & - \\
\hline Exotermicidade & $+0,17$ & $+0,17$ & $+0,92$ & $+0,99$ \\
\hline
\end{tabular}


dímero oxidado (figura 4.9). O grupo $\mathrm{OH}$ permanece intacto, mas inclinado na direção do dímero, conforme as modificações dos ângulos $\mathrm{Si}_{1}-\mathrm{O}-\mathrm{Si}_{2}$ e $\mathrm{H}_{1}-\mathrm{Si}_{1}-\mathrm{O}-$

Tabela 4.4: Parâmetros estruturais otimizados para a imagem inicial $\left(\mathrm{C}_{C-S i l}\right)$, o primeiro estado de transição $\left(\mathrm{TS} 1_{C-O D}\right)$, a configuração fisissorvida $\left.\left(\mathrm{P}_{C-O D}\right)\right)$, o segundo estado de transição $\left(\mathrm{TS} 2_{C-O D}\right)$ e a configuração final com o O quimissorvido no dímero $\left(\mathrm{C}_{C-O D}\right)$. Os símbolos utilizados na tabela estão definidos na figura 4.8 . Distâncias de ligação são dadas em $\AA$ e os ângulos em graus $\left(^{\circ}\right)$. Os valores mostrados entre parênteses foram retirados das referências [92, 134, 135, 137].

\begin{tabular}{|c|c|c|c|c|c|}
\hline & $\mathrm{C}_{C-S i l}$ & $\mathrm{TS} 1_{C-O D}$ & $\mathrm{P}_{C-O D}$ & $\mathrm{TS} 2_{C-O D}$ & $\mathrm{C}_{C-O D}$ \\
\hline \multirow[t]{2}{*}{$\mathrm{Si}_{1}-\mathrm{Si}_{2}$} & 2,40 & 2,58 & 3,55 & 3,40 & 3,13 \\
\hline & - & $\left(2,77^{2}\right)$ & - & - & - \\
\hline $\mathrm{Si}_{n 1}-\mathrm{Si}_{n 2}$ & 2,28 & 2,30 & 2,26 & 2,27 & 2,27 \\
\hline \multirow[t]{2}{*}{$\mathrm{H}_{1}-\mathrm{O}$} & 0,98 & 0,98 & 0,98 & 1,23 & 2,54 \\
\hline & - & - & - & $\left(1.24^{4}\right)$ & - \\
\hline \multirow[t]{2}{*}{$\mathrm{O}-\mathrm{Si}_{1}$} & 1,67 & 1,71 & 1,95 & 1,87 & 1,68 \\
\hline & $\left(1,69^{4}\right)$ & $\left(1,82^{2}\right)$ & $\left(2,07^{4}\right)$ & - & $\left(1,68^{3}\right)$ \\
\hline \multirow[t]{2}{*}{$\mathrm{O}-\mathrm{Si}_{2}$} & 3,40 & 2,40 & 1,80 & 1,72 & 1,66 \\
\hline & - & $\left(2,03^{6}\right)$ & $\left(1.78^{4}\right)$ & - & $\left(1,68^{5}\right)$ \\
\hline \multirow[t]{2}{*}{$\mathrm{H}_{1}-\mathrm{Si}_{1}$} & 2,29 & 2,31 & 2,35 & 1,70 & 1,50 \\
\hline & - & - & - & $\left(1,70^{4}\right)$ & - \\
\hline$\theta\left(\mathrm{Si}_{n 1}-\mathrm{Si}_{n 2}\right)$ & 18,00 & 19,35 & $-6,78$ & 13,14 & 16,11 \\
\hline $\mathrm{H}_{1}-\mathrm{Si}_{1}-\mathrm{O}$ & 22,22 & 22,22 & 24,12 & 39,95 & 106,46 \\
\hline $\mathrm{Si}_{1}-\mathrm{O}-\mathrm{Si}_{2}$ & 41,07 & 75,96 & 142,52 & 143,09 & 139,75 \\
\hline $\mathrm{H}_{1}-\mathrm{Si}_{1}-\mathrm{O}-\mathrm{Si}_{2}$ & 177,41 & 5,39 & 179,87 & 179,93 & 179,96 \\
\hline $\mathrm{Si}_{1}-\mathrm{O}-\mathrm{Si}_{2}-\mathrm{H}_{2}$ & 70,45 & 80,55 & 179,07 & 179,83 & 179,82 \\
\hline $\mathrm{H}_{1}-\mathrm{Si}_{1}-\mathrm{Si}_{2}-\mathrm{H}_{2}$ & 18,67 & 19,43 & 0,72 & 0,05 & 0,17 \\
\hline
\end{tabular}


$\mathrm{Si}_{2}$ na tabela 4.4. Identificamos um ganho de energia de $\Delta \mathrm{E}=0,34 \mathrm{eV}$ (em relação $\left.\mathrm{TS}_{C-O D}\right)$ quando o sistema evolui para uma situação na qual o átomo de O está em coordenação tripla (tabela 4.4, distâncias $\mathrm{Si}_{1}-\mathrm{Si}_{2}, \mathrm{H}_{1}-\mathrm{O}, \mathrm{O}-\mathrm{Si}_{1}$ e O-Si 2 ). Nomeamos esta configuração por $\mathrm{P}_{C-O D}$. Não podemos afirmar se este ganho de energia ocorre devido, em sua totalidade ou parcialmente, à tricoordenação do $\mathrm{O}$ e / ou à inserção deste átomo no dímero, uma vez que identificamos a inversão do ângulo $\theta\left(\mathrm{Si}_{n 1} \mathrm{Si}_{n 2}\right)$. Assim, a reconstrução da superfície varia de $(2 \times 1)$ para uma conformação localmente próxima à $\mathrm{p}(2 \mathrm{x} 2)$ que é energeticamente favorecida em relação à $(2 \mathrm{x} 1)$ (capítulo 3). Esta variação da reconstrução pode contribuir para a profundidade do poço de potencial $\mathrm{P}_{C-O D}$, aumentando a segunda barreira de energia (TS2 $\left.2_{C-O D}\right)$. Se a $\mathrm{P}_{C-O D}$ não existisse, teríamos um segundo estado de transição situado à $\approx+0,71$ eV e não $+0,89 \mathrm{eV}$, listado na tabela 4.3. Este segundo estado de transição está associado à transferência do $\mathrm{H}_{1}$ para o $\mathrm{Si}_{1}$ e tem energia de ativação $50 \%$ menor relativamente à primeira. As isosuperfícies de densidade eletrônica da estrutura TS2 $2_{C-O D}$ estão na figura 4.9. Durante todo o processo de oxidação do dímero, a distância interatômica entre os átomos $\mathrm{H}_{2}$ e $\mathrm{Si}_{2}$ praticamente não altera.

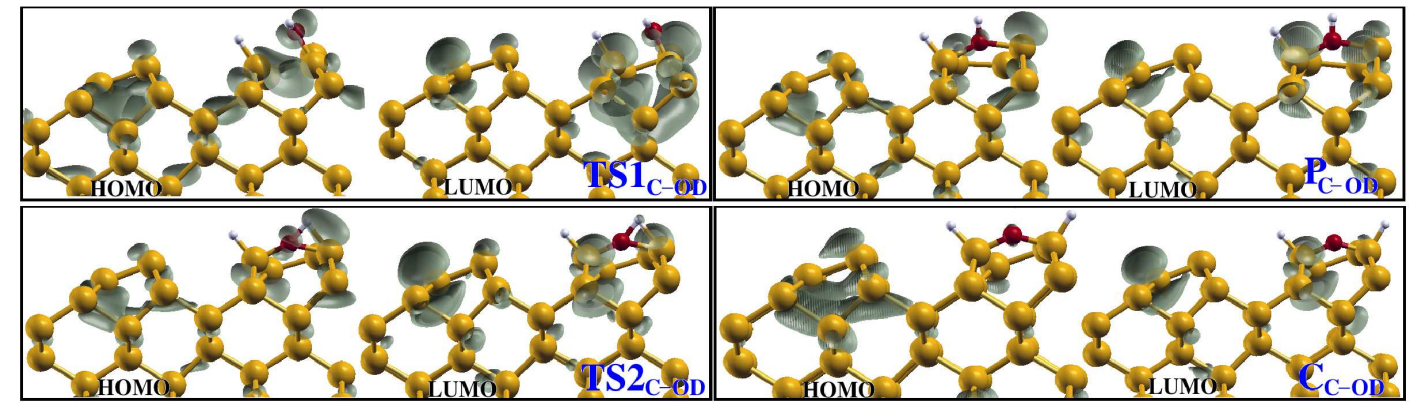

Figura 4.9: Isosuperfícies de densidade eletrônica associada ao mais alto orbital ocupado - HOMO (à esquerda) e ao mais baixo orbital desocupado - LUMO (à direita) para alguns pontos especiais ao longo do MEP mostrado na figura 4.8: o primeiro estado de transição $\left(\mathrm{TS}_{C-O D}\right)$, a configuração fisissorvida $\left(\mathrm{P}_{C-O D}\right)$, o segundo estado de transição $\left(\mathrm{TS} 2_{C-O D}\right)$ e a configuração final com o O quimissorvido no dímero $\left(\mathrm{C}_{C-O D}\right)$. 
Passando agora à inserção no back-bond, dois caminhos de reação distintos podem ser vistos nas figuras 4.10 e 4.11. Diferenças de energias, relativas ao sistemas isolados para pontos relevantes destes MEPs estão reunidos na tabela 4.3. Concentraremos nossas discussões nos resultados mostrados na figura 4.10, uma vez que este caminho está associado a uma barreira de reação menor que aquela mostrada na figura 4.11. Variações de distâncias e ângulos de ligação são listados na tabela 4.5 e comparados com os resultados teóricos da literatura [137].

Diferentemente do MEP para a oxidação do dímero (figura 4.8), há apenas uma barreira de energia a ser transposta para a oxidação da back-bond. No estado de transição, $\mathrm{TS}_{C 1-B B}$, o oxigênio está ligado apenas ao $\mathrm{Si}_{1}$. Na estrutura final, $\mathrm{C}_{C-B B}$, o ângulo de ligação $\mathrm{Si}_{2 n d 2}-\mathrm{O}-\mathrm{Si}_{1}$ aproxima-se do valor obtido para o óxido de $\mathrm{Si}$ (alpha-quartzo), que é da ordem de $139,31^{\circ}$. A formação das ligações $\mathrm{Si}_{2 n d 1}-\mathrm{O}$ e $\mathrm{O}-\mathrm{Si}_{1}$ exige considerável deformação angular da superfície, estando, portanto, associada a uma barreira de reação $\approx 30 \%$ maior que aquela obtida para a oxidação do dímero. Comparativamente à estrutura $\mathrm{TS}_{C-O D}$ (figura 4.9), a isosuperfície densidade eletrônica associada ao HOMO mostra que há maior hibridização entre os estados eletrônicos do $\mathrm{O}$ e da superfície em $\mathrm{TS}_{C 1-B B}$ (figura 4.12).

Os resultados discutidos anteriormente mostram que, por argumentos de estabilidade e cinéticos, a formação $\mathrm{C}_{C-O D}$ é favorecida em relação à produção de $\mathrm{C}_{C-B B}$. O defeito $\mathrm{C}_{C-O D}$ é $0,47 \mathrm{eV}$ mais estável que $\mathrm{C}_{C-B B}$, enquanto a exotermicidade (em relação à $\left.\mathrm{C}_{C-S i l}\right)$ é de $0,66 \mathrm{eV}$ para a inserção de $\mathrm{O}$ no dímero e apenas $0,17 \mathrm{eV}$ quando a reação conduz à oxidação no back-bond. Ambos os resultados estão em descordo com alguns dos cálculos dos aglomerados moleculares publicados anteriormente [135,137,140]. Mas, Weldon e colaboradores [128] predizem que a estrutura $\mathrm{C}_{C-O D}$ é $0,3 \mathrm{eV}$ mais estável que $\mathrm{C}_{C-B B}$. Resultado que está em razoável acordo com o nosso. Quanto à cinética, dados reunidos na tabela 4.3, mostram divergência daqueles encontrados nos trabalhos teóricos de Watanabe e colaboradores [137]: não concordamos que a inserção na back-bond seja mais viável que a oxidação do dímero. Quantitativamente, a diferença relativa entre a primeira barreira de energia 


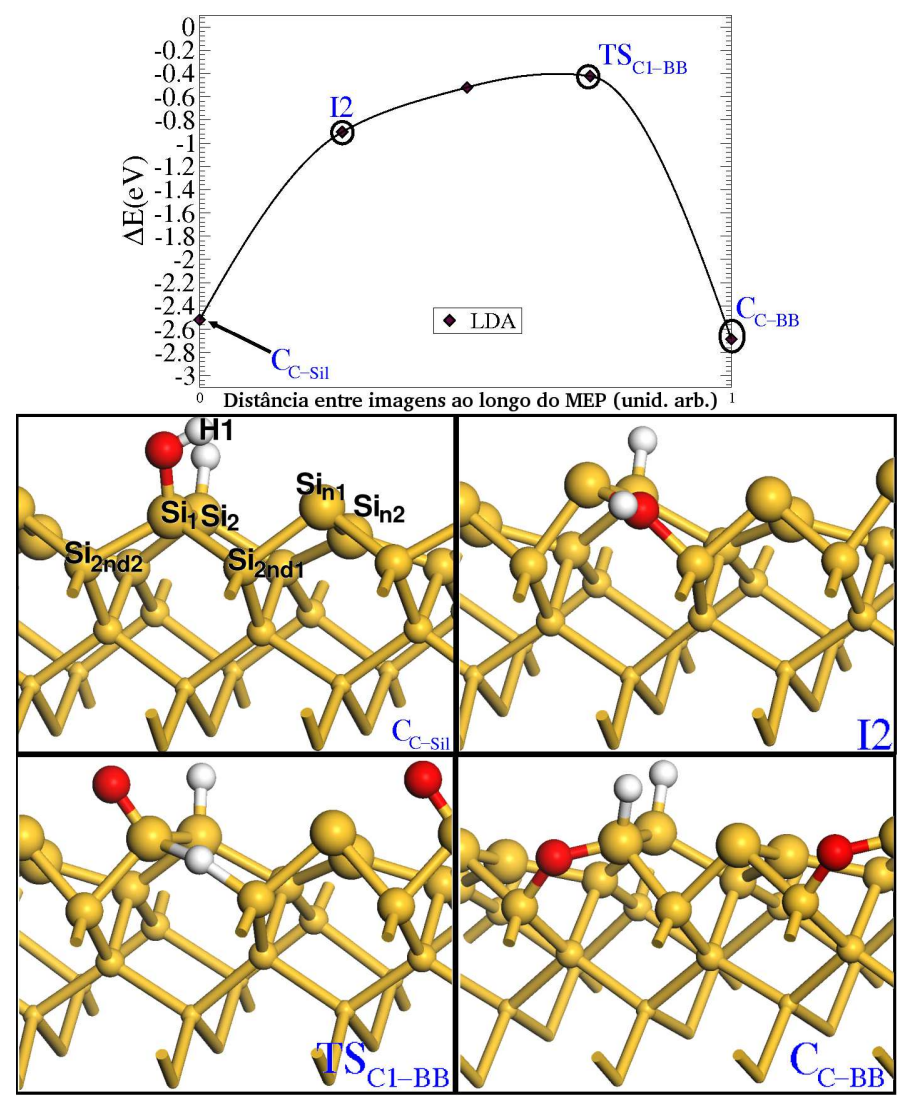

Figura 4.10: Caminho de menor energia, MEP, para a dissociação de H-Si-Si-OH (configuração $\mathrm{C}_{C-S i l}$, figura 4.5) em $\mathrm{H}-\mathrm{Si}-\mathrm{Si}(\mathrm{O})-\mathrm{H}\left(\mathrm{C}_{C-B B}\right)$, sobre a superfíce de $\operatorname{Si}(100)(2 \mathrm{x} 1)$ (a linha no gráfico é apenas um guia para os olhos). No eixo das ordenadas, temos a energia $(\mathrm{eV})$, onde o zero de energia corresponde à soma das energias totais (em eV) para os subsistemas isolados (molécula de água isolada e superfície de $\operatorname{Si}(100)(2 x 1))$. Ilustramos ainda as configurações atômicas para alguns pontos especiais ao longo do MEP: a imagem inicial $\left(\mathrm{C}_{C-S i l}\right)$, a segunda imagem do MEP (I2), o estado de transição $\left(\mathrm{TS}_{C 1-B B}\right)$, e a configuração final com o $\mathrm{O}$ quimissorvido no sítio de back-bond $\left(\mathrm{C}_{C-B B}\right)$.

$\left(\mathrm{TS}_{C-O D}\right)$ para a formação de $\mathrm{C}_{C-O D}$ é grande $(\approx 76 \%)$. Para a segunda barreira de energia $\left(\mathrm{TS}_{C-O D}\right)$, estamos em acordo com os dados reportados em [137], mas não com o resultado de Stefanov e Raghavachari [135].

A reação de conversão de $\mathrm{C}_{C-S i l}$ em $\mathrm{C}_{C-B B}$ também foi estudada por Watan- 

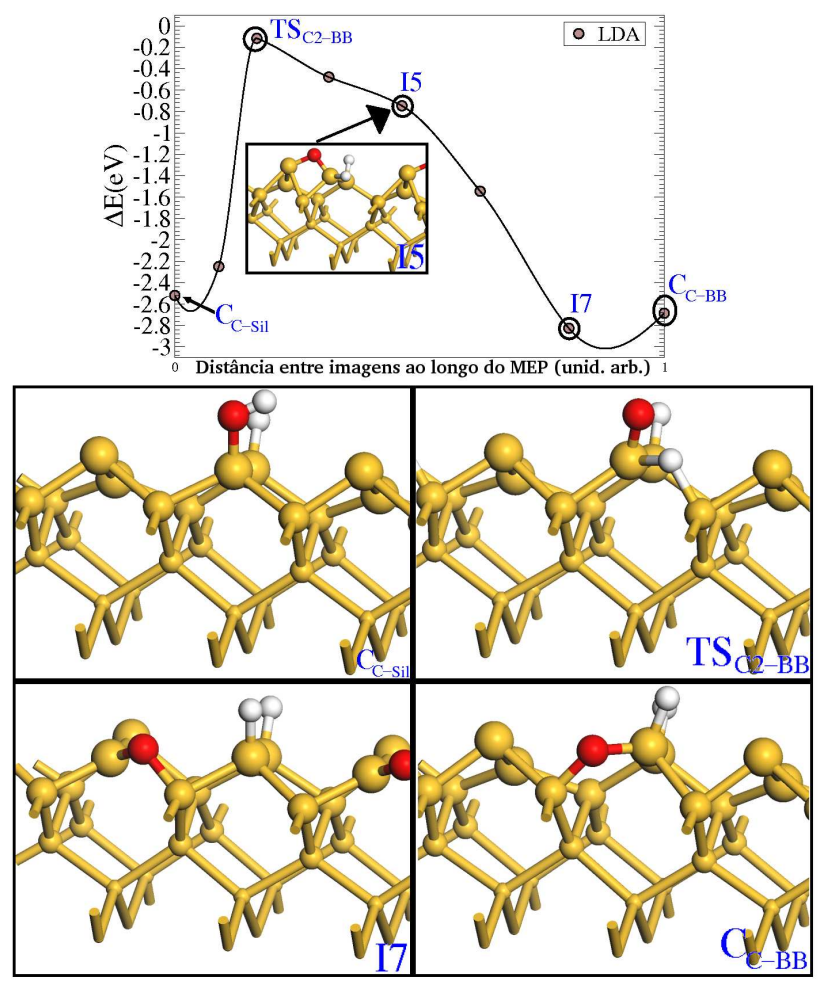

Figura 4.11: Caminho de menor energia, MEP, para a dissociação de H-Si-Si-OH (configuração $\mathrm{C}_{C-S i l}$, figura 4.5) em $\mathrm{H}-\mathrm{Si}-\mathrm{Si}(\mathrm{O})-\mathrm{H}\left(\mathrm{C}_{C-B B}\right)$, sobre a superfíce de $\operatorname{Si}(100)(2 x 1)$ (a linha no gráfico é apenas um guia para os olhos). No eixo das ordenadas, temos a energia $(\mathrm{eV})$, onde o zero de energia corresponde à soma das energias totais (em eV) para os subsistemas isolados (molécula de água isolada e superfície de $\mathrm{Si}(100)(2 \mathrm{x} 1))$. Ilustramos ainda as configurações atômicas para alguns pontos especiais ao longo do MEP: a imagem inicial $\left(\mathrm{C}_{C-S i l}\right)$, o estado de transição $\left(\mathrm{TS}_{C 2-B B}\right)$, a sétima imagem do MEP (I7), e a configuração final com o O quimissorvido no sítio de back-bond $\left(\mathrm{C}_{C-B B}\right)$. Mostramos também a configuração atômica para a quinta imagem do MEP (I5).

abe e colaboradores [137]. Os autores mostram que há duas barreiras de reação com enerigas de ativação de, respectivamente, $+2,36$ (tabela 4.3 ) e 0,84 eV. Não identificamos um segundo estado de transição para esta reação, como reportado. Analisando os caminhos de reação para conversão de $\mathrm{C}_{C-S i l}$ em $\mathrm{C}_{C-O D}$ e $\mathrm{C}_{C-B B}$, 
podemos afirmar que a oxidação do dímero é um evento favorável, corroborando a interpretação dos dados experimentais de Weldon e colaboradores [128]. Neste caso, nossos resultados divergem dos cálculos de Watanabe e colaboradores [137].

Admitindo que a dependência com a temperatura para a oxidação dos dímeros e

Tabela 4.5: Parâmetros estruturais otimizados para a imagem inicial $\left(\mathrm{C}_{C-S i l}\right)$, a segunda imagem do MEP (I2), o estado de transição $\left(\mathrm{TS}_{C 1-B B}\right)$, e a configuração final com o $\mathrm{O}$ quimissorvido no sítio de back-bond $\left(\mathrm{C}_{C-B B}\right)$. Os símbolos utilizados na tabela estão definidos na figura 4.10. Distâncias de ligação são dadas em $\AA$ e os ângulos em graus $\left(^{\circ}\right)$. Comparamos nossos resultados com os dados obtidos a partir de cálculos de energia total da referência [137] e calculados utilizando aproximação B3LYP.

\begin{tabular}{lccccc}
\hline \hline & $\mathrm{C}_{C-S i l}$ & $\mathrm{I} 2$ & $\mathrm{TS}_{C 1-B B}$ & $\mathrm{C}_{C-B B}$ & $\mathrm{TS}_{C 1-B B}[137]$ \\
\hline Dist. $(\AA)$ & & & & & \\
$\mathrm{Si}_{1}-\mathrm{Si}_{2}$ & 2,40 & 2,42 & 2,36 & 2,39 & - \\
$\mathrm{Si}_{n 1}-\mathrm{Si}_{n 2}$ & 2,29 & 2,30 & 2,33 & 2,28 & - \\
$\mathrm{H}_{1}-\mathrm{O}$ & 0,98 & 0,98 & 2,92 & 2,54 & - \\
$\mathrm{O}_{-} \mathrm{Si}_{1}$ & 1,67 & 1,88 & 1,58 & 1,65 & 2,20 \\
$\mathrm{H}_{1}-\mathrm{Si}_{1}$ & 2,28 & 2,36 & 1,74 & 1,50 & - \\
$\mathrm{Si}_{2 n d 1}-\mathrm{O}$ & 3,36 & 1,82 & 4,54 & 3,29 & 1,77 \\
$\mathrm{Si}_{2 n d 1}-\mathrm{H}_{1}$ & 3,38 & 2,38 & 1,65 & 3,16 & - \\
$\mathrm{Si}_{2 n d 2}-\mathrm{O}$ & 3,36 & 3,20 & 3,06 & 1,67 & - \\
$\mathrm{Si}_{2 n d 2}-\mathrm{H}_{1}$ & 4,26 & 3,40 & 3,14 & 4,16 & - \\
\hline $\left.\mathrm{Angulos}^{\circ}\right)$ & & & & & - \\
$\mathrm{H}_{1}-\mathrm{O}-\mathrm{Si}_{1}$ & 116,24 & 107,16 & 30,03 & 107,36 & - \\
$\mathrm{Si}_{2 n d 2}-\mathrm{O}-\mathrm{Si}_{1}$ & 40,15 & 46,98 & 47,39 & 128,89 & - \\
$\mathrm{Si}_{2 n d 1}-\mathrm{O}-\mathrm{Si}_{1}$ & 112,52 & 134,31 & 27,33 & 40,78 & - \\
\hline \hline
\end{tabular}




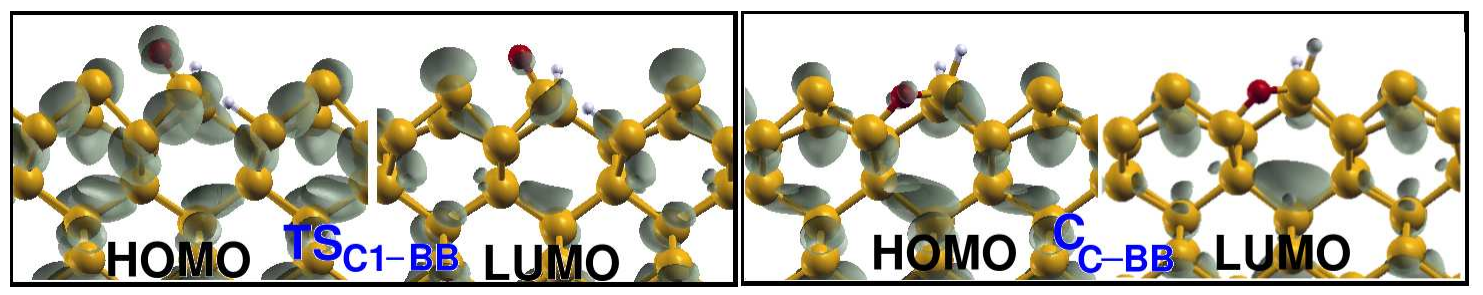

Figura 4.12: Isosuperfícies de densidade eletrônica associada ao mais alto orbital ocupado - HOMO (à esquerda) e ao mais baixo orbital desocupado - LUMO (à direita) para o estado de transição $\left(\mathrm{TS}_{C 1-B B}\right)$ e a configuração final com o O quimissorvido no sítio de back-bond $\left(\mathrm{C}_{C-B B}\right)$ ao longo do MEP mostrado na figura 4.10.

da back-bond tenha um comportamento tipo Arrhenius (veja apêndice A), podemos estimar a temperatura em que as barreiras de energia, mostradas na tabela 4.3, podem ser vencidas. Isto nos indica que a produção de $\mathrm{C}_{C-O D}$ ocorrerá a temperaturas de $\mathrm{T} \approx 559 \mathrm{~K}$ (a segunda barreira de energia já pode ser vencida em temperaturas da ordem de $322 \mathrm{~K}$ ). Para a formação de $\mathrm{C}_{C-B B}$, obtemos que a reação ocorrerá a $\mathrm{T} \approx 763 \mathrm{~K}$. Estas estimativas concordam com a interpretação dos resultados experimentais [128] mencionados anteriormente, visto que todas as medidas de IR, as quais permitiram concluir que a inserção de $\mathrm{O}$ ocorria nos dímeros, foram realizadas em $\mathrm{T}=675 \mathrm{~K}$, temperatura na qual, segundo nossas estimativas, poderíamos observar a formação de $\mathrm{C}_{C-O D}$, mas não de $\mathrm{C}_{C-B B}$.

\section{Reatividade da superfície $\operatorname{Si}(100)(2 \times 1)$ e efeitos de reação "colaborativa"}

Apresentamos, na figura 4.13, o caminho de reação para a conversão de $\mathrm{C}_{C-S i l}$ em $\mathrm{C}_{C-O D}$, porém calculado com uma fatia $(2 \times 2)$. O resultado é semelhante ao mostrado na figura 4.8, cujo cálculo foi feito para uma fatia (4x2). Umas das diferenças entre os dois resultados é a configuração atômica da imagem denominada de $\mathrm{P}_{C-O D}$ e mostrada juntamente com o MEP. 


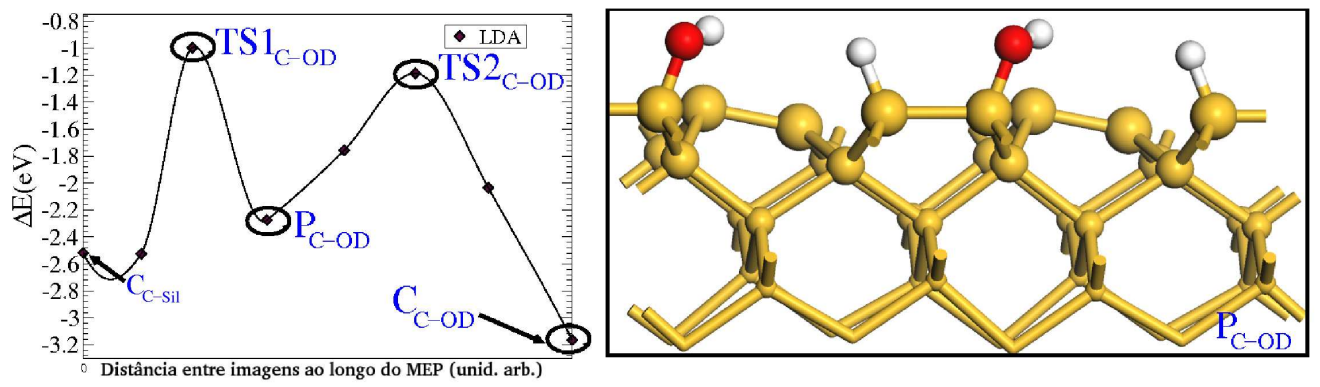

Figura 4.13: Caminho de menor energia, MEP, para a dissociação de $\mathrm{H}-\mathrm{Si}-\mathrm{Si}-\mathrm{OH}$ (configuração $\mathrm{C}_{C-S i l}$, figura 4.5) em $\mathrm{H}-\mathrm{Si}-\mathrm{O}-\mathrm{Si}-\mathrm{H}\left(\mathrm{C}_{C-O D}\right)$, sobre a superfíce de $\operatorname{Si}(100)(2 x 1)$ (a linha no gráfico é apenas um guia para os olhos). No eixo das ordenadas, temos a energia $(\mathrm{eV})$, onde o zero de energia corresponde à soma das energias totais (em eV) para os subsistemas isolados (molécula de água isolada e superfície de $\operatorname{Si}(100)(2 \times 1))$. Mostramos também a configuração atômica para a configuração fisissorvida $\mathrm{P}_{C-O D}$.

Neste caso, devido a alta reatividade da superfície limpa, forma-se uma ligação $\mathrm{H}-\mathrm{Si}_{1}-\mathrm{Si}_{2}-\mathrm{OH}$ no vale da superfície. Esta situação é energeticamente confortável, inclusive mais confortável que a situação $\mathrm{P}_{C-O D}$ mostrada na figura 4.8. As variações de energia ao longo do caminho de reação estão listadas na tabela 4.6. A reação "colaborativa" e "consertada" tem como consequência o aumento de $\approx 18 \%$ na energia de ativação para o processo de inserção do átomo de oxigênio no dímero, enquanto as diferenças de energias entre os pontos inicial e final do MEP é de apenas 0,027 e 0,014 eV, respectivamente. Este efeito de perfeita sincronia entre os átomos, que desaparece nos cálculos realizados com a fatia maior, pode ser atribuído à interação entre as imagens periódicas do sistema, causado pela alta reatividade desta superfície. 


\subsection{Conclusões Parciais}

A investigação das propriedades cinéticas das reação entre a molécula de água e a superfície $\mathrm{Si}(100)(2 \mathrm{x} 1)$ trouxe a luz alguns aspectos interessantes sobre este processo de oxidação. Nossos resultados mostram que a reação entre a água e a superfície ocorre independemente da posição em que a molécula atinge a superfície. Em acordo com evidências experimentais [95], o ataque oxidativo procede através a presença de um precursor molecular, promovendo a interação correlacionada da molécula com 2 dangling bonds da superfície. O precursor molecular já havia sido estudado teoricamente [90-92], mas, nossos resultados indicam que a interação entre adsorbato e adsorvente inicia antes do que foi mencionado nestes trabalhos. Outra constatação importante foi que a barreira de energia líquida para a formação de $C_{C-S i l}$ é pelo menos uma ordem de grandeza menor do que se havia predito anteriormente [90-92].

Considerando os possíveis caminhos de decomposição das unidades $\mathrm{C}_{C-S i l}$, constatamos que somado ao fato de que a inserção do átomo de $\mathrm{O}$ no dímero $\left(\mathrm{C}_{C-O D}\right)$

Tabela 4.6: Diferenças de energias relativas à energia total dos subsistemas isolados (molécula de água isolada e superfície de $\operatorname{Si}(100)(2 \times 1)$ ) para alguns pontos das barreiras de reação mostradas nas figuras 4.8 e 4.13 .

\begin{tabular}{lcc}
\hline \hline \multicolumn{3}{c}{$\mathrm{C}_{C-S i l} \rightarrow \mathrm{C}_{C-O D}$} \\
\hline $\mathrm{C}_{C-\text { Sil }}(2 \times 2)$ & $(4 \times 2)$ \\
$\mathrm{TS} 1_{C-O D}$ & $-2,52$ & $-2,49$ \\
$\mathrm{P}_{C-O D}$ & 1,52 & 1,54 \\
$\mathrm{TS} 2_{C-O D}$ & $-1,28$ & $-0,34$ \\
$\mathrm{C}_{C-O D}$ & 1,09 & 0,89 \\
Dessorção $(\leftarrow)$ & $+1,98$ & $+2,73$ \\
Exotermicidade & $+0,65$ & $+0,66$ \\
\hline \hline
\end{tabular}


ser 0,47 eV mais estável que a oxidação de um sítio de back-bond $\left(\mathrm{C}_{C-B B}\right)$, a barreira de reação favorece a oxidação dos dímeros da superfície. Ambos os resultados estão em desacordo com os cálculos anteriores baseados em aglomerados moleculares [137] que predizem as estruturas $\mathrm{C}_{C-O D}$ e $\mathrm{C}_{C-B B}$ como energeticamente degeneradas. Por fim, podemos afirmar que nossos resultados corroboram os dados experimentais de Weldon e colaboradores [128]. Desta forma, estamos confiantes na eficácia da metodologia que empregaremos para estudos de reações de oxidação em superfícies hidrogenadas. 


\section{Capítulo 5}

\section{Reação entre a molécula de $\mathrm{H}_{2} \mathrm{O}$ e a}

Superfície Monohidrogenada $\mathrm{H}_{2} \mathrm{O} / \mathrm{Si}(100)(2 \times 1): \mathrm{H}$

No capítulo anterior, apresentamos os resultados relacionados aos processos de quimissorção de $\mathrm{H}_{2} \mathrm{O}$ na superfície $\mathrm{Si}(100)(2 \times 1)$, e neste capítulo, nos dedicaremos à reação entre a molécula de água e a superfície $\mathrm{Si}(100)(2 \mathrm{x} 1): \mathrm{H}$ (monohidrogenada) ideal.

Diferentemente da interação entre água e a superfície limpa, dados experimentais para processos de oxidação em superfícies passivadas são escassos. Muito pouco é conhecido sobre as propriedades cinéticas e os produtos resultantes desta interação e somente um número limitado de experimentos de espectroscopia de infravermelho [118-121] estão disponíveis.

Uma superfície completamente hidrogenada poderia ser hidrofóbica [142] em consequência da ausência de dangling bonds. De fato, as unidades $\mathrm{SiH}_{2}$ retardam os processos de oxidação, e sua presença nas reconstruções $\operatorname{Si}(100)(3 \times 1): H$ e $\operatorname{Si}(100)(1 x 1): H$ tornam estas estruturas mais resistentes aos danos oxidativos quando comparadas às superfícies $\operatorname{Si}(100)(2 \times 1)$ :H. Nota-se que modificações consideráveis no espectro de 
infravermelho das estruturas $\mathrm{Si}(100)(3 \mathrm{x} 1)$ :H e $\mathrm{Si}(100)(1 \mathrm{x} 1)$ :H só aparecem para um fluxo de água $\approx 150 \%$ maior que aquele para a superfície monohidrogenada [118]. A seguir comentamos os dados disponíveis.

\subsection{Revisão de Dados Experimentais e Teóricos}

Espectros de infravermelho obtidos após a reação entre 100, 500 e 2000 L de água em fase gasosa e a superfície $\operatorname{Si}(100)(2 \mathrm{x} 1): H$ são reproduzidos das referências [118] e [121] na figura 5.1. As medidas foram efetuadas em 373 e $300 \mathrm{~K}$. Os espectros são apresentados como a razão entre o espectro da superfície antes e depois da exposição ao vapor de água.
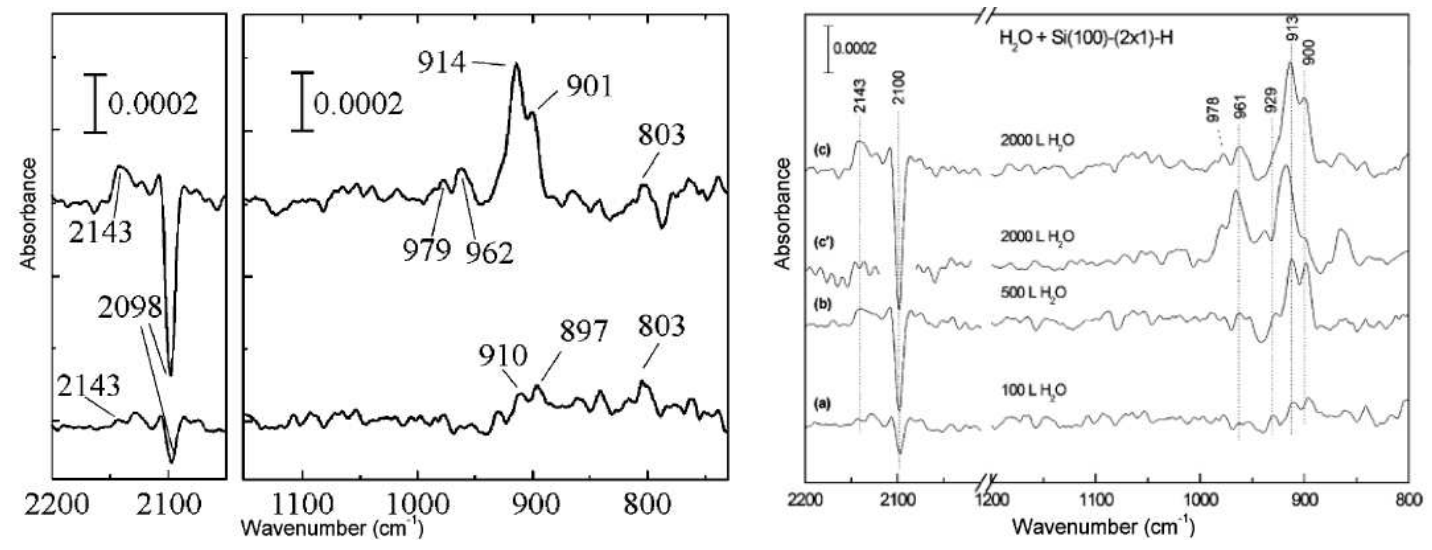

Figura 5.1: Espectro IR adaptado das referências [118] e [121] para a reação entre $\operatorname{Si}(100)(2 \mathrm{x} 1): H$ e vapor de água. Os resultados mostrados no gráfico à esquerda referem-se à dados coletados para $\mathrm{T}=373 \mathrm{~K}$ e para fluxo de água estimado em 100 L (parte mais baixa do gráfico) e 2000 L (parte mais alta do gráfico). Para os dados mostrados no gráfico à direita, pode-se observar o espectro obtido quando (a) 100 L, (b) $500 \mathrm{~L}$, (c) $2000 \mathrm{~L}$ de $\mathrm{H}_{2} \mathrm{O}$ interagem com a superfície monohidrogenada, a $373 \mathrm{~K}$ e (c’) $2000 \mathrm{~L}$, a $300 \mathrm{~K}$.

Foram realizados, pelos mesmos pesquisadores [118-121,143] cálculos de primeiros princípios, baseados na aproximação de Hartree-Fock, utilizados na interpretação 
dos picos vibracionais obtidos experimentalmente. De forma semelhante ao que se observa na maioria dos cálculos publicados, a superfície foi modelada através de aglomerados moleculares (cluster), cujas estruturas são mostradas na figura 5.2 (da referência [121]).

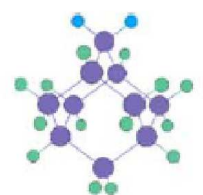

(a) $\mathrm{H}-\mathrm{Si}-\mathrm{H}$

ID

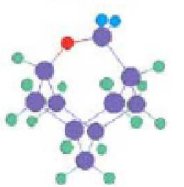

(e) $\mathrm{H}-\mathrm{Si}(\mathrm{O})-\mathrm{H}$
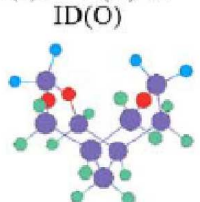

(i) $\mathrm{H}_{2} \mathrm{Si}(\mathrm{O})_{2} \cdots \mathrm{Si}(\mathrm{O}) \mathrm{H}_{2}$ $\mathrm{AD}(\mathrm{OO}, \mathrm{O})$

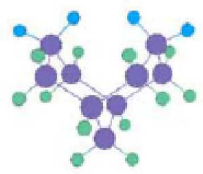

(b) $\mathrm{H}_{2} \mathrm{Si}^{\cdots} \cdot \mathrm{SiH}_{2}$ $\mathrm{AD}$

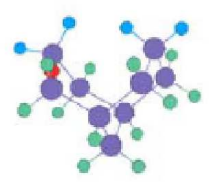

(f) $\mathrm{H}_{2} \mathrm{Si}(\mathrm{O}) \cdots \mathrm{SiH}$ $\mathrm{AD}(\mathrm{O})$

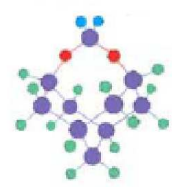

(j) $\mathrm{H}-\mathrm{Si}(\mathrm{O})_{2}-\mathrm{H}$ ID $(00)$

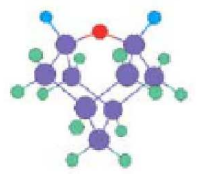

(c) $\mathrm{H}-\mathrm{Si}-\mathrm{O}-\mathrm{Si}-\mathrm{H}$ $\mathrm{CM}(\mathrm{M})$

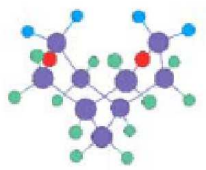

(g) $\mathrm{H}_{2} \mathrm{Si}(O) \cdots \mathrm{Si}(\mathrm{O}) \mathrm{H}_{2}$ (h) $\mathrm{H}_{2} \mathrm{Si}(\mathrm{O}) \cdots \mathrm{Si}(\mathrm{O}) \mathrm{H}_{2}$ $\mathrm{AD}(\mathrm{O}, \mathrm{O})$

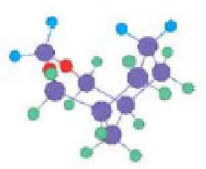

(k) $\mathrm{H}_{2} \mathrm{Si}(\mathrm{O})_{2} \cdots \mathrm{SiH}_{2} \quad$ (1) $\mathrm{H}_{2} \mathrm{Si}(\mathrm{O})_{3} \cdots \mathrm{Si}(\mathrm{O})_{2} \mathrm{H}_{2}$ $\mathrm{AD}(\mathrm{OO})$

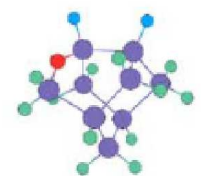

(d) $\mathrm{H}-\mathrm{Si}(\mathrm{O})-\mathrm{Si}-\mathrm{H}$ $\mathrm{CM}(\mathrm{O})$

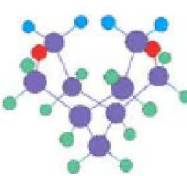
$\mathrm{AD}\left(0,0^{\prime}\right)$

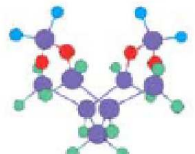
$\mathrm{AD}(00,00)$

Figura 5.2: Modelos de diferentes aglomerados moleculares empregados nos cálculos de modos vibracionais, da figura 1 da referência [121], utilizadas para interpretar resultados experimentais da reação entre $\mathrm{Si}(100)(2 \mathrm{x} 1): \mathrm{H}$ e $\mathrm{H}_{2} \mathrm{O}$. Os átomos de $\mathrm{O}$ estão em vermelho, os átomos de Si e H em azul. Em verde átomos de "saturação", tritium: H + um nêutron [121].

Sabendo-se que a frequência vibracional em $2100 \mathrm{~cm}^{-1}$ está associada à movimentos de estiramento das unidades $\mathrm{Si}-\mathrm{H}$ dos grupos $\mathrm{H}-\mathrm{Si}-\mathrm{Si}-\mathrm{H}$, a análise da decomposição deste pico indica o grau de degradação da superfície devido à interação com as moléculas de água. Neste caso verifica-se, através da integral da absorbância, a destruição de 25 a 100\% das espécies H-Si-Si-H quando o fluxo de água em contato com o substrato varia de 100 para 2000 L. A interpretação destes números mostra basicamente que a passivação da superfície pode dificultar, mas não impedir os processos de oxidação molhada. A comparação dos resultados mostrados nas fig- 
uras 5.1 e 4.1 evidencia que o fluxo necessário para a destruição de $100 \%$ dos grupos monohidrogenados é 2000 vezes maior que o fluxo responsável pela cobertura total da superfície limpa com unidades $\mathrm{H}-\mathrm{Si}-\mathrm{Si}-\mathrm{OH}$. Os espectros de IR (figura 5.1) juntamente com os cálculos dos modos vibracionais listados nas tabelas 5.1 e 5.2 nos fornecem algumas informações. Restringimos aqui aos resultados pertinentes à fase inicial de oxidação, ou seja, sem interação de uma impureza de O com outra.

O espectro vibracional resultante da exposição da superfície monohidrogenada a 2000 L de água é constituído por picos em 900, 913, 929, 961 e $978 \mathrm{~cm}^{-1}$, o que sugere que a oxidação promove a inserção de O nas back-bonds do Si, subsequente aglomeração dos átomos de $\mathrm{O}$, após estarem inseridos na segunda camada atômica, e a formação de unidades $\mathrm{SiH}_{2}$. Watanabe e colaboradores [118-121,143], utilizando cálculos de energia total, em conjunto com os resultados experimentais, propõem um modelo para a interação entre $\mathrm{H}_{2} \mathrm{O}$ e a superfície $\operatorname{Si}(100)(2 \times 1): \mathrm{H}$ no qual a reação poderia ser descrita pela dissociação da molécula de água sobre a superfície hidrogenada, formando um estado metaestável que, posteriormente, evolui para a inserção do O na back-bond do Si (5.1):

$$
\mathrm{H}_{2} \mathrm{O}+\mathrm{H}-\mathrm{Si}-\mathrm{Si}-\mathrm{H} \longrightarrow \mathrm{H}_{2} \mathrm{Si} \ldots \mathrm{H}-\mathrm{Si}-\mathrm{OH} \quad \longrightarrow \quad \mathrm{H}_{2} \mathrm{Si} \ldots \mathrm{Si}(\mathrm{O}) \mathrm{H}_{2}
$$

Entretanto, este estado metaestável não poderia ser detectado devido ao curto tempo de vida. Esta proposta tem por base os resultados observados para a oxidação molhada na superfície limpa, que mostram a dissociação da molécula sobre os átomos dos dímeros (figura 4.5). Com base nos cálculos de energia total, Watanabe et al [143] prevêem que a altura das barreiras para a inserção do grupo $\mathrm{OH}$ na backbond do Si e a migração do H para a superfície $\left(\mathrm{H}_{2} \mathrm{Si}\right.$...H-Si-OH $\longrightarrow \mathrm{H}_{2} \mathrm{Si}$...Si(O) $\left.\mathrm{H}_{2}\right)$ seria de, respectivamente, 0,8 e 1,82 eV. Ainda segundo a interpretação dos autores desse trabalho [143], a primeira barreira pode ser vencida termicamente, mas a segunda não, sendo mediada por tunelamento; a $373 \mathrm{~K}\left(100^{\circ} \mathrm{C}\right)$, a probabilidade de tunelamento da barreira de migração do $\mathrm{H}$ seria de 8,7\%, justificando o mecanismo 
Tabela 5.1: Frequêcias vibracionais experimentais $\left(\mathrm{em} \mathrm{cm}^{-1}\right)$, juntamente com a possível estrutura geométrica responsável pelo surgimento dos picos de absorção de infravermelho mostrados na figura 5.1 para a reação $\mathrm{H}_{2} \mathrm{O}+\mathrm{Si}(100)(2 \mathrm{x} 1): \mathrm{H}$. Os símbolos utilizados nesta tabela estão definidos na figura 5.2. Os símbolos $\delta$ e $\nu$ são utilizados para designar modos vibracionais tipo "dobramento" e "estiramento" de ligações.

\begin{tabular}{c|c|c|c}
\hline \hline Frequêcias & Referência & Espécie em movimento & Modo vibracional \\
\hline 743 & {$[127,128]$} & $\mathrm{H}-\mathrm{Si}-\mathrm{O}-\mathrm{Si}-\mathrm{H}$ & $\delta(\mathrm{Si}-\mathrm{H})_{C M}$ \\
757 & {$[127,128]$} & $\mathrm{H}-\mathrm{Si}-\mathrm{O}-\mathrm{Si}(\mathrm{O})_{2}-\mathrm{H}$ & $\delta(\mathrm{Si}-\mathrm{H})_{C M, O O}$ \\
785 & {$[118,121]$} & $\mathrm{H}-\mathrm{Si}-\mathrm{O}-\mathrm{Si}-\mathrm{H}$ & $\delta(\mathrm{Si}-\mathrm{H})_{C M(M)}$ \\
777 & {$[118,121]$} & $\mathrm{H}-\mathrm{Si}-(\mathrm{O})-\mathrm{Si}-\mathrm{H}$ & $\delta(\mathrm{Si}-\mathrm{H})_{C M(O)}$ \\
799 & {$[127,128]$} & $\mathrm{H}-\mathrm{Si}-\mathrm{O}-\mathrm{Si}-\mathrm{H}$ & $\delta(\mathrm{Si}-\mathrm{H})_{C M}$ \\
$803-805$ & {$[118,121]$} & $\mathrm{H}-\mathrm{Si}(\mathrm{O})-\mathrm{O}-\mathrm{Si}-\mathrm{H}$ & $\delta(\mathrm{Si}-\mathrm{H})_{C M(O, M)}$ \\
$803-805$ & {$[118,121]$} & $\mathrm{H}-\mathrm{Si}(\mathrm{O})_{2}-\mathrm{Si}(\mathrm{O})-\mathrm{H}$ & $\delta(\mathrm{Si}-\mathrm{H})_{C M(O O, O)}$ \\
$803-805$ & {$[118,121]$} & $\mathrm{H}-\mathrm{Si}(\mathrm{O})_{2}-\mathrm{O}-\mathrm{Si}(\mathrm{O})-\mathrm{H}$ & $\delta(\mathrm{Si}-\mathrm{H})_{C M(O O, M, O)}$ \\
$815-824$ & {$[118,121]$} & $\mathrm{H}-\mathrm{Si}(\mathrm{O})-\mathrm{O}-\mathrm{Si}-\mathrm{H}$ & $\delta(\mathrm{Si}-\mathrm{H})_{C M(O, M)}$ \\
$815-824$ & {$[118,121]$} & $\mathrm{H}-\mathrm{Si}(O)_{2}-\mathrm{Si}-\mathrm{H}$ & $\delta(\mathrm{Si}-\mathrm{H})_{C M(M, O O)}$ \\
821 & {$[118]$} & $\mathrm{H}-\mathrm{Si}-\mathrm{Si}-\mathrm{OH}$ & $\delta(\mathrm{Si}-\mathrm{OH})$ \\
830 & {$[118,121]$} & $\mathrm{H}-\mathrm{Si}(\mathrm{O})-\mathrm{O}-\mathrm{Si}(\mathrm{O})-\mathrm{H}$ & $\delta(\mathrm{Si}-\mathrm{H})_{C M\left(O, M, O^{\prime}\right)}$ \\
$840-860$ & {$[118,121]$} & $\mathrm{H}-\mathrm{Si}(\mathrm{O})_{2}-\mathrm{O}-\mathrm{Si}(\mathrm{O})_{2}-\mathrm{H}$ & $\left.\delta(\mathrm{Si}-\mathrm{H})_{C M(O O, M, O O}\right)$ \\
845 & {$[118,121]$} & $\mathrm{H}-\mathrm{Si}(\mathrm{O})_{2}-\mathrm{O}-\mathrm{Si}-\mathrm{H}$ & $(\mathrm{Si}-\mathrm{H})_{C M(O O, M}$ \\
850 & {$[118,121]$} & $\mathrm{H}-\mathrm{Si}(\mathrm{O})_{2}-\mathrm{O}-\mathrm{Si}(\mathrm{O})-\mathrm{H}$ & $\delta(\mathrm{Si}-\mathrm{H})_{C M(O O, M, O)}$ \\
\hline \hline
\end{tabular}

proposto. Discutiremos com mais detalhes este mecanismo de reação ao longo deste capítulo.

Estamos interessados nos estágios iniciais de oxidação na superfície $\operatorname{Si}(100)(2 x 1): H$, deste modo, analisamos o espectro de infravermelho adquirido quando uma pequena 
Tabela 5.2: Frequêcias vibracionais experimentais $\left(\mathrm{em} \mathrm{cm}^{-1}\right)$, juntamente com a possível estrutura geométrica responsável pelo surgimento dos picos de absorção de infravermelho mostrados na figura 5.1 para a reação $\mathrm{H}_{2} \mathrm{O}+\mathrm{Si}(100)(2 \mathrm{x} 1): \mathrm{H}$. Os símbolos utilizados nesta tabela estão definidos na figura 5.2. Os símbolos $\delta$ e $\nu$ são utilizados para designar modos vibracionais tipo "dobramento" e "estiramento" de ligações.

\begin{tabular}{|c|c|c|c|}
\hline Frequêcias & Referência & Espécie & Modo vibracional \\
\hline 900 & {$[118,121]$} & $\mathrm{H}-\mathrm{Si}-\mathrm{H}$ & $\delta(\mathrm{Si}-\mathrm{H})_{I D}$ \\
\hline 913 & {$[118,121]$} & $H_{2} \mathrm{Si} \ldots \mathrm{Si} H_{2}$ & $\delta(\mathrm{Si}-\mathrm{H})_{A D}$ \\
\hline 929 & {$[118,121]$} & $\mathrm{H}-\mathrm{Si}(\mathrm{O})-\mathrm{H}$ & $\delta(\mathrm{Si}-\mathrm{H})_{I D(O)}$ \\
\hline 961 & {$[118,121]$} & $\mathrm{H}-\mathrm{Si}(O)_{2}-\mathrm{H}$ & $\delta(\mathrm{Si}-\mathrm{H})_{I D(O O)}$ \\
\hline $978-983$ & {$[118,121]$} & $H_{2} \mathrm{Si}(O)_{2} \ldots \mathrm{Si}(\mathrm{O}) H_{2}$ & $\delta(\mathrm{Si}-\mathrm{H})_{A D(O O, O)}$ \\
\hline $978-983$ & {$[118,121]$} & $H_{2} \mathrm{Si}(O)_{2} \ldots \mathrm{Si}_{2}$ & $\delta(\mathrm{Si}-\mathrm{H})_{A D(O O)}$ \\
\hline $978-983$ & {$[118,121]$} & $H_{2} \mathrm{Si}(O)_{2} \ldots \mathrm{Si}(O)_{2} H_{2}$ & $\delta(\mathrm{Si}-\mathrm{H})_{A D(O O, O O)}$ \\
\hline 2081 & {$[118,121]$} & $\mathrm{H}-\mathrm{Si}-\mathrm{Si}-\mathrm{OH}$ & $\delta(\mathrm{Si}-\mathrm{H})$ \\
\hline 2100 & {$[118,121]$} & $\mathrm{H}-\mathrm{Si}-\mathrm{Si}-\mathrm{H}$ & $\nu(\mathrm{Si}-\mathrm{H})_{C M}$ \\
\hline 2109 & {$[127,128]$} & $\mathrm{H}-\mathrm{Si}-(\mathrm{O})-\mathrm{Si}-\mathrm{H}$ & $\nu(\mathrm{Si}-\mathrm{H})_{C M(O)}$ \\
\hline 2120 & {$[127,128]$} & $\mathrm{H}-\mathrm{Si}(\mathrm{O})-(\mathrm{O})-\mathrm{Si}-\mathrm{H}$ & $\nu(\mathrm{Si}-\mathrm{H})_{C M(O, M)}$ \\
\hline 2118 & {$[127,128]$} & $\mathrm{H}-\mathrm{Si}-\mathrm{O}-\mathrm{Si}-\mathrm{H}$ & $\nu(\mathrm{Si}-\mathrm{H})_{C M}$ \\
\hline 2143 & {$[118,121]$} & $\mathrm{H}-\mathrm{Si}(O)_{2}-\mathrm{Si}(\mathrm{O})-\mathrm{H}$ & $\nu(\mathrm{Si}-\mathrm{H})_{C M(O O, O)}$ \\
\hline 2143 & {$[118,121]$} & $\mathrm{H}-\mathrm{Si}(O)_{2}-\mathrm{Si}(O)_{2}-\mathrm{H}$ & $\nu(\mathrm{Si}-\mathrm{H})_{C M}(O O, O O)$ \\
\hline 2143 & {$[118,121]$} & $\mathrm{H}_{2} \mathrm{Si}(O)_{2} \ldots \mathrm{Si}(\mathrm{O}) H_{2}$ & $\nu(\mathrm{Si}-\mathrm{H})_{A D(O O, O)}$ \\
\hline 2143 & {$[118,121]$} & $\mathrm{H}-\mathrm{Si}(O)_{2}-\mathrm{Si}-\mathrm{H}$ & $\nu(\mathrm{Si}-\mathrm{H})_{C M(O O)}$ \\
\hline 2143 & {$[118,121]$} & $H_{2} \mathrm{Si}(O)_{2} \ldots \mathrm{Si}(O)_{2} H_{2}$ & $\nu(\mathrm{Si}-\mathrm{H})_{A D(O O, O O)}$ \\
\hline
\end{tabular}

quantidade de vapor de água reage com esta superfície. Experimentalmente, estes dados correspondem ao fluxo de $100 \mathrm{~L}$, menor fluxo experimental relatado na lit- 
eratura. Podemos ver dos espectros modos vibracionais situados em: 803, $\approx 818$,

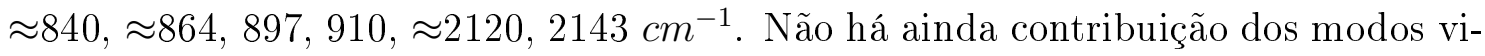
bracionais em 962 e $979 \mathrm{~cm}^{-1}$. De acordo com as tabelas 5.1 e 5.2 , podemos concluir que neste fluxo a maioria dos dímeros ainda está intacta $\mathrm{H}-\mathrm{Si}-\mathrm{Si}-\mathrm{H}$, com oxigênio na back-bond, ou tem um oxigênio inserido $\mathrm{H}-\mathrm{Si}-\mathrm{O}-\mathrm{Si}-\mathrm{H}$ (configurações $\mathrm{CM}$ ). É possível que também terminações silanol estejam presentes $\left(\approx 820 \mathrm{~cm}^{-1}\right)$. Nota-se ainda que a banda de absorção em $\approx 2120 \mathrm{~cm}^{-1}$ é mais intensa que aquela localizada em $2143 \mathrm{~cm}^{-1}$, corroborando a hipótese de que, se houver quebra do dímero e formação de $\mathrm{H}_{2} \mathrm{Si}$...Si $(\mathrm{O}) \mathrm{H}_{2}$, isto ocorrerá em pequenas quantidades. Além disso a banda em $2120 \mathrm{~cm}^{-1}$ é identificada com a presença de apenas uma impureza de oxigênio no dímero, on-dimer ou na back-bond, enquanto a segunda está identificada com a presença de mais de um átomo de oxigênio muito próximos, assim a predominânia da primeira é condizente com a condição de baixo fluxo. As próximas seções serão dedicadas à discussão, baseada em nossos resultados clássicos e ab initio, de questões concernentes ao problema da oxidação molhada na superfície $\operatorname{Si}(100)(2 x 1): H$.

\subsection{Nossos Resultados}

Como descrito nos capítulos anteriores, calculamos as barreiras de reação para dissociação da molécula isolada na superfície através do método NEB, que é flexível quanto aos pontos intermediários mas parte de duas configurações, inicial e final, pré-definidas.

Nossa metodologia é partir de configurações iniciais escolhidas utilizando métodos clássicos, uma vez que as interações de van der Waals não são incluídas nos métodos de primeiros princípios utilizados aqui. De forma que este foi um passo inicial importante, que possibilitou uma análise mais realista de como ocorrem as interações iniciais entre a molécula de água e a superfície $\operatorname{Si}(100)(2 \times 1): H$. 


\subsubsection{Deposição de moléculas de água sobre $\operatorname{Si}(100)(2 \times 1): H$ por Dinâmica Molecular Clássica}

Para simular a interação de moléculas de água e a superfície monohidrogenada em ambiente de ultra alto vácuo e temperatura finita, realizamos simulações de DMC de impulso da molécula sobre a superfície. A superfície é representada por uma fatia com dimensão lateral (8x6) monohidrogenada em ambas as faces, 10 camadas de Si, e região de vácuo de $\approx 67 \AA$ (figura 5.3). Nosso objetivo é simular as condições descritas nas referências $[118,120,121]$, para os quais a oxidação foi realizada em $\mathrm{T}=373 \mathrm{~K}$ por vapor de água, e portanto atribuímos à molécula uma velocidade inicial, na direção da superfície compatível com a tempetura utilizada nos experimentos. O tempo total de simulação foi de 7 ps e passo para integração das equações de movimento de $\Delta \mathrm{t}=0,001$ ps. Em alguns casos, realizamos simulações por até 12 ps, permitindo que a molécula pudesse interagir com a superfície durante um intervalo de tempo maior. A cada 200 passos de dinâmica, as cargas atômicas foram recalculadas, usando o método do charge equilibration [144]. Tanto a fatia quanto a molécula foram previamente otimizadas com o respectivo campo de força antes do início dos cálculos.
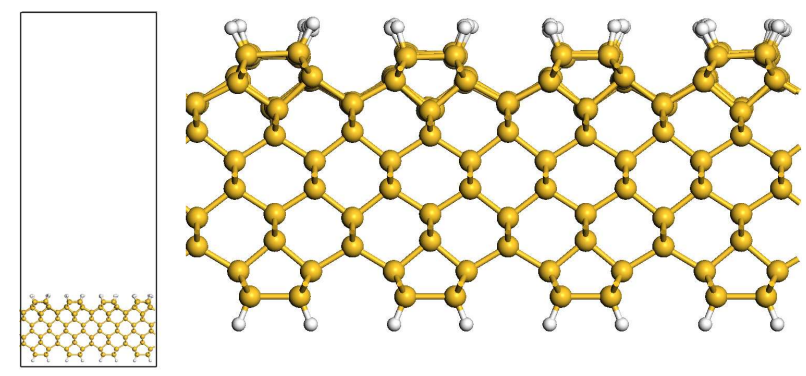

Figura 5.3: Célula unitária (8x6) utilizada nas simulações de dinâmica molecular clássica DMC. À esquerda mostramos a célula usada para representar a $\operatorname{Si}(100)(2 \times 1): H$, enquanto na figura à direita, vemos, em detalhe, um instantâneo das posições atômicas dentro da supercélula.

A primeira questão que investigamos foi qual o sítio preferido pela molécula 
de água para interagir com a superfície. Realizamos 10 simulações para cada um dos campos de força nas quais apenas uma molécula era colocada em contato com a superfície. Nas condições especificadas anteriormente e com o uso do campo de força UFF [145], averiguamos que em $70 \%$ dos casos a aproximação ocorreu por cima de uma fila de dímeros, e em $30 \%$ por entre vales da superfície. Repetindo os cálculos com o potencial empírico PCFF [146], obtivemos resultados muito semelhantes: $75 \%$ da moléculas próximas a um dímero, enquanto $25 \%$ em uma região de vale. As configurações atômicas finais para as duas situações são mostradas na figura 5.4. A orientação da molécula em relação à superfície, bem como a distância eram ligeiramente diferentes em cada um dos resultados. Na figura 5.4, mostramos uma configuração característica para cada situação. Incluímos as distâncias entre os átomos de $\mathrm{O}$ com os átomos de Si mais próximos. Assim, mesmo que a aproximação inicial seja preferivelmente "sobre o dímero", não devemos descartar a "sobre o vale" e estudaremos ambas.

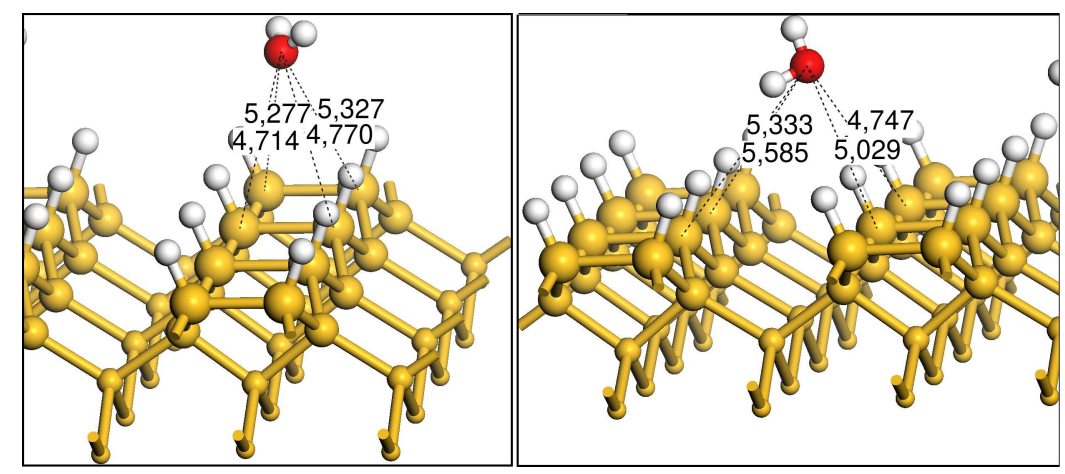

Figura 5.4: Posições finais para a interação entre uma molécula de água e a superfície $\operatorname{Si}(100)(8 \times 6): H$ para dois diferentes sítios de adsorção: sobre dímero e sobre vale.

\subsubsection{Configurações iniciais e finais: Cálculos de Primeiros Princípios}

Tendo estabelecido como se dá a interação inicial entre molécula e superfície, o procedimento adotado aqui foi otimizar, utilizando LDA-PZ e GGA-PW91, algumas 
das configurações finais da DMC, como aquelas mostradas na figura 5.4, para que essas pudessem ser utilizadas como as imagens iniciais da "fita elástica". Optamos por utilizar as estruturas obtidas com o PCFF, uma vez que para este potencial empírico a distância $\mathrm{Si}-\mathrm{Si}$ do dímero diferia de apenas $\approx 2,5 \%$ do nosso resultado DFT-LDA-PZ. As relaxações estruturais para os estados fisissorvidos foram feitas mantendo a coordenada $z$ do átomo de O fixa.

Devido ao elevado custo computacional dos cálculos de caminho de reação, a viabilidade dos mesmos está diretamente ligada ao tamanho da célula unitária empregada nas simulações. Assim, decidimos representar a superfície por uma fatia (2x2), formada por 6 camadas de Si e 4 átomos de Si por camada, monohidrogenada no lado "superior" e "inferior", separadas por uma camada de vácuo de $\approx 19$ A. A molécula de água reage apenas no lado "superior" (direção positiva do eixo $z$ ) com a superfície. Esta dimensão lateral é a menor possível que podemos supor seja suficiente para mantera as moléculas de água sem interação uma com a outra, mas temos $50 \%$ de dímeros "ocupados". Sendo a distância entre as imagens periódicas da molécula de 7,66 A. Como medida de confiabilidade, verificamos que os valores de energia de ligação e os parâmetros estruturais não sofrem alterações quando os cálculos são realizados com uma célula unitária $(4 \times 4)$, na qual as distâncias entre as imagens periódicas passa a $\approx 15,3 \AA$ (tabela 5.3). As estruturas otimizadas para as configurações nas quais as moléculas de água encontram-se fisissorvidas sobre a fileira de dímeros ou sobre o vale da superfície $\operatorname{Si}(100)(2 \times 1): H$, podem ser vistas na figuras 5.5. Estas estruturas foram denominadas P1, P2 e P3. Nas estruturas P1 e P3, a molécula de água aproxima-se da superfície sobre a fileira de dímeros, mas as posições relativas entre os átomos de O e Si diferem. Em P2 a molécula de água está posicionada no vale. Listamos, na tabela 5.3, os valores de energia de ligação e distâncias $\mathrm{Si}-\mathrm{O}\left(\mathrm{R}_{S i-O}\right)$ medidas entre os átomos de $\mathrm{Si}$ e $\mathrm{O}$ mais próximos. Apesar destas estruturas serem previstas como fisissorvidas por ambos os métodos de cálculo, a energia de fisissorção é muito pequena (da ordem de meV). Além disso os valores de energia total foram obtidos com métodos DFT padrão, que não de- 
screvem adequadamente as interações de van der Waals [147]. Assim, não podemos distinguir, por estabilidade, as configurações P1 e P3. Utilizaremos as estruturas P1 e P2 como pontos iniciais para os cálculos de caminho de reação "sobre-o-dímero" e "sobre-o-vale".

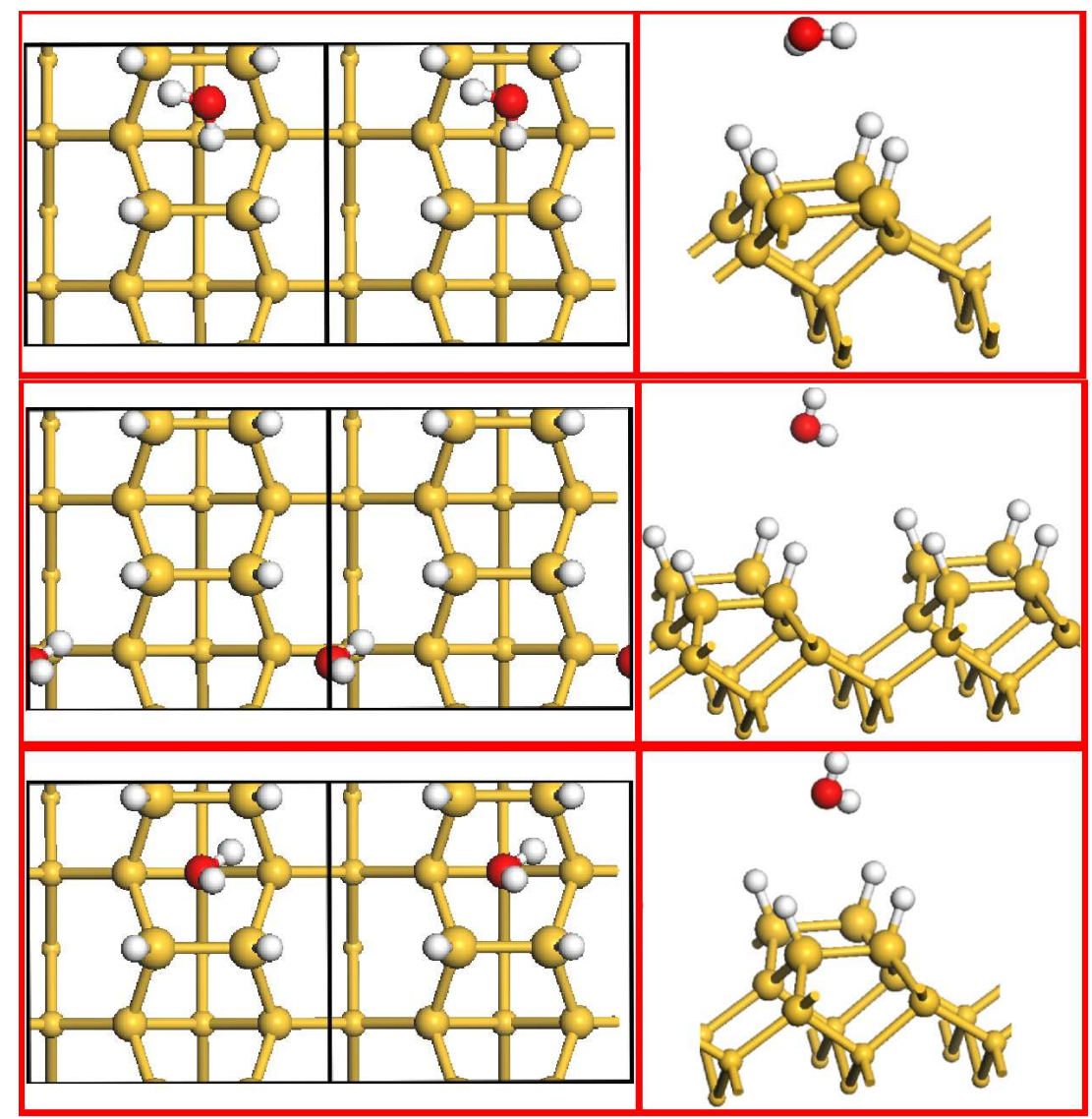

Figura 5.5: Configurações estruturais otimizadas para as situações fisissorvidas: P1 (superior), P2 (intermediário) e P3 (inferior). Os átomos de O são representados por esferas vermelhas, os átomos de $\mathrm{H}$ por esferas brancas, enquanto os átomos de Si são representados em amarelo. O tamanho das esferas amarelas está relacionado com a posição dos átomos de Si na fatia usada em nossas simulações. Os retângulos pretos delimitam a célula unitária.

Necessitamos ainda as configurações finais para os cálculos dos caminhos de reação. Motivados pelos resultados experimentais [118-121] discutidos previamente, 
Tabela 5.3: Energias de ligação (eV/molécula) e distâncias interatômicas $(\AA)$ entre os átomos de $\mathrm{Si}$ e $\mathrm{O}$ mais próximos nas estruturas fisissorvidas e quimissorvidas (figuras 5.5 e 5.6). Todos os resultados referem-se a cálculos com uma supercélula (2x2), exceto quando identificado.

\begin{tabular}{lcccccccc}
\hline \hline & $\mathrm{P} 1$ & $\mathrm{P} 1(4 \mathrm{x} 4)$ & $\mathrm{P} 2$ & $\mathrm{P} 3$ & $\mathrm{C}_{S i l}$ & $\mathrm{C}_{B B+H 2}$ & $\mathrm{C}_{B B}$ & $\mathrm{C}_{O D}$ \\
\hline$\triangle \mathrm{E}_{L D A}$ & $-0,0421$ & $-0,0454$ & $-0,03$ & $-0,04$ & $-0,71$ & $-0,61$ & $-1,11$ & $-1,18$ \\
$\triangle \mathrm{E}_{G G A}$ & $-0,03$ & - & $-0,03$ & $-0,04$ & $-0,55$ & $-0,87$ & $-1,13$ & $-1,43$ \\
$\mathrm{R}_{S i-O}(\AA)$ & 4,67 & 4,66 & 4,80 & 4,78 & 1,67 & 1,67 & 1,67 & 1,67 \\
\hline \hline
\end{tabular}

temos interesse em calcular o MEP para o processo de oxidação descrito pela equação 5.1. Para tal, otimizamos as configurações quimissorvidas $\mathrm{H}_{2} \mathrm{Si}$...H-Si-OH e $\mathrm{H}_{2} \mathrm{Si}$... $\mathrm{Si}(\mathrm{O}) \mathrm{H}_{2}$. Denominamos estas estruturas por $\mathrm{C}_{S i l}$ e $\mathrm{C}_{B B}$, respectivamente. Conforme mencionamos no capítulo 4, o termo silanol refere-se à presença de unidades Si-OH na superfície. As geometrias otimizadas são mostradas na figura 5.6. A estrutura nomeada de $\mathrm{C}_{S i l}$ é obtida pela dissociação parcial da molécula de água, cujos fragmentos $\mathrm{H}$ e $\mathrm{OH}$, conectam aos átomos de $\mathrm{Si}$ que pertenciam a uma unidade $\mathrm{H}-\mathrm{Si}-$ $\mathrm{Si}-\mathrm{H}$, da qual a ligação $\mathrm{Si}-\mathrm{Si}$ foi quebrada. $\mathrm{Em}_{B B}$, o átomo de O está conectado a átomos de Si pertencentes à primeira e segunda camadas atômicas (back-bond) e os átomos de H estão na superfície.

Além dessas configurações, propomos duas novas situações de quimissorção, denominadas por $\mathrm{C}_{O D}$ e $\mathrm{C}_{B B+H 2}$ (figura 5.6). Para a configuração $\mathrm{C}_{O D}$, temos a inserção de $\mathrm{O}$ no dímero, com a liberação de uma molécula de $\mathrm{H}_{2}$. A estrutura é muito semelhante àquela mostrada na figura 4.8 e é frequentemente encontrada após a oxidação molhada da superfície $\operatorname{Si}(100)(2 \times 1)$, mas não tem sido mencionada como um possível produto da reação entre água e a superfície monohidrogenada. Por outro lado, nossos resultados indicam (tabela 5.3) que $\mathrm{C}_{O D}$ é mais estável que $\mathrm{C}_{B B}$ e $\mathrm{C}_{\text {Sil }}$ por $0,3(0,06)$ e $0,88(0,46) \mathrm{eV}$, respectivamente, e, comparativamente 
às configurações $\mathrm{C}_{B B}$ e $\mathrm{C}_{O D}$, o defeito $\mathrm{C}_{S i l}$ é a situação quimissorvida menos estável para a dissociação da molécula de água, em acordo com dados experimentais e teóricos anteriores $[118,121,143,148]$. Na estrutura $\mathrm{C}_{B B+H 2}$ também há liberação de uma molécula de $\mathrm{H}_{2}$, mas o átomo de Oxigênio está quimissorvido na back-bond e a ligação Si-Si do dímero não é quebrada. Valores de energia de ligação obtidos com a aproximção LDA-PZ mostram que a inserção de $\mathrm{O}$ na back-bond $\left(\mathrm{C}_{B B+H 2}\right)$, mas preservando a ligação $\mathrm{Si}-\mathrm{Si}$ via liberação de uma molécula de $\mathrm{H}_{2}$, é um defeito energeticamente menos favorável $\mathrm{C}_{\text {Sil }}$ de $0,1 \mathrm{eV}$. O resultado GGA-PW91 prediz que esta estrutura é favorecida de $0,32 \mathrm{eV}$ quando comparada à formação de silanol nesta superfície. Discutiremos a viabilidade cinética da formação de $\mathrm{C}_{B B+H 2}$ como um produto da oxidação molhada da superfície monohidrogenada no decorrer deste capítulo.

\subsubsection{Caminhos de reação: cálculos quânticos}

Passamos agora aos resultados para os caminhos de menor energia para os quais ocorre a oxidação da superfície $\operatorname{Si}(100)(2 \times 1): H$, tendo como ponto inicial as estruturas $\mathrm{P} 1$ e/ou P2 e promovendo a inserção de átomos de $\mathrm{O}$ no dímero $\left(\mathrm{C}_{S i l}\right.$ e $\left.\mathrm{C}_{O D}\right)$ e na back-bond $\left(\mathrm{C}_{B B}\right.$ e $\left.\mathrm{C}_{B B+H 2}\right)$.

\section{$\mathbf{P} 1 \longrightarrow \mathbf{C}_{S i l}$ e $\mathbf{P} 2 \longrightarrow \mathbf{C}_{S i l}$}

Este seria, segundo a proposta experimental [118-121], o primeiro passo da oxidação que culmina com a inserção do O na back-bond do Si. Nossos resultados para o MEP, calculados com LDA-PZ e GGA-PW91, podem ser vistos na figura 5.7. Verificamos que o caminho de reação seguido pelo sistema para a formação do defeito $\mathrm{C}_{\text {Sil }}$, calculado com ambos os funcionais, são exatamente os mesmos, ou seja, cada ponto na curva LDA-PZ tem um correspondente na curva GGA-PW91, com parâmetros estruturais muito semelhantes, o que pode ser visto comparando os valores de distâncias de ligação listados na tabela 5.4. Mesmo assim, temos três 


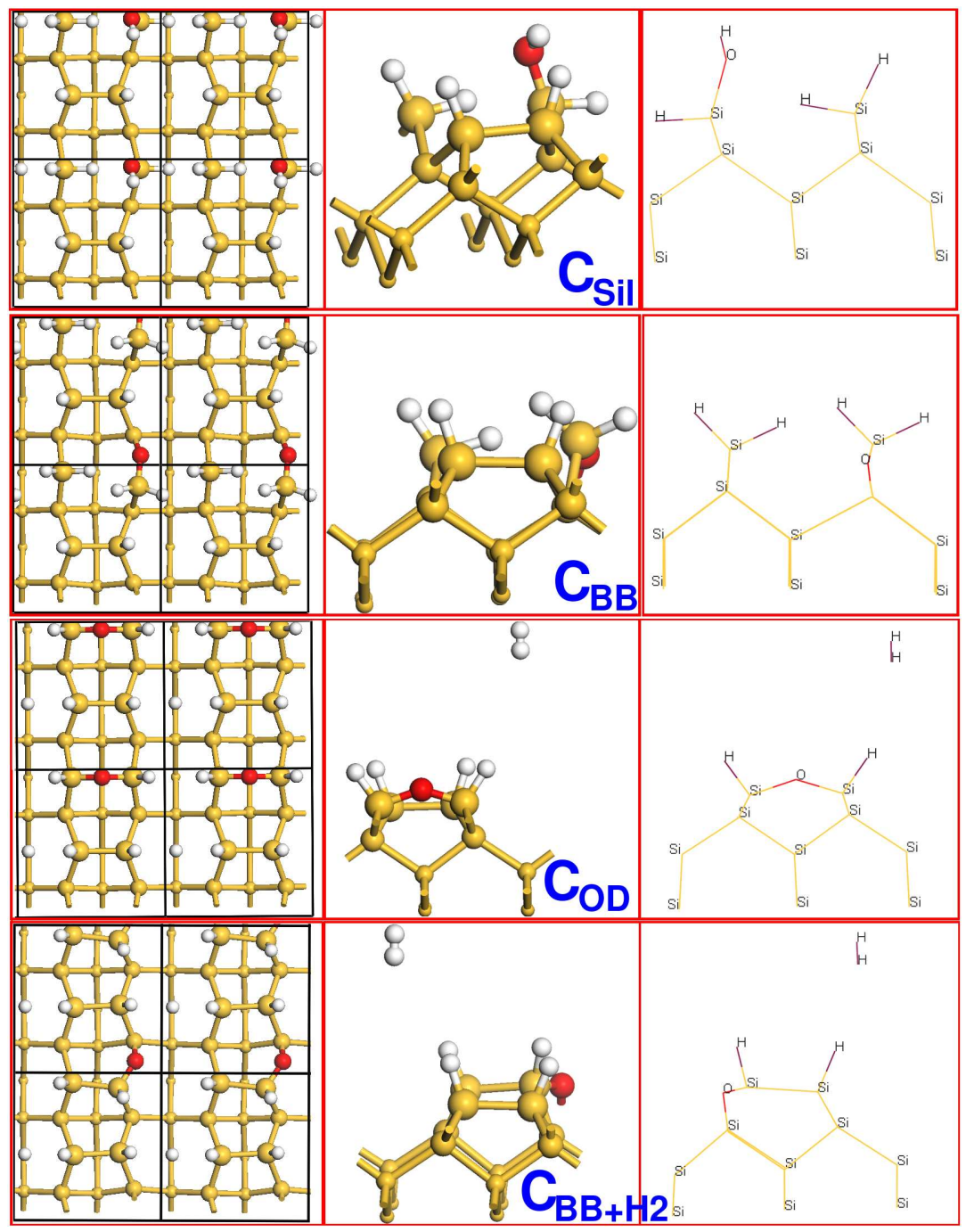

Figura 5.6: Representação das estruturas otimizadas para as situações quimissorvidas: $\mathrm{C}_{S i l}$ (superior), $\mathrm{C}_{B B}, \mathrm{C}_{O D}$ e $\mathrm{C}_{B B+H 2}$ (inferior). Os átomos de $\mathrm{O}$ são representados por esferas vermelhas, os átomos de $\mathrm{H}$ por esferas brancas, enquanto os átomos de Si são representados em amarelo. O tamanho das esferas amarelas está relacionado com a posição dos átomos de Si na fatia usada em nossas simulações. Os retângulos pretos delimitam a célula unitária.

pontos de desacordo entre os resultados LDA-PZ e GGA-PW91. Primeiramente, como mostrado na tabela 5.3, cálculos com a aproximação local predizem que o defeito $\mathrm{C}_{\text {Sil }}$ mais estável do que o obtido com a aproximação GGA-PW91. Um 
segundo ponto refere-se à situação fisissorvida $\mathrm{P}_{\text {Sil }}$, identificada no MEP calculado com LDA-PZ e com energia de fisissorção razoável de $\Delta \mathrm{E}=0,12 \mathrm{eV}$ : esta estrutura não é predita como uma situação de fisissorção nos cálculos GGA-PW91. Apesar de identificarmos, em ambos os caminhos, uma imagem com parâmetros estruturais semelhantes, os resultados para a energia dos diferentes funcionais não são os mesmos. Finalmente, a barreira de energia está subestimada em $29 \%$ nos cálculos LDA-PZ, relativamente ao resultado GGA-PW91.

Tabela 5.4: Distâncias interatômicas $(\AA)$ para a superfície $\operatorname{Si}(100)(2 \mathrm{x} 1): \mathrm{H}$, a imagem inicial (P1), o estado de transição $\left(\mathrm{TS}_{S i l}\right)$ e a configuração quimissorvida $\left(\mathrm{C}_{\text {Sil }}\right)$ resultantes do processo de oxidação molhada na superfície monohidrogenada. Resultados referentes ao funcional GGA encontra-se entre parênteses. Os símbolos utilizados nas definições das distâncias são aqueles da figura 5.7.

\begin{tabular}{lcc|cc}
\hline \hline & \multirow{3}{*}{$\mathrm{Si}(100)$} & \multicolumn{2}{|c}{$\mathrm{P} 1 \rightarrow \mathrm{C}_{S i l}$} \\
\cline { 4 - 5 } & $(2 \mathrm{x} 1): \mathrm{H}$ & $\mathrm{P} 1$ & $\mathrm{TS}_{S i l}$ & $\mathrm{C}_{S i l}$ \\
\hline $\mathrm{H}-\mathrm{Si}$ & $1,50(1,50)$ & $1,50(1,50)$ & $1,50(1,50)$ & $1,50(1,50)$ \\
$\mathrm{Si}_{1}-\mathrm{Si}_{2}$ & $2,41(2,44)$ & $2,41(2,44)$ & $3,03(3,12)$ & $3,94(4,01)$ \\
$\mathrm{H}_{w 1}-\mathrm{O}$ & - & $0,97(0,98)$ & $0,99(0,99)$ & $0,98(0,97)$ \\
$\mathrm{H}_{w 2}-\mathrm{O}$ & - & $0,98(0,97)$ & $1,02(1,02)$ & $2,40(2,47)$ \\
$\mathrm{O}_{-} \mathrm{Si}_{1}$ & - & $4,66(4,64)$ & $1,95(1,97)$ & $1,67(1,67)$ \\
$\mathrm{O}_{-} \mathrm{Si}_{2}$ & - & $4,66(4,78)$ & $3,01(3,06)$ & $3,84(3,90)$ \\
$\mathrm{O}_{-} \mathrm{Si}_{2 n d 1}$ & - & - & $3,85(3,88)$ & $3,36(3,39)$ \\
$\mathrm{Si}_{1}-\mathrm{H}_{w 1}$ & - & - & $2,54(2,54)$ & $2,29(2,28)$ \\
$\mathrm{H}_{w 1}-\mathrm{Si}_{2 n d 2}$ & - & - & $3,82(3,81)$ & $3,60(3,59)$ \\
\hline \hline
\end{tabular}

A incorporação de $\mathrm{O}$ na superfície ocorre via um estado de transição, $\mathrm{TS}_{S i l}$, no qual o oxigênio está assimetricamente coordenado por 2 átomos de $\mathrm{H}$ e pelo átomo $\mathrm{Si}_{1}$; a situação é instável pois o átomo $\mathrm{Si}_{2}$ tem uma dangling bond, já que a ligação 


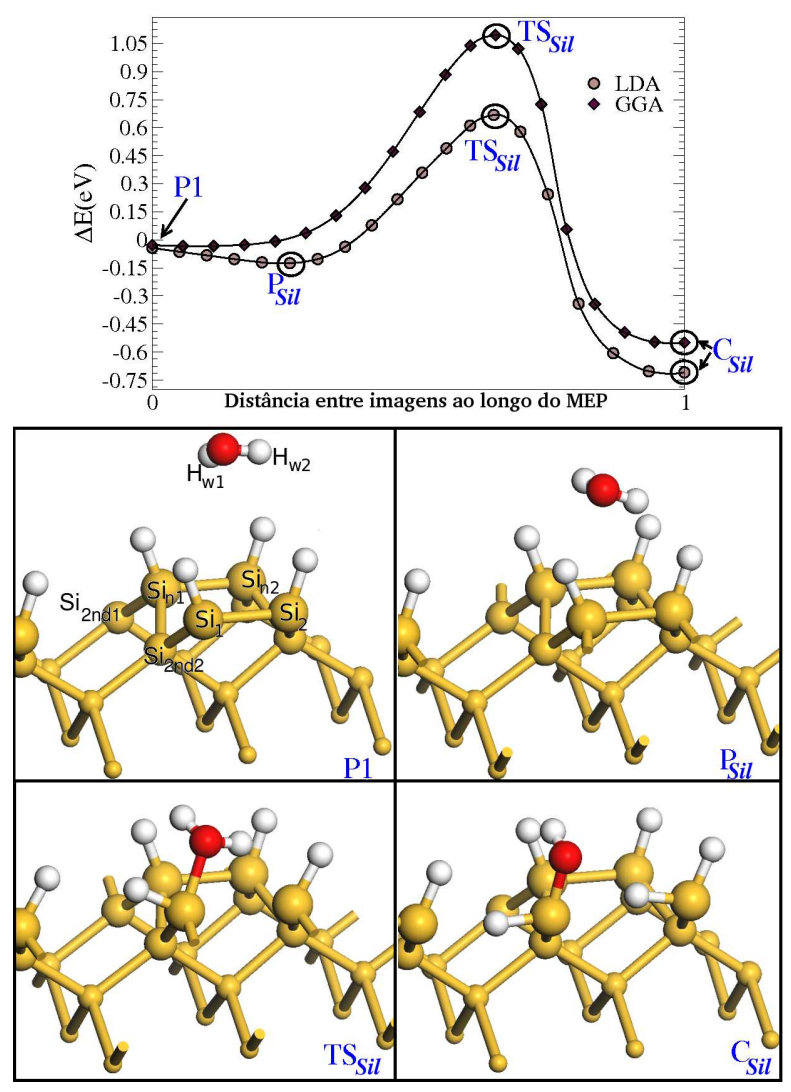

Figura 5.7: Caminho de menor energia, MEP, para a dissociação da molécula de $\mathrm{H}_{2} \mathrm{O}$ sobre a superfíce de $\mathrm{Si}(100)(2 \mathrm{x} 1): \mathrm{H}$, com formação de $\mathrm{C}_{S i l}$ (a linha no gráfico é apenas um guia para os olhos), calculados com LDA-PZ (círculos) e GGA-PW91 (losângulos). No eixo das ordenadas temos a energia em eV, onde o zero de energia corresponde à soma das energias totais (em eV) para os subsistemas isolados (molécula isolada e superfície de $\operatorname{Si}(100)(2 \mathrm{x} 1): \mathrm{H})$. Ilustramos ainda as configurações atômicas para alguns pontos especiais ao longo do MEP: a imagem inicial (P1), a configuração fisissorvida $\left(\mathrm{P}_{\text {Sil }}\right)$, o estado de transição $\left(\mathrm{TS}_{\text {Sil }}\right)$ e a configuração final quimissorvida $\left(\mathrm{C}_{\text {Sil }}\right)$.

$\mathrm{Si}_{1}-\mathrm{Si}_{2}$ foi rompida. Também aqui há uma interação correlacionada da molécula de água com a superfície, isto é, as ligações $\mathrm{O}-\mathrm{H}$ não estão quebradas quando o oxigênio aproxima do $\mathrm{Si}_{1}$. Este comportamento assemelha-se àquele predito experimentalmente por Andersohn e Kohler [95] para a oxidação molhada na superfície 
$\operatorname{Si}(100)(2 \mathrm{x} 1)$ e discutido na seção 4.2.1. Analisando a densidade total de estados (DOS) e sua projeção sobre os átomos $\mathrm{Si}_{1}, \mathrm{Si}_{2}, \mathrm{Si}_{n 1}, \mathrm{H}_{w 1}, \mathrm{H}_{w 2}$ e O (figura 5.8), notamos que os estados eletrônicos mais altos originalmente pertencentes à molécula de água, encontram-se quase que completamente deslocalizados sobre a banda de valência da superfície, diferentemente da estrutura inicial P1. Apenas o orbital de semi caroço do átomo de $\mathrm{O}$ continua localizado, a $\approx-23,25 \mathrm{eV}$. Outra característica é a "presença" da dangling bond sobre o $\mathrm{Si}_{2}$, conforme pode ser averiguado no surgimento do pico nítido (marcado com uma seta) na PDOS. Este efeito não é observado na PDOS do $\mathrm{Si}_{1}$, mostrando que a ligação $\mathrm{Si}_{1}-\mathrm{O}$ foi realmente estabelecida.

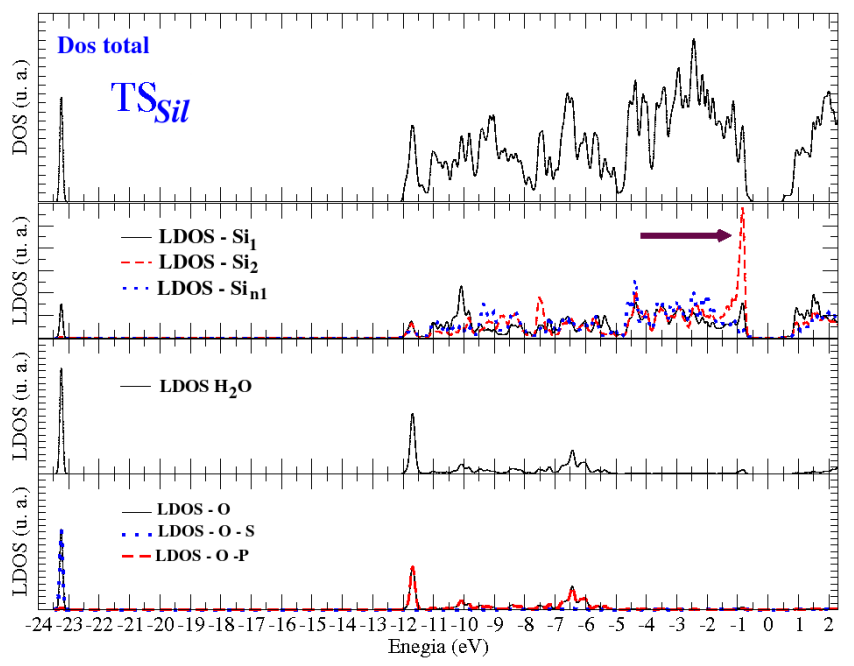

Figura 5.8: Densidade total de Estados para o estado de transição, $\operatorname{TS}_{S i l}$ (veja figura 5.7) e suas projeções sobre os átomos de $\mathrm{Si}_{1}, \mathrm{Si}_{2}, \mathrm{Si}_{n 1}, \mathrm{H}_{w 1}, \mathrm{H}_{w 2}$ e O. O zero de energia coincide com o nível de Fermi do sistema.

A energia do sistema descresce continuamente à medida que $\mathrm{H}_{w 2}$ é transferido para o $\mathrm{Si}_{2}$ e o Oxigênio torna-se firmemente ligado ao $\mathrm{Si}_{1}$. Esta sequência de eventos fica melhor evidenciada na figura 5.9, na qual regraficamos o MEP mostrado na figura 5.7, mas em função da distância $\mathrm{Si}_{1}-\mathrm{O}$. Valores para altura de barreiras desta reação, calculadas com ambos os funcionais de troca e correlação, são sumarizadas na tabela 5.5. Nota-se que, uma vez formada, a estrutura $\mathrm{C}_{S i l}$ não pode se dessorver facilmente desta superfície, já que nossos resultados mostram que existe uma alta 
barreira de dessorção. A barreira de energia para a formação do defeito $\mathrm{C}_{\text {Sil }}$ independe do posicionamento inicial da molécula de água, se sobre a fileira de dímeros ou se na região de vale. Conforme listado na tabela 5.5, as alturas da barreira de reação $\left(\operatorname{TS}_{P 2 \rightarrow S i l}\right)$ bem como a de dessorção (Dess. $\left.\left(\mathrm{C}_{P 2 \rightarrow \text { Sil }}\right)\right)$, cuja configuração inicial foi o estado fisissorvido denominado de P2, são idênticas àquelas obtidas para a formação de $\mathrm{C}_{\text {Sil }}$ tendo como ponto inicial a configuração P1. Em ambos os casos o caminho de reação está associado também a mesma geometria para o estado de transição.

Comparado os resultados mostrados nas figuras 5.7 e 5.9 com aqueles discutidos anteriormente para a dissociação da molécula de água na superfície limpa (figura 4.5), compreendemos as medidas que predizem coeficiente de adsorção próximo à unidade para água em $\operatorname{Si}(100)(2 x 1)$, mas reatividade limitada para a superfície monohidrogenada nas mesmas condições [84,118, 119, 121].

$\mathrm{C}_{S i l} \longrightarrow \mathrm{C}_{B B}$

Nossos resultados indicam que a barreira de energia para a conversão $\mathrm{C}_{S i l}$ em $\mathrm{C}_{B B}$ é muito alta (tabela 5.5). A energia de inserção no back-bond poderia ser influenciada pelo tamanho reduzido da célula unitária, uma vez que as distorções subsuperficiais são razoavelmente fortes. Assim calculamos os caminhos de reação para supercélulas (2x2) e (2x4), mostrados na figura 5.10 em conjunto com a geometria otimizada para algumas imagens do caminho. As diferenças de energias são pequenas, mostrando a localidade do fenômeno. Em ambos os casos, o resultado para a conversão de $\mathrm{C}_{S i l}$ em $\mathrm{C}_{B B}$ mostra duas barreiras de energia a serem vencidas. A primeira, muito alta, está associada à quebra da ligação $\mathrm{H}_{w 1}-\mathrm{O}$ que conduz a um "compartilhamento de proton" (uma ligação com o $\mathrm{H}_{w 1}$ ) entre os átomos $\mathrm{Si}_{1}$ e $\mathrm{Si}_{2 n d 2}$. A variação da curva de energia em função da distância $\mathrm{H}_{w 1}-\mathrm{O}$ é mostrada na figura 5.11(a), à esquerda. Observa-se, depois deste ponto, que o sistema evolui para uma situação energeticamente mais confortável, uma vez que $\mathrm{H}_{w 1}$ aproxima-se preferencialmente do $\mathrm{Si}_{2 n d 2}$, enquanto a distância $\mathrm{Si}-\mathrm{O}$ converge para valores tipicamente encontrados 


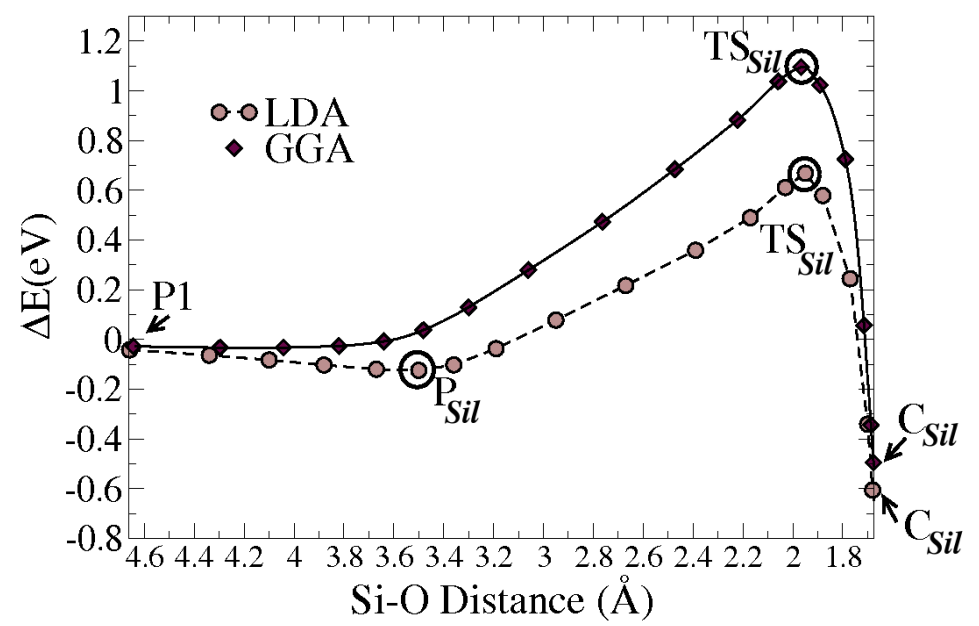

Figura 5.9: Caminho de menor energia, MEP, para a dissociação da molécula de $\mathrm{H}_{2} \mathrm{O}$ sobre a superfíce de $\mathrm{Si}(100)(2 \mathrm{x} 1): \mathrm{H}$, com formação de $\mathrm{C}_{S i l}$ (a linha no gráfico é apenas um guia para os olhos), calculados com LDA-PZ (círculos) e GGAPW91 (losângulos). No eixo das abscissas temos os valores das distâncias $\mathrm{Si}_{1}-\mathrm{O}$ nas diferentes imagens utilizadas na construção da fita elástica, enquanto no eixo das ordenadas, temos a energia em eV, onde o zero de energia corresponde à soma das energias totais (em eV) para os subsistemas isolados (molécula isolada e superfície de $\operatorname{Si}(100)(2 \mathrm{x} 1): H)$. Os pontos marcados por uma elipse delimitam a posição de alguns pontos especiais ao longo do MEP: a imagem inicial (P1), a configuração fisissorvida $\left(\mathrm{P}_{\text {Sil }}\right)$, o estado de transição $\left(\mathrm{TS}_{\text {Sil }}\right)$ e a configuração final quimissorvida $\left(\mathrm{C}_{\text {Sil }}\right)$, ilustrados na figura 5.7.

em estruturas com ligações $\mathrm{Si}=\mathrm{O}$ [149]. Todavia, a barreira de dessorção é de apenas $+0,47 \mathrm{eV}$, indicando que a reação pode também reverter. A formação de $\mathrm{C}_{B B}$ ainda depende que uma segunda barreira de energia seja vencida, e, neste caso, a energia necessária é mais baixa.

Outra possível rota para conversão de $\mathrm{C}_{S i l}$ em $\mathrm{C}_{B B}$ é mostrada na figura 5.11(b). Este MEP consiste em uma sequência de eventos distinta da descrita anteriormente: a primeira barreira $\left(\mathrm{TS} 1-\mathrm{A}_{1 S i l \rightarrow B B}\right)$ de reação é para a inserção do $\mathrm{O}$ na back-bond e, somente após este evento, o $\mathrm{H}_{w 1}$ conecta-se ao $\mathrm{Si}_{1}$. Entretanto, esta rota é ainda 
Tabela 5.5: Barreiras de energia (eV) para a quimissorção de $\mathrm{H}_{2} \mathrm{O}$ na superficie $\operatorname{Si}(100)(2 x 1): H$. As alturas de barreiras de dessorção estão indicadas abreviadamente por Dess.. Incluímos também estimativas das temperaturas para as quais cada uma das barreiras pode ser vencida. Estas estimativas foram baseadas na Lei de Arrhenius (apêndice A).

\begin{tabular}{|c|c|c|c|c|}
\hline & $\mathrm{E}_{L D A}(\mathrm{eV})$ & $\mathrm{E}_{G G A}(\mathrm{eV})$ & $\mathrm{T}_{L D A}(\mathrm{~K})$ & $\mathrm{T}_{G G A}(\mathrm{~K})$ \\
\hline $\mathrm{TS}_{P 1 \rightarrow S i l}$ & 0,792 & 1,122 & 288,6 & 408,7 \\
\hline Dess. $\left(\mathrm{C}_{P 1 \leftarrow S i l}\right)$ & 1,501 & 1,645 & 546,6 & 599,0 \\
\hline $\mathrm{TS}_{P 2 \rightarrow S i l}$ & 0,794 & - & 289,0 & - \\
\hline Dess. $\left(\mathrm{C}_{P 2 \leftarrow S i l}\right)$ & 1,502 & - & 547,1 & - \\
\hline $\mathrm{TS} 1_{S i l \rightarrow B B}(2 \times 2)$ & 2,412 & - & 878,3 & - \\
\hline Dess.1 $\left(\mathrm{C}_{S i l \leftarrow B B}\right)(2 \mathrm{x} 2)$ & 0,516 & - & 187,9 & - \\
\hline $\mathrm{TS} 2_{S i l \rightarrow B B}(2 \times 2)$ & 0,747 & - & 271,9 & - \\
\hline Dess.2 $\left(\mathrm{C}_{S i l \leftarrow B B}\right)(2 \mathrm{x} 2)$ & 3,047 & - & 1109,7 & - \\
\hline $\mathrm{TS}_{S i l \rightarrow B B}(2 \mathrm{x} 4)$ & 2,303 & - & 838,5 & - \\
\hline Dess.1 $\left(\mathrm{C}_{S i l \leftarrow B B}\right)(2 \mathrm{x} 4)$ & 0,472 & - & 171,7 & - \\
\hline $\mathrm{TS} 2_{S i l \rightarrow B B}(2 \mathrm{x} 4)$ & 0,767 & - & 279,1 & - \\
\hline Dess.2 $\left(\mathrm{C}_{S i l \leftarrow B B}\right)(2 \mathrm{x} 4)$ & 3,048 & - & 1110,1 & - \\
\hline $\mathrm{TS}_{1-\mathrm{A}_{1 S i l \rightarrow B B}(2 \times 2)}$ & 2,751 & - & 1001,7 & - \\
\hline Dess.1-A $\left(\mathrm{C}_{S i l \leftarrow B B}\right)(2 \times 2)$ & 2,881 & - & 1049,0 & - \\
\hline $\mathrm{TS} 2-\mathrm{A}_{2 S i l \rightarrow B B}(2 \times 2)$ & 0,815 & - & 296,7 & - \\
\hline Dess.2-A $\left(\mathrm{C}_{S i l \leftarrow B B}\right)(2 \times 2)$ & 1,090 & - & 396,8 & - \\
\hline
\end{tabular}

mais ineficiente que aquela mostrada na figura 5.10 e, face a estes resultados, é difícil explicar esta conversão nas condições experimentais descritas na seção 5.1. Uma vez que os experimentos $[118,119,121]$ são realizados em 300 ou 373 K, não nos parece que o caminho de reação da equação 5.1 seja realista para produzir $\mathrm{C}_{B B}$ 

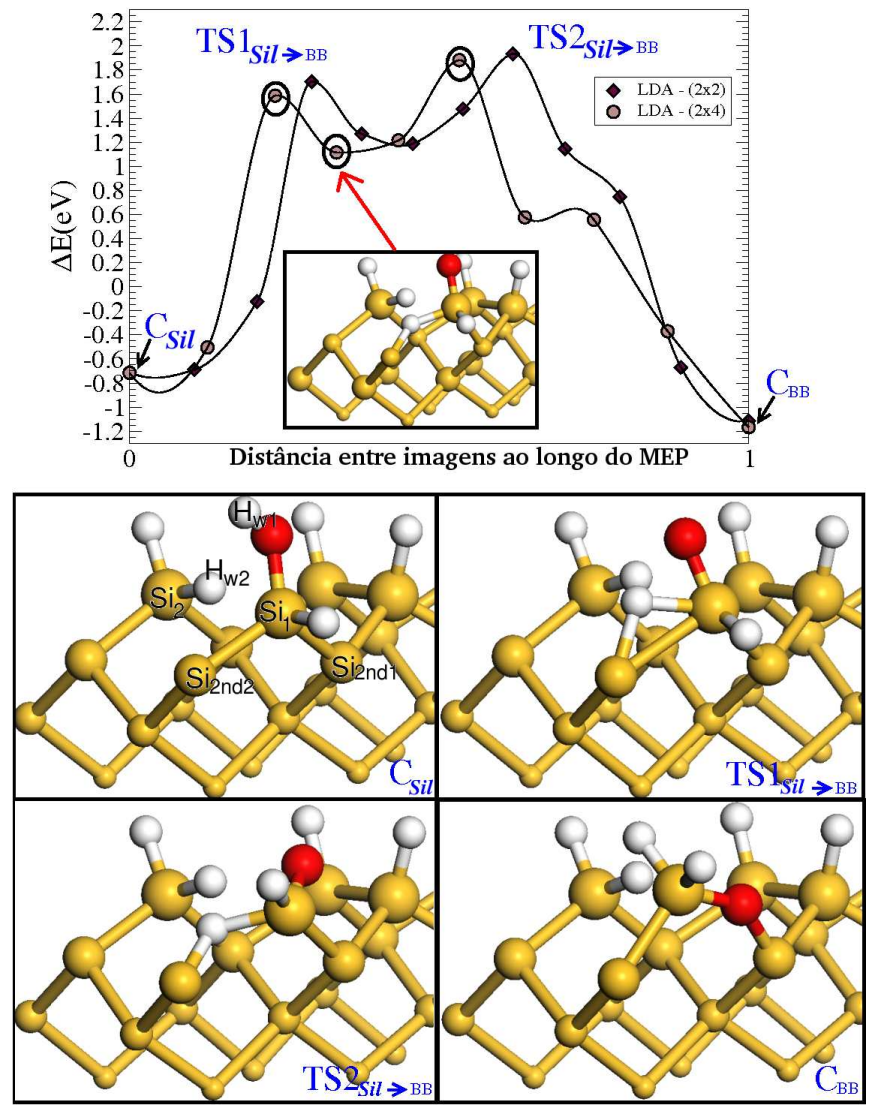

Figura 5.10: Caminho de menor energia, MEP, para a conversão $\mathrm{C}_{S i l}$ em $\mathrm{C}_{B B}$, calculados com LDA-PZ para supercélulas (2x2) (losângulos) e (2x4) (círculos). No eixo das ordenadas temos a energia em eV, onde o zero de energia corresponde à soma das energias totais (em eV) para os subsistemas isolados (molécula isolada e superfície de $\operatorname{Si}(100)(2 \times 1): H)$. Ilustramos ainda as configurações atômicas para alguns pontos especiais ao longo do MEP: a imagem inicial $\left(\mathrm{C}_{S i l}\right)$, o primeiro estado de transição $\left(\mathrm{TS}_{S i l \rightarrow B B}\right)$, a configuração otimizada para a quarta imagem do MEP (inserida no gráfico), o segundo estado de transição $\left(\mathrm{TS} 2_{S i l \rightarrow B B}\right)$ e a configuração final quimissorvida $\left(\mathrm{C}_{B B}\right)$.

nas temperaturas mencionadas. Mudando de estratégia, fizemos muitos cálculos de caminhos de reação partindo de $\mathrm{P} 2$ para tentarmos a quimissorção de $\mathrm{O}$ na backbond. Muitos deles tinham como estágio intermediário a posição "on-dimer", mas sempre as barreiras de energia são altas, chegando a $\approx 3 \mathrm{eV}$, o que pode favorecer o 
retorno à configurção silanol.

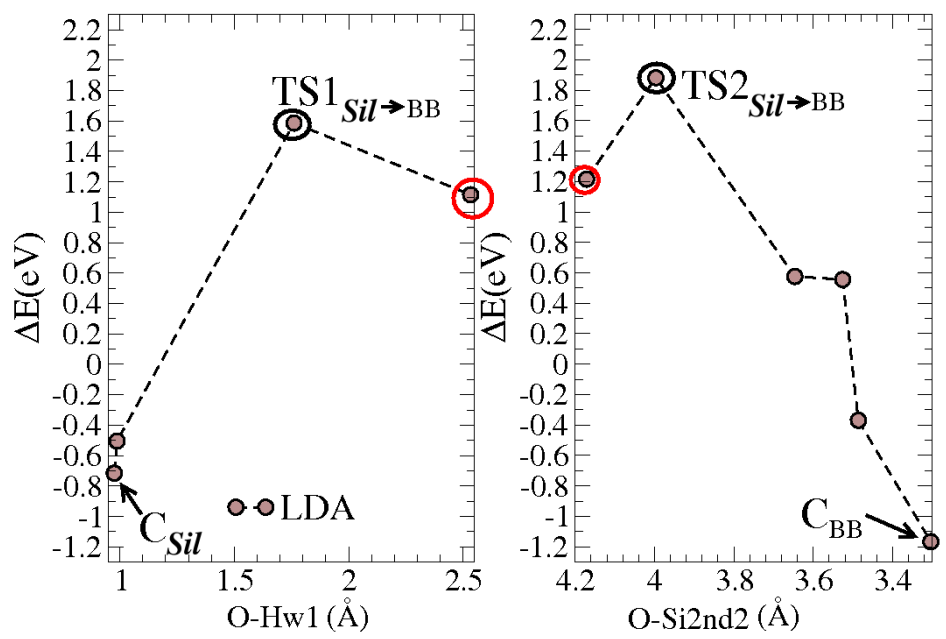

(a)

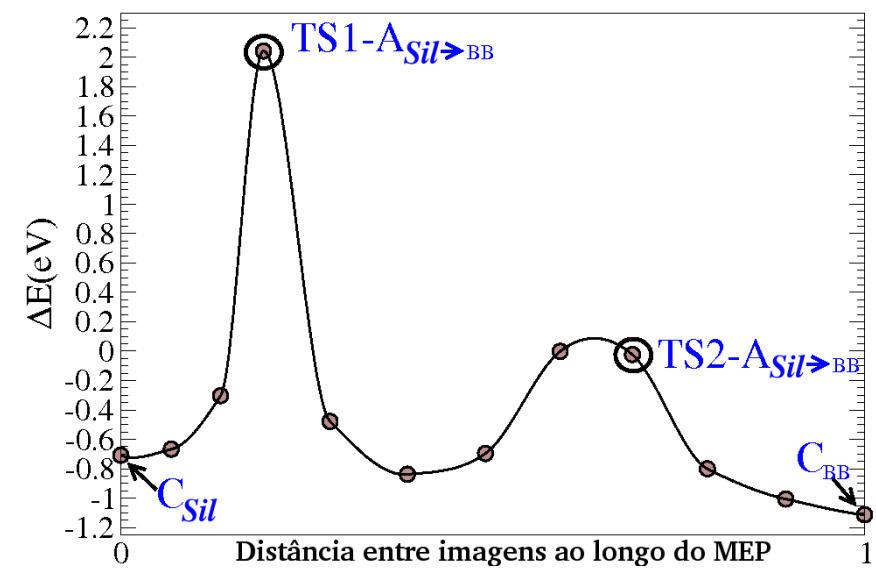

(b) $\mathrm{C}_{\text {Sil }} \rightarrow \mathrm{C}_{B B}$ - MEP alternativo

Figura 5.11: Em (a), caminho de menor energia, MEP, para a conversão $\mathrm{C}_{\text {Sil }}$ em $\mathrm{C}_{B B}$, calculados com LDA-PZ para a supercélula $(2 \mathrm{x} 4)$. No eixo das abscissas temos os valores das distâncias $\mathrm{O}-\mathrm{H}_{w 1}$ (iniciando em $\mathrm{C}_{\text {Sil }}$ até a quarta imagem do MEP) e O-Si $i_{2 n d 2}$ (iniciando na quinta imagem do MEP até $\mathrm{C}_{B B}$ ). Em (b) apresentamos o MEP alternativo para a conversão de $\mathrm{C}_{S i l}$ em $\mathrm{C}_{B B}$. 
Tabela 5.6: Distâncias interatômicas $(\AA)$ para a superfície $\operatorname{Si}(100)(2 \mathrm{x} 1): \mathrm{H}$, os estados de transição $\left(\mathrm{TS}_{1 S i l \rightarrow B B}\right.$ and $\left.\mathrm{TS}_{2 S i l \rightarrow B B}\right)$ e a configuração quimissorvida $\left(\mathrm{C}_{B B}\right)$ resultantes do processo de conversão de $\mathrm{C}_{S i l}$ em $\mathrm{C}_{B B}$ (figura 5.10).

\begin{tabular}{lc|ccc}
\hline \hline & \multirow{2}{*}{$\mathrm{Si}(100)$} & \multicolumn{3}{|c}{$\mathrm{C}_{S i l} \rightarrow \mathrm{C}_{B B}$} \\
\cline { 3 - 5 }$(\AA)$ & $(2 \times 1): \mathrm{H}$ & $\mathrm{TS}_{\text {Sil } \rightarrow B B}$ & $\mathrm{TS}_{\text {Sil } \rightarrow B B}$ & $\mathrm{C}_{B B}$ \\
\hline $\mathrm{H}-\mathrm{Si}$ & 1,50 & 1,50 & 1,50 & 1,50 \\
$\mathrm{Si}_{1}-\mathrm{Si}_{2}$ & 2,41 & 4,01 & 4,22 & 4,00 \\
$\mathrm{H}_{w 1}-\mathrm{O}$ & - & 1,76 & 2,51 & 2,59 \\
$\mathrm{H}_{w 2}-\mathrm{O}$ & - & 2,29 & 2,17 & 2,72 \\
$\mathrm{O}_{-} \mathrm{Si}_{1}$ & - & 1,57 & 1,61 & 1,66 \\
$\mathrm{O}_{-} \mathrm{Si}_{2}$ & - & 3,78 & 3,57 & 4,08 \\
$\mathrm{O}_{-} \mathrm{Si}_{2 n d 1}$ & - & 3,55 & 2,25 & 1,67 \\
$\mathrm{Si}_{1}-\mathrm{H}_{w 1}$ & - & 1,70 & 1,71 & 1,49 \\
$\mathrm{H}_{w 1}-\mathrm{Si}_{2 n d 2}$ & - & 1,65 & 1,57 & 3,16 \\
\hline \hline
\end{tabular}

$\mathbf{P 2} \longrightarrow \mathbf{C}_{B B+H 2}$

Diante dos resultados anteriores com barreiras altas, e das provas experimentais de que a superfície monohidrogenada é de fato oxidada por água, iniciamos uma procura por rotas alternativas de oxidação, e neste ponto consideramos a inclusão do átomo de $\mathrm{O}$ com a liberação simultânea de uma molécula de $\mathrm{H}_{2}, \mathrm{C}_{B B+H 2}$. Tomamos como ponto inicial a configuração P2, ou seja, sobre-o-vale, utilizando a célula $(2 \times 2)$. Mostramos, nas figuras 5.12 e 5.13, o MEP calculado para dois caminhos distintos, contendo 10 e 15 imagens. Os dois resultados diferem entre si, e inclusive os estados de transição, $\mathrm{T}_{B B+H 2}$, estão associados a diferentes configurações geométricas (tabela 5.7). Mais detalhes sobre a evolução da reação podem ser vistos na figura 5.14 , onde graficamos a variação de energia ao longo do caminho de reação como função das distâncias $\mathrm{Si}_{1}-\mathrm{O}$ e $\mathrm{O}-\mathrm{H}_{w 1}$. 


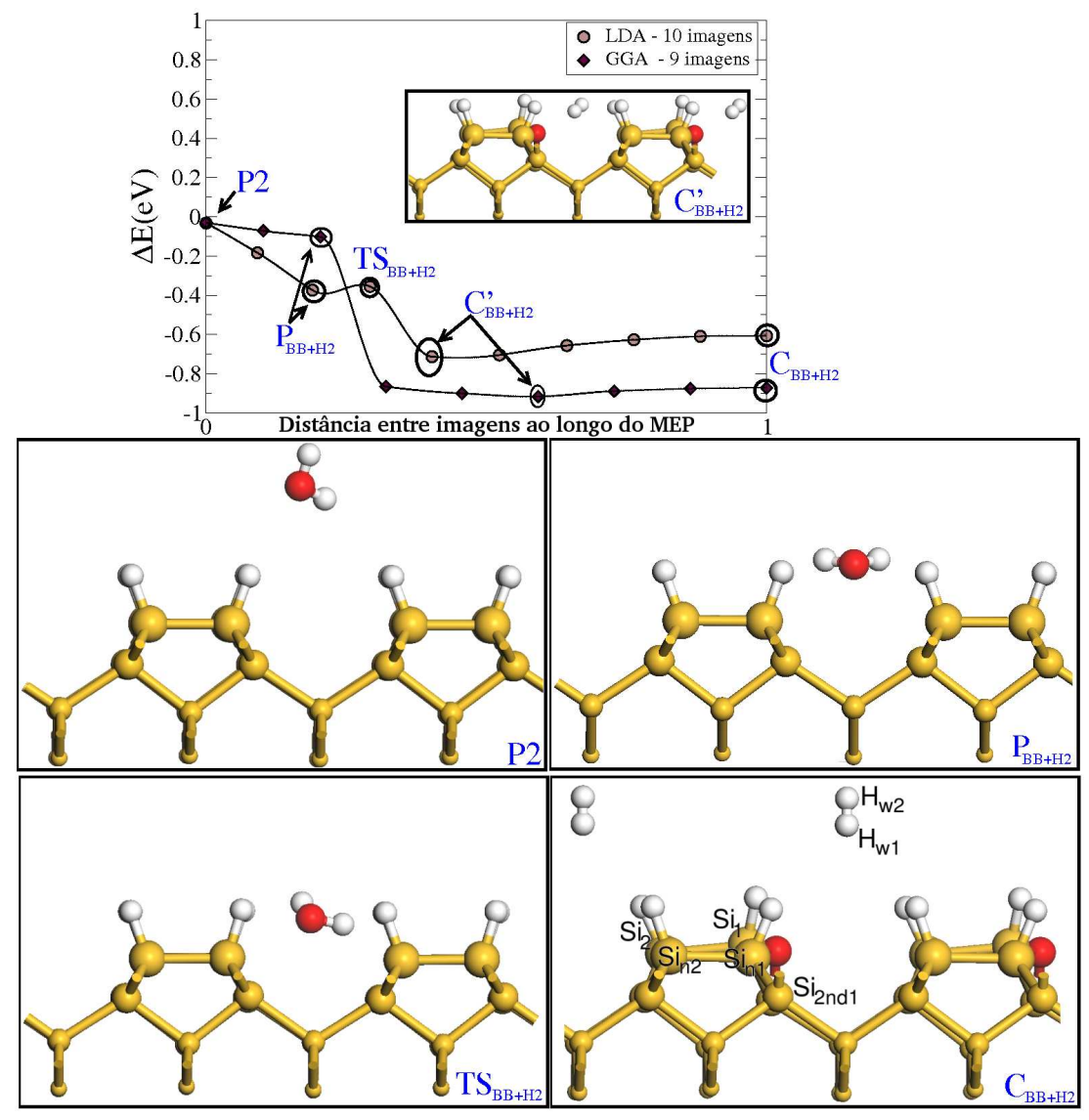

Figura 5.12: Caminho de menor energia, MEP, para a conversão P2 em $\mathrm{C}_{B B+H 2}$ (a linha no gráfico é apenas um guia para os olhos), calculados com LDA-PZ e GGAPW91 para uma fita elástica contendo 10 imagens. No eixo das ordenadas temos a energia em eV, onde o zero de energia corresponde à soma das energias totais (em eV) para os subsistemas isolados (molécula isolada e superfície de $\mathrm{Si}(100)(2 \mathrm{x} 1): \mathrm{H})$. Ilustramos ainda as configurações atômicas otimizadas para alguns pontos especiais ao longo do MEP: a imagem inicial (P2), a configuração fisissorvida $\left(\mathrm{P}_{B B+H 2}\right)$, o estado de transição $\left(\mathrm{TS}_{B B+H 2}\right)$ e a configurações quimissorvidas $\mathrm{C}_{B B+H 2}^{\prime}$ (inserida no gráfico) e $\mathrm{C}_{B B+H 2}$.

Para o MEP calculado com menos imagens, obtemos que a molécula de água adsorveria sem barreira de energia sobre a superfície monohidrogenada. Se fosse este o caso, mesmo levando em conta a menor probabilidade de ocorrência de posiciona- 


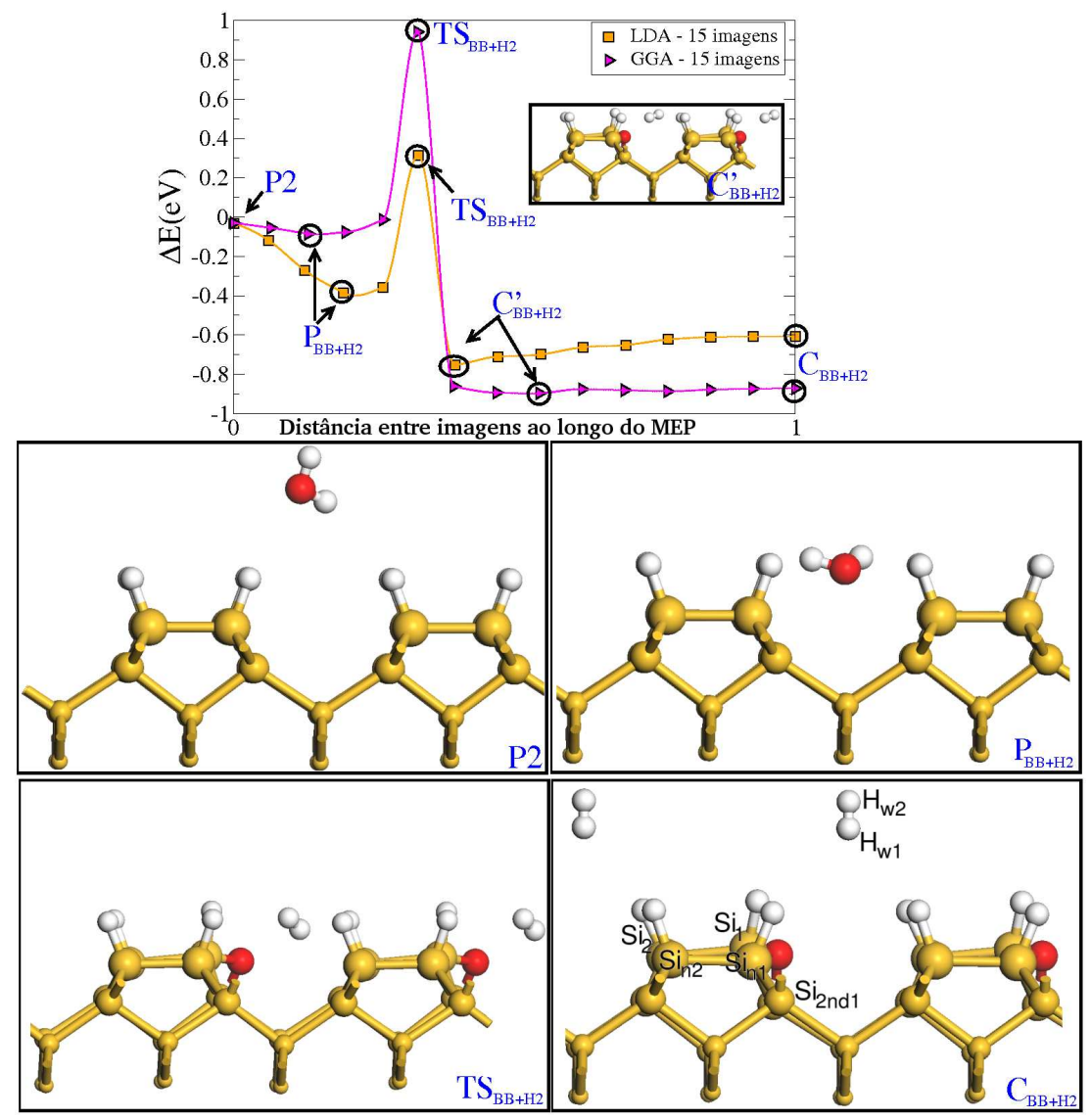

Figura 5.13: Caminho de menor energia, MEP, para a conversão P2 em $\mathrm{C}_{B B+H 2}$ (a linha no gráfico é apenas um guia para os olhos), calculados com LDA-PZ e GGAPW91 para uma fita elástica contendo 15 imagens. No eixo das ordenadas temos a energia em eV, onde o zero de energia corresponde à soma das energias totais (em eV) para os subsistemas isolados (molécula isolada e superfície de $\mathrm{Si}(100)(2 \mathrm{x} 1): \mathrm{H})$. Ilustramos ainda as configurações atômicas otimizadas para alguns pontos especiais ao longo do MEP: a imagem inicial (P2), a configuração fisissorvida $\left(\mathrm{P}_{B B+H 2}\right)$, o estado de transição $\left(\mathrm{TS}_{B B+H 2}\right)$ e a configurações quimissorvidas $\mathrm{C}_{B B+H 2}^{\prime}$ (inserida no gráfico) e $\mathrm{C}_{B B+H 2}$.

mento inicial, poderíamos esperar condições de oxidação mais semelhantes àquela observada para a superfície limpa (figura 4.1), enquanto se sabe que esta superfície é mais resistente. O refinamento do caminho de reação é um passo importante do 
teste de consistência dos resultados. Uma vez que nosso objetivo era estudar este MEP em particular, foi necessário, ao aumentar a discretização, empregar o método denominado NEB-manual pela especial dificuldade encontrada.
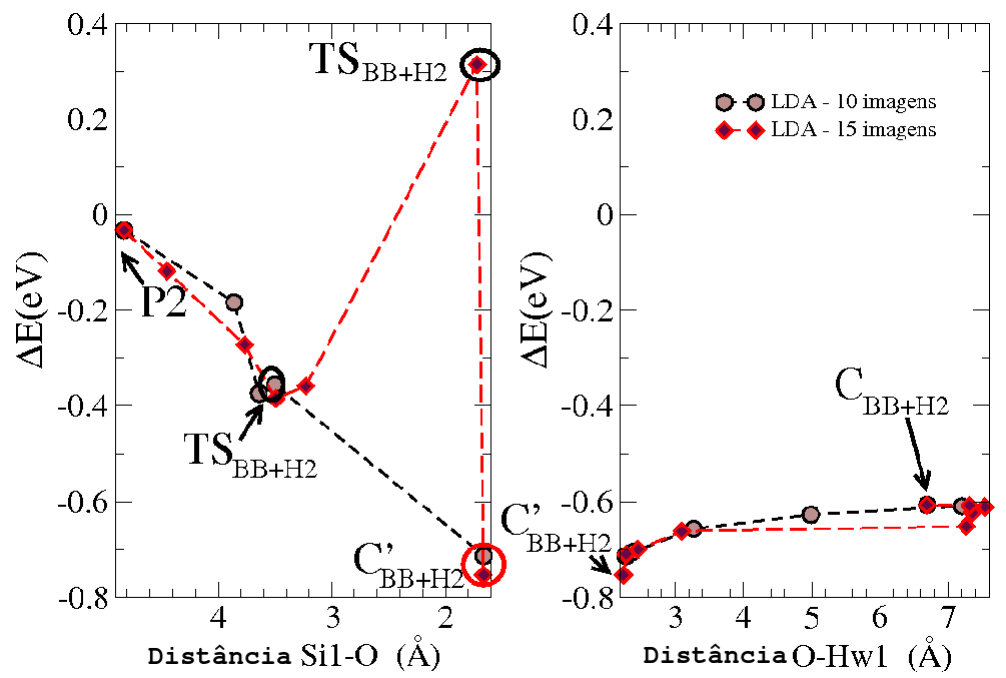

Figura 5.14: Caminho de menor energia, MEP, para a conversão de $\mathrm{P} 2$ em $\mathrm{C}_{B B+H 2}$, calculados com LDA-PZ para uma fita elástica contendo 10 (círculos marrons) e 15 imagens (losângulos vermelhos). No eixo das abscissas temos os valores das distâncias $\mathrm{Si}_{1}-\mathrm{O}$ (iniciando em $\mathrm{P} 2$ até a configuração $\mathrm{C}_{B B+H 2}^{\prime}$ ) e $\mathrm{O}-\mathrm{H}_{w 1}$ (iniciando na qa configuração $\mathrm{C}_{B B+H 2}^{\prime}$ até $\left.\mathrm{C}_{B B+H 2}\right)$. O zero de energia do gráfico corresponde à soma das energias totais (em eV) para os subsistemas isolados (água em fase gasosa e superfície de $\operatorname{Si}(100)(2 \times 1))$. 
Tabela 5.7: Distâncias interatômicas ( $\AA$ ) para a superfície $\mathrm{Si}(100)(2 \mathrm{x} 1)$ :H, a imagem inicial (P2), a configuração fisissorvidas $\left(\mathrm{P}_{B B+H 2}\right)$, o estado de transição $\left(\mathrm{TS}_{B B+H 2}\right)$ e as configurações quimissorvidas $\left(\mathrm{C}_{B B+H 2}^{\prime}\right.$ e $\left.\mathrm{C}_{B B+H 2}\right)$ resultantes do processo de oxidação molhada na superfície monohidrogenada (figuras 5.12 e 5.13). Resultados referentes ao funcional GGA encontrase entre parênteses. Os símbolos utilizados nas definições das distâncias são aqueles da figura 5.12 e 5.13

\begin{tabular}{|c|c|c|c|c|c|c|c|c|c|}
\hline$(\AA)$ & $\operatorname{Si}(100)$ & $\mathrm{P} 2$ & $\mathrm{P}_{B B+H 2}$ & $\mathrm{P}_{B B+H 2}$ & $\mathrm{TS}_{B B+H 2}$ & $\mathrm{TS}_{B B+H 2}$ & $\mathrm{C}_{B B+H 2}^{\prime}$ & $\mathrm{C}_{B B+H 2}^{\prime}$ & $\mathrm{C}_{B B+H 2}$ \\
\hline $\mathrm{H}-\mathrm{Si}$ & $1,50(1,50)$ & $1,50(1,50)$ & $1,50(1,50)$ & $1,51(1,50)$ & 1,50 & $1,48(1,47)$ & $1,50(1,50)$ & $1,50(1,50)$ & $1,50(1,50)$ \\
\hline $\mathrm{Si}_{1}-\mathrm{Si}_{2}$ & $2,41(2,44)$ & $2,42(2,44)$ & $2,41(2,43)$ & $2,41(2,43)$ & 2,41 & $2,51(2,61)$ & $2,40(2,44)$ & $2,42(2,44)$ & $2,42(2,44)$ \\
\hline $\mathrm{O}-\mathrm{Si}_{1}$ & - & $4,83(4,79)$ & $3,64(3,64)$ & $3,49(3,63)$ & 3,50 & $1,72(1,78)$ & $1,66(1,66)$ & $1,66(1,67)$ & $1,66(1,66)$ \\
\hline $\mathrm{O}-\mathrm{Si}_{2 n d 1}$ & - & $5,47(5,44)$ & $3,48(3,62)$ & $3,27(3,74)$ & 3,01 & $1,71(1,74)$ & $1,67(1,68)$ & $1,68(1,68)$ & $1,68(1,68)$ \\
\hline $\mathrm{O}-\mathrm{H}_{w 1}$ & - & $0,98(0,97)$ & $0,98(0,98)$ & $0,98(0,98)$ & 0,98 & $2,12(2,03)$ & $2,28(3,64)$ & $2,24(2,62)$ & $6,69(6,75)$ \\
\hline $\mathrm{O}-\mathrm{H}_{w 2}$ & - & $0,98(0,98)$ & $0,98(0,98)$ & $0,98(0,97)$ & 0,99 & $2,31(2,29)$ & $2,95(4,30)$ & $2,98(3,37)$ & $7,36(7,40)$ \\
\hline
\end{tabular}


Com o refinamento os resultados são diferentes, pois temos agora uma barreira de reação não muito menor que aquelas encontradas para a reação através do silanol. A altura de barreira para a formação de $\mathrm{C}_{B B+H 2}$ a partir de $\mathrm{P} 2$, condiz com a reação ocorrendo em temperatura menores que $300 \mathrm{~K}$, conforme resultados sumarizados na tabela 5.8. As barreiras de energia a serem vencidas para a produção de silanol $\left(\mathrm{C}_{\text {Sil }}\right.$, tabela 5.5), são da mesma ordem que a encontrada para a formação direta de $\mathrm{C}_{B B+H 2}$. Isto se verifica, quer a formação de silanol tenha como ponto inicial a configuração P1 ou a P2 (tabela 5.5). No entanto, para que a reação $B B+H_{2}$ tenha sucesso, o sítio de ataque deve ser P2, a molécula de água deve se inserir na região de vale da superfície $\operatorname{Si}(100)(2 x 1): H$. Munidos de argumentos baseados apenas na geometria do sistema, podemos, em primeira análise avaliar que a oxidação, tendo como ponto inicial P2, seja viável e facilitada. Simplificadamente, podemos considerar que o diâmetro de uma molécula de água é $\approx 1,55 \AA$. Na superfície, a distância entre os átomos de hidrogênio de fileiras de dímeros adjacentes é de $\approx 4,2$ A, ou seja, é possível a inserção.

Podemos ver das figuras 5.12 e 5.13 o instantâneo da imagem relativa à configuração fisissorvida, $\mathrm{P}_{B B+H 2}$, na qual os átomos de $\mathrm{H}$ da superfície e da molécula estão como que em interação atrativa: este fenômeno é ligado à situação particular das superfícies de Si hidrogenadas, nas quais se constata uma distribuição de cargas ímpar [150], com os átomos de H negativamente carregados. Calculamos as cargas utilizando o método de Hirshfeld e obtemos que os átomos de Si estão associados a uma carga de $+0,04$ e, enquanto os átomos de $\mathrm{H}$ recebem -0,04 e. Uma vez nessa configuração, a molécula pode retorcer ou ultrapassar a barreira e dissociar-se, o que implicaria na oxidação direta da back-bond.

Em suma, nossos resultados (figuras 5.12 e 5.13) mostram que o sítio de ataque é importante e, especificamente, para a configuração P2, obtemos possibilidade de oxidação na back-bond. Voltando à hipótese experimental (equação 5.1) de que a configuração silanol deveria comparecer como intermediária, baseados nos resultados mostrados nas figuras 5.12 e 5.13 e na tabela 5.8, propomos a alternativa direta como 
Tabela 5.8: Barreiras de energia $(\mathrm{eV})$ para a quimissorção de $\mathrm{H}_{2} \mathrm{O}$ na superficie $\operatorname{Si}(100)(2 \mathrm{x} 1): H$ investigadas neste trabalho. As alturas de barreiras de dessorção estão indicadas abreviadamente por Dess.. Incluímos também estimativas das temperaturas para as quais cada uma das barreiras pode ser vencida. Estas estimativas foram baseadas na Lei de Arrhenius (apêndice A).

\begin{tabular}{lcccc}
\hline \hline & $\mathrm{E}_{L D A}(\mathrm{eV})$ & $\mathrm{E}_{G G A}(\mathrm{eV})$ & $\mathrm{T}_{L D A}(\mathrm{~K})$ & $\mathrm{T}_{G G A}(\mathrm{~K})$ \\
\hline TS $_{B B+H 2}(10$ imagens $)$ & 0,019 & 0,000 & 6,8 & 0,0 \\
Dess. $\left(\mathrm{C}_{B B+H 2}^{\prime}\right)(10$ imagens $)$ & 0,840 & 0,917 & 304,1 & 333,9 \\
Dess. $\left(\mathrm{C}_{B B+H 2}\right)(10$ imagens $)$ & 0,852 & 0,872 & 310,2 & 317,5 \\
\hline TS $_{B B+H 2}(15$ imagens $)$ & 0,699 & 1,027 & 254,4 & 374,1 \\
Dess. $\left(\mathrm{C}_{B B+H 2}^{\prime}\right)(15$ imagens $)$ & 1,067 & 1,924 & 388,6 & $700, .7$ \\
Dess. $\left(\mathrm{C}_{B B+H 2}\right)(15$ imagens $)$ & 1,306 & 1,899 & 475,5 & 691,6 \\
\hline TS & 1,969 & - & 717,1 & \\
Dess. $(B B+H 2 \rightarrow B B$ & 2,378 & - & 865,8 & \\
\hline \hline
\end{tabular}

mais realista (equação 5.2):

$$
\mathrm{H}_{2} \mathrm{O}+\mathrm{H}-\mathrm{Si}-\mathrm{Si}-\mathrm{H} \longrightarrow \mathrm{H}-\mathrm{Si}(\mathrm{O})-\mathrm{Si}-\mathrm{H}+\mathrm{H}_{2} \uparrow
$$

Como último comentário, notamos uma estrutura da molécula de $\mathrm{H}_{2}$ fisissorvida, $\mathrm{C}_{B B+H 2}^{\prime}$, com energia de fisissorção $0,15 \mathrm{eV}$ (LDA-PZ - 15 imagens). Investigamos neste ponto se haveria dissociação da molécula de $\mathrm{H}_{2}$ com saturação dos dímeros próximos o que levaria à configuração $\mathrm{C}_{B B}$. O MEP está mostrado na figura 5.15 e o ponto inicial é a oitava réplica do caminho de reação da figura figura 5.12. Entretanto, a altura de barreira (tabela 5.8) de energia para a conversão de $\mathrm{C}_{B B+H 2}^{\prime}$ em $\mathrm{C}_{B B}$ é alta o suficiente para coibir tal processo nas condições experimentais $(\mathrm{T}=373 \mathrm{~K})$. 


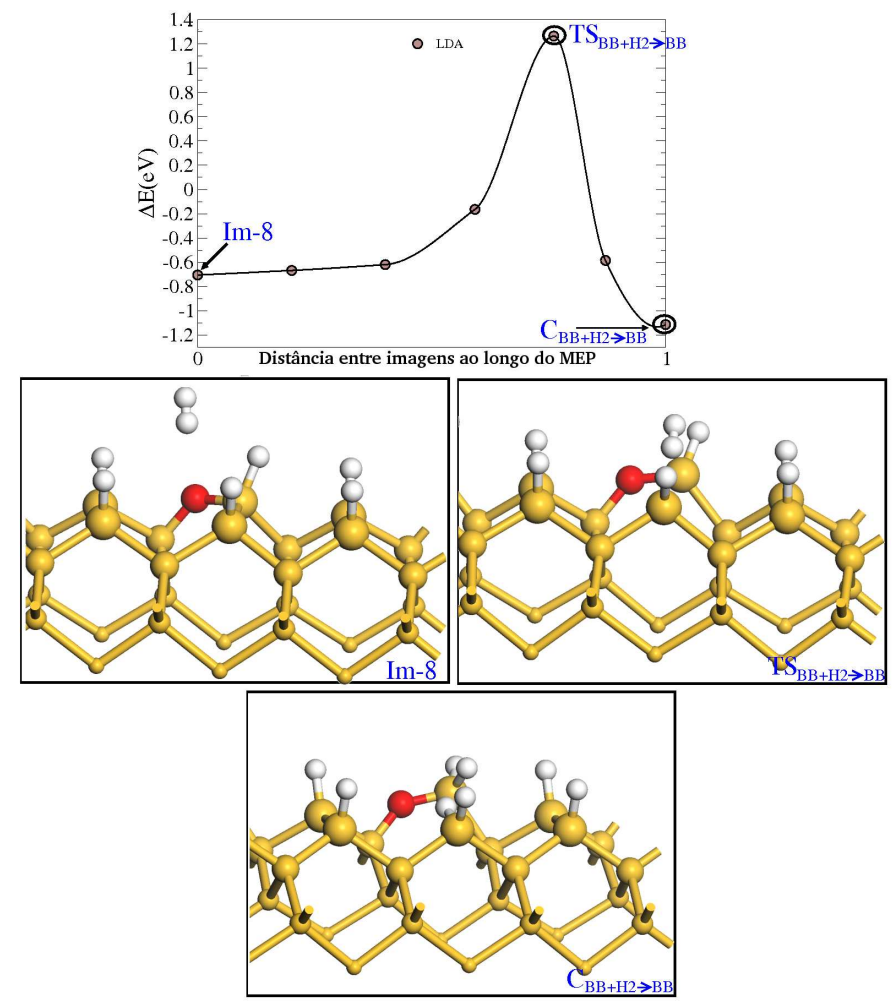

Figura 5.15: Caminho de menor energia, MEP, para a conversão $\mathrm{C}_{B B+H 2}$ em $\mathrm{C}_{B B}$ (a linha no gráfico é apenas um guia para os olhos), calculados com LDA-PZ. No eixo das ordenadas temos a energia em eV, onde o zero de energia corresponde à soma das energias totais (em eV) para os subsistemas isolados (molécula isolada e superfície de $\operatorname{Si}(100)(2 \times 1): H)$. Ilustramos ainda as configurações atômicas otimizadas para alguns pontos especiais ao longo do MEP: a imagem inicial (Im-8 oitava imagem do MEP mostrado na figura figuras 5.12), o estado de transição $\left(\operatorname{TS}_{B B+H 2 \rightarrow B B}\right)$ e a configuração quimissorvida $\mathrm{C}_{B B}$.

\section{$\mathbf{P} 1 \longrightarrow \mathbf{C}_{O D}$}

Conforme comentamos na seção 5.1, o espectro vibracional da superfície monohidrogenada após a oxidação com um fluxo de 100 L de água, é constituído majoritariamente por picos situados em regiões abaixo de $900 \mathrm{~cm}^{-1}$. Isto sugere que são formadas espécies nas quais a superfície oxidada mantém intacto o padrão de dímeros. A primeira possibilidade de tal ocorrência foi investigada na seção 5.2 .3 e a segunda 
será analisada aqui. Neste caso, focalizaremos nossa atenção ao processo de inserção de O no dímero, a partir da configuração P1. O MEP e as respectivas configurações otimizadas para P1, a estrutura fisissorvida $\left(\mathrm{P}_{O D 1}\right)$, os estados de transição $\left(\mathrm{TS}_{\text {Sil }}\right.$ e $\left.\mathrm{TS}_{O D 2}\right)$ e algumas configurações quimissorvidas $\left(\mathrm{C}_{S i l}, \mathrm{C}_{O D}^{\prime}\right.$ e $\left.\mathrm{C}_{O D}\right)$ podem ser observadas na figura 5.16. Todos os pontos na curva LDA-PZ tem um correspondente na curva GGA-PW91 e as diferenças entre eles são muito semelhantes à aquelas que discutimos para os resultados mostrados na figura 5.7. A primeira e a segunda barreiras de reação estão subestimadas por, respectivamente, $\approx 21$ e $24 \%$ nos cálculos LDA-PZ em relação aos resultados GGA-PW91 (tabela 5.9). Notamos também que a imagem denominada $\mathrm{P}_{O D 1}$ é um estado fisissorvido somente nos resultados LDAPZ. Além disso, os cálculos GGA-PW91 mostram que $\mathrm{C}_{O D}$ é $0,26 \mathrm{eV}$ mais estável comparativamente à LDA-PZ, um comportamento atípico.

Nossas simulações para o MEP mostrado na figura 5.16 conduzem a um resultado interessante: o primeiro passo para converter P1 em $\mathrm{C}_{O D}$ ocorre através da formação de $\mathrm{C}_{\text {Sil }}$, inclusive com o mesmo estado de transição (até o silanol) identificado na figura 5.7 e também na figura 5.16. Esclarecemos que não houve a imposição desse intermediário durante a montagem do caminho de reação. Conforme descrito no capítulo 2, somente as imagens inicial (P1) e final $\left(\mathrm{C}_{O D}\right)$ foram mantidas fixas durante o cálculo. Este resultado indica que $\mathrm{C}_{\text {Sil }}$ seja um precursor para a formação de $\mathrm{C}_{O D}$. Também aqui, como nos resultados discutidos anteriormente, a barreira de dessorção é alta o suficiente para coibir a reação no sentido reverso (tabela 5.9) ao mesmo tempo que somente uma pequena barreira de energia deve ser ultrapassada para reação final com o átomo de $\mathrm{O}$ esteja inserido no dímero. Desta forma, se $\mathrm{C}_{S i l}$ é formado, existe uma alta probabilidade de $\mathrm{C}_{O D}$ seja produzido. A barreira importante nesta reação final é a formação da molécula de $\mathrm{H}_{2}$, como é visto na figura 5.16, passagem de $\mathrm{TS}_{O D 2}$ a $\mathrm{C}_{O D}^{\prime}$. Apresentamos, na tabela 5.10, uma lista com a variação de parâmetros estruturais relevantes para a conversão de $\mathrm{C}_{S i l}$ em $\mathrm{C}_{O D}$. Aqui também vemos a presença de uma molécula de $\mathrm{H}_{2}$ fisissorvida (LDA-PZ). 


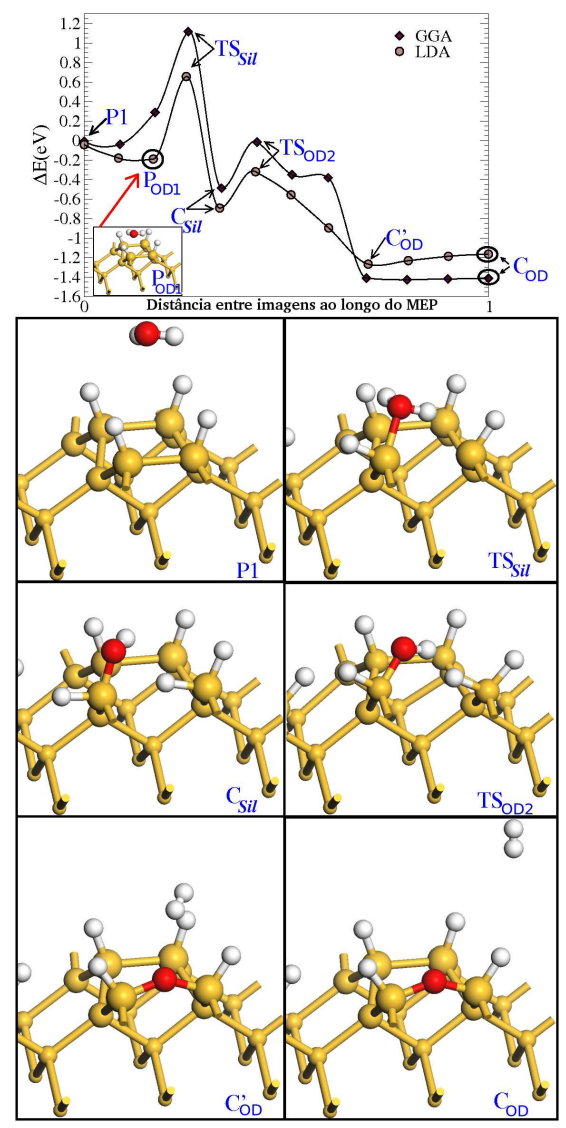

Figura 5.16: Caminho de menor energia, MEP, para a dissociação da molécula de $\mathrm{H}_{2} \mathrm{O}$ sobre a superfíce de $\mathrm{Si}(100)(2 \mathrm{x} 1): \mathrm{H}$, inciando em P1 e levando à formação de $\mathrm{C}_{O D}$ (a linha no gráfico é apenas um guia para os olhos), calculados com LDA-PZ (círculos) e GGA-PW91 (losângulos). No eixo das ordenadas temos a energia em $\mathrm{eV}$, onde o zero de energia corresponde à soma das energias totais (em eV) para os subsistemas isolados (molécula isolada e superfície de $\operatorname{Si}(100)(2 \times 1): H$ ). Ilustramos ainda as configurações atômicas otimizadas para alguns pontos especiais ao longo do MEP: a imagem inicial (P1), a configuração fisissorvida ( $\mathrm{P}_{O D 1}$, inserida no gráfico), o primeiro estado de transição $\left(\mathrm{TS}_{S i l}\right)$, a primeira configuração quimissorvida $\left(\mathrm{C}_{S i l}\right)$, o segundo estado de transição $\left(\mathrm{TS}_{O D 2}\right), \mathrm{C}_{O D}^{\prime}$ e a configuração final quimissorvida $\left(\mathrm{C}_{O D}\right)$.

$\mathrm{C}_{S i l} \longrightarrow \mathrm{C}_{O D}$

Analisamos agora com mais detalhe a segunda barreira de energia da figura 5.16. Recalculamos o MEP para a conversão de $\mathrm{C}_{S i l}$ em $\mathrm{C}_{O D}$, tendo como ponto inicial a 
Tabela 5.9: Barreiras de energia $(\mathrm{eV})$ para a quimissorção de $\mathrm{H}_{2} \mathrm{O}$ na superficie $\operatorname{Si}(100)(2 \mathrm{x} 1): H$ investigadas neste trabalho. As alturas de barreiras de dessorção estão indicadas abreviadamente por Dess.. Incluímos também estimativas das temperaturas para as quais cada uma das barreiras pode ser vencida. Estas estimativas foram baseadas na Lei de Arrhenius (apêndice A).

\begin{tabular}{lcccc}
\hline \hline & $\mathrm{E}_{L D A}(\mathrm{eV})$ & $\mathrm{E}_{G G A}(\mathrm{eV})$ & $\mathrm{T}_{L D A}(\mathrm{~K})$ & $\mathrm{T}_{G G A}(\mathrm{~K})$ \\
\hline \hline $\mathrm{TS}_{S i l}$ & 0,846 & 1,120 & 308,0 & 407,8 \\
Dess. $\left(\mathrm{TS}_{S i l}\right)$ & 1,538 & 1,604 & 560,0 & 584,1 \\
TS $O D 2$ & 0,372 & 0,472 & 135,5 & 172,0 \\
Dess. $\left(\mathrm{C}_{O D}^{\prime}\right)$ & 2,113 & 2,543 & 769,3 & 925,9 \\
Dess. $\left(\mathrm{C}_{O D}\right)$ & 2,010 & 2,529 & 731,9 & 921,1 \\
\hline TS & 0,470 & 0,529 & 171,3 & 192,7 \\
Dess. $\left(\mathrm{C}_{S i l \rightarrow O D}\right)$ & 0,974 & 1,423 & 354,8 & 518,0 \\
\hline TS & 2,245 & - & 817,4 & - \\
Dess. $\left(\mathrm{C}_{O D+H 2}\right)$ & 3,971 & - & 1446,2 & - \\
\hline TS & 2,289 & - & 833,5 & - \\
Dess. $\left(\mathrm{C}_{O D \rightarrow B B}\right)$ & 2,673 & - & 973,3 & - \\
\hline \hline
\end{tabular}

estrutura $\mathrm{C}_{S i l}$ e ponto final $\mathrm{C}_{O D}^{\prime}$, devidamente otimizadas: isto é importante, pois o método CI-NEB garante-nos descrição adequada da barreira de mais alta energia, a qual está livre para convergir para o ponto de sela. Quanto à presença de uma segunda barreira de energia na fita elástica, não teremos esta mesma garantia. Os resultados estão graficados na figura 5.17 e as distâncias interatômicas para pontos relevantes do caminho de reação, estão listadas na tabela 5.10. O estado de transição $\mathrm{TS}_{S i l \rightarrow O D}$ é similar ao já previamente calculado $\left(\mathrm{TS}_{O D 2}\right)$ e não identificamos diferenças significativas em relação à barreira de reação calculada anteriormente (tabela 5.9). Consequentemente, nossos resultados indicam é que defeitos HSi-O-SiH po- 
Tabela 5.10: Distâncias interatômicas $(\AA)$ para os estados de transição (TS TD2 $_{\text {e }}$ $\left.\mathrm{TS}_{S i l \rightarrow O D}\right)$ e as configurações quimissorvidas $\left(\mathrm{C}_{O D}^{\prime}\right.$ e $\left.\mathrm{C}_{O D}\right)$ resultantes do processo de oxidação molhada na superfície monohidrogenada (figuras 5.16 e 5.17). Resultados referentes ao funcional GGA encontra-se entre parênteses.

\begin{tabular}{l|ccc|cc}
\hline \hline \multirow{2}{*}{$(\AA)$} & \multicolumn{3}{|c|}{$\mathrm{P} 1 \rightarrow \mathrm{C}_{O D}$} & \multicolumn{2}{c}{$\mathrm{C}_{O D} \rightarrow \mathrm{C}_{O D}^{\prime}$} \\
\cline { 2 - 6 } & $\mathrm{TS}_{O D 2}$ & $\mathrm{C}_{O D}^{\prime}$ & $\mathrm{C}_{O D}$ & $\mathrm{TS}_{S i l \rightarrow O D}$ & $\mathrm{C}_{O D}^{\prime}$ \\
\hline $\mathrm{H}-\mathrm{Si}$ & $1,50(1,50)$ & $1,50(1,50)$ & $1,50(1,50)$ & $1,50(1,50)$ & $1,50(1,50)$ \\
$\mathrm{Si}_{1}-\mathrm{Si}_{2}$ & $3,88(3,90)$ & $3,17(3,17)$ & $3,17(3,17)$ & $3,87(3,92)$ & $3,17(3,17)$ \\
$\mathrm{H}_{w 1}-\mathrm{O}$ & $0,98(0,97)$ & $2,62(4,42)$ & $7,43(7,45)$ & $0,98(0,97)$ & $4,51(4,42)$ \\
$\mathrm{H}_{w 2}-\mathrm{O}$ & $2,11(2,10)$ & $3,36(4,93)$ & $7,95(7,98)$ & $2,21(2,25)$ & $5,06(4,93)$ \\
$\mathrm{O}_{-} \mathrm{Si}_{1}$ & $1,67(1,67)$ & $1,67(1,67)$ & $1,67(1,67)$ & $1,68(1,68)$ & $1,67(1,67)$ \\
$\mathrm{O}_{-} \mathrm{Si}_{2}$ & $3,36(3,42)$ & $1,67(1,67)$ & $1,67(1,67)$ & $3,06(3,09)$ & $1,67(1,67)$ \\
$\mathrm{H}_{2}-$ Super. & $-(-)$ & $2,62(2,41)$ & $4,80(4,78)$ & $-(-)$ & $2,34(2,41)$ \\
\hline \hline
\end{tabular}

dem ser facilmente formados se grupos $\mathrm{Si}-\mathrm{OH}$ estiverem presentes na superfície $\mathrm{Si}(100)(2 \mathrm{x} 1): \mathrm{H}$. Identificamos que durante a conversão $\mathrm{C}_{S i l}$ em $\mathrm{C}_{O D}$, o resíduo desta reação, neste caso, uma molécula de $\mathrm{H}_{2}$, encontra-se novamente em uma situação fisissorvida na superfície. Este mesmo comportamento foi também averiguado para a produção de $\mathrm{C}_{B B+H 2}$. As estruturas denominadas por $\mathrm{C}_{B B+H 2}^{\prime}$ (figuras 5.12 e $5.13)$ e $\mathrm{C}_{O D}^{\prime}$ (figura 5.16) têm energia $\Delta \mathrm{E}=-0,15$ e $\Delta \mathrm{E}=-0.1 \mathrm{eV}$ menor que as configurações finais de cada um destes caminhos de reação, $\mathrm{C}_{B B+H 2}$ e $\mathrm{C}_{O D}$. Este efeito é consideravelmente menor nos cálculos GGA-PW91 e a diferença de energia entre $\mathrm{C}_{O D}^{\prime}$ e $\mathrm{C}_{O D}$ é da ordem de $\Delta=-0.01 \mathrm{eV}$. Desde que a molécula de $\mathrm{H}_{2}$ está energeticamente ligada à superfície, uma hipótese plausível seria de que ao invés de se afastar da mesma, cada um dos átomos de $\mathrm{H}$ se ligasse ao dímero vizinho do defeito $\mathrm{H}-\mathrm{Si}-\mathrm{O}-\mathrm{Si}-\mathrm{H}$, gerando duas unidades dihidrogenadas, $\mathrm{H}-\mathrm{Si}_{n 1}-\mathrm{H}$ e $\mathrm{H}-\mathrm{Si}_{n 2}-\mathrm{H}$. Denominamos a estrutura resultante por $\mathrm{C}_{O D+H 2}$, cuja exotermicidade (em relação 
a $\left.\mathrm{C}_{O D}\right)$ é de $\Delta \mathrm{E} \simeq 0.6 \mathrm{eV}$, e a barreira foi incluída na tabela 5.9. Os cálculos foram realizados com uma supercélula (4x3), uma vez que a formação das estruturas dihidrogenada provocam grandes deformações laterais. Nossa simulação leva a uma barreira de energia suficientemente alta para coibir a reação entre a molécula de $\mathrm{H}_{2}$ e o dímero, resultado semelhante ao obtido anteriormente para a conversão de $\mathrm{C}_{B B+H 2}^{\prime}$ em $\mathrm{C}_{B B+H 2}$ (figura 5.15).

Os resultados apresentados até este ponto, permitem-nos elaborar algumas conclusões importantes. Nossos cálculos de caminhos de reação para a oxidação da superfície monohidrogenada sugerem que embora a presença de espécies $\mathrm{C}_{\text {Sil }}$ não seja claramente identificada nas medidas de FTIR [118,119,121], isto não significa que não sejam produzidas, em concordância com a interpretação dada pelos autores do trabalho experimental [118,120,121]. De fato, nossas simulações são consistente com a hipótese de que os grupos $\mathrm{Si}-\mathrm{OH}$ são formados, mas são prontamente convertidos em $C_{O D}$, assim outra forma de reescrever a hipótese da equação 5.1, é (equação $5.3)$ :

$$
\mathrm{H}_{2} \mathrm{O}+\mathrm{H}-\mathrm{Si}-\mathrm{Si}-\mathrm{H} \longrightarrow \mathrm{H}_{2} \mathrm{Si} \ldots \mathrm{HO}-\mathrm{Si}-\mathrm{H} \longrightarrow \mathrm{H}-\mathrm{Si}-\mathrm{O}-\mathrm{Si}-\mathrm{H}+\mathrm{H}_{2} \uparrow
$$

Isto implica que não concordamos com o modelo proposto nas referências [118-121, 143] e espresso na equação 5.1, o qual supõe a conversão de $\mathrm{C}_{S i l}$ em $\mathrm{C}_{B B}$.

Outra rota possível seria a conversão $\mathrm{C}_{O D} \rightarrow \mathrm{C}_{B B}$, mas nossos resultados indicam que esssa (tabela 5.9) é tão difícil quanto a sua produção a partir de $\mathrm{C}_{\text {Sil }}$. Nossas simulações mostram que a barreira de energia para ambos os casos (tabelas 5.5 e 5.9) é aproximadamente a mesma, mas com diferentes ganhos de energia na configuração final. A produção de $\mathrm{C}_{B B}$ a partir de $\mathrm{C}_{S i l}$ conduz a um ganho de energia de $0,4 \mathrm{eV}$, mas para a sua formação via $\mathrm{C}_{O D}$ a exotermicidade é de apenas $0,06 \mathrm{eV}$. 


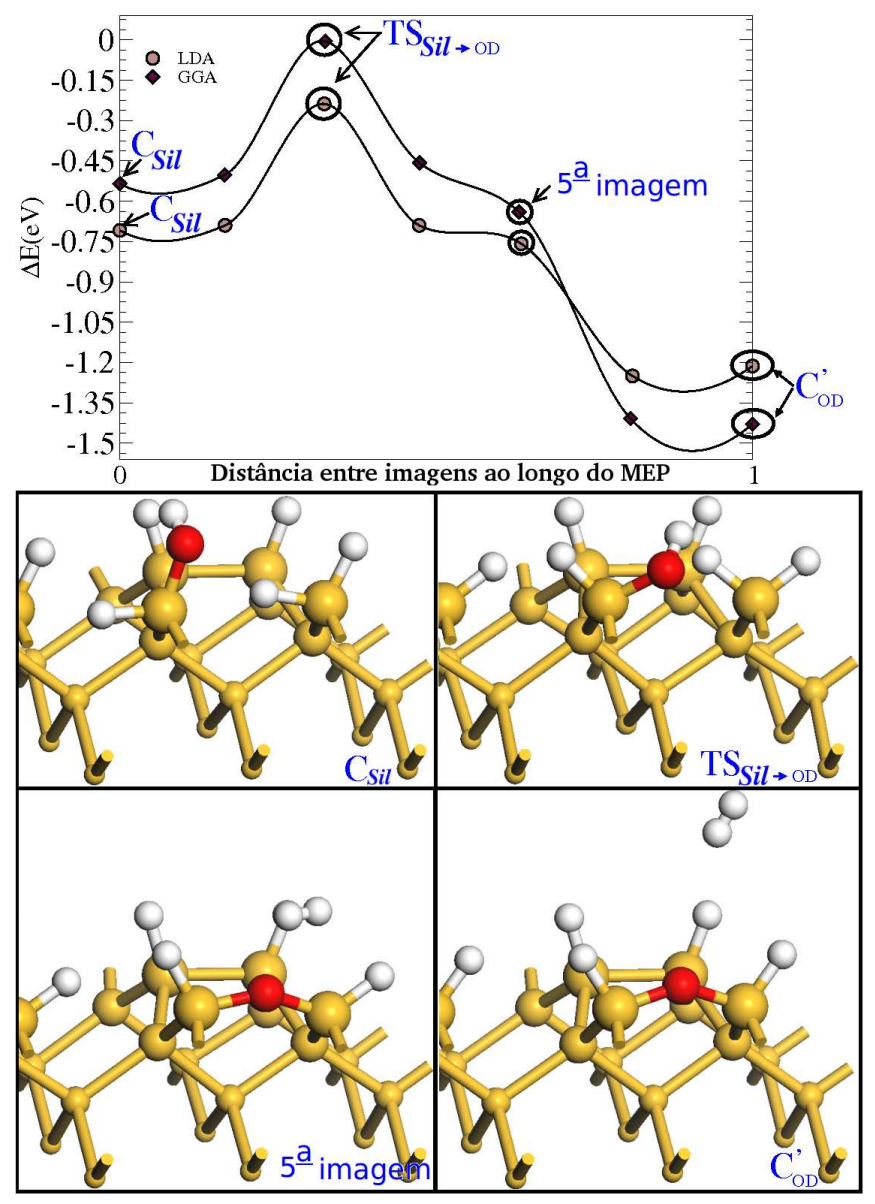

Figura 5.17: Caminho de menor energia, MEP, para a dissociação da molécula de $\mathrm{H}_{2} \mathrm{O}$ sobre a superfíce de $\mathrm{Si}(100)(2 \times 1): H$, inciando em $\mathrm{C}_{\text {Sil }}$ e levando à formação de $\mathrm{C}_{O D}^{\prime}$ (a linha no gráfico é apenas um guia para os olhos), calculados com LDA-PZ (círculos) e GGA-PW91 (losângulos). No eixo das ordenadas temos a energia em $\mathrm{eV}$, onde o zero de energia corresponde à soma das energias totais (em eV) para os subsistemas isolados (molécula isolada e superfície de $\operatorname{Si}(100)(2 \times 1): H$ ). Ilustramos ainda as configurações atômicas otimizadas para alguns pontos especiais ao longo do MEP: a imagem inicial $\left(\mathrm{C}_{S i l}\right)$, o estado de transição $\left(\mathrm{TS}_{S i l \rightarrow O D}\right)$, a quinta do MEP e a configuração final quimissorvida $\left(\mathrm{C}_{O D}^{\prime}\right)$.

\subsection{Conclusões Parciais}

Nossas investigações sobre a dissociação da molécula de água sobre a superfície $\operatorname{Si}(100)(2 \mathrm{x} 1): H$ revelaram que a barreira de energia para a formação do defeito $\mathrm{C}_{\text {Sil }}$ 
independe do posicionamento inicial da molécula de água e pode proceder em temperatura ambiente. Todavia, a conversão de $\mathrm{C}_{S i l}$ em $\mathrm{C}_{B B}$ está condicionado a uma barreira de reação alta o suficiente para coibir ou limitar drasticamente a oxidação dos sítios sub-superficiais. Propusemos duas novas rotas alternativas de oxidação, e mostramos que a inclusão do átomo de $\mathrm{O}$, com a liberação simultânea de uma molécula de $\mathrm{H}_{2}$, na back-bond $\left(\mathrm{C}_{B B+H_{2}}\right)$ ou no dímero $\left(\mathrm{C}_{O D}\right)$ têm barreira de energia da mesma ordem daquela associada à produção de $\mathrm{C}_{S i l}$. A formação de $\mathrm{C}_{B B+H 2}$ é restrita ao ataque oxidativo através da região de vale da superfície, enquanto o caminho de reação que conduz à oxidação do dímero tem como estágio intermediário $\mathrm{C}_{\text {Sil }}$. De forma que, se os grupos $\mathrm{Si}-\mathrm{OH}$ estiverem presentes, eles serão prontamente convertidos em $\mathrm{C}_{O D}$, mas não em $\mathrm{C}_{B B}$.

Os efeitos de interações de dispersão de van der Waals, longo alcance, sabidamente desprezados em aproximações DFT padrão, não foram aqui considerados. Notamos que as barreiras de energias calculadas com o funcional LDA-PZ foram sempre menores que aquelas obtidas com a aproximação GGA-PW91, quando calculadas, enquanto o caminho seguido pelo sistema não foi alterado. Detectamos ainda que, os estados fisissorvidos obtidos quando a energia de troca e correlação foi representada pelo funcional local, ou estavam com o ganho de energia superestimado ou não eram situações fisissorvidas nos cálculos GGA-PW91. Quanto aos valores de energia de ligação, em geral a LDA-PZ prediz estruturas mais ligadas em relação aos GGAs, mas para alguns defeitos investigados aqui, identificamos um comportamento contrário: as energias de ligação LDA-PZ são menores que as preditas com a aproximação GGA-PW91. Tais efeitos identificados sobre energias e MEPs aparecem também na descrição das ligações de hidrogênio em água, que tem sido debatida [70].

Na reação com a superfície, a ruptura da ligação O-H é inevitável e sempre está ligada, segundo nossos cálculos, à barreira mais alta, o que podemos assim prever é que, mesmo que todas as barreiras estejam subestimadas, a nossa proposta de caminhos preferidos à reação continua válida. 
Embora os nossos resultados tenham sido calculados com a melhor metodologia possível para cálculos de MEP, esta não é infalível. Tentamos analisar todas as possibilidades que nos pareceram razoáveis para a dissociação da molécula de água, mas devido à grande quantidade de graus de liberdade envolvidos nos casos investigados aqui, podem existir outros caminhos de reação entre os estados inicial e final investigados de cada cálculo. Notamos também que nos caminhos de reação nos quais há quebras de ligações, como os investigados neste trabalho, o processo de convergência é extremamente lento e custoso computacionalmente, o que sem dúvida foi um fator limitante do número de simulações possível. 


\section{Capítulo 6}

\section{Imagens Teóricas de STM:}

\section{Identificação Direta dos Sítios de}

\section{Oxidação nas Superfícies}

\section{$\operatorname{Si}(100)(2 \times 1)$ Limpas ou}

\section{Hidrogenadas}

Como discutimos nos capítulos anteriores, a identificação dos sítios de quimissorção do oxigênio é uma tarefa árdua, e parte das dificuldades vem do uso de técnicas indiretas [123]. Por outro lado, na área de física de superfícies grandes progressos têm sido obtidos devido ao advento de técnicas diretas para sondagem destes sistemas, como a microscopia de tunelamento (STM - Scanning Tunneling Microscopy) [71]. Por ser sensível aos detalhes da região de primeira camada da superfície, essa é uma ferramenta especialmente afim ao nosso estudo de oxidação inicial e, vários exemplos de aplicações dessa técnica ao estudo dos processos de oxidação na superfície $\operatorname{Si}(100)$ serão discutidos neste capítulo. Nosso objetivo aqui é, através de simulações de STM, distinguir as diferentes espécies resultantes da quimissorção de oxigênio pela reação 
com água. Esperamos que o material apresentado possa ser útil na indentificação dos sítios de defeito e também possa motivar novas investigações experimentais.

\subsection{Revisão de Dados Experimentais e Teóricos}

Detalhes sobre a estrutura atômica das superfícies obtidas na direção cristalográfica (100) do Si foram objeto de extensa discussão, e cinco anos após a invenção do STM [71], já era possível separar regiões das amostras de Si(100) limpa em suas diferentes reconstruções: $(2 \mathrm{x} 1), \mathrm{p}(2 \mathrm{x} 2)$ e c $(4 \mathrm{x} 2)$ [81], resultados comprovados por experimentos utilizando a técnica LEED [94]. Os trabalhos pioneiros de Hamers e colaboradores $[81,151]$ mostram que as imagens de STM estão associadas à presença de várias regiões "apagadas". Essas áreas escuras foram atribuídas à existência de defeitos que são ainda fruto de debate na área científica [95, 132, 139, 140], inclusive aqueles denominados tipo $\mathrm{C}$, que sabemos tratar-se de estruturas resultantes de quimissorção de moléculas de água sobre a superfície Si(100) [95,132,139,140]. Como vimo, os sítios de oxidação podem ser superficiais ou subsuperficiais, do tipo backbond [118, 128-130, 152].

Para superfícies hidrogenadas, a observação de reconstruções através de imagens de STM é também bem estabelecida, mas sua interpretação foi objeto de longo debate científico durante o período de 1988 a 1993 [82,83,98, 100,107]. Enquanto alguns pesquisadores atribuíam o sinal intenso dos estados ocupados aos grupos $\mathrm{H}-$ Si, com intensidade mais fraca sobre o eixo da ligação $\mathrm{Si}-\mathrm{Si}$, outros grupos atribuíam esse máximo da corrente de tunelamento às unidades $\mathrm{Si}-\mathrm{Si}$, sem a participação dos átomos de $\mathrm{H}$, pois os estados eletrônicos associados surgiriam a $\approx 4,5 \mathrm{eV}$ abaixo do nível de Fermi. Em 1993 esta controvérsia foi resolvida com um trabalho de Wang et al [107], confirmando que o sinal de tunelamento dos estados ocupados é constituído basicamente por 2 regiões circulares intensas por célula unitária separadas por uma distância de $3.3 \pm 0.1 \AA$. Também foi confirmada a presença de um máximo menos intenso sobre o eixo da ligação $\mathrm{HSi}-\mathrm{SiH}$, características previamente reportadas por 
Hamers et al [82]. Nossos cálculos mostram que a distância entre os átomos de H pertencentes a um mesmo dímero, $\mathrm{H} \cdots \mathrm{H}$, é de $3,4 \AA$, demonstrando o quão precisos podem ser os resultados obtidos por análise dos perfis de STM.

Passando ao problema da oxidação, os estudos de STM [45, 107, 131, 153] se somam aos de HREELS (High-Resolution Electron Energy Loss Spectroscopy) [154156], SR-PES (Synchrotron Radiation Photoemission Spectroscopy) [157], AES (Auger Electron Spectroscopy) [158] e FTIR [118,119,121,157,158] para demostrar que a passivação por H pode retardar, mas não impedir os processos que culminam com a reação entre oxigênio e o Si. A interpretação dos resultados é, entretanto, mais complexa.

\subsection{Nossos Resultados}

Apresentamos aqui o perfil de tunelamento para todas as configurações finais quimissorvidas discutidas nos capítulos anteriores. Os resultados foram obtidos utilizando LDA-PZ, com as superfícies de Si, limpa e hidrogenada, representadas pelo modelo de fatias, mas empregando uma supercélula maior: $(4 \times 6)$. Esta supercélula é grande o suficiente para permitir a visualização do perfil de tunelamento com maior realismo para comparação com as imagens experimentais. Em todos os casos, a camada de vácuo entre duas fatias consecutivas é de $\approx 14,8 \AA$. Como nos cálculos anteriores, as fatias são constituídas por 6 camadas de Si para as superfícies hidrogenadas e 8 para as superfícies limpas. As imagens de STM foram calculadas empregando a aproximação de Tersoff-Hamann [75] no modo corrente constante, para a resolução da densidade utilizando a integração no ponto $\Gamma$. Os estados que contribuem para a corrente de tunelamento são aqueles localizados entre a energia de Fermi, $\mathrm{E}_{f}$, e $\mathrm{E}_{f}+\mathrm{V}_{e V}$ e com projeção espacial na região da ponta do microscópio. Deste modo, para as voltagens de varredura de $-1,0 \mathrm{eV}(-2 \mathrm{eV})$, acessamos os estados situados no intervalo entre a $\mathrm{E}_{f}$ e $\mathrm{E}_{f}-1,0 \mathrm{eV}\left(\mathrm{E}_{f}\right.$ e $\left.\mathrm{E}_{f}-2 \mathrm{eV}\right)$, que promovem tunelamento entre os estados ocupados e a ponta do microscópio. Similarmente, a inversão no sinal 
das voltagens de varredura, promovendo corrente de tunelamento entre a ponta e os estados vazios, permite-nos mapear a densidade local de estados associada aos níveis desocupados e situados no intervalo entre a $\mathrm{E}_{f}$ e $\mathrm{E}_{f}+1,0 \mathrm{eV}\left(\mathrm{E}_{f}\right.$ e $\mathrm{E}_{f}+2$ $\mathrm{eV})$.

Quanto à convergência, esta estratégia nos permitiu a confirmação adicional da estrutura realizada para todas as configurações finais, pois para os resultados utilizando até 10 pontos $\mathrm{k}$ na ZB da superfície observamos que os parâmetros estruturais obtidos diferiam relativamente de, no máximo, 0,002 $\AA$ para as distâncias de ligação Si-Si, Si-H e Si-O. A estabilidade dos defeitos também não se altera. E, para a geometria convergida com 10 pontos k, não identificamos mudanças nas propriedades eletrônicas quando a resolução da densidade foi obtida com até 20 pontos k na ZB. Assim, concluímos que apenas um ponto k é suficiente para a descrição das propriedades estruturais e eletrônicas dos defeitos.

\subsubsection{Superfícies $\operatorname{Si}(100) c(4 \times 2), \operatorname{Si}(100)(2 \times 1)$ e $\operatorname{Si}(100)(2 \times 1): H$}

As propriedades estruturais para as reconstruções $\operatorname{Si}(100) c(4 \times 2), \operatorname{Si}(100)(2 \times 1)$ e $\mathrm{Si}(100)(2 \mathrm{x} 1): \mathrm{H}$ foram discutidas no capítulo 3. Aqui discutiremos as propriedades eletrônicas destes sistemas e as imagens de STM para voltagens de varredura $\left(\mathrm{V}_{e V}\right)$ de $\mp 1,0$ e $\mp 2 \mathrm{eV}$. Os mapas de STM para as superfícies $\operatorname{Si}(100)$ c(4x2) e $\operatorname{Si}(100)(2 \times 1)$, calculados para $\mathrm{V}_{e V}=\mp 1,0 \mathrm{eV}$, são mostrados na figura 6.1 juntamente com o resultado para a superfície $\operatorname{Si}(100)(2 \times 1): H$, calculado para $\mathrm{V}_{e V}=\mp 2,0 \mathrm{eV}$.

O padrão de STM antes e depois da reação com H é muito diferente, mas a formação de dímeros pode ser reconhecida em todas elas. Para as reconstruções c $(4 \times 2)$ e $(2 \times 1)$, as imagens dos estados ocupados têm contribuição majoritária dos átomos $\mathrm{Si}_{u p}$ e identifica-se ainda um sinal de intensidade mais fraca situado sobre o eixo da ligação $\mathrm{Si}_{d}-\mathrm{Si}_{\text {up }}$. Estas imagens permitem-nos distinguir as reconstruções da superfície Si(100), já que o arranjo tipo zig-zag alternado, discutido na seção 3.2.1, e característico da reconstrução c $(4 \times 2)$, é precisamente identificado e difere 

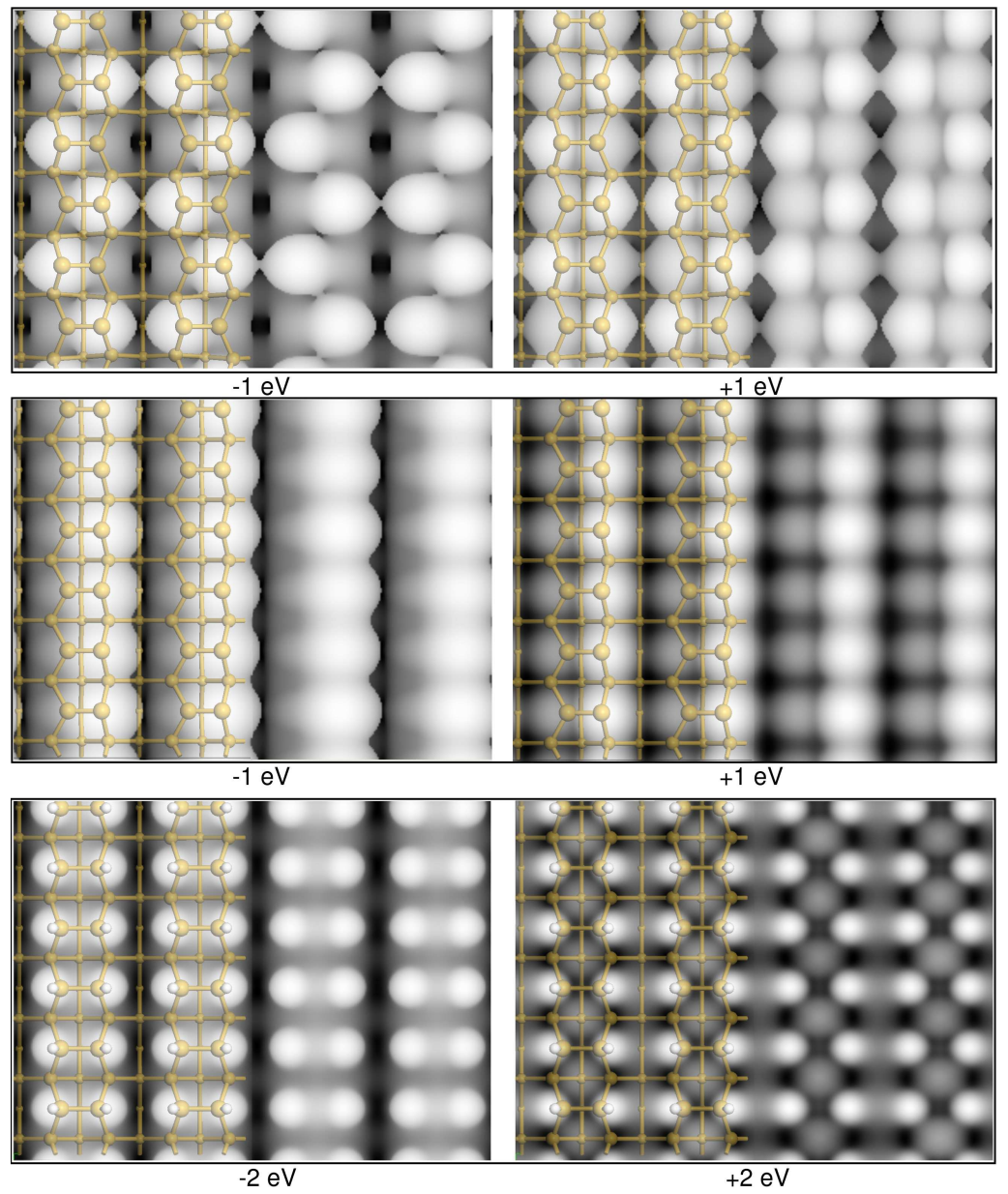

Figura 6.1: Simulação de mapa de STM em modo de corrente constante para as superfícies $\operatorname{Si}(100)$ c(4x2) (acima), $\operatorname{Si}(100)(2 x 1)$ (no meio) e $\operatorname{Si}(100)(2 x 1): H$ (abaixo). Os valores de voltagens de varredura são incluídos na respectiva imagem. Para voltagens negativas (à esquerda) temos as imagens dos estados ocupados, para voltagens positivas (à direita) dos estados desocupados.

do sinal de tunelamento da superfície $(2 \times 1)$. No caso dos estados vazios para ambas as reconstruções da superfície limpa, as imagens são constituídas por dois círculos claros, um deles sobre os átomos de Si das posições up (mais intenso) e o outro sobre o Si down (mais fraco), sendo essa diferença intensa mais visível na (2x1). Notamos duas regiões de mínimo de intensidade: um sobre o eixo da ligação $\mathrm{Si}_{d}-\mathrm{Si}_{u p}$ e outro mais profundo entre as fileiras de dímeros. Estes efeitos são explicáveis em termos 
das propriedades eletrônicas e, como consequência, estruturais destes sistemas. Os átomos de $\mathrm{Si}_{d}$ estão posicionados $\approx 0,67$ - 0,81 $\AA$ abaixo dos átomos de $\mathrm{Si}_{u p}$, e essa assimetria estrutural é associada a uma distribuição assimétrica dos estados eletrônicos na superfície. No intervalo de energia situado entre $\mathrm{E}_{f}$ e $\mathrm{E}_{f}-1 \mathrm{eV}$, os estados eletrônicos são localizados principalmente sobre os átomos de $\mathrm{Si}_{u p}$, sendo que a contribuição dos átomos da posição down é desprezível. Como resultado natural, a intensidade do sinal de tunelamento para o $\mathrm{Si}_{u p}$ é dominante em voltagens negativas. Já o fundo da banda de condução é majoritariamente situado nos átomos $\mathrm{Si}_{d}$ e permite que, em voltagens positivas, ambos os átomos do dímero sejam visualizados para a mesma corrente, e mesmo que a aquisição do sinal seja feita no modo de altura constante (imagens não mostradas aqui). As propriedades do sinal de STM obtidas aqui para as superfícies $\operatorname{Si}(100) c(4 \times 2)$ e $\operatorname{Si}(100)(2 \times 1)$ estão de acordo com os resultados experimentais [80, 82, 83, 85, 86].

Quanto ao mapa de tunelamento para a superfície monohidrogenada (6.1), o sinal de maior intensidade tem origem sobre as unidades $\mathrm{Si}-\mathrm{H}$ que compõem o dímero hidrogenado. Para a imagem dos estados ocupados, a corrente de tunelamento exibe um mínimo profundo na região de vale, enquanto há um sinal intenso localizado sobre os grupos $\mathrm{Si}-\mathrm{H}$, que se sobrepõem no eixo da ligação $\mathrm{Si}-\mathrm{Si}$ [82]. Neste caso, o dímero é simétrico e cada uma das unidades $\mathrm{Si}-\mathrm{H}$ é visível. Em regime de voltagem positiva, ainda observamos o padrão de sinal intenso sobre os grupos Si-H, porém o mínimo de intensidade do sinal ocorre sobre o eixo da ligação Si-Si. Identificamos também um sinal de intensidade fraca, sobre a fileira de dímeros e entre dímeros adjacentes. As caracterísiticas observadas na figura 6.1, formam um arranjo diferente do padrão listrado das imagens dos estados ocupados.

Vale a pena discutir em mais detalhes a contribuição dos átomos de H para as imagens de STM. Estes átomos são os primeiros a interagir com a ponta do microscópio, uma vez que são os átomos mais altos da superfície. Contudo, não poderiam contribuir para o sinal de STM se não houvesse sobreposição efetiva dos seus estados eletrônicos com aqueles da ponta. A LDOS (figura 6.2) mostra que 


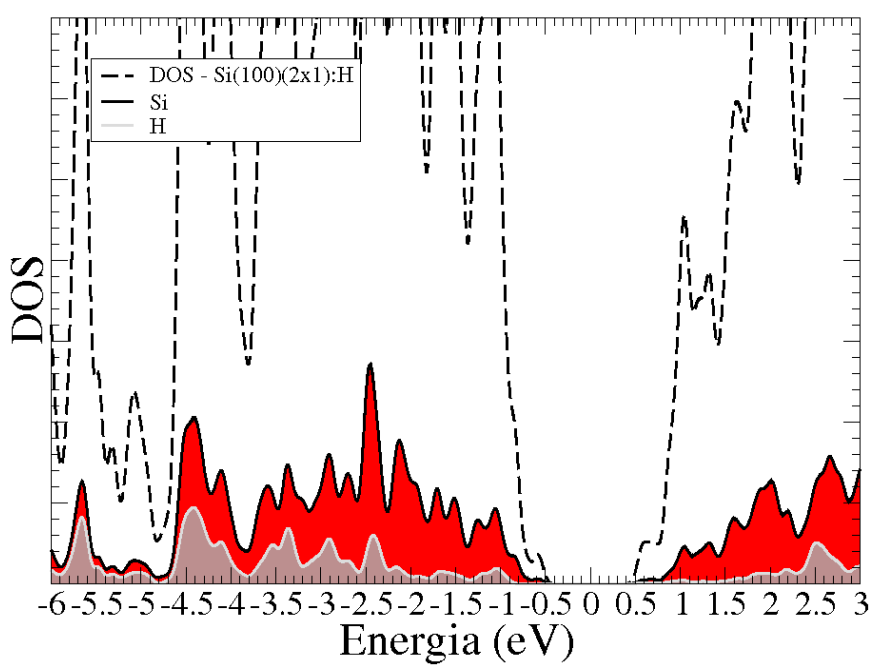

Figura 6.2: Densidade total de estados - DOS - (linha preta tracejada), e densidade local de estados - LDOS (projeção da DOS) sobre os orbitais dos átomos de Si e H das unidades H-Si-Si-H da superfície $\mathrm{Si}(100)(2 \mathrm{x} 1): H$. O zero de energia corresponde ao nível de Fermi do sistema. Para facilitar a visualização, multiplicamos a LDOS associada aos átomos por 3.

os estados $1 s$ do hidrogênio apresentam picos nítidos situados entre $-4,4 \mathrm{e}-2,5 \mathrm{eV}$, evidenciando que os orbitais associados ao dímero na supefície limpa se afastam consideravelmente do nível de Fermi, após a hidrogenação. Mas esta região não está incluída no intervalo de energia utilizado para gerar as imagens de STM da figura 6.1. Assim, o que garante a contribuição dos átomos de H para a corrente de tunelamento, é a hibridização eficiente do nível $1 s$ do H por toda a banda de valência da superfície $\operatorname{Si}(100)(2 \times 1): H$, inclusive tendo contribuição não nula para os estados eletrônicos situados entre 1 e $2 \mathrm{eV}$ abaixo do nível de Fermi [82,83,107]. Apesar da contribuição dos estados eletrônicos do H ser pequena quando comparada ao Si estes átomos, por estarem sobre a superfície, podem ser visualizados. 


\subsection{2 $\quad \mathrm{H}_{2} \mathrm{O} / \mathrm{Si}(100) \mathrm{c}(4 \times 2)$ e $\mathrm{H}_{2} \mathrm{O} / \mathrm{Si}(100)(2 \times 1)$}

Inicialmente, iremos discutir as modificações das imagens de STM após a dissociação da molécula de água sobre as superfícies $\operatorname{Si}(100)(2 \times 1)$ e $\operatorname{Si}(100) c(4 \times 2)$, dando origem às unidades $\mathrm{H}-\mathrm{Si}-\mathrm{Si}-\mathrm{OH}$ (denominadas $\mathrm{C}_{C-S i l}$ ), cujas propriedades estruturais e eletrônicas, assim como a cinética de reação foram discutidas na seção 4.2.1. Por clareza, nos referiremos as estas estruturas por $\mathrm{C}_{C-S i l} @(2 \mathrm{x} 1)$ e $\mathrm{C}_{C-S i l} @ \mathrm{c}(4 \mathrm{x} 2)$, para as reconstruções $(2 \times 1)$ ou c $(4 \times 2)$ da superfície, respectivamente. As estruturas otimizadas para a formação destes defeitos, empregando uma supercélula (4x6) são mostradas na figura 6.3.

As fileiras de dímeros contíguas àquela na qual há o defeito silanol não são afetadas pela presença do mesmo. Além disso, (tabela 6.1) o defeito tende a estar confinado em um único dímero. As variações relativas das distâncias $\mathrm{Si}_{n 1}-\mathrm{Si}_{n 2}$ e $\mathrm{Si}_{n 3}-\mathrm{Si}_{n 4}$ comparadas à aquelas observadas para dímeros distantes ao grupo silanol é da ordem de 0,5 e $1 \%$ para as reconstruções $\operatorname{Si}(100)(2 \times 1)$ e $\operatorname{Si}(100) c(4 x 2)$, respectivamente. Pequenas modificações também são observadas para o ângulo $\theta$, que varia até $2^{\circ}$ na $\mathrm{C}_{C-S i l} @_{\mathrm{c}}(4 \mathrm{x} 2)$, mas este efeito é praticamente nulo na estrutura $\mathrm{C}_{C-S i l} @(2 \mathrm{x} 1)$. Quanto às unidades $\mathrm{H}-\mathrm{Si}-\mathrm{Si}-\mathrm{OH}$ em si, os parâmetros estruturais praticamente não variam, quando comparamos os valores obtidos para as estruturas $\mathrm{C}_{C-S i l}, \mathrm{C}_{C-S i l} @(2 \mathrm{x} 1)$ e $\mathrm{C}_{C-S i l} @ \mathrm{c}(4 \mathrm{x} 2)$. As energias de ligação para $\mathrm{C}_{C-S i l} @(2 \mathrm{x} 1)$ e $\mathrm{C}_{C-S i l} @ \mathrm{c}(4 \mathrm{x} 2)$ são mostradas na tabela 6.2 e diferem de, respectivamente, 0,12 e $0,02 \mathrm{eV}$ do valor calculado para $\mathrm{C}_{C-S i l}$ (tabela 4.2).

A análise dos mapas de STM, em regime de voltagens negativa ou positiva, para as estruturas $\mathrm{C}_{C-S i l} @(2 \mathrm{x} 1)$ e $\mathrm{C}_{C-S i l} @ \mathrm{c}(4 \mathrm{x} 2)$ (figura 6.4) refletem o confinamento eletrônico do defeito: não notamos mudança no mapa de tunelamento sobre os dímeros denominados de $\mathrm{Si}_{n 1}-\mathrm{Si}_{n 2}$ ou $\mathrm{Si}_{n 3}-\mathrm{Si}_{n 4}$. A presença das unidades $\mathrm{H}-\mathrm{Si}-\mathrm{Si}-$ $\mathrm{OH}$ nesta superfície limpa é caracterizada tanto na imagem dos estados ocupados quanto desocupados, pela diminuição de intensidade do sinal de tunelamento sobre o grupo silanol, ainda que este grupo seja o mais alto na superfície. Isto está em total 


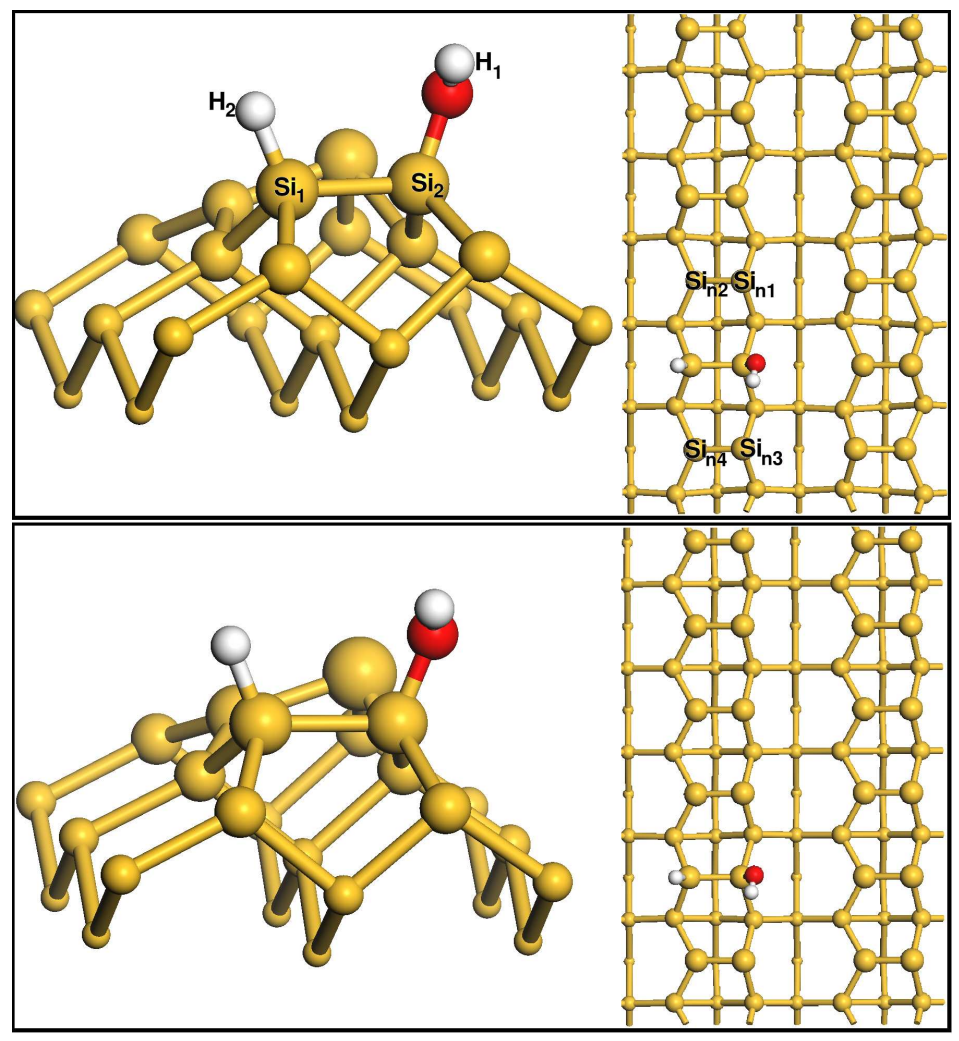

Figura 6.3: Visão lateral e de topo das configurações otimizadas para o defeito tipo silanol, denominados $\mathrm{C}_{C-S i l} @ \mathrm{c}(4 \mathrm{x} 2)$ e $\mathrm{C}_{C-S i l} @(2 \mathrm{x} 1)$, nas superfícies $\operatorname{Si}(100) \mathrm{c}(4 \mathrm{x} 2)$ (acima) e $\mathrm{Si}(100)(2 \times 1)$ (abaixo). Os átomos de $\mathrm{H}$ são representados por esferas brancas, o átomo de $\mathrm{O}$ em vermelho e os átomos de Si em amarelo. O tamanho das esferas amarelas está relacionado com a posição dos átomos de Si na fatia usada em nossas simulações.

acordo com as características observadas na densidade de estados do sistema (resultados não mostrados aqui), uma vez que a passivação dos dímeros com os fragmentos $\mathrm{H}$ e $\mathrm{OH}$ promove um afastamento dos estados eletrônicos da região próxima ao nível de Fermi e, portanto, esta região se torna visível em relação àquelas formadas pelos dímeros.

Para as imagens dos estados ocupados, a identificação do grupo silanol é responsável pelo surgimento de um padrão de 2 pontos sobre o dímero passivado. Neste caso, é possível reconhecer cada um dos grupos ( $\mathrm{Si}-\mathrm{H}$ e $\mathrm{Si}-\mathrm{OH}$ ) que com- 
põem o defeito sendo a contribuição para a corrente de tunelamento vinda de $\mathrm{H}-\mathrm{Si}$ mais fraca que a do $\mathrm{Si}-\mathrm{OH}$. O sinal de STM dos dímeros oxidados não difere significativamente entre a reconstrução c(4x2) ( $\left.\mathrm{C}_{C-S i l} @ \mathrm{c}(4 \mathrm{x} 2)\right)$ e $(2 \mathrm{x} 1)\left(\mathrm{C}_{C-S i l} @(2 \mathrm{x} 1)\right)$. Conforme averiguado experimentalmente [95], a identificação dos grupos H-Si e Si$\mathrm{OH}$ é facilitada quando analisamos os mapas de corrente de tunelamento em regime de voltagens positivas: temos 2 círculos brilhantes por dímero e a região do defeito encontra-se mais apagada. De fato, a região próxima à unidade $\mathrm{Si}-\mathrm{OH}$ está

Tabela 6.1: Parâmetros estruturais calculados para a configurações quimissorvidas $\mathrm{C}_{C-S i l}, \mathrm{C}_{C-S i l} @(2 \times 1)$ e $\mathrm{C}_{C-S i l} @ \mathrm{c}(4 \times 2)$. Os símbolos utilizados na tabela estão definidos nas figuras 4.5 e 6.3. Distâncias de ligação são dadas em $\AA$ e ângulos em graus $\left(^{\circ}\right)$.

\begin{tabular}{lccc}
\hline \hline & $\mathrm{C}_{C-S i l}$ & $\mathrm{C}_{C-S i l} @(2 \times 1)$ & $\mathrm{C}_{C-S i l} @ \mathrm{c}(4 \mathrm{x} 2)$ \\
\hline Dist. $(\AA)$ & & & \\
$\mathrm{Si}_{1}-\mathrm{Si}_{2}$ & 2,40 & 2,40 & 2,40 \\
$\mathrm{Si}_{n 1}-\mathrm{Si}_{n 2}$ & 2,28 & 2,28 & 2,30 \\
$\mathrm{Si}_{n 3}-\mathrm{Si}_{n 4}$ & 2,28 & 2,28 & 2,29 \\
$\mathrm{H}_{1}-\mathrm{O}$ & 0,98 & 0,98 & 0,98 \\
$\mathrm{O}-\mathrm{Si}_{1}$ & 1,67 & 1,67 & 1,67 \\
$\mathrm{H}_{2}-\mathrm{Si}_{2}$ & 1,50 & 1,50 & 1,50 \\
\hline$\hat{\mathrm{Ang}}\left({ }^{\circ}\right)$ & & & 1,1 \\
$\theta\left(\mathrm{Si}_{1}-\mathrm{Si}_{2}\right)$ & $-1,5$ & 1,2 & 19,3 \\
$\theta\left(\mathrm{Si}_{n 1}-\mathrm{Si}_{n 2}\right)$ & 18,2 & 19,6 & 19,0 \\
$\theta\left(\mathrm{Si}_{n 3}-\mathrm{Si}_{n 4}\right)$ & 18,2 & 19,7 & 117,5 \\
$\mathrm{Si}_{1}-\mathrm{O}-\mathrm{H}_{1}$ & 117,8 & 117,8 & 111,1 \\
$\mathrm{Si}_{2}-\mathrm{Si}_{1}-\mathrm{O}$ & 112,0 & 111,7 & 69,1 \\
$\mathrm{Si}_{2}-\mathrm{Si}_{1}-\mathrm{O}-\mathrm{H}_{1}$ & 67,2 & 67,8 & \\
\hline \hline
\end{tabular}




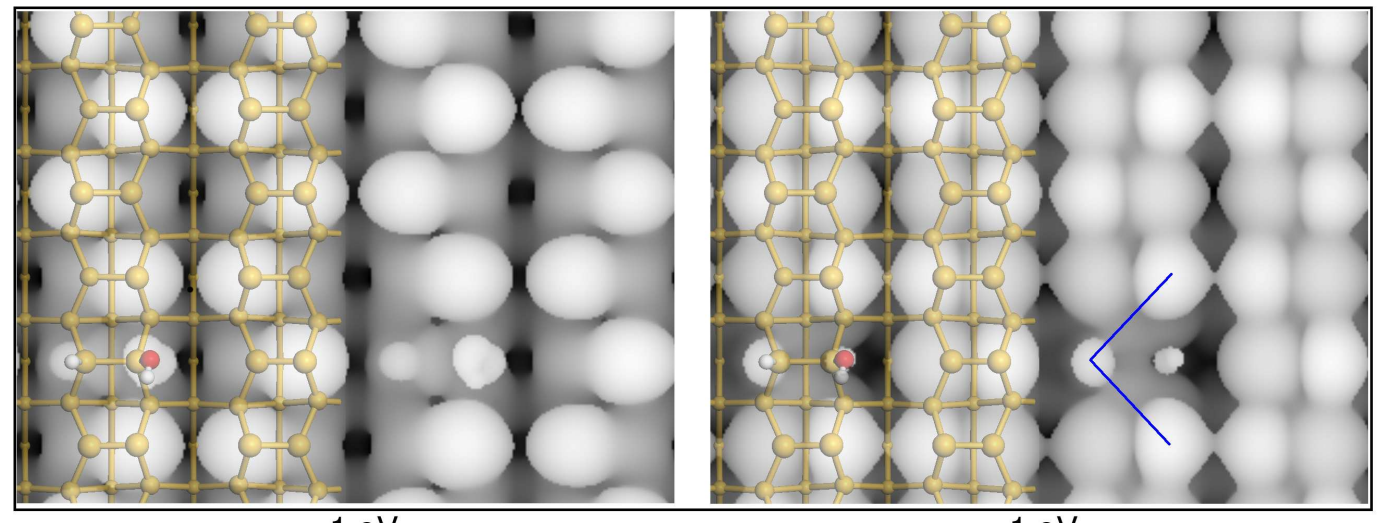

$-1 \mathrm{eV}$

$+1 \mathrm{eV}$

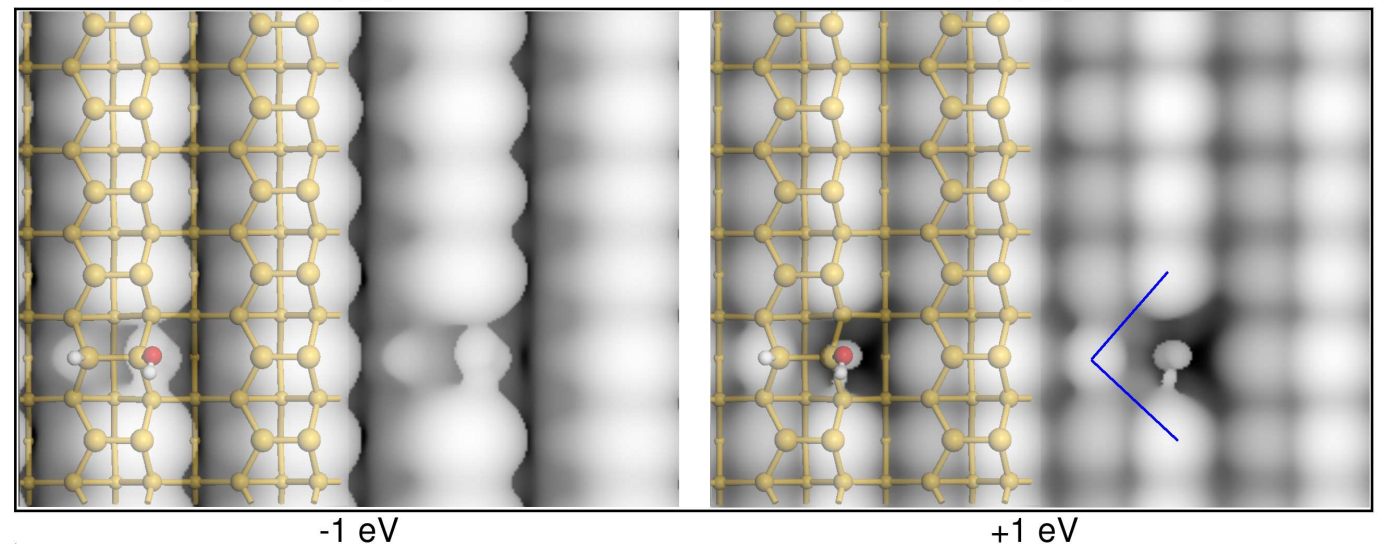

Figura 6.4: Simulação de mapa de STM em modo de corrente constante para os defeitos tipo silanol, denominados $\mathrm{C}_{C-S i l} @ \mathrm{c}(4 \times 2)$ e $\mathrm{C}_{C-S i l} @(2 \mathrm{x} 1)$, quando presente nas reconstruções $\operatorname{Si}(100) c(4 \times 2)$ (acima) e $\operatorname{Si}(100)(2 \times 1)$ (abaixo). Os valores de voltagens de varredura são incluídos na respectiva imagem. Para voltagens negativas (à esquerda) temos as imagens dos estados ocupados, para voltagens positivas (à direita) dos estados desocupados.

totalmente escura, sendo que sua extensão é maior na estrutura $\mathrm{C}_{C-S i l} @(2 \mathrm{x} 1)$. Em contraste com as imagens dos estados ocupados, aqui os grupo hidrogenados ( $\mathrm{Si}$ H) aparecem mais claros e definem com a vizinhança um sinal de intensidade com padrão " $V$ " (linhas azuis na figura 6.4).

Durante anos, estas áreas escuras foram, muitas vezes, indevidamente atribuídas à ausência de grupos $\mathrm{Si}-\mathrm{Si}$ (missing dimer). Somente em 1993 estudos realizados por Andersohn e Kohler [95] mostraram que estas regiões estavam relacionadas a 
processos de oxidação molhada. Por fim, ressaltamos que as características das imagens de STM estão de acordo com os relatos experimentais [95, 132, 140,152] e também com os resultados de simulações na superfície $\operatorname{Si}(100) \mathrm{p}(2 \times 2)$, realizadas por Okano e Oshiyama [139]. Encontramos também imagens de STM simuladas para a estrutura $C_{C-S i l} @ c(4 \times 2)$ [132], mas não foi possível compararmos resultados, visto que, devido à qualidade da figura, sequer podemos reconhecer o sinal de STM para as regiões limpas da superfície.

Tabela 6.2: Energias de ligação, $\Delta \mathrm{E}(\mathrm{eV})$, para estruturas resultantes dos processos de quimissorção de água nas superfícies $\operatorname{Si}(100)$ c(4x2) e $\operatorname{Si}(100)(2 \times 1)$. Os resultados referem-se aos cálculos com uma supercélula (4x6) e inserimos também os dados das tabelas 4.2 e 4.3 , obtidos para uma supercélula $(2 \times 2)$.

\begin{tabular}{lc|c}
\hline \hline Estrutura & $\Delta \mathrm{E} @(4 \mathrm{x} 6)(\mathrm{eV})$ & $\Delta \mathrm{E} @(2 \mathrm{x} 2)(\mathrm{eV})$ \\
\hline $\mathrm{C}_{C-S i l} @ \mathrm{c}(4 \mathrm{x} 2)$ & $-2,50$ & - \\
$\mathrm{C}_{C-S i l} @(2 \mathrm{x} 1)$ & $-2,64$ & $-2,52$ \\
\hline $\mathrm{C}_{C-O D} @ \mathrm{c}(4 \mathrm{x} 2)$ & $-3,14$ & - \\
$\mathrm{C}_{C-O D} @(2 \mathrm{x} 1)$ & $-3,26$ & $-3,15$ \\
\hline $\mathrm{C}_{C-B B} @ \mathrm{c}(4 \mathrm{x} 2)$ & $-2,92$ & - \\
$\mathrm{C}_{C-B B} @(2 \mathrm{x} 1)$ & $-2,82$ & $-2,69$ \\
\hline \hline
\end{tabular}

Passamos à análise das estruturas resultantes da decomposição das espécies silanol, discutidas na seção 4.2.2. As geometrias otimizadas para os defeitos resultantes da inserção do $\mathrm{O}$ entre os átomos de Si do dímero são mostradas na figura 6.5. Denominamos por $\mathrm{C}_{C-O D} @_{\mathrm{c}}(4 \mathrm{x} 2)$ o defeito $\mathrm{C}_{C-O D}$ na superfície $\mathrm{c}(4 \mathrm{x} 2)$ e por $\mathrm{C}_{C-O D} @(2 \mathrm{x} 1)$ quando presente na reconstrução $(2 \mathrm{x} 1)$. Novamente ambos os defeitos estão confinados a uma fileira de dímeros, e os dados resumidos na tabela 6.3 mostram que a estrutura $\mathrm{C}_{C-O D}$ provoca maiores variações no ângulo de inclinação dos dímeros $(\theta)$ ajdacentes ao defeito, quando estão inseridos em uma vizinhança 
$\mathrm{c}(4 \mathrm{x} 2)$. As diferenças relativas à superfície limpa (tabela 3.1) situam-se no intervalo entre 12,7 - 26,8\%. Para a reconstrução (2x1), esta alteração em $\theta$ é da ordem de $5 \%$. Os parâmetros estruturais otimizados para o dímero oxidado em si são praticamente iguais nas estruturas $\mathrm{C}_{C-O D}, \mathrm{C}_{C-O D} @(2 \mathrm{x} 1)$ e $\mathrm{C}_{C-O D} @ \mathrm{c}(4 \mathrm{x} 2)$. As energias de ligação para $\mathrm{C}_{C-O D} @(2 \mathrm{x} 1)$ e $\mathrm{C}_{C-O D} @ \mathrm{c}(4 \mathrm{x} 2)$ estão na tabela 6.2. Estes números diferem de 0,01 e 0,1 eV do resultado obtido para a célula (2x2) (tabela 4.3), análogo ao observado para a mesma comparação quando o defeito $\mathrm{C}_{C-\text { Sil }}$ é formado.

Tabela 6.3: Parâmetros estruturais calculados para a configurações quimissorvidas $\mathrm{C}_{C-O D}, \mathrm{C}_{C-O D} @(2 \mathrm{x} 1)$ e $\mathrm{C}_{C-O D} @ \mathrm{c}(4 \mathrm{x} 2)$. Os símbolos utilizados na tabela estão definidos nas figuras 4.8 e 6.5. Distâncias de ligação são dadas em $\AA$ e os ângulos em graus $\left(^{\circ}\right)$.

\begin{tabular}{lccc}
\hline \hline & $\mathrm{C}_{C-O D}$ & $\mathrm{C}_{C-O D} @(2 \times 1)$ & $\mathrm{C}_{C-O D} @_{\mathrm{c}}(4 \mathrm{x} 2)$ \\
\hline Dist. $(\AA)$ & & & \\
$\mathrm{Si}_{1}-\mathrm{Si}_{2}$ & 3,13 & 3,12 & 3,12 \\
$\mathrm{Si}_{n 1}-\mathrm{Si}_{n 2}$ & 2,27 & 2,27 & 2,28 \\
$\mathrm{Si}_{n 3}-\mathrm{Si}_{n 4}$ & 2,27 & 2,27 & 2,28 \\
$\mathrm{O}-\mathrm{Si}_{1}$ & 1,68 & 1,68 & 1,66 \\
$\mathrm{O}-\mathrm{Si}_{2}$ & 1,66 & 1,66 & 1,68 \\
\hline$\left.\hat{\mathrm{Ang}}{ }^{\circ}{ }^{\circ}\right)$ & & & \\
$\theta\left(\mathrm{Si}_{1}-\mathrm{Si}_{2}\right)$ & 1,37 & 0,18 & 2,18 \\
$\theta\left(\mathrm{Si}_{n 1}-\mathrm{Si}_{n 2}\right)$ & 16,1 & 18,6 & 14,7 \\
$\theta\left(\mathrm{Si}_{n 3}-\mathrm{Si}_{n 4}\right)$ & 16,1 & 18,6 & 14,7 \\
$\mathrm{H}_{1}-\mathrm{Si}_{1}-\mathrm{O}$ & 106,5 & 106,3 & 108,2 \\
$\mathrm{Si}_{1}-\mathrm{O}-\mathrm{Si}_{2}$ & 139,8 & 138,5 & 138,6 \\
\hline \hline
\end{tabular}

As imagens de STM para os estados ocupados e desocupados das estruturas $\mathrm{C}_{C-O D} @ \mathrm{c}(4 \mathrm{x} 2)$ e $\mathrm{C}_{C-O D} @(2 \mathrm{x} 1)$ podem ser visualizados na figura $6.6 \mathrm{e}$, em ambos os casos, comprovamos a localidade do defeito $\mathrm{C}_{C-O D}$. Semelhante ao comporta- 


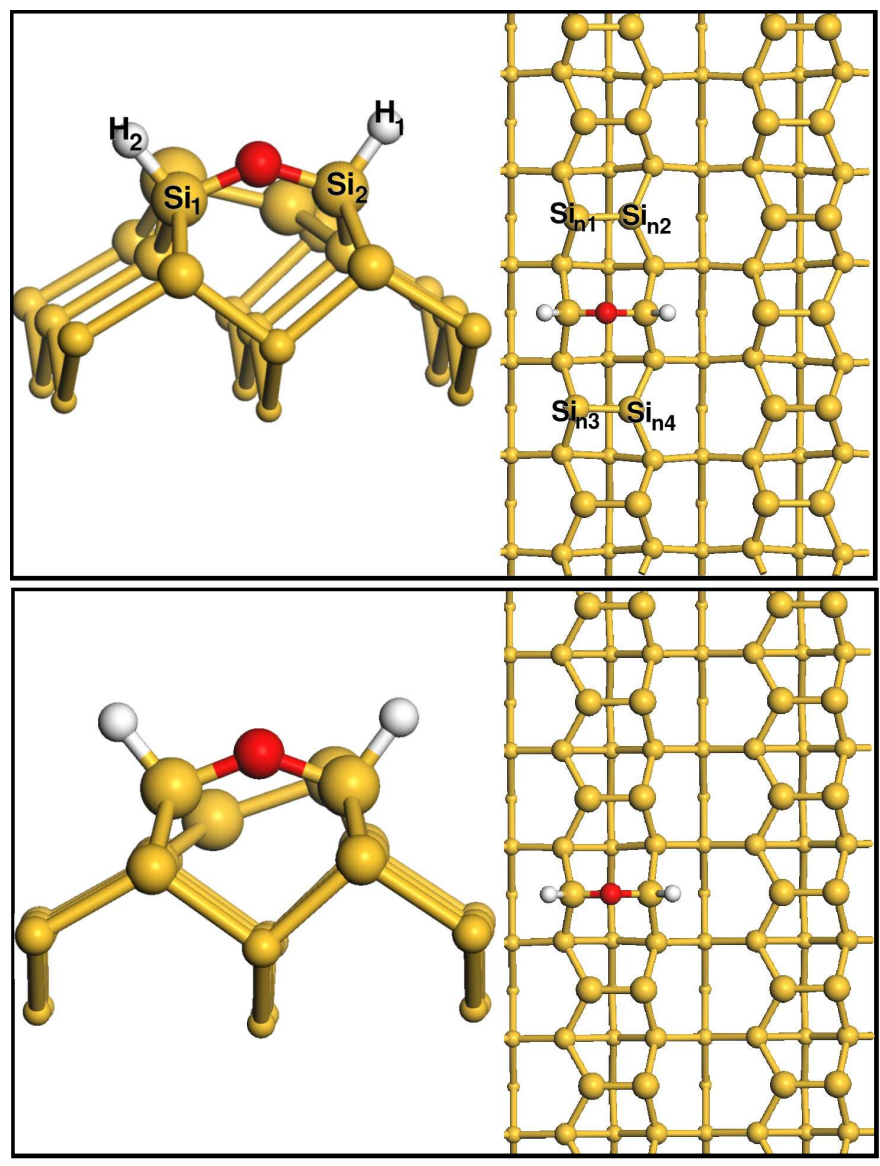

Figura 6.5: Visão lateral e de topo das configurações otimizadas para o defeito tipo on-dimer, denominados de $\mathrm{C}_{C-O D} @ \mathrm{c}(4 \mathrm{x} 2)$ e $\mathrm{C}_{C-O D} @(2 \mathrm{x} 1)$, nas superfícies $\operatorname{Si}(100) c(4 \times 2)$ (acima) e $\operatorname{Si}(100)(2 \times 1)$ (abaixo). Os átomos de H são representados por esferas brancas, o átomo de $\mathrm{O}$ em vermelho e os átomos de Si em amarelo. O tamanho das esferas amarelas está relacionado com a posição dos átomos de Si na fatia usada em nossas simulações.

mento dos grupos $\mathrm{C}_{C-S i l}$, também aqui, a região de defeito está associada à menor intensidade de tunelamento quando comparada ao sinal vindo dos dímeros inafetados. Para as imagens obtidas em regime de voltagens negativas, identificamos três regiões brilhantes e de intensidades semelhantes sobre cada uma das unidades $\mathrm{Si}-\mathrm{H}$ e sobre o átomo de $\mathrm{O}$, mas sempre menos intenso que o sinal normal da superfície não oxidada. Devido à baixa intensidade de sinal sobre este átomo em relação aos 
dímeros inafetados, pode ser que a resolução experimental não permita sua identificação. E, de fato, é este o caso. Trenhaile e colaboradores [131] mostraram que, após o aquecimento da superfície $\mathrm{Si}(100)(2 \times 1)$ :Cl oxidada por água, surgem defeitos cujas propriedades do sinal de tunelamento (voltagens negativas) são aquelas mostradas na figura 6.3. Não se detectou o sinal do átomo de oxigênio, o qual está associado a uma região apagada. Neste caso, os estados eletrônicos do O estão eficientemente hibridizados com a banda de valência da superfície, inclusive alcançando o topo desta banda (resultados não mostrados). Para a região $1 \mathrm{eV}$ abaixo e acima do nível de Fermi, os estados eletrônicos são dominados pelo Si e têm pequena contribuição do O. Assim sendo, em condições ideais como a nossa, o sinal fraco deste átomo é detectado, mas em condições experimentais, é possível que este efeito seja mascarado pelo sinal muito mais intenso vindo de outras regiões da amostra. A pequena intensidade de sinal também foi teoricamente observada em sítios oxidados para a superfície $\operatorname{Si}(111)$ [159].

As imagens dos estados desocupados também exibem o padrão de três regiões brilhantes sobre o grupo $\mathrm{C}_{C-O D}$. A região do defeito está mais escura que relativamente se observa para as imagens dos estados ocupados e o sinal de tunelamento sobre as unidades $\mathrm{H}_{1}-\mathrm{Si}_{1}$ e $\mathrm{Si}_{2}-\mathrm{H}_{2}$ é diferente. Na estrutura $\mathrm{C}_{C-O D} @ \mathrm{c}(4 \mathrm{x} 2)$ a unidade $\mathrm{H}_{1}-\mathrm{Si}_{1}$ está mais clara que a $\mathrm{Si}_{2}-\mathrm{H}_{2}$, enquanto o contrário foi obtido para a $\mathrm{C}_{C-O D} @(2 \mathrm{x} 1)$. Este comportamento assimétrico é consequência dos diferentes comprimentos de ligação, $\mathrm{O}-\mathrm{Si}_{1}$ e O-Si ${ }_{2}$ (tabela 6.3).

Por fim, passamos às estruturas resultantes da inserção do $\mathrm{O}$ em um sítio de back-bond. A geometria relaxada para as configuração $\mathrm{C}_{C-B B} @ \mathrm{c}(4 \mathrm{x} 2)$ e também $\mathrm{C}_{C-B B} @(2 \mathrm{x} 1)$ são mostradas na figura 6.7. Assim como $\mathrm{C}_{C-S i l}$ e $\mathrm{C}_{C-O D}$, este também é um defeito confinado a uma fileira de dímeros e, conforme já comentamos (seção 4.2.2), a inserção de $\mathrm{O}$ em um sítio entre a primeira e a segunda camada da superfície provoca deformações angulares consideráveis na estrutura. Não somente o dímero oxidado se desloca para fora da superfície, com o eixo Si-Si desviado de sua direção original, mas os dímeros adjacentes também são desviados. Estas 

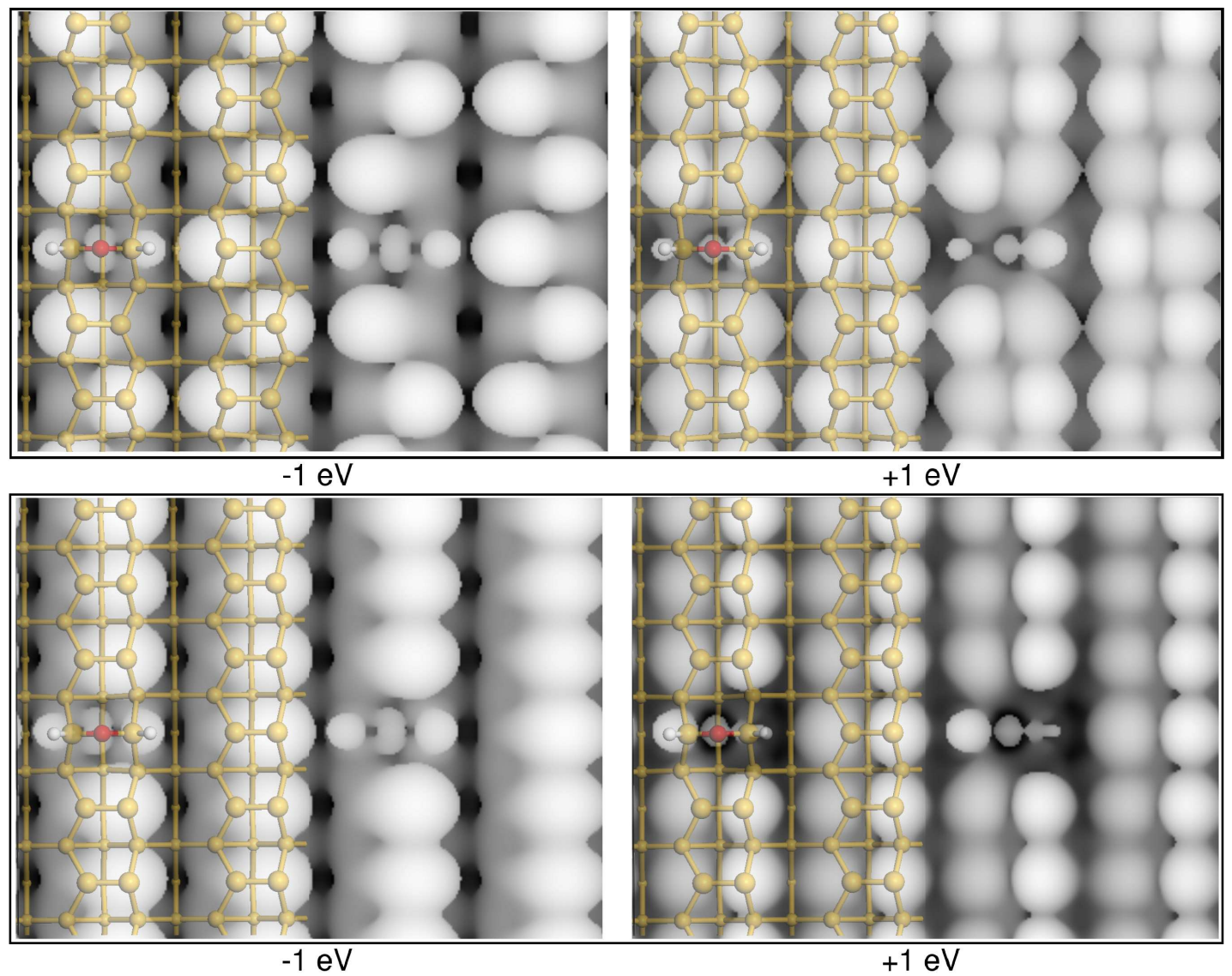

Figura 6.6: Simulação de mapa de STM em modo de corrente constante para os defeitos tipo on-dimer, denominados $\mathrm{C}_{C-O D} @ \mathrm{c}(4 \mathrm{x} 2)$ e $\mathrm{C}_{C-O D} @(2 \mathrm{x} 1)$, quando presentes nas reconstruções $\operatorname{Si}(100) c(4 \times 2)$ (acima) e $\operatorname{Si}(100)(2 \times 1)$ (abaixo). Os valores de voltagens de varredura são incluídos na respectiva imagem. Para voltagens negativas (à esquerda) temos as imagens dos estados ocupados, para voltagens positivas (à direita) dos estados desocupados.

modificações têm por finalidade acomodar o defeito, mas ainda assim, o ângulo da ligação $\mathrm{Si}_{2 n d 2}-\mathrm{O}-\mathrm{Si}_{1}$ é relativamente menor que o valor obtido para o óxido de $\mathrm{Si}$. Constatamos (tabela 6.4) que a diferença relativa ao alpha-quartzo é de, respectivamente, 7,$5 ; 6,7$ e 4,2\% nas estruturas $\mathrm{C}_{C-B B}$ (figura 4.10$), \mathrm{C}_{C-B B} @_{\mathrm{c}}(4 \times 2)$ e $\mathrm{C}_{C-B B} @(2 \mathrm{x} 1)$. Temos assim, uma indicativa de porque os valores de energia de ligação para a inserção em um sítio de back-bond, calculados para uma supercélula 
(2x2) (tabela 4.3), são 0,23 e $0,13 \mathrm{eV}$ maiores que o resultado mostrado na tabela 6.2 para as estruturas $\mathrm{C}_{C-B B} @(2 \mathrm{x} 1)$ e $\mathrm{C}_{C-B B} @ \mathrm{c}(4 \mathrm{x} 2)$, nesta ordem.

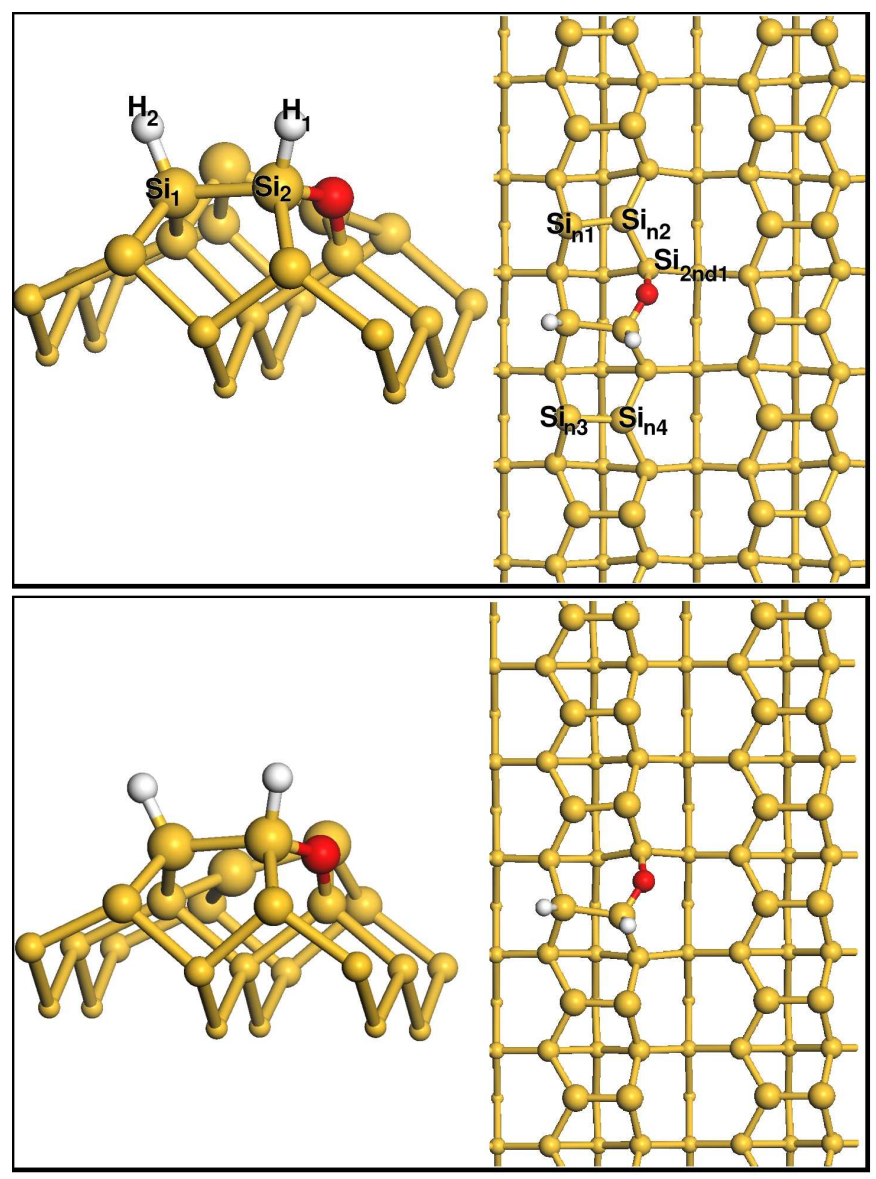

Figura 6.7: Visão lateral e de topo das configurações otimizadas para o defeito tipo back-bond, denominados de $\mathrm{C}_{C-B B} @ \mathrm{c}(4 \mathrm{x} 2)$ e $\mathrm{C}_{C-B B} @(2 \mathrm{x} 1)$, nas superfícies $\operatorname{Si}(100) c(4 \times 2)$ (acima) e $\operatorname{Si}(100)(2 \times 1)$ (abaixo). Os átomos de H são representados por esferas brancas, o átomo de $\mathrm{O}$ em vermelho e os átomos de $\mathrm{Si}$ em amarelo. $\mathrm{O}$ tamanho das esferas amarelas está relacionado com a posição dos átomos de Si na fatia usada em nossas simulações.

As imagens de STM das estruturas $\mathrm{C}_{C-B B} @ \mathrm{c}(4 \mathrm{x} 2)$ e $\mathrm{C}_{C-B B} @(2 \mathrm{x} 1)$ para voltagens negativa e positiva são mostradas na figura 6.6. O dímero oxidado está associado às regiões mais escuras do mapa de corrente de tunelamente, entretanto o efeito é mais nítido nas imagens dos estados desocupados. Cada uma das unidades $\mathrm{Si}-\mathrm{H}$ 
do grupo $\mathrm{H}-\mathrm{Si}-(\mathrm{O}) \mathrm{Si}-\mathrm{H}$ é visível através do aparecimento de um padrão de 2 pontos claros somado à aquele já mencionado sobre o oxigênio, que frisamos estar mais apagado em relação aos dímeros. Em todos os mapas de STM, o sinal dos grupos hidrogenados mostra o desvio já comentado, conforme evidenciado pela linha azul na figura 6.8. Este deslocamento é da ordem de 0,7 A. Apesar das características descritas, a detecção deste defeito pode ser difícil e acreditamos que as imagens dos estados ocupados sejam mais úteis, uma vez que exibem quebra de simetria mais fácil de se identificar.

Tabela 6.4: Parâmetros estruturais calculados para a configurações quimissorvidas $\mathrm{C}_{C-O D}, \mathrm{C}_{C-O D} @(2 \mathrm{x} 1)$ e $\mathrm{C}_{C-O D} @ \mathrm{c}(4 \mathrm{x} 2)$. Os símbolos utilizados na tabela estão definidos nas figuras 4.10 e 6.7. Distâncias de ligação são dadas em $\AA$ e ângulos em graus $\left(^{\circ}\right)$.

\begin{tabular}{lccc}
\hline \hline & $\mathrm{C}_{C-B B}$ & $\mathrm{C}_{C-B B} @(2 \mathrm{x} 1)$ & $\mathrm{C}_{C-B B} @ \mathrm{c}(4 \mathrm{x} 2)$ \\
\hline Dist. $(\AA)$ & & & \\
$\mathrm{Si}_{1}-\mathrm{Si}_{2}$ & 2,39 & 2,39 & 2,38 \\
$\mathrm{Si}_{n 1}-\mathrm{Si}_{n 2}$ & 2,28 & 2,28 & 2,31 \\
$\mathrm{Si}_{n 3}-\mathrm{Si}_{n 4}$ & 2,28 & 2,28 & 2,31 \\
$\mathrm{O}-\mathrm{Si}_{1}$ & 1,65 & 1,66 & 1,67 \\
$\mathrm{O}-\mathrm{Si}_{2 n d 2}$ & 1,67 & 1,67 & 1,67 \\
$\mathrm{H}_{1}-\mathrm{Si}_{1}$ & 1,50 & 1,50 & 1,50 \\
\hline$\left.\hat{\mathrm{Angulos}}{ }^{\circ}\right)$ & & & 17,4 \\
$\theta\left(\mathrm{Si}_{n 1}-\mathrm{Si}_{n 2}\right)$ & 20,0 & 19,5 & 16,9 \\
$\theta\left(\mathrm{Si}_{n 3}-\mathrm{Si}_{n 4}\right)$ & 20,0 & 20,3 & 106,3 \\
$\mathrm{H}_{1}-\mathrm{O}-\mathrm{Si}_{1}$ & 107,4 & 107,6 & 130,6 \\
$\mathrm{Si}_{2 n d 2}-\mathrm{O}-\mathrm{Si}_{1}$ & 128,9 & 133,4 & \\
\hline \hline
\end{tabular}



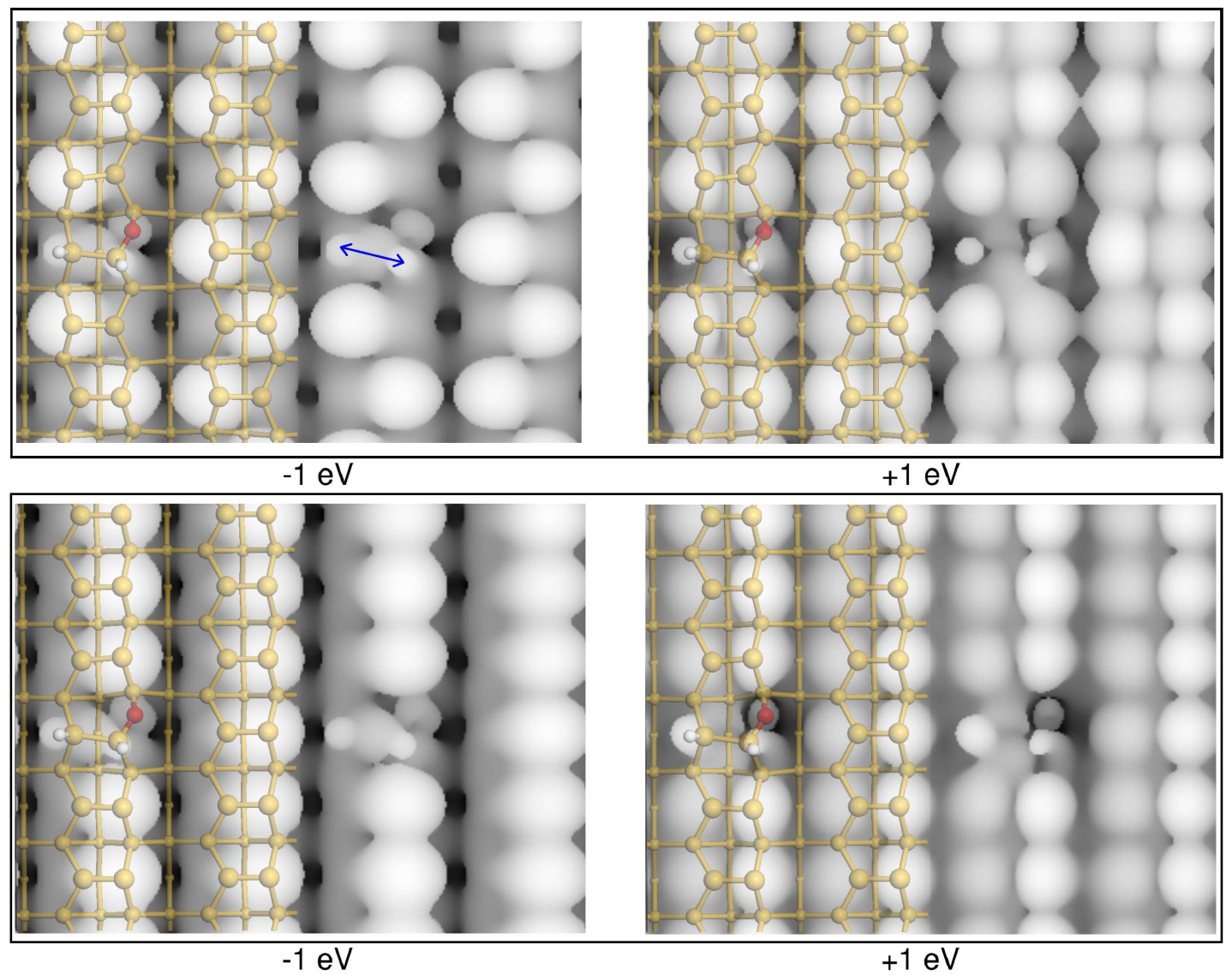

Figura 6.8: Simulação de mapa de STM em modo de corrente constante para os defeitos tipo back-bond, denominados $\mathrm{C}_{C-B B} @ \mathrm{c}(4 \mathrm{x} 2)$ e $\mathrm{C}_{C-B B} @(2 \mathrm{x} 1)$, quando presente nas reconstruções $\operatorname{Si}(100) c(4 \times 2)$ (acima) e $\operatorname{Si}(100)(2 \times 1)$ (abaixo). Os valores de voltagens de varredura são incluídos na respectiva imagem. Para voltagens negativas (à esquerda) temos as imagens dos estados ocupados, para voltagens positivas (à direita) dos estados desocupados.

\subsection{3 $\quad \mathrm{H}_{2} \mathrm{O} / \mathrm{Si}(100)(2 \times 1): \mathrm{H}$}

$\mathrm{Na}$ figura 6.9, apresentamos a geometria relaxada para o defeito $\mathrm{C}_{\text {Sil }}$, estrutura semelhante à mostrada na figura 5.6, mas resultante de um cálculo de relaxação utilizando uma supercélula $(4 \times 6)$. O defeito não afeta fileiras de dímeros vizinhas, e sua influência na vizinhança dentro de uma mesma fileira é pequena. Contudo, a utilização de uma célula unitária maior permite que os átomos $\mathrm{Si}_{1}$ e $\mathrm{Si}_{2}$ se afastem 
$\approx 10 \%$ mais que na supercélula menor (tabela 6.5). O rearranjo estrutural tem um efeito interessante sobre as unidades dihidrogenadas: as estruturas $\mathrm{SiH}_{2}$ na célula unitária (2x2) têm um comportamento similar à aquele identificado para a reconstrução $\operatorname{Si}(100)(1 \times 1): H$ em sua forma "canted" (capítulo 3, figura 3.8(b)), ao passo que a relaxação estrutural na supercélula $(4 \mathrm{x} 6)$ conduz a um comportamento de natureza semelhante aos grupos dihidrogenados na reconstrução $\operatorname{Si}(100)(3 \times 1): H$ (capítulo 3, figura 3.8(a)). Como consequência, a energia de ligação para a geometria mostrada na figura 6.9 é $0,28 \mathrm{eV}$ maior que aquela calculada para a estrutura $\mathrm{C}_{S i l} @(2 \mathrm{x} 2)$ (tabela 6.6). O rebaixamento da energia é resultado da possibilidade de relaxação lateral na célula $(4 \times 6)$, que permite maior estabilização desta estrutura. E não deve afetar muito a altura da barreira de reação (tabela 5.5), pois a barreira está relacionada ao rompimento da ligação Si-Si e estiramento das ligações $\mathrm{OH}$.

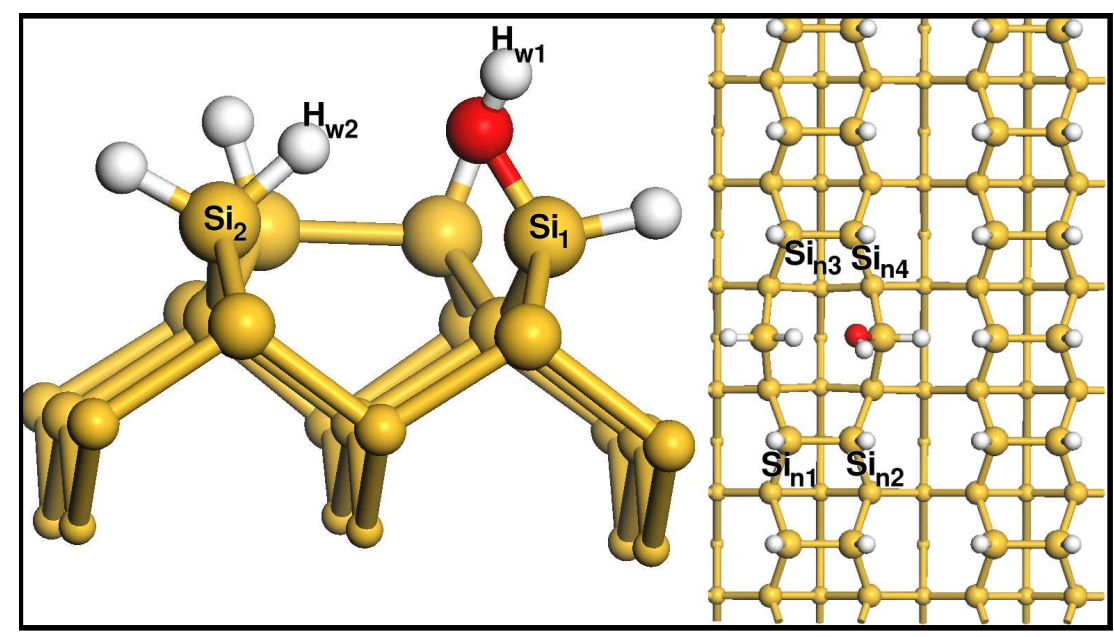

Figura 6.9: Visão lateral e de topo da configuração otimizada para o defeito tipo silanol, denominado de $\mathrm{C}_{S i l}$, na superfície $\mathrm{Si}(100)(2 \mathrm{x} 1): H$. Os átomos de H são representados por esferas brancas, o átomo de $\mathrm{O}$ em vermelho e os átomos de $\mathrm{Si}$ em amarelo. O tamanho das esferas amarelas está relacionado com a posição dos átomos de Si na fatia usada em nossas simulações.

Apresentamos na figura 6.10 imagens de STM para regime de voltagens negativa e positiva para essa estrutura. A imagem dos estados ocupados e desocupados têm 
características bem marcadas na região localizada sobre o grupo $\mathrm{H}-\mathrm{Si}-\mathrm{H} \cdot \cdots \mathrm{H}-\mathrm{O}-\mathrm{Si}-$ $\mathrm{H}$ : as unidades $\mathrm{H}-\mathrm{Si}$ assim como $\mathrm{O}-\mathrm{Si}-\mathrm{H}$ estão associadas a màximos de intensidade, sendo que o sinal sobre a unidade $\mathrm{H}-\mathrm{O}-\mathrm{Si}$ é mais forte e comparável à intensidade de sinal dos dímeros monohidrogenados. Uma região de mínimo profundo é identificada nas áreas próximas ao oxigênio, interrompendo o padrão de mínimo raso sobre a fileira de dímeros e o perfil "listrado" característico a superfície $\mathrm{Si}(100)(2 \mathrm{x1}$ ):H (figura 6.1). O sinal de STM estende-se sobre o vale em ambos os lados, dada a presença dos dois átomos de $\mathrm{H}$ adicionais. Para as imagens dos estados desocupados, o sinal mais intenso em todo o mapa de STM está posicionado sobre a unidade $\mathrm{O}-\mathrm{Si}-\mathrm{H}$ e tem

Tabela 6.5: Parâmetros estruturais calculados para a configurações quimissorvidas $\mathrm{C}_{S i l} @(4 \mathrm{x} 6)$ e $\mathrm{C}_{S i l} @ \mathrm{c}(2 \mathrm{x} 2)$ (tabela 5.4). Os símbolos utilizados na tabela estão definidos nas figuras 6.9 e 5.7. Distâncias de ligação são dadas em Å e ângulos em graus $\left(^{\circ}\right)$.

\begin{tabular}{lcc}
\hline \hline & $\mathrm{C}_{S i l} @(4 \times 6)$ & $\mathrm{C}_{S i l} @(2 \times 2)$ \\
\hline Dist. $(\AA)$ & & \\
$\mathrm{H}-\mathrm{Si}$ & 1,50 & 1,50 \\
$\mathrm{Si}_{1}-\mathrm{Si}_{2}$ & 4,36 & 3,94 \\
$\mathrm{Si}_{n 1}-\mathrm{Si}_{n 2}$ & 2,42 & 2,42 \\
$\mathrm{Si}_{n 3}-\mathrm{Si}_{n 4}$ & 2,42 & 2,42 \\
$\mathrm{H}_{w 1}-\mathrm{O}$ & 0,98 & 0,98 \\
$\mathrm{H}_{w 2}-\mathrm{O}$ & 2,37 & 2,40 \\
$\mathrm{O}_{-} \mathrm{Si}_{1}$ & 1,67 & 1,67 \\
$\mathrm{O}_{-} \mathrm{Si}_{2}$ & 3,69 & 3,84 \\
\hline $\left.\mathrm{Angulos}{ }^{\circ}\right)$ & & \\
$\mathrm{O}-\mathrm{Si}_{1}-\mathrm{H}$ & 109,42 & 107,43 \\
$\mathrm{H}_{w 2}-\mathrm{Si}_{2}-\mathrm{H}$ & 109,42 & 105,15 \\
\hline \hline
\end{tabular}


Tabela 6.6: Energias de ligação, $\Delta \mathrm{E}(\mathrm{eV})$, para estruturas resultantes dos processos de quimissorção de água na superfície $\operatorname{Si}(100)(2 \times 1): H$. Todos os resultados referem-se à cálculos com uma supercélula $(4 \times 6)$, todavia para facilitar comparações, inserimos os dados da tabela 5.3, obtidos para uma supercélula (2x2).

\begin{tabular}{lc|c}
\hline \hline Estrutura & $\Delta \mathrm{E} @(4 \mathrm{x} 6)(\mathrm{eV})$ & $\Delta \mathrm{E} @(2 \mathrm{x} 2)(\mathrm{eV})$ \\
\hline $\mathrm{C}_{S i l}$ & $-0,99$ & $-0,71$ \\
$\mathrm{C}_{B B+H 2}$ & $-0,74$ & $-0,61$ \\
$\mathrm{C}_{B B}$ & $-1,41$ & $-1,11$ \\
$\mathrm{C}_{O D}$ & $-1,20$ & $-1,18$ \\
$\mathrm{C}_{O D+H 2}$ & $-1,87$ & $-1,59$ \\
\hline \hline
\end{tabular}

grande extensão espacial. Este comportamento é bem diferente daquele observado para grupo silanol na superfície limpa (figura 6.4).

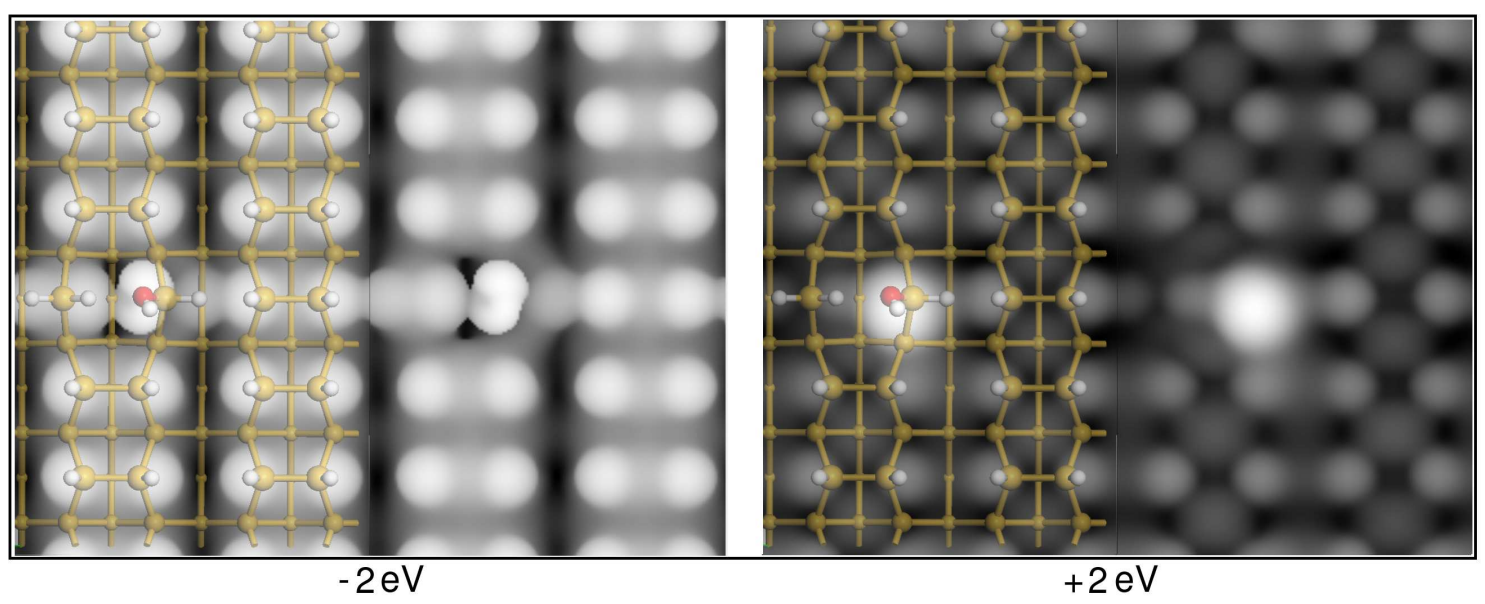

Figura 6.10: Simulação de mapa de STM em modo de corrente constante para os defeitos tipo silanol, denominado de $\mathrm{C}_{S i l}$, na superfície $\operatorname{Si}(100)(2 \mathrm{x} 1)$ :H. Os valores de voltagens de varredura são incluídos na respectiva imagem. Para voltagens negativas (à esquerda) temos as imagens dos estados ocupados, para voltagens positivas (à direita) dos estados desocupados. 
Passamos agora aos resultados para inserção no back-bond, defeitos $\mathrm{C}_{B B+H 2}$ e $\mathrm{C}_{B B}$, para os quais a geometria otimizada, utilizando célula (4x6), é mostrada na figura 6.11. Para $\mathrm{C}_{B B+H 2}$ o resíduo de reação foi retirado da célula unitária para a simulação das imagens de STM, mas foi mantida na supercélula quando fizemos o cálculo da energia de ligação (tabela 6.6). Na estrutura de $\mathrm{C}_{B B}$ os dois átomos de $\mathrm{H}$ estão conectados aos átomos de $\mathrm{Si}_{1}$ e $\mathrm{Si}_{2}$ e a ligação $\mathrm{Si}_{1}-\mathrm{Si}_{2}$ foi rompida. Listamos, na tabela 6.7, uma comparação entre alguns parâmetros estruturais otimizados para as estruturas $\mathrm{C}_{B B+H 2} @(4 \mathrm{x} 6), \mathrm{C}_{B B+H 2} @(2 \mathrm{x} 2), \mathrm{C}_{B B} @(4 \mathrm{x} 6)$ e $\mathrm{C}_{B B} @(2 \mathrm{x} 2)$. Em todos os casos, a distância $\mathrm{Si}-\mathrm{O}$ é aproximadamete a mesma, sendo que, há uma tendência de que o átomo de $\mathrm{O}$ se aproxime mais do átomo de $\mathrm{Si}$ de superfície $\left(\mathrm{Si}_{1}\right)$. A quebra do dímero permite um aumento de $\approx 10 \%$ no valor do ângulo $\mathrm{Si}_{1}-\mathrm{O}-\mathrm{Si}_{2 n d 1}$. A estrutura $\mathrm{C}_{B B+H 2} @(4 \times 6)\left(\mathrm{C}_{B B+H 2} @(2 \mathrm{x} 2)\right)$ tem energia de ligação 0,67 $(0,50) \mathrm{eV}$ maior que $\mathrm{C}_{B B} @(4 \times 6)\left(\mathrm{C}_{B B} @(2 \times 2)\right)$ refletindo o ganho de energia vinda da dissociação da molécula de $\mathrm{H}_{2}$. Em ambos defeitos há deslocamento ( $\Delta y$, tabela 6.7) dos grupo $\mathrm{Si}_{1}-\mathrm{H}$ em direção ao dímero vizinho $\left(\mathrm{Si}_{n 3}-\mathrm{Si}_{n 4}\right)$. Devido à falta de espaço para dissipação da tensão provocada por este movimento nas supercélulas $(2 \times 2)$, observamos que os valores de energia de ligação das geometrias $\mathrm{C}_{B B+H 2} @(2 \mathrm{x} 2)$ e $\mathrm{C}_{B B} @(2 \mathrm{x} 2)$ diferem de 0,13 e $0,29 \mathrm{eV}$, respectivamente dos valores obtidos para os mesmos defeitos, mas com uma célula maior. Para $C_{B B} @(2 \times 2)$ a diferença é maior porque além do deslocamento do grupo $\mathrm{Si}_{1}-\mathrm{H}$, existe ainda a repulsão entre os dois grupos hidrogenados, resultantes da quebra do dímero.

Na figura 6.12, apresentamos os mapas de corrente de tunelamento para os defeitos denominados de $\mathrm{C}_{B B+H 2} @(4 \times 6)$ e $\mathrm{C}_{B B} @(4 \times 6)$. O reconhecimento do defeito $\mathrm{C}_{B B}$ pode ser realizado tanto para perfil de corrente de tunelamento dos estados ocupados quanto dos desocupados. As mudanças provocadas pela inserção de $\mathrm{O}$ na back-bond, sem quebra do dímero $\left(\mathrm{C}_{B B+H 2}\right)$, são mais difíceis de serem detectadas. Para voltagens negativas observamos apenas um pequeno deslocamento do ponto brilhante situado sobre o grupo $\mathrm{Si}_{1}-\mathrm{H}$ e o surgimento do sinal de tunelamento sobre o átomo de oxigênio, porém menos intenso que o observado para as demais 

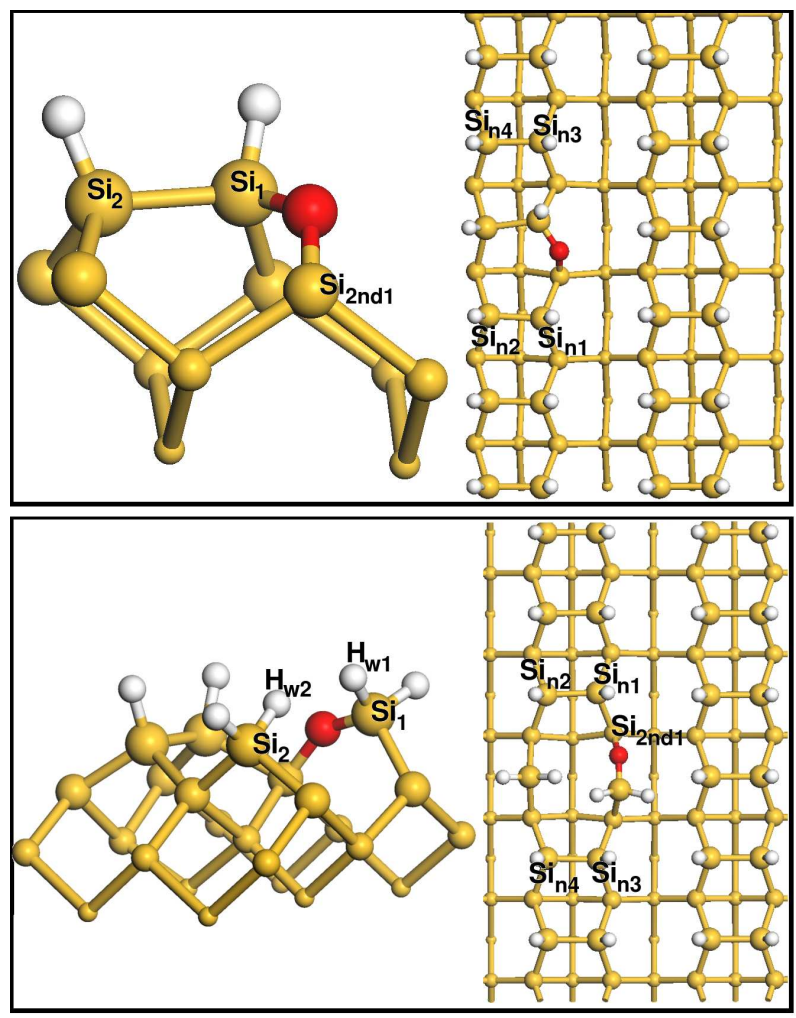

Figura 6.11: Visão lateral e de topo da configuração otimizada para os defeitos denominados de $\mathrm{C}_{B B+H 2}$ e $\mathrm{C}_{B B}$, na superfície $\mathrm{Si}(100)(2 \mathrm{x} 1)$ :H. A estrutura $\mathrm{C}_{B B+H 2}$ é aquela mostrada na figura 5.6, sem a molécula de $\mathrm{H}_{2}$, que foi removida para os cálculos das imagens de STM. Os átomos de H são representados por esferas brancas, o átomo de $\mathrm{O}$ em vermelho e os átomos de $\mathrm{Si}$ em amarelo. O tamanho das esferas amarelas está relacionado com a posição dos átomos de Si na fatia usada em nossas simulações.

regiões hidrogenadas. O padrão listrado não foi interrompido. O grupo $\mathrm{Si}_{1}-\mathrm{H}$ têm intensidade de sinal maior que aquela vinda dos outros grupos monohidrogenados, uma vez que esta estrutura está $\approx 0,3 \AA$ acima dos demais átomos da superfície. Para as imagens dos estados desocupados, o grupo $\mathrm{Si}_{1}-\mathrm{H}$ está ainda associado ao sinal mais intenso na superfície e a ligação com o O provoca o surgimento de uma área totalmente apagada próxima a este átomo. Desta forma, a unidade $\mathrm{Si}_{1}(\mathrm{O})-\mathrm{H}$ provoca uma assimetria característica no sinal de tunelamento. A região está de- 
limitada por um quadrado azul na figura 6.12. O reconhecimento das regiões da superfície monohidrogenada onde se formam estruturas $\mathrm{C}_{B B+H 2}$ vem da detecção do sinal assimétrico, porque o oxigênio praticamente não é visível. As imagens dos estados ocupados são similares àquelas obtidas por Skliar e Willis [152].

Já nas imagens de STM para a estrutura $\mathrm{C}_{B B}$ (figura 6.12) existe uma pequena contribuição do O. Na imagem dos estados ocupados, surge um mínimo profundo da corrente de tunelamento sobre as fileiras de dímeros, enquanto as duas unidades dihidrogenadas são marcadas por dois pontos brilhantes e com forma circular alon-

Tabela 6.7: Parâmetros estruturais calculados para a configurações quimissorvidas $\mathrm{C}_{B B+H 2} @(4 \mathrm{x} 6), \mathrm{C}_{B B+H 2} @ \mathrm{c}(2 \mathrm{x} 2), \mathrm{C}_{B B} @(4 \mathrm{x} 6)$ e $\mathrm{C}_{B B} @(2 \mathrm{x} 2)$ (tabela 5.6). Os símbolos utilizados na tabela estão definidos nas figuras 5.10 e 6.11. Distâncias de ligação são dadas em $\AA$ e ângulos em graus $\left(^{\circ}\right)$.

\begin{tabular}{lcc|cc}
\hline \hline & $\mathrm{C}_{B B+H 2} @(4 \mathrm{x} 6)$ & $\mathrm{C}_{B B+H 2} @(2 \mathrm{x} 2)$ & $\mathrm{C}_{B B} @(4 \mathrm{x} 6)$ & $\mathrm{C}_{B B} @(2 \mathrm{x} 2)$ \\
\hline Dist. $(\AA)$ & 2,42 & 2,42 & 4,29 & \\
$\mathrm{Si}_{1}-\mathrm{Si}_{2}$ & 2,41 & 2,40 & 2,42 & 2,41 \\
$\mathrm{Si}_{n 1}-\mathrm{Si}_{n 2}$ & 2,41 & 2,40 & 2,42 & 2,41 \\
$\mathrm{Si}_{n 3}-\mathrm{Si}_{n 4}$ & 1,66 & 1,66 & 1,65 & 1,66 \\
$\mathrm{O}-\mathrm{Si}_{1}$ & 1,67 & 1,68 & 1,66 & 1,67 \\
$\mathrm{O}-\mathrm{Si}_{2 n d 1}$ & - & - & 1,50 & 1,49 \\
$\mathrm{Si}_{1}-\mathrm{H}_{w 1}$ & 0,32 & 0,27 & 0,62 & 0,76 \\
$\Delta y(S i 1-S i 2)$ & 0,73 & 0,74 & 0,87 & 1,01 \\
$\Delta y(H-H)$ & & & & \\
\hline $\mathrm{Ang}_{\left({ }^{\circ}\right)}$ & 129,4 & 125,0 & 143,8 & 140,8 \\
$\mathrm{Si}_{1}-\mathrm{O}-\mathrm{Si}_{2 n d 1}$ & - & - & 108,6 & 106,8 \\
$\mathrm{H}_{w 1}-\mathrm{Si}_{1}-\mathrm{H}$ & - & - & 108,4 & 107,0 \\
$\mathrm{H}_{w 2}-\mathrm{Si}_{2}-\mathrm{H}$ & & &
\end{tabular}



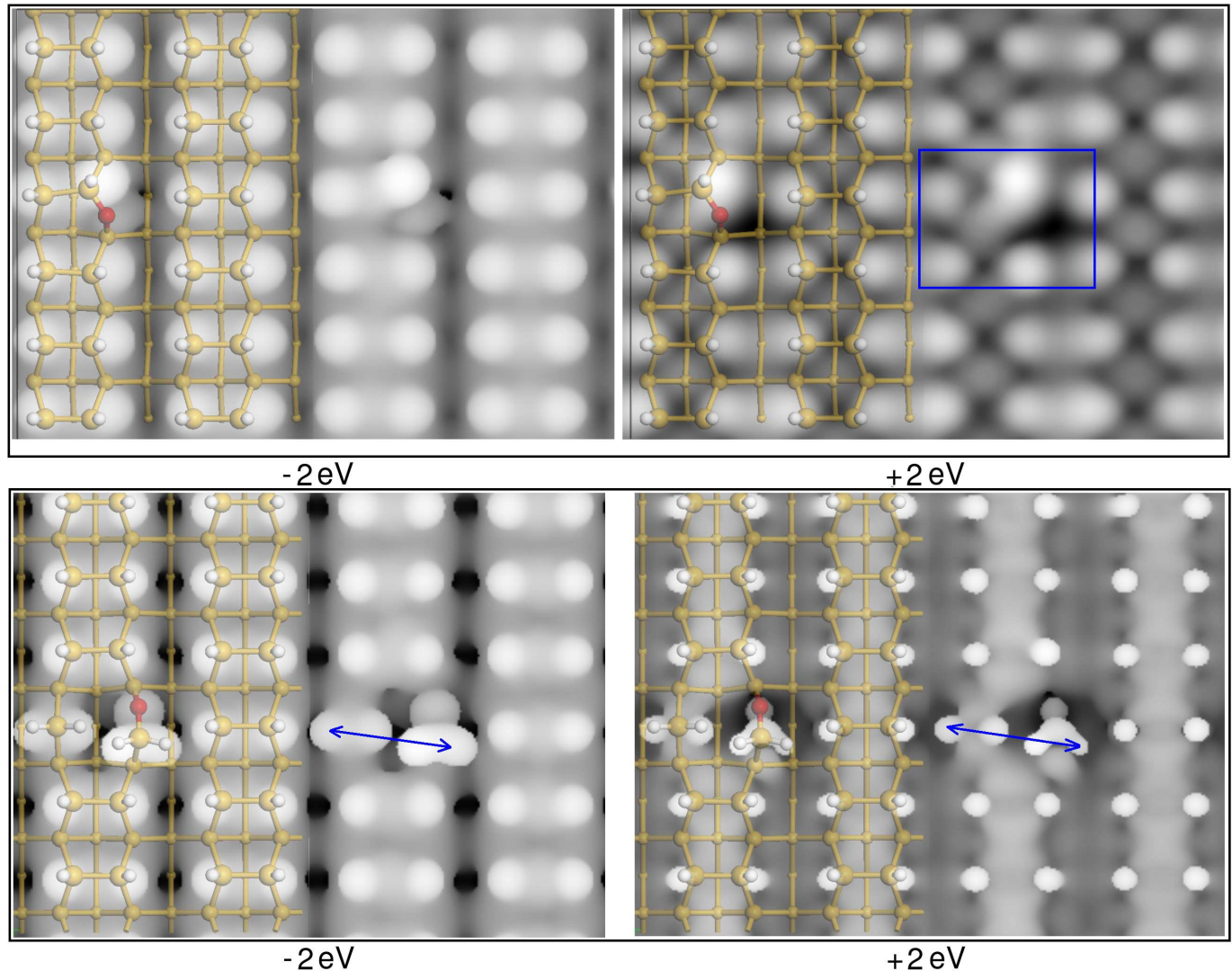

Figura 6.12: Simulação de mapa de STM em modo de corrente constante para os defeitos $\mathrm{C}_{B B+H 2}$ e $\mathrm{C}_{B B}$, na superfície $\mathrm{Si}(100)(2 \mathrm{x} 1): \mathrm{H}$. A estrutura $\mathrm{C}_{B B+H 2}$ é aquela mostrada na figura 5.6, mas sem a molécula de $\mathrm{H}_{2}$, que foi removida para os cálculos das imagens de STM. Os valores de voltagens de varredura são incluídos na respectiva imagem. Para voltagens negativas (à esquerda) temos as imagens dos estados ocupados, para voltagens positivas (à direita) dos estados desocupados.

gada. O deslocamento do grupo $\mathrm{SiH}_{2}$ em relação $\mathrm{Si}_{1}(\mathrm{O})-\mathrm{H}_{2}$ também é percebido (seta azul na figura 6.12) e facilita o reconhecimento deste defeito. Para o mapa dos estados desocupados, somado ao deslocamento do sinal de STM sobre os grupos dihidrogenados, oxidados ou não, há uma região nitidamente apagada nas proximidades do grupo $\mathrm{Si}_{1}(\mathrm{O})-\mathrm{H}_{2}$. Este perfil de sinal auxilia a identificação do defeito $\mathrm{C}_{B B}$ por meio de experimentos de STM. A distinção entre os defeitos $\mathrm{C}_{\text {Sil }}$ (figura 6.10) e $\mathrm{C}_{B B}$ (figura 6.12) é factível para os estados desocupados. 
As geometrias relaxadas para os defeitos produzidos pela inserção de oxigênio no dímero, $\mathrm{C}_{O D}$ e $\mathrm{C}_{O D+H 2}$, são mostradas na figura 6.13. Em ambas estruturas o dímero está oxidado, mas em $\mathrm{C}_{O D+H_{2}}$ o grupo $\mathrm{H}-\mathrm{Si}-\mathrm{O}-\mathrm{Si}-\mathrm{H}$ tem como vizinho duas unidades dihidrogenadas. A tensão envolvida na formação de $\mathrm{C}_{O D}$ é menor que aquelas resultantes da oxidação de sítios de back-bond ou formação de unidades dihidrogenadas e este é um defeito que pode ser acomodado em uma supercélula (2x2). Corroboram para esta conclusão os valores de energia de ligação listados na tabela 6.6 e, adicionalmente, a listagem de comparações entre os parâmetros estruturais obtidos para simulações utilizando supercélulas (2x2) e (4x6) (tabela 6.8). A diferença de energia é de apenas $0,02 \mathrm{eV}$. Novamente, temos ganho de energia pela dissociação de $\mathrm{H}_{2}$ (tabela 6.8).

As "assinaturas" destes defeitos nas imagens de STM para ambos os regimes de voltagem (negativa e positiva) são marcadas por retângulos azuis na figura 6.14. Detectamos aqui, assim como nos outros defeitos simulados, uma contribuição pequena do O para as imagens de corrente de tunelamento. Para voltagens de varredura negativa, o padrão listrado, característico da superfície monohidrogenada (figura 6.1), é pouco alterado sobre as unidades $\mathrm{H}-\mathrm{Si}_{1}-\mathrm{O}-\mathrm{Si}_{2}-\mathrm{H}$. Traçamos linhas vermelhas sobre os pontos brilhantes ao redor do defeito, para evidenciar o deslocamento do sinal de tunelamento sobre os grupos $\mathrm{H}-\mathrm{Si}_{1}$ e $\mathrm{Si}_{2}-\mathrm{H}$. Já comentamos na seção 6.2 .2 sobre resultados experimentais obtidos por Trenhaile e colaboradores [131]. Foi identificado sinal de STM com o perfil descrito para o defeito $\mathrm{C}_{O D}$ em experimentos nos quais promoveu-se a oxidação molhada da superfície $\operatorname{Si}(100)(2 \times 1)$ em regime de baixos fluxos e posteriormente a saturação das "dangling bonds" com Cl. Estes defeitos foram designados por split dimer e, como consequência da baixa intensidade de sinal de tunelamento, os dados experimentais não mostram a presença do $\mathrm{O}$, mas as imagens têm as características da região delimitada pelas linhas em vermelho na figura 6.14. Quanto ao defeito $\mathrm{C}_{O D+H 2}$, a imagem dos estados ocupados pode ser descrita como uma soma das caracteríticas devido a inserção de O entre as ligações $\mathrm{Si}_{1}-\mathrm{Si}_{2}$ e o sinal vindo das 2 unidades $\mathrm{SiH}_{2}$, marcadas por sinal brilhante com 


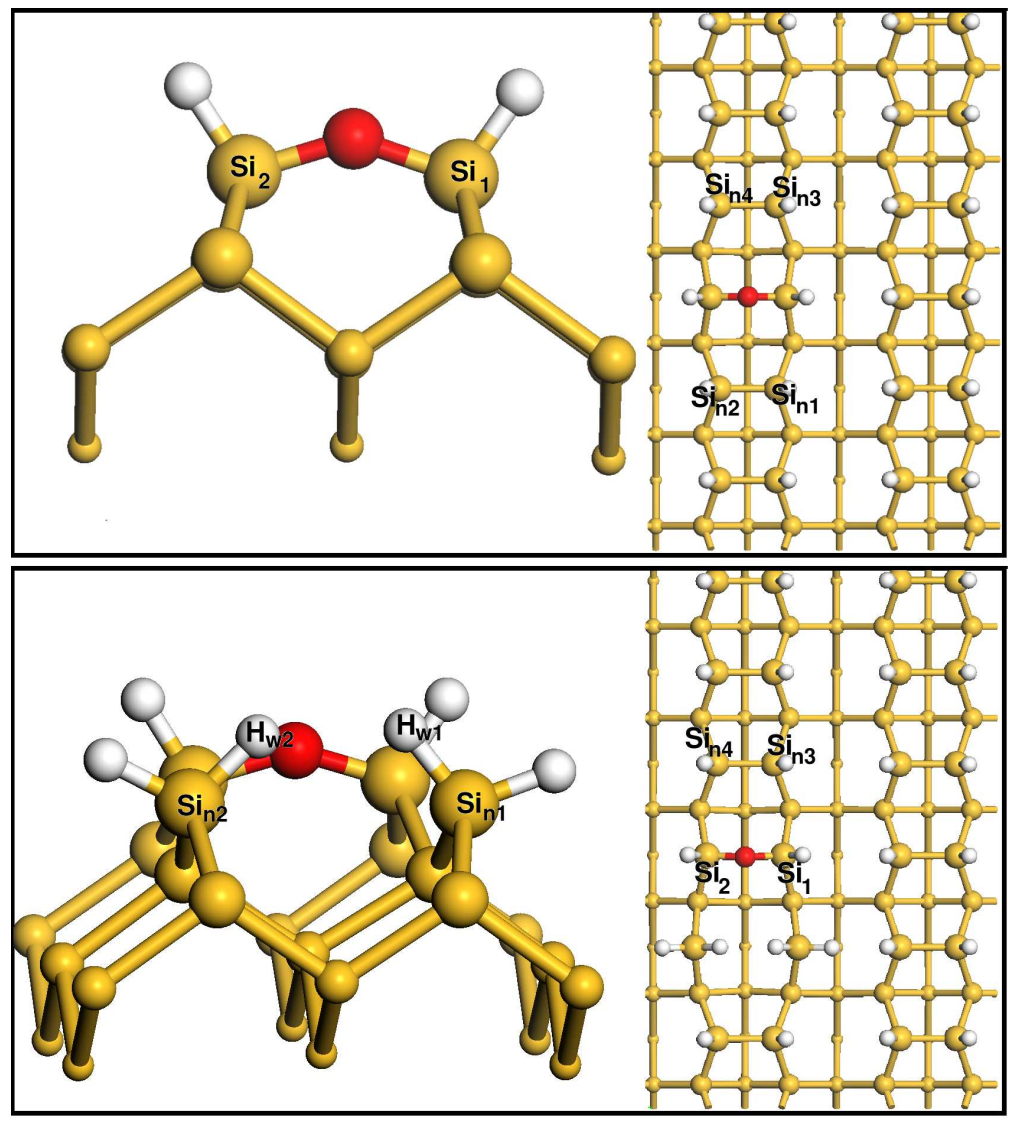

Figura 6.13: Visão lateral e de topo da configuração otimizada para os defeitos denominados de $\mathrm{C}_{O D}$ e $\mathrm{C}_{O D+H 2}$, na superfície $\mathrm{Si}(100)(2 \mathrm{x} 1): \mathrm{H}$. A estrutura $\mathrm{C}_{O D}$ é aquela mostrada na figura 5.6, mas sem a molécula de $\mathrm{H}_{2}$, que foi removida para os cálculos das imagens de STM. Os átomos de H são representados por esferas brancas, o átomo de $\mathrm{O}$ em vermelho e os átomos de Si em amarelo. O tamanho das esferas amarelas está relacionado com a posição dos átomos de Si na fatia usada em nossas simulações.

formato elíptico alongado estendendo sobre a região vale da superfície.

Passando às imagens dos estados desocupados, para o defeito $\mathrm{C}_{O D}$ o sinal de STM sobre o grupo oxidado é o mais intenso da superfície e apresenta forma tipo losângulo, envolto em uma região apagada e de simetria quadrada (quadrado azul na figura 6.14), diferenças que podem ser prontamente comparadas com as regiões inafetadas (delimitada em vermelho). Para a estrutura $\mathrm{C}_{O D+H 2}$, este sinal está 
acoplado ao sinal de STM das unidades dihidrogenadas adjacentes, e a região escura circundando o defeito tem extensão ainda aumentada.

Tabela 6.8: Parâmetros estruturais calculados para a configurações quimissorvidas $\mathrm{C}_{O D} @(4 \mathrm{x} 6), \mathrm{C}_{O D} @(2 \mathrm{x} 2)$ (tabela 5.9), $\mathrm{C}_{O D+H 2} @(4 \mathrm{x} 6), \mathrm{C}_{O D+H 2} @(2 \mathrm{x} 2) \mathrm{e}$ $\mathrm{C}_{O D+B B} @(4 \mathrm{x} 6)$. Os símbolos utilizados na tabela estão definidos nas figuras 5.16, 6.13 e 6.15. Utilizamos o símbolo $(O)$ para nos referirmos a um átomo de oxigênio inserido em um sítio de back-bond. Distâncias de ligação são dadas em Å e ângulos em graus $\left(^{\circ}\right)$.

\begin{tabular}{|c|c|c|c|c|c|}
\hline & $\begin{array}{l}\mathrm{C}_{O D} \\
(4 \times 6)\end{array}$ & $\begin{array}{l}\mathrm{C}_{O D} \\
(2 \times 2)\end{array}$ & $\begin{array}{c}\mathrm{C}_{O D+H 2} \\
(4 \times 6)\end{array}$ & $\begin{array}{c}\mathrm{C}_{O D+H 2} \\
(2 \mathrm{x} 2)\end{array}$ & $\begin{array}{c}\mathrm{C}_{O D+B B} \\
(4 \mathrm{x} 6)\end{array}$ \\
\hline \multicolumn{6}{|l|}{ Dist. $(\AA)$} \\
\hline $\mathrm{Si}_{1}-\mathrm{Si}_{2}$ & 3,18 & 3,17 & 3,20 & 3,20 & 3,22 \\
\hline $\mathrm{Si}_{n 1}-\mathrm{Si}_{n 2}$ & 2,41 & 2,41 & 4,35 & 3,89 & 2,41 \\
\hline $\mathrm{Si}_{n 3}-\mathrm{Si}_{n 4}$ & 2,42 & 2,41 & 2,41 & - & 2,41 \\
\hline $\mathrm{O}-\mathrm{Si}_{1}$ & 1,67 & 1,67 & 1,67 & 1,67 & 1,65 \\
\hline $\mathrm{O}-\mathrm{Si}_{2}$ & 1,67 & 1,67 & 1,67 & 1,67 & 1,67 \\
\hline$(\mathrm{O})-\mathrm{Si}_{2 n d 1}$ & - & - & - & - & 1,67 \\
\hline$(\mathrm{O})-\mathrm{Si}_{1}$ & - & - & - & - & 1,65 \\
\hline $\mathrm{H}-\mathrm{H}$ & 3,41 & 3,38 & 3,41 & - & 3,41 \\
\hline $\mathrm{H}-\mathrm{H}_{O D}$ & 4,86 & 4,88 & 4,81 & 4,83 & 4,71 \\
\hline$\left.\Delta y_{(S i 1-S i 2}\right)$ & - & - & - & - & 0,38 \\
\hline$\Delta y_{(H-H)}$ & - & - & - & - & 0,78 \\
\hline \multicolumn{6}{|l|}{ Âng. $\left(^{\circ}\right)$} \\
\hline $\mathrm{Si}_{1}-\mathrm{O}-\mathrm{Si}_{2}$ & 144,1 & 143,5 & 146,8 & 147,3 & 151,7 \\
\hline $\mathrm{Si}_{1}-(\mathrm{O})-\mathrm{Si}_{2 n d 1}$ & - & - & 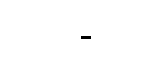 & - & 132,6 \\
\hline $\mathrm{H}_{w 1}-\mathrm{Si}_{n 1}-\mathrm{H}$ & - & - & 108,5 & 105,3 & - \\
\hline $\mathrm{H}_{w 2}-\mathrm{Si}_{n 2}-\mathrm{H}$ & - & - & 108,3 & 105,7 & - \\
\hline
\end{tabular}



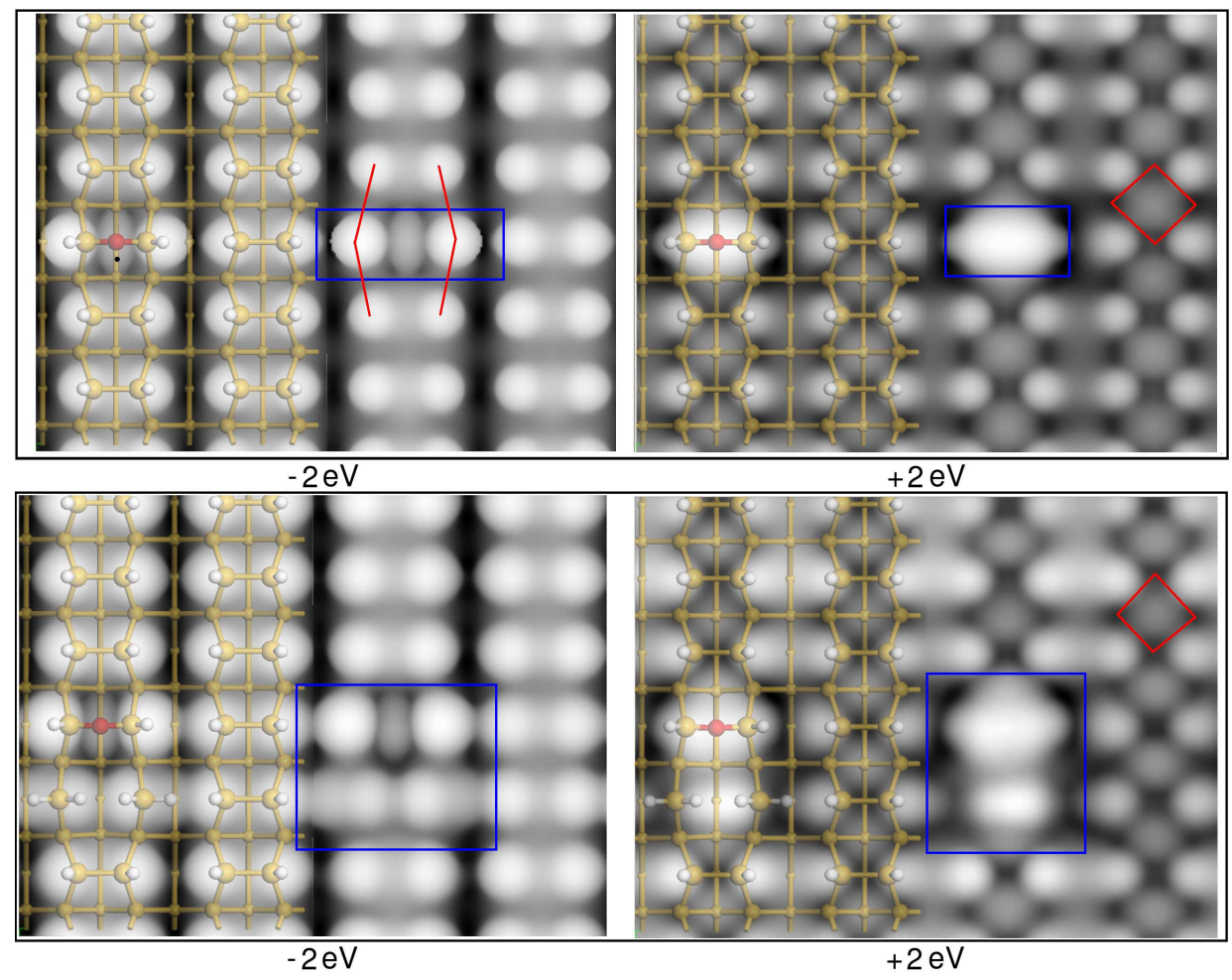

Figura 6.14: Simulação de mapa de STM em modo de corrente constante para os defeitos $\mathrm{C}_{O D}$ e $\mathrm{C}_{O D+H 2}$, na superfície $\mathrm{Si}(100)(2 \mathrm{x} 1): \mathrm{H}$. A estrutura $\mathrm{C}_{O D}$ é aquela mostrada na figura 5.6, mas sem a molécula de $\mathrm{H}_{2}$, que foi removida para os cálculos das imagens de STM. Os valores de voltagens de varredura são incluídos na respectiva imagem. Para voltagens negativas (à esquerda) temos as imagens dos estados ocupados, para voltagens positivas (à direita) dos estados desocupados.

Investigações sobre processos de oxidação molhada em superfícies $\operatorname{Si}(100)(2 \times 1)$ (seção 4.1) e $\operatorname{Si}(100)(2 \times 1): H$ (5.1), empregando espectroscopia de infravermelho, frequentemente relatam picos vibracionais situados em $803-805$ e $2162 \mathrm{~cm}^{-1}$ (tabela 5.1). Cálculos de primeiros princípios [118-121, 127, 128, 130, 135, 143], baseados na aproximação de Hartree-Fock, atribuem estes modos vibracionais à estruturas oxidadas tipo $\mathrm{H}-\mathrm{Si}(\mathrm{O})-\mathrm{O}-\mathrm{Si}-\mathrm{H}$, para qual a geometria otimizada está na figura 6.15 e alguns parâmetros estruturais relevantes são listados na tabela 6.8.

Não estudamos as propriedades cinéticas para múltiplas inserções de $O$, mas 


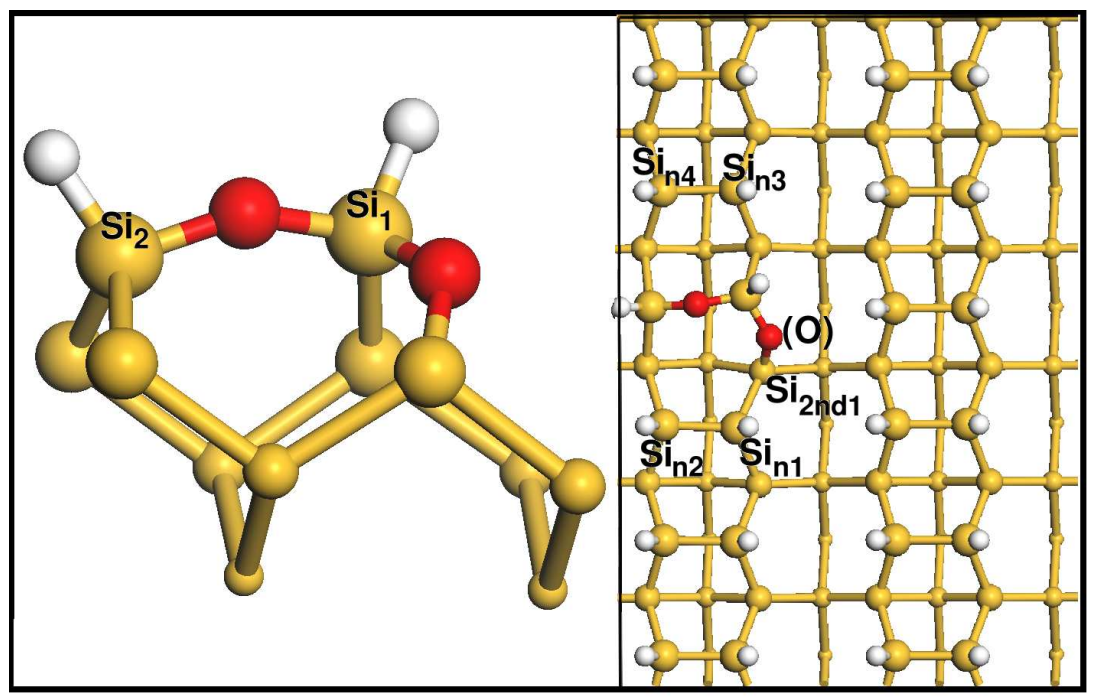

Figura 6.15: Visão lateral e de topo da configuração otimizada para o defeito H-Si(O)-O-Si-H, formado por inserção de 2 átomos de oxigênio na superfície $\operatorname{Si}(100)(2 \mathrm{x} 1): H$. Na notação utilizada neste trabalho este defeito é formado pela junção de $\mathrm{C}_{O D}$ e $\mathrm{C}_{B B+H 2}$. Os átomos de $\mathrm{H}$ são representados por esferas brancas, o átomo de $\mathrm{O}$ em vermelho e os átomos de $\mathrm{Si}$ em amarelo. O tamanho das esferas amarelas está relacionado com a posição dos átomos de Si na fatia usada em nossas simulações.

simulamos os mapas de STM para esta estrutura, a fim de identificar as diferenças do perfil de corrente de tunelamento quando os defeitos $\mathrm{C}_{B B+H 2}$ e $\mathrm{C}_{O D}$ estão associados à mesma região da amostra. O resultado para a simulação pode ser visto na figura 6.16 e rotulamos este defeito por $\mathrm{C}_{O D+B B}$. O que vemos da comparação entre as figuras 6.12, 6.14 e 6.16 é a dificuldade de distinção entre as duas estruturas por STM, o que deriva da pouca visibilidade do átomo de oxigênio on-dimer.

\subsubsection{O $/ \mathrm{Si}(100) \mathrm{c}(4 \times 2)$ e $\mathrm{O} / \mathrm{Si}(100)(2 \times 1)$}

Nesta última seção, voltamos a analisar defeitos nas superfícies não passivadas, $\operatorname{Si}(100) c(4 \times 2)$ e $\operatorname{Si}(100)(2 \times 1)$, mas na ausência de átomos de hidrogênio. Os sítios de oxidação são aqueles já discutidos anteriormente, na seção 6.2.2: o dímero e a back- 


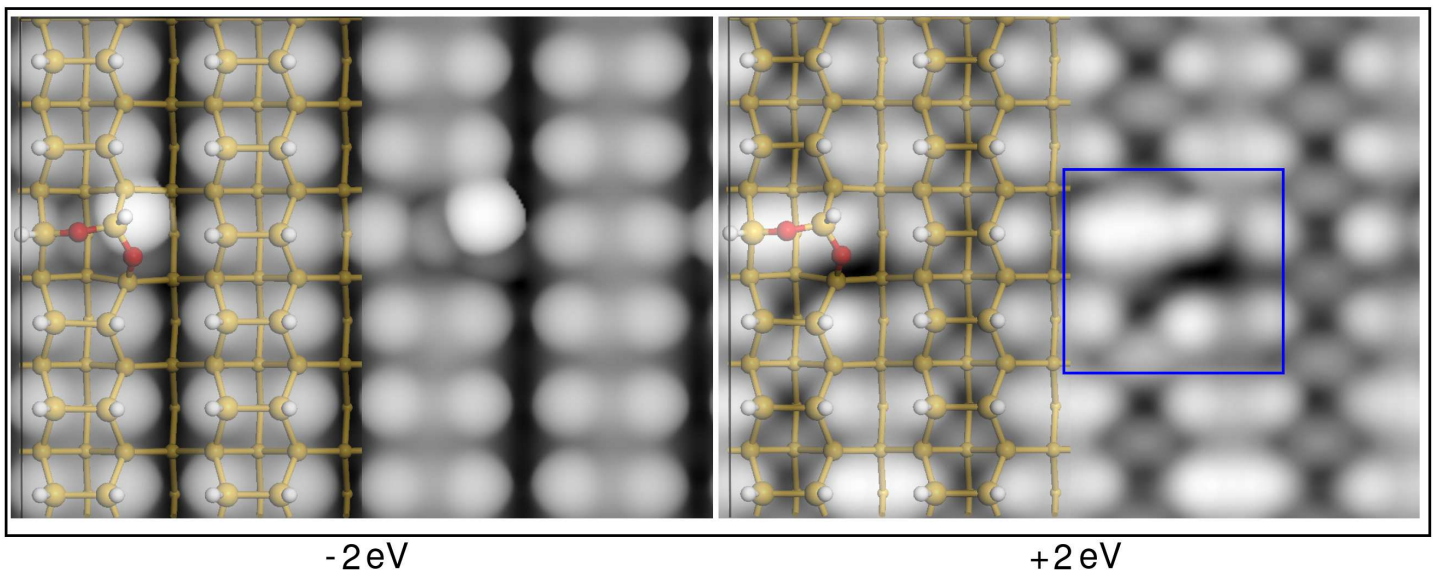

Figura 6.16: Simulação de mapa de STM em modo de corrente constante para o defeito $\mathrm{H}-\mathrm{Si}(\mathrm{O})-\mathrm{O}-\mathrm{Si}-\mathrm{H}$, formado por inserção de 2 átomos de oxigênio na superfície $\operatorname{Si}(100)(2 \mathrm{x} 1): H$. Na notação utilizada neste trabalho este defeito é formado pela junção de $\mathrm{C}_{O D}$ e $\mathrm{C}_{B B+H 2}$ e o rotulamos por $\mathrm{C}_{O D+B B}$. Os valores de voltagens de varredura são incluídos na respectiva imagem. Para voltagens negativas (à esquerda) temos as imagens dos estados ocupados, para voltagens positivas (à direita) dos estados desocupados.

bond, agora para defeitos devido exclusivamente à quimissorção de um ou dois átomos de oxigênio entre as ligações Si-Si. Não realizamos nenhum estudo relacionado à cinética de processos de quimissorção e nos limitaremos a discutir a geometria, estabilidade energética e mapas de STM. Nosso objetivo é obter características que possam ser utilizadas para identificar estruturas oxidadas em experimentos de microscopia de tunelamento.

$\mathrm{Na}$ figura 6.17, apresentamos a estrutura relaxada para os defeitos resultantes da inserção um átomo de oxigênio em um sítio de back-bond: $\mathrm{C}_{O-B B-u p} @_{\mathrm{c}}(4 \mathrm{x} 2)$, $\mathrm{C}_{O-B B-u p} @(2 \mathrm{x} 1), \mathrm{C}_{O-B B-\text { down }} \mathrm{c}_{\mathrm{c}}(4 \mathrm{x} 2)$ e $\mathrm{C}_{O-B B-\text { down }} @(2 \mathrm{x} 1)$. Parâmetros estruturais e energias de ligação com o O são reunidos nas tabelas 6.9 e 6.10, respectivamente. Nossos resultados estão próximos àqueles obtidos em outros cálculos teóricos para estes defeitos referentes a estruturas otimizadas em fatias (2x2) [160] e cálculos de aglomerados moleculares [161]. 


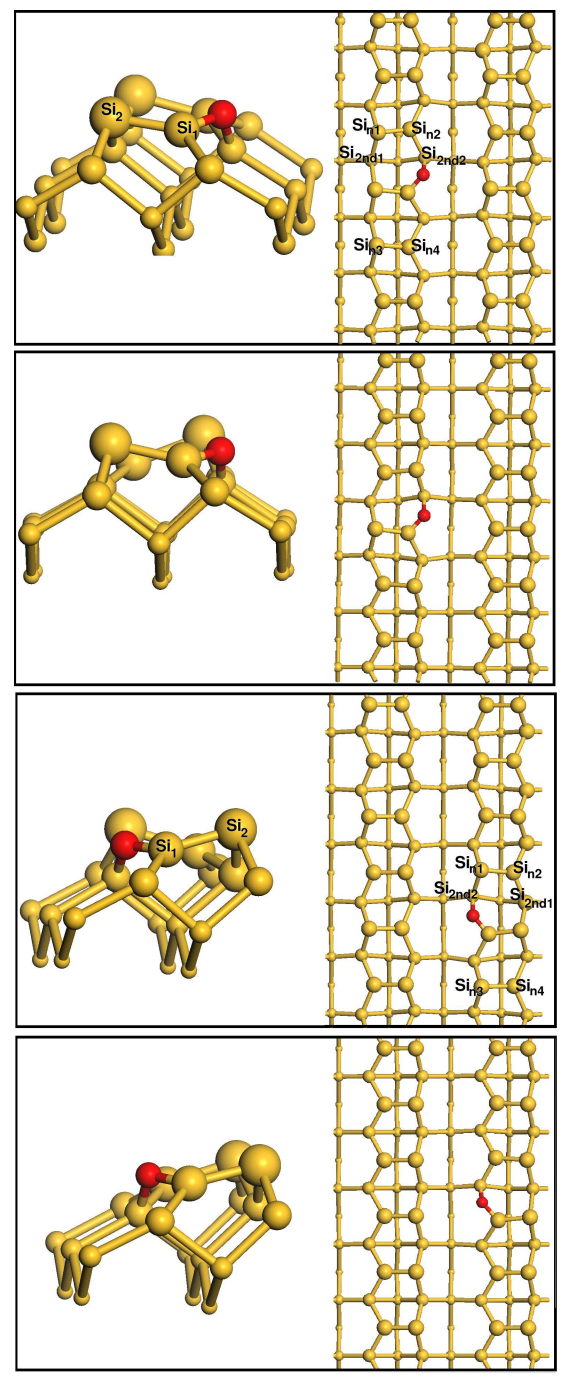

Figura 6.17: Visão lateral e de topo da configuração otimizada para os defeitos gerados pela quimissorção de oxigênio na back-bond das superfícies $\operatorname{Si}(100)$ c $(4 \times 2)$ e $\mathrm{Si}(100)(2 \mathrm{x} 1)$. Denominamos estes defeitos por $\mathrm{C}_{O-B B-u p} @ \mathrm{c}(4 \mathrm{x} 2), \mathrm{C}_{O-B B-u p} @(2 \mathrm{x} 1)$, $\mathrm{C}_{O-B B-\text { down }} @ \mathrm{c}(4 \mathrm{x} 2)$ e $\mathrm{C}_{O-B B-\text { down }} @(2 \mathrm{x} 1)$. Os átomos de $\mathrm{O}$ são representados por esferas vermelhas e os átomos de Si por esferas amarelas. O tamanho das esferas amarelas está relacionado com a posição dos átomos de Si na fatia usada em nossas simulações.

A estabilidade do sistema depende sensivelmente da vizinhança da impureza. A quimissorção de $\mathrm{O}$ que resulta na estrutura $\mathrm{C}_{O-B B-u p} @(2 \mathrm{x} 1)$, altera o padrão de 
posicionamento de um dos átomos do dímero de up-up-up para up-down-up. Conforme mencionamos no capítulo 3, o perfil de dímeros assimétricos com zig-zag alternado tende a baixar a energia do sistema. Entretanto, quando analisamos a geometria otimizada para $\mathrm{C}_{O-B B-u p} @_{\mathrm{c}}(4 \mathrm{x} 2)$, notamos que o arranjo de dímeros torna-se down-down-down, aumentando a energia desta estrutura. Para $\mathrm{C}_{O-B B-d o w n} @_{\mathrm{c}}(4 \mathrm{x} 2)$, o arranjo dos dímeros é dado up-down-up. Apesar da quimissorção de $\mathrm{O}$ não ser proibida em átomos de Si da posição up ou down no dímero, as estruturas oxidadas com geometria final que exibe o padrão de reconstrução zig-zag são energeticamente favorecidas.

Tabela 6.9: Parâmetros estruturais calculados para a configurações quimissorvidas $\mathrm{C}_{O-B B-u p} \mathrm{c}_{\mathrm{c}}(4 \mathrm{x} 2), \mathrm{C}_{O-B B-u p} @(2 \mathrm{x} 1), \mathrm{C}_{O-B B-\text { down }} \mathrm{c}_{\mathrm{c}}(4 \mathrm{x} 2)$ e $\mathrm{C}_{O-B B-\text { down }} @(2 \mathrm{x} 1)$. Os símbolos utilizados na tabela estão definidos nas figuras 6.17. Distâncias de ligação são dadas em $\AA$ e ângulos em graus $\left(^{\circ}\right)$.

\begin{tabular}{|c|c|c|c|c|}
\hline & $\begin{array}{c}\mathrm{C}_{O-B B-u p} \\
@_{c}(4 \times 2)\end{array}$ & $\begin{array}{c}\mathrm{C}_{O-B B-u p} \\
@(2 \times 1)\end{array}$ & $\begin{array}{c}\mathrm{C}_{O-B B-\text { down }} \\
\mathrm{a}_{\mathrm{c}}(4 \mathrm{x} 2)\end{array}$ & $\begin{array}{c}\mathrm{C}_{O-B B-\text { down }} \\
@(2 \mathrm{x} 1)\end{array}$ \\
\hline \multicolumn{5}{|l|}{ Dist. $(\AA)$} \\
\hline $\mathrm{Si}_{1}-\mathrm{Si}_{2}$ & 2,24 & 2,30 & 2,29 & 2,26 \\
\hline $\mathrm{Si}_{n 1}-\mathrm{Si}_{n 2}$ & 2,29 & 2,30 & 2,31 & 2,27 \\
\hline $\mathrm{Si}_{n 3}-\mathrm{Si}_{n 4}$ & 2,30 & 2,31 & 2,33 & 2,28 \\
\hline $\mathrm{O}-\mathrm{Si}_{1}$ & 1,66 & 1,64 & 1,64 & 1,65 \\
\hline $\mathrm{Si}_{2 n d 2}-\mathrm{O}$ & 1,70 & 1,70 & 1,70 & 1,70 \\
\hline \multicolumn{5}{|l|}{ Âng. $\left(^{\circ}\right)$} \\
\hline$\theta\left(\mathrm{Si}_{1}-\mathrm{Si}_{2}\right)$ & 8,4 & 13,0 & 15,9 & 14,2 \\
\hline$\theta\left(\mathrm{Si}_{n 1}-\mathrm{Si}_{n 2}\right)$ & 16,3 & 19,9 & 16,2 & 18,6 \\
\hline$\theta\left(\mathrm{Si}_{n 3}-\mathrm{Si}_{n 4}\right)$ & 16,6 & 21,5 & 18,5 & 20,3 \\
\hline $\mathrm{Si}_{2 n d 2}-\mathrm{O}-\mathrm{Si}_{1}$ & 114,7 & 119,7 & 126,2 & 118,9 \\
\hline
\end{tabular}


Tabela 6.10: Energias de ligação $(\mathrm{eV})$ com o Oxigênio, $\Delta \mathrm{E}_{O}$, e água, $\Delta \mathrm{E}_{H_{2} O}$, para estruturas resultantes dos processos de quimissorção de água ou oxigênio nas superfícies $\operatorname{Si}(100) c(4 \times 2), \operatorname{Si}(100)(2 \times 1)$ e $\operatorname{Si}(100)(2 \times 1): H$. Todos os resultados referem-se à cálculos com uma supercélula $(4 \times 6)$.

\begin{tabular}{lc}
\hline \hline Estrutura & $\Delta \mathrm{E}_{O}(\mathrm{eV})$ \\
\hline $\mathrm{C}_{O-B B-u p} @ \mathrm{c}(4 \mathrm{x} 2)$ & $-10,11$ \\
$\mathrm{C}_{O-B B-u p} @(2 \mathrm{x} 1)$ & $-10,38$ \\
$\mathrm{C}_{O-B B-\text { down }} @ \mathrm{c}(4 \mathrm{x} 2)$ & $-10,31$ \\
$\mathrm{C}_{O-B B-\text { down }} @(2 \mathrm{x} 1)$ & $-10,15$ \\
$\mathrm{C}_{O-O D} @ \mathrm{c}(4 \mathrm{x} 2)$ & $-10,05$ \\
$\mathrm{C}_{O-O D} @(2 \mathrm{x} 1)$ & $-10,18$ \\
$\mathrm{C}_{O-O D+B B} @ \mathrm{c}(4 \mathrm{x} 2)$ & $-20,21$ \\
$\mathrm{C}_{O-O D+B B} @(2 \mathrm{x} 1)$ & $-20,48$ \\
\hline \hline
\end{tabular}

Os efeitos discutidos anteriormente são refletidos nas imagens de STM mostrados na figura 6.18, principalmente nas obtidas para voltagem negativa (região delimitada por retângulos). O defeito provocado pela inserção de O nas imagens dos estados ocupados de qualquer das estruturas é quase imperceptível, em contraste com os resultados mostrados na figura 6.8 para os defeitos back-bond. Para a imagem dos estados desocupados, em todos os casos, nota-se a formação de uma região apagada circundando o O. Novamente, como em qualquer caso anterior de inserção de O na back-bond, o efeito mais visível é o deslocamento diagonal do sinal do dímero afetado (figura 6.18), que também afeta a vizinhança do defeito, permitindo melhor acomodação do grupo Si-(O)-Si na estrutura da superfície. Estas características também foram relatadas por Uchiyama e Tsukada [160], mas não foram observadas por Miyamoto [162]. Conforme já comentamos, devido ao baixo valores de corrente de tunelamento sobre o oxigênio, a presença deste átomo é de detecção muito difícil 
em condições experimentais, em acordo com as sugestõe de Hamers e Wang [86].
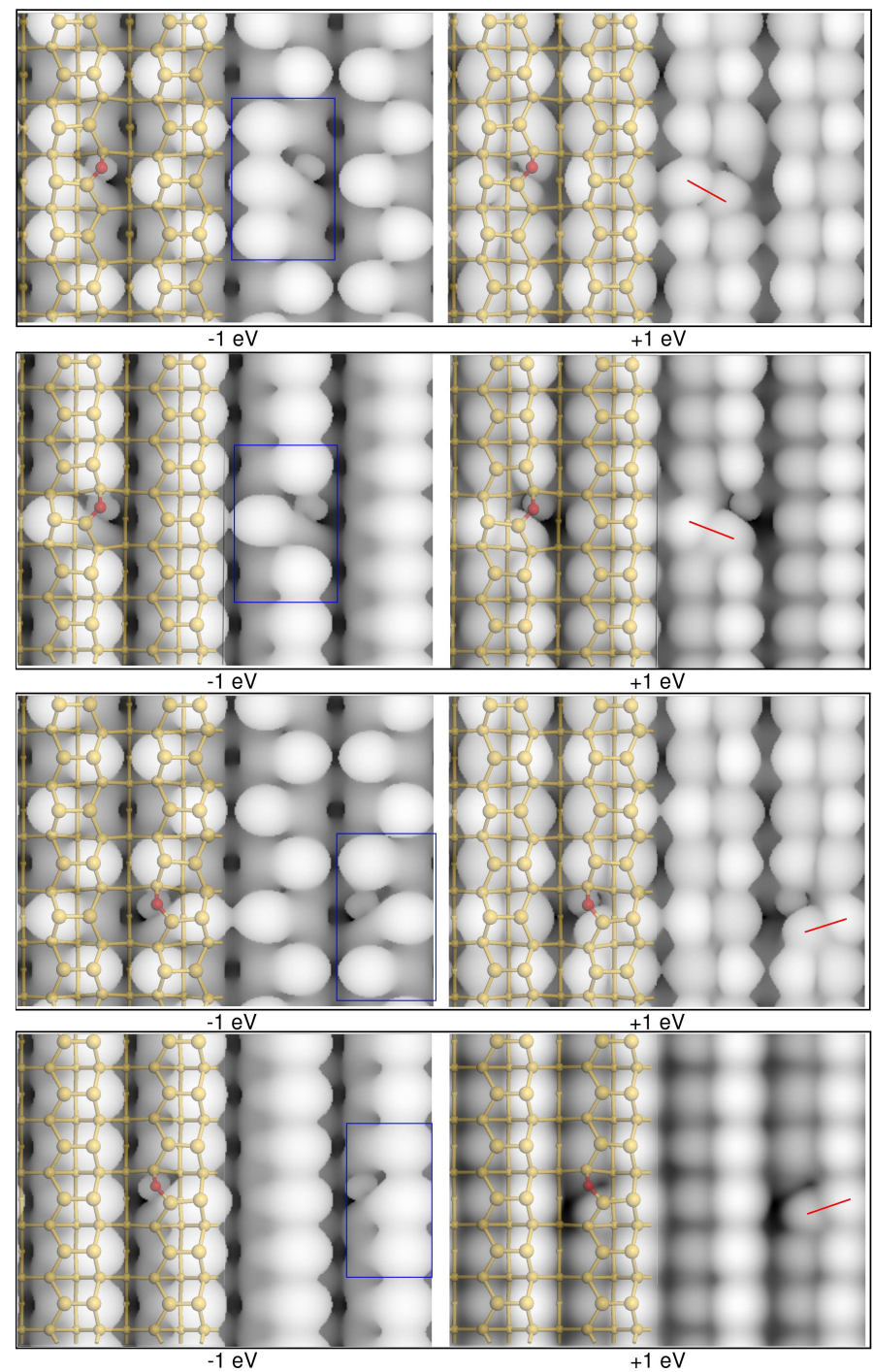

Figura 6.18: Simulação de mapa de STM em modo de corrente constante para os defeitos gerados pela quimissorção de oxigênio na back-bond das superfícies $\operatorname{Si}(100) c(4 \times 2)$ e $\operatorname{Si}(100)(2 \times 1)$.Denominamos estes defeitos por $C_{O-B B-u p} @ c(4 \times 2)$, $\mathrm{C}_{O-B B-u p} @(2 \mathrm{x} 1), \mathrm{C}_{O-B B-\text { down }} @ \mathrm{c}(4 \mathrm{x} 2)$ e $\mathrm{C}_{O-B B-d o w n} @(2 \mathrm{x} 1)$. Os valores de voltagens de varredura são incluídos na respectiva imagem. Para voltagens negativas (à esquerda) temos as imagens dos estados ocupados, para voltagens positivas (à direita) dos estados desocupados.

As estruturas otimizadas para os defeitos $\mathrm{C}_{O-O D} @ \mathrm{c}(4 \mathrm{x} 2)$ e $\mathrm{C}_{O-O D} @(2 \mathrm{x} 1)$, resul- 
tantes da oxidação do dímero, são mostradas na figura 6.19.A estrutura $\mathrm{C}_{O-O D} @(2 \mathrm{x} 1)$ tem energia de ligação $0,13 \mathrm{eV}$ menor que $\mathrm{C}_{O-O D} @(2 \mathrm{x} 1)$. Esta diferença poderia ser ainda maior, uma vez que a reação com o O promove a inversão do padrão up-up-up da fileira de dímero na superfície $(2 \times 1)$. Repetimos os cálculos de otimização para a $\mathrm{C}_{O-O D} @(2 \mathrm{x} 1)$, nos quais iniciamos com o átomo $\mathrm{Si}_{1}$ na posição down. Em todos os casos, a configuração final foi aquela mostrada na figura 6.19. Para a c(4x2), o padrão down-up-down foi preservado. Ainda sobre os dados de energia de ligação, notamos que a oxidação molhada do dímero (tabela 6.2) é favorecida em relação aos sítios de back-bond, e para a inserção de $\mathrm{O}$ isolado o resultado se inverte (tabela 6.10). As estruturas $\mathrm{C}_{O-B B-u p} @(2 \mathrm{x} 1)$ e $\mathrm{C}_{O-B B-\text { down }} @ \mathrm{c}(4 \mathrm{x} 2)$ são favorecidas $(\Delta \mathrm{E} \approx 0,2-0,25$ eV) quando comparadas a $\mathrm{C}_{O-O D} @(2 \mathrm{x} 1)$ e $\mathrm{C}_{O-O D} @ \mathrm{c}(4 \mathrm{x} 2)$, nesta ordem. De fato, a preferência energética do $\mathrm{O}$ por sítios de back-bond tem sido extensivamente relatada em trabalhos teóricos [123,160,161] e experimentais [86,123,149,163]. Nossos resultados estão em acordo com os valores de $\Delta \mathrm{E}$ obtidos por Hemeryck e colaboradores [163], e diferem em aproximadamente $0,1 \mathrm{eV}$ dos dados da referência [160]. A oxidação do dímero, conforme os dados listados na tabela 6.11, mantém a estrutura de dímero assimétrico. Análises da distribuição de cargas de Lowdin evidenciam que, neste caso, os átomos denominados $\mathrm{Si}_{1}$ e $\mathrm{Si}_{2}$ encontram-se positivamente carregados, mas a carga positiva sobre $\mathrm{Si}_{2}$ é muito maior que a observada sobre $\mathrm{Si}_{1}$. Este efeito não ocorre nas estruturas $\mathrm{C}_{O-B B-u p} @(2 \mathrm{x} 1)$ e $\mathrm{C}_{O-B B-\text { down }} @ \mathrm{c}(4 \mathrm{x} 2)$, nas quais o átomo de Si da posição up encontra-se negativamente carregado.

As imagens de STM para os defeitos $\mathrm{C}_{O-O D} @ \mathrm{c}(4 \mathrm{x} 2)$ e $\mathrm{C}_{O-O D} @(2 \mathrm{x} 1)$ estão na figura 6.20. O átomo $\mathrm{Si}_{1}$ é o mais alto da superfície e também tem a maior contribuição para a densidade de estados, no topo da banda de valência e no fundo da banda de condução do sistema, de forma que está associado ao sinal de tunelamento mais intenso, seja nas imagens dos estados ocupados ou desocupados. Para o tunelamento em regime de voltagens negativas, a presença do O é melhor visualizada para a estrutura $\mathrm{C}_{O-O D} @(2 \mathrm{x} 1)$ (região delimitada por um quadrado azul na figura 6.20). Para os mapas dos estados desocupados, os pontos brilhantes localiza- 


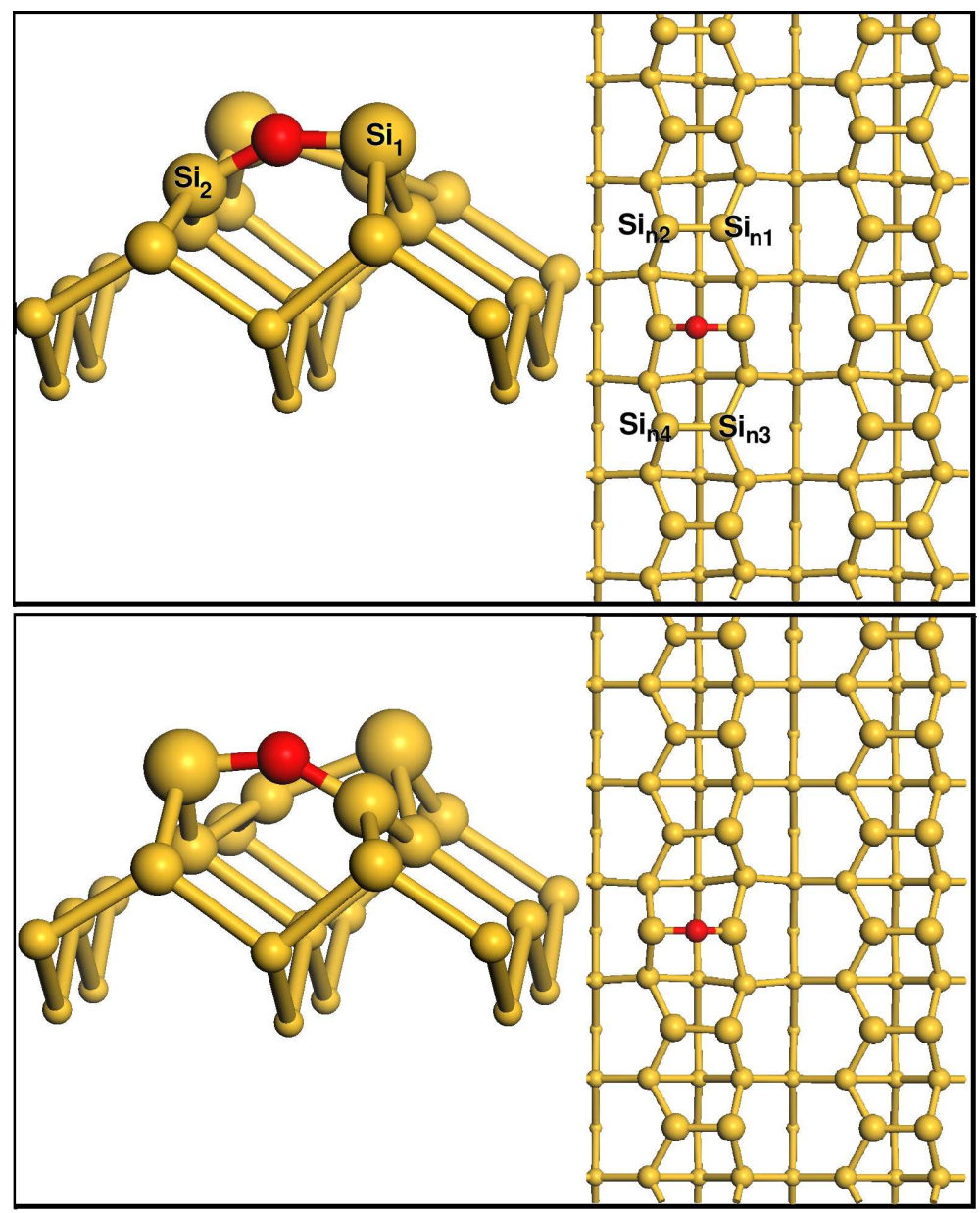

Figura 6.19: Visão lateral e de topo da configuração otimizada para os defeitos gerados pela quimissorção de oxigênio no dímero das superfícies $\operatorname{Si}(100) c(4 \times 2)$ e $\mathrm{Si}(100)(2 \mathrm{x} 1)$. Denominamos estes defeitos por $\mathrm{C}_{O-O D} @ \mathrm{c}(4 \mathrm{x} 2)$ e $\mathrm{C}_{O-O D} @(2 \mathrm{x} 1)$. Os átomos de O são representados por esferas vermelhas e os átomos de Si por esferas amarelas. O tamanho das esferas amarelas está relacionado com a posição dos átomos de Si na fatia usada em nossas simulações.

dos sobre o dímero oxidadado encontram-se mais afastados (linhas azuis na figura 6.20). O perfil de tunelamento das regiões oxidadas assemelha ao relatado na referência [160]. O perfil de tunelamento das estruturas $\mathrm{C}_{O-O D} @ \mathrm{c}(4 \mathrm{x} 2)$ e $\mathrm{C}_{O-O D} @(2 \mathrm{x} 1)$ é muito diferente daquele obtido discutido para a oxidação molhada $\mathrm{C}_{C-O D} @ \mathrm{c}(4 \mathrm{x} 2)$ e $\mathrm{C}_{C-O D} @(2 \mathrm{x} 1)$ (figura 6.6). 
Para finalizar esta seção, analisaremos as mudanças resultantes da combinação dos defeitos produzidos pela inserção de $\mathrm{O}$ no dímero e na back-bond: $\mathrm{C}_{O-O D+B B} \mathrm{c}_{\mathrm{c}}(4 \mathrm{x} 2)$ e $C_{O-O D+B B} @(2 \times 1)$. As estruturas otimizadas são mostradas na figura 6.21. Estes defeitos são apontados como o produto mais estável da decomposição de $\mathrm{O}_{2}$ sobre a superfície limpa [123]. Valores de parâmetros estruturais relevantes foram lista-

Tabela 6.11: Parâmetros estruturais calculados para a configurações quimissorvidas $\mathrm{C}_{O-O D} @ \mathrm{c}(4 \mathrm{x} 2), \mathrm{C}_{O-O D} @(2 \mathrm{x} 1), \mathrm{C}_{O-O D+B B} @ \mathrm{c}(4 \mathrm{x} 2) \mathrm{e}_{O-O D+B B} @(2 \mathrm{x} 1)$. Utilizamos o símbolo $(O)$ para nos referirmos a um átomo de oxigênio inserido em um sítio de back-bond. Os símbolos utilizados na tabela estão definidos nas figuras 6.19 e 6.21. Distâncias de ligação são dadas em $\AA$ e ângulos em graus $\left(^{\circ}\right)$.

\begin{tabular}{lcccc}
\hline \hline & $\mathrm{C}_{O-O D}$ & $\mathrm{C}_{O-O D}$ & $\mathrm{C}_{O-O D+B B}$ & $\mathrm{C}_{O-O D+B B}$ \\
& $\mathrm{ac}_{\mathrm{c}}(4 \mathrm{x} 2)$ & $@(2 \mathrm{x} 1)$ & $\mathrm{a}_{\mathrm{c}}(4 \mathrm{x} 2)$ & $@(2 \mathrm{x} 1)$ \\
\hline Dist. $(\AA)$ & & & & \\
$\mathrm{Si}_{1}-\mathrm{Si}_{2}$ & 3,22 & 3,19 & 3,26 & 3,15 \\
$\mathrm{Si}_{n 1}-\mathrm{Si}_{n 2}$ & 2,32 & 2,31 & 2,32 & 2,31 \\
$\mathrm{Si}_{n 3}-\mathrm{Si}_{n 4}$ & 2,32 & 2,31 & 2,33 & 2,33 \\
$\mathrm{O}-\mathrm{Si}_{1}$ & 1,71 & 1,73 & 1,71 & 1,60 \\
$\mathrm{O}-\mathrm{Si}_{2}$ & 1,62 & 1,62 & 1,62 & 1,75 \\
$(\mathrm{O})-\mathrm{Si}_{1}$ & - & - & 1,68 & 1,61 \\
$\mathrm{Si}_{2 n d 1}-(\mathrm{O})$ & - & - & 1,65 & 1,74 \\
\hline$\left.\hat{\mathrm{Ang}}_{(}{ }^{\circ}\right)$ & & & & \\
$\theta\left(\mathrm{Si}_{1}-\mathrm{Si}_{2}\right)$ & 13,7 & 11,6 & 22,8 & 7,1 \\
$\theta\left(\mathrm{Si}_{n 1}-\mathrm{Si}_{n 2}\right)$ & 17,3 & 89,9 & 18,2 & 19,9 \\
$\theta\left(\mathrm{Si}_{n 3}-\mathrm{Si}_{n 4}\right)$ & 17,0 & 21,3 & 18,9 & 22,3 \\
$\mathrm{Si}_{1}-\mathrm{O}-\mathrm{Si}_{2}$ & 150,8 & 144,9 & 156,2 & 140,2 \\
$\mathrm{Si}_{2 n d 1}-\mathrm{O}-\mathrm{Si}_{1}$ & - & - & 143,3 & 114,8 \\
\hline \hline
\end{tabular}



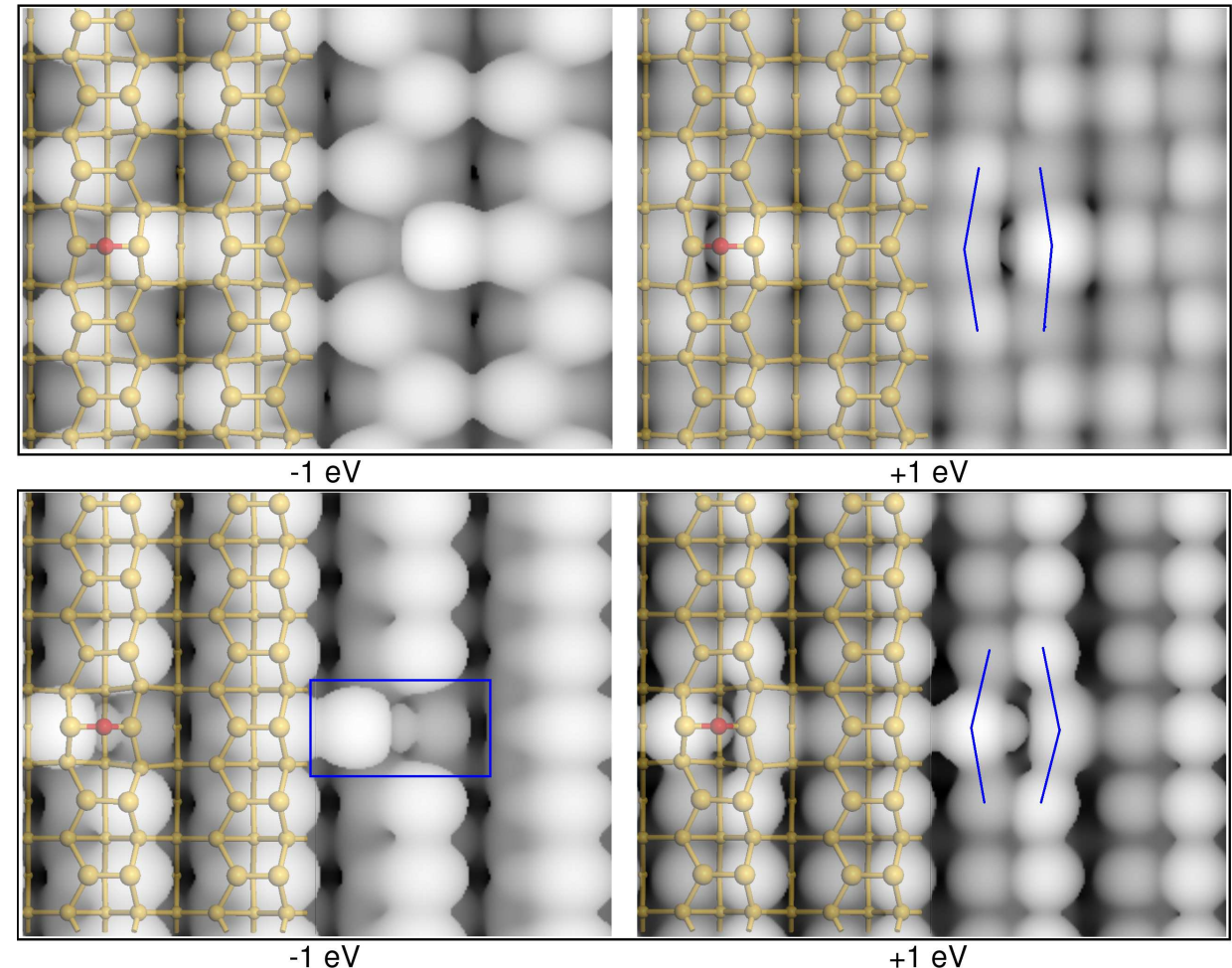

Figura 6.20: Simulação de mapa de STM em modo de corrente constante para os defeitos gerados pela quimissorção de oxigênio no dímero das superfícies $\operatorname{Si}(100) c(4 \times 2)$ e $\operatorname{Si}(100)(2 \times 1)$. Denominamos estes defeitos por $\mathrm{C}_{O-O D} @ \mathrm{c}(4 \mathrm{x} 2)$ e $\mathrm{C}_{O-O D} @(2 \mathrm{x} 1)$. Os valores de voltagens de varredura são incluídos na respectiva imagem. Para voltagens negativas (à esquerda) temos as imagens dos estados ocupados, para voltagens positivas (à direita) dos estados desocupados.

dos na tabela 6.11. Para a estrutura $\mathrm{C}_{O-O D+B B} @_{\mathrm{c}}(4 \mathrm{x} 2)$, o átomo de oxigênio do sítio da back-bond está conectado a um átomo da posição up, enquanto na estrutura $\mathrm{C}_{O-O D+B B} @(2 \mathrm{x} 1)$, esta ligação foi estabelecida com um átomo da posição down.

As imagens de STM para as situações de dupla oxidação estão na figura 6.22. A identificação da região oxidada em regime de voltagem negativa é muito difícil. Por sua vez, as imagens dos estados desocupados mostram algumas características interessantes, que estão delimitadas pelas linhas azuis e é similar ao observado para os defeitos $\mathrm{C}_{O-O D}$. Para a estrutura $\mathrm{C}_{O-O D+B B} @(2 \mathrm{x} 1)$, identificamos ligeiro deslo- 


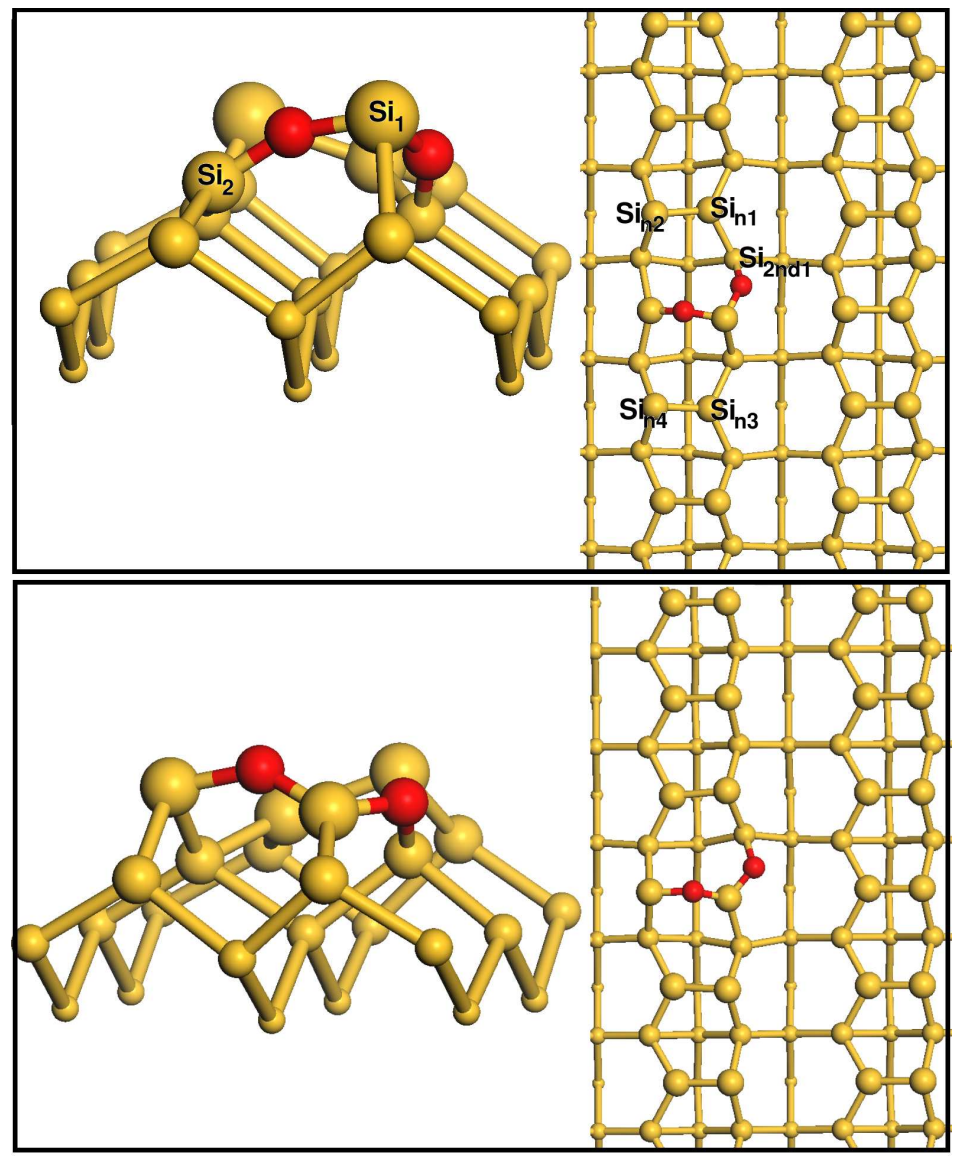

Figura 6.21: Visão lateral e de topo da configuração otimizada para os defeitos gerados pela quimissorção de átomos de oxigênio no dímero e na back-bond das superfícies $\operatorname{Si}(100) c(4 \times 2)$ e $\operatorname{Si}(100)(2 \times 1)$. Denominamos estes defeitos por $C_{O-O D+B B} @ c(4 \times 2)$ e $\mathrm{C}_{O-O D+B B} @(2 \mathrm{x} 1)$. Os átomos de $\mathrm{O}$ são representados por esferas vermelhas e os átomos de Si por esferas amarelas. O tamanho das esferas amarelas está relacionado com a posição dos átomos de Si na fatia usada em nossas simulações.

camento dos pontos brilhantes sobre o dímero $\mathrm{Si}_{n 3}-\mathrm{Si}_{n 4}$ (a linha verde serve de guia para os olhos). Este efeito já havia sido observado nas estruturas $\mathrm{C}_{O-B B} @(2 \mathrm{x} 1)$, porém aqui seu efeito é pequeno. Este deslocamento também foi relatado por Hemeryck e colaboradores [123] que observaram o surgimento de uma região brilhante no dímero adjacente ao sítio oxidado. A interpretação dada na referência foi que o grupo oxidado foi apagado enquanto o dímero contíguo tornou-se mais bril- 
hante. Baseado em nossos resultados, o grupo oxidado permanece brilhante, porém o deslocamento do sinal de STM faz parecer que o vizinho está mais brilhante.

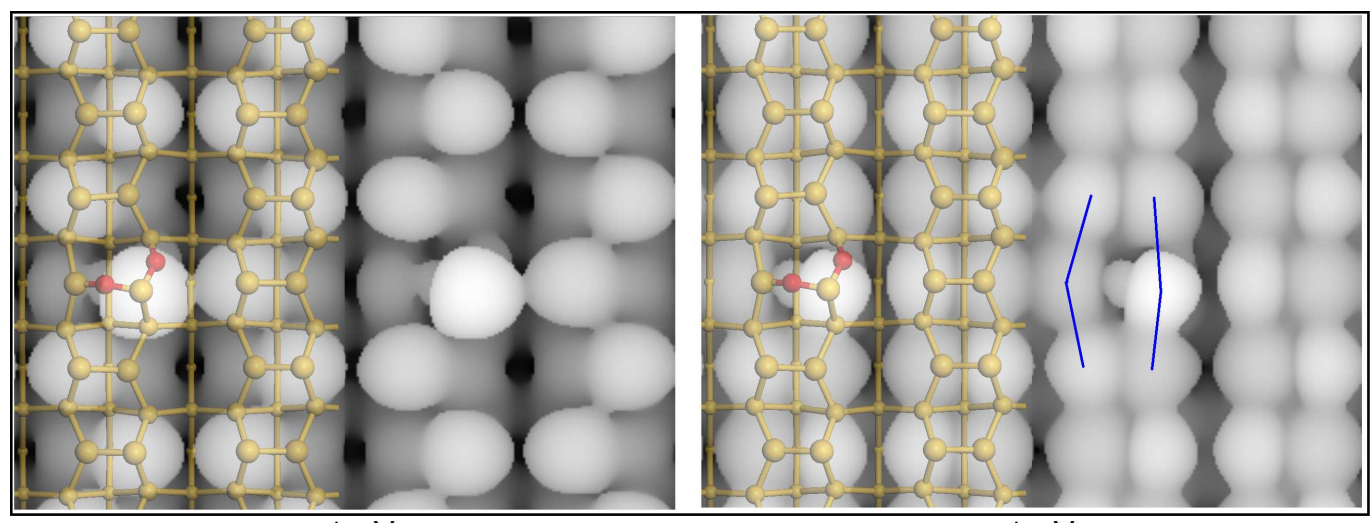

$-1 \mathrm{eV}$

$+1 \mathrm{eV}$

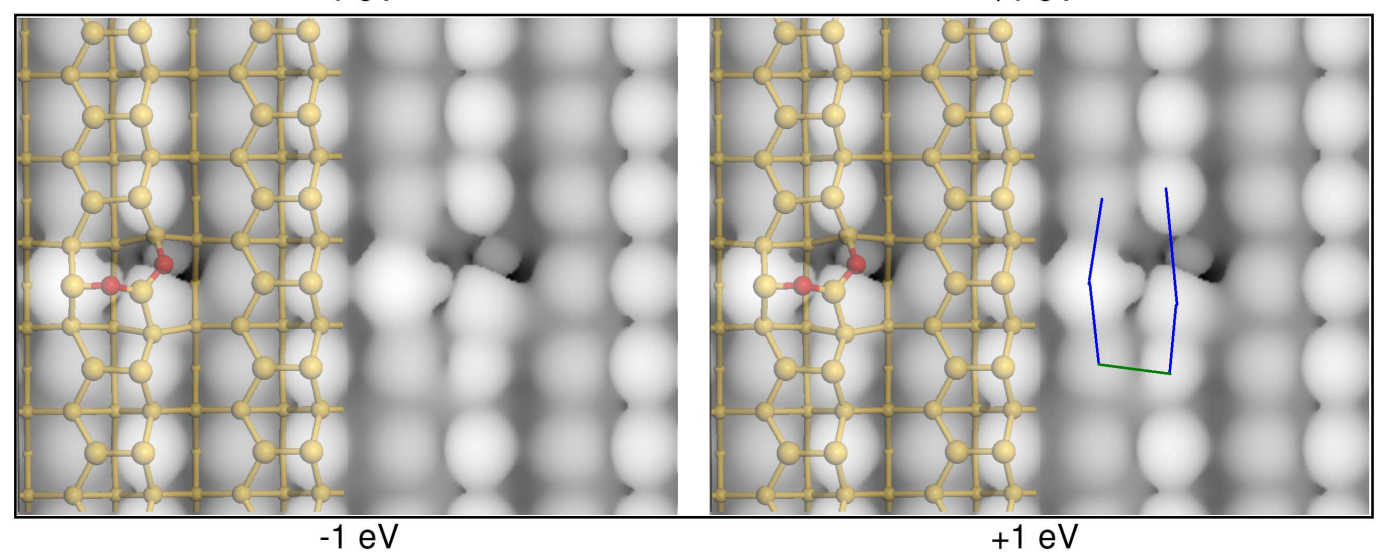

Figura 6.22: Simulação de mapa de STM em modo de corrente constante para os defeitos gerados pela quimissorção de átomos de oxigênio no dímero e na backbond das superfícies $\operatorname{Si}(100)$ c $(4 \times 2)$ e $\operatorname{Si}(100)(2 \times 1)$. Denominamos estes defeitos por $\mathrm{C}_{O-O D+B B} @ \mathrm{c}(4 \mathrm{x} 2)$ e $\mathrm{C}_{O-O D+B B} @(2 \mathrm{x} 1)$. Os valores de voltagens de varredura são incluídos na respectiva imagem. Para voltagens negativas (à esquerda) temos as imagens dos estados ocupados, para voltagens positivas (à direita) dos estados desocupados. 


\subsection{Conclusões Parciais}

Para as superfícies $\operatorname{Si}(100) c(4 \times 2)$ e $\operatorname{Si}(100)(2 \times 1)$, nossas simulações evidenciam que a quimissorção de $\mathrm{O}$, via processos de oxidação molhada, produz alterações locais no perfil de corrente de tunelamento que podem auxiliar na detecção experimental dos defeitos $\mathrm{C}_{C-S i l}, \mathrm{C}_{C-O D}$ e $\mathrm{C}_{C-B B}$. A ligação com $\mathrm{O}$ e $\mathrm{H}$ conduz ao surgimento de áreas relativamente mais apagadas que o sinal vindo dos dímeros intactos. Em todos os casos, o efeito é mais pronunciado nas imagens de estados desocupados. Apesar da aparência apagada, comum às estruturas $\mathrm{C}_{C-S i l}, \mathrm{C}_{C-O D}$ e $\mathrm{C}_{C-B B}$, os defeitos produzidos na reação com água, diferem daqueles denominados missing dimer, porque as unidades H-Si são sempre visíveis. Demonstramos ainda que os sítios de oxidação denominados $\mathrm{C}_{C-S i l}$ e $\mathrm{C}_{C-O D}$ são mais evidentes em mapas obtidos em regimes de voltagens negativas, contrastando com a estrutura $\mathrm{C}_{C-B B}$, cuja presença nos parece mais nítida nas imagens dos estados desocupados. Salientamos que os defeitos produzidos por oxidação molhada podem ser prontamente diferenciados daqueles nos quais somente $\mathrm{O}$ atômico ou molecular foram responsáveis pela oxidação.

Quanto aos defeitos provenientes da dissociação da molécula de água sobre as superfícies passivadas, nossos resultados sugerem que o átomo de oxigênio está sempre circundado por regiões apagadas. Mas, mostramos que o senso comum de que sua deteção em é sempre indireta, não se sustenta. Para as imagens dos estados ocupados, a presença do O está sempre associada a baixos valores de corrente de tunelamento (excessão ao defeito $\mathrm{C}_{S i l}$ ) e, em razão disto, são indiretamente detectados. Todavia, mostramos que, nas imagens dos estados desocupados dos defeitos $\mathrm{C}_{S i l}, \mathrm{C}_{O D}, \mathrm{C}_{O D+H 2}$ e $\mathrm{C}_{O D+B B}$, o sítio oxidado é a região com maiores valores de corrente na amostra. Este efeito é resultado natural da localização em sítios de superfície, possibilitando que a pequena contribuição do $\mathrm{O}$ para os estados eletrônicos nas vizinhanças do nível de Fermi possam ser detectados. Quando a oxidação se dá na back-bond, as regiões apagadas e a assimetria do sinal de STM, obtido sobre condições de voltagem positiva, podem ser úteis na identificação de estruturas como 
aquelas denominadas $\mathrm{C}_{B B+H 2}$ e $\mathrm{C}_{B B}$.

Por fim, esperamos que este trabalho possa motivar estudos experimentais sobre os estágios iniciais de decomposição de moléculas de água sobre esta superfície, fenômeno sobre o qual muitas questões permanecem sem respostas. Também temos a expectativa de que os resultados apresentados aqui possam ser úteis na interpretação dos resultados já existentes. 


\section{Capítulo 7}

\section{Conclusões}

Neste trabalho estudamos processos de absorção de água em superfícies de silício, simulando os estágios iniciais de oxidação molhada, focalizando as superfícies $\operatorname{Si}(100)$ limpa e monohidrogenada. Nossa estratégia foi extrair, de dados experimentais de literatura, as possíveis configurações estáveis da situação oxidada, ou seja, a molécula já dissociada e o átomo de oxigênio já inserido na primeira camada da superfície, sendo os dois átomos de hidrogênio também inseridos, ou com uma molécula residual de hidrogênio. Jás configurações prováveis para a aproximação da molécula à superfície foram simuladas desde o início, dada a inexistência de dados experimentais. Apenas essa escolha de configuração inicial foi realizada utilizando métodos empíricos de dinâmica molecular clássica. Todos os demais resultados foram obtidos utilizando métodos quânticos de estado-da-arte da estrutura eletrônica, no formalismo de Teoria do Funcional da Densidade - DFT, com dois funcionais ab initio diferentes para o termo de troca e correlação. As simulações foram realizadas para a superfície estendida, com condições periódicas de contorno, no modelo de fatias,

e com células laterais de diferentes dimensões dependendo do caso específico. A densidade eletrônica foi expandida em ondas planas, e o tratamento dos caroços atômicos foi aproximado pelo modelo de pseudopotenciais.

Para a superfície limpa, estudamos configurações de formação de silanol superficial ( $\left.\mathrm{H}-\mathrm{Si}-\mathrm{Si}-\mathrm{OH}, \mathrm{C}_{C-S i l}\right)$, e ainda a passagem do átomo de oxigênio à configuração 
intersticial aos átomos do dímero afetado, "on-dimer" ( $\left.\mathrm{H}-\mathrm{Si}-\mathrm{O}-\mathrm{Si}-\mathrm{H}, \mathrm{C}_{C-O D}\right)$, e à situação subsuperficial "back-bond" (H-Si-Si $\left.(\mathrm{O})-\mathrm{H}, \mathrm{C}_{C-B B}\right)$. Nossos resultados mostraram que a interação dissociativa entre a molécula de água e a superfície $\operatorname{Si}(100)(2 \mathrm{x} 1)$ independe do sítio de ataque. A presença da molécula foi suficiente para promover a inversão de posição entre os átomos de $\mathrm{Si}_{\text {up }}$ e $\mathrm{Si}_{\text {down }}$ sem que houvesse uma barreira de energia associada a este processo. A quimissorção procedeu através da adsorção molecular e posterior formação de unidades $\mathrm{C}_{C \text {-Sil }}$, isto é, este processo foi mediado por um precursor molecular responsável pela interação correlacionada entre a molécula e a superfície, em conformidade com os resultados experimentais. A investigação das possíveis rotas de dissociação das espécies $\mathrm{C}_{C-S i l}$ evidenciaram que a oxidação dos dímeros $\mathrm{C}_{C-O D}$ é energética e cineticamente favorável em relação à oxidação da back-bond $\mathrm{C}_{C-B B}$. Estes resultados corroboram dados experimentais de Weldon e colaboradores [128] e encontram-se em desacordo com os cálculos de aglomerados moleculares [137].

As configurações quimissorvidas principais na superfície $\mathrm{Si}(100)(2 x 1): H$, segundo os dados de literatura, foram por nós denominadas de $\mathrm{C}_{\text {Sil }}\left(\mathrm{H}_{2} \mathrm{Si} \cdot \cdots \mathrm{H}-\mathrm{Si}-\mathrm{OH}\right)$ quando ocorre a quebra de um dímero com saturação completa dos dois átomos de $\mathrm{Si}$, e uma terminação silanol permanece na superfície; $\mathrm{C}_{B B}\left(\mathrm{H}_{2} \mathrm{Si} \cdots \mathrm{Si}(\mathrm{O}) \mathrm{H}_{2}\right)$ quando a quebra do dímero também ocorre, mas as terminações superficiais são dihidrogenadas e o átomo de oxigênio está subsuperficial, na "back-bond" do silício. Estudamos ainda configurações sem ruptura de dímero, $\mathrm{C}_{B B+H 2}$, com o átomo de oxigênio na "back-bond" e uma molécula de $\mathrm{H}_{2}$ residual $\left(\mathrm{H}-\mathrm{Si}-\mathrm{Si}(\mathrm{O}) \mathrm{H}+\mathrm{H}_{2}\right)$; e finalmente, a configuração $\mathrm{C}_{O D}$ com o átomo de oxigênio interticial aos átomos do dímero, "ondimer", e uma molécula de $\mathrm{H}_{2}$ residual ( $\left.\mathrm{H}-\mathrm{Si}-\mathrm{O}-\mathrm{Si}-\mathrm{H}+\mathrm{H}_{2}\right)$. Em ordem crescente de energia de ligação dos cálculos LDA-PZ, os defeitos foram: $\mathrm{C}_{B B+H 2}, \mathrm{C}_{S i l}, \mathrm{C}_{B B} \mathrm{e}$ $\mathrm{C}_{O D}$. Com o funcional GGA-PW91, obtivemos: $\mathrm{C}_{S i l}, \mathrm{C}_{B B+H 2}, \mathrm{C}_{B B}$ e $\mathrm{C}_{O D}$.

A reação com a molécula de água é dificultada, mas não impedida pelo processo de passivação da superfície $\operatorname{Si}(100)(2 \times 1): H$, uma vez que as barreiras de reação demonstram tratar-se de um processo factível. A reação que culmina com a pro- 
dução de $\mathrm{C}_{\text {Sil }}$ guarda algumas semelhanças com a dissociação da molécula de água na superfície limpa. Também aqui, o ataque oxidativo mostrou-se independente da posição na qual a molécula se aproxima dos átomos de Si que compõem o dímero: seja por sobre a fileira de dímeros (P1) ou na região de vale (P2). Notamos ainda que a interação com a supefície ocorre de forma correlacionada, com adsorção molecular e posterior dissociação.

A rota de oxidação que tem sido proposta nos trabalhos experimentais $\mathrm{C}_{S i l} \rightarrow$ $\mathrm{C}_{B B}$, segundo nossos resultados não é cineticamente viável. A formação de $\mathrm{C}_{\text {Sil }}$ está associada a uma barreira de energia que pode ser vencida termicamente nas condições experimentais, mas sua conversão em $\mathrm{C}_{B B}$, conforme sugerido, deve superar uma barreira de reação alta o suficiente para coibir ou restringir drasticamente sua produção. Dada a baixa probabilidade de se explicar os fenômenos oxidativos na superfície passivada através da conversão de $\mathrm{C}_{S i l}$ em $\mathrm{C}_{B B}$, apresentamos duas novas rotas de oxidação, que, segundo nossos cálculos, podem ser alternativas viáveis. Uma delas é a oxidação do dímero. Neste caso, detectamos que existem duas barreiras de energia a serem vencidas para a formação de $\mathrm{C}_{O D}$. A primeira delas e a de mais alta energia está relacionada à formação de $\mathrm{C}_{\text {Sil }}$, que ocorre espontaneâmente, sem qualquer imposição a priori, o que a caracteriza como caminho natural de inserção. Mostramos que o segundo passo desta reação (isto é, a inserção do O no dímero) é um processo para o qual temos redução da ordem de $56 \%$ na altura da barreira de energia associada à produção de $\mathrm{C}_{S i l}$. Assim, a conversão de $\mathrm{C}_{S i l}$ em $\mathrm{C}_{O D}$ é um evento cineticamente favorecido.

A quimissorção direta do oxigênio na back-bond, mas preservando a ligação SiSi do dímero oxidado (estrutura denominada $\mathrm{C}_{B B+H_{2}}$ ) resulta cineticamente mais viável inclusive que a produção de $\mathrm{C}_{\text {Sil }}$. Neste caso, nossos resultados indicam uma reação interessante, por ser dependente da posição de ataque à superfície.

As alternativas: $\mathrm{C}_{B B+H 2} \rightarrow \mathrm{C}_{B B}$ ou $\mathrm{C}_{O D} \rightarrow \mathrm{C}_{B B}$ também são inviáveis. Assim, os dados mostram que, nas condições experimentais, se houver inserção de $\mathrm{O}$ em sítios de back-bond, é mais provável que a estrutura $\mathrm{C}_{B B+H 2}$ seja formada. 
Como análise final dos sistemas estudados, simulamos os mapas obteníveis através de microscopia de tunelamento - STM para as estruturas quimissorvidas, tanto na superfície limpa como na hidrogenada. As alterações do perfil de corrente de tunelamento nas regiões afetadas pelos defeitos constituem uma forma eficiente e direta de estudo de reconhecimento do sítio oxidado. Nossas análises demonstram que, especialmente para as superfícies passivadas, o estudo do sinal de STM em regime de voltagem positiva pode ser bastante adequado na identificação de produtos da oxidação.

A identificação do sítio oxidado é na maioria das vezes bastante fácil, e deve ser baseada não na localização do átomo de oxigênio em si, mas na alteração local do padrão da superfície original, com assimetrias características. Esperamos que nosso trabalho seja, assim, útil na análise de superfícies de Si em fase inicial de oxidação. 


\section{Apêndice A}

\section{Taxas de reação e Lei de Arrhenius}

Em geral, a velocidade de reação ou taxa de reação entre dois reagentes $[A]$ e $[B]$ pode ser escrita como (A.1):

$$
v=k(T)[A]^{a}[B]^{b}
$$

na qual o coeficiente $k$, normalmente espresso em unidades de inverso de segundos $\left(\mathrm{s}^{-1}\right)$, é denominado de constante de velocidade ou constante de taxa de reação. Este coeficiente não depende da concentração de reagentes, mas tem dependência na temperatura. Para muitas reações, a dependência de $k \times 1 / \mathrm{T}$ é experimentalmente determinada como sendo linear. Esta espressão conhecida como Lei de Arrhenius [164] e é espressa como (A.2):

$$
\ln k=\ln A-\frac{E a}{K_{B}} \frac{1}{T} \Longrightarrow k=A e^{\frac{-E_{a}}{K_{B} T}} \Longrightarrow k=\frac{K_{B} T}{h} e^{\frac{-E_{a}}{K_{B} T}}
$$

onde $\mathrm{T}$ é a temperatura, $\mathrm{K}_{B}$ é a constante de Boltzmann, $\mathrm{E}_{a}$ é a energia de ativação, $h$ é a constante de Planck e $A$ é o fator de frequência, também espresso em unidades de $\mathrm{s}^{-1}$. Podemos assumir que o fator de frequência $A$ (ponto onde a reta intercepta o eixo das ordenadas) expressa o número de vezes em que os reagentes [A] e [B] encontram-se em uma situação de contato que tende para a configuração do estado de transição. Neste caso, pequenas oscilações em torno desta configuração irão determinar se os reagentes ultrapassarão a barreira de reação $\mathrm{E}_{a}$ ou voltarão às 
suas configurações iniciais. A fração das colisões que têm energia maior $\mathrm{E}_{a}$ é determinada pela distribuição de Boltzmann. Ou seja, o produto $A$ pela distribuição de Boltzmann é uma medida do número de "colisões" entre [A] e [B] que têm energia suficiente para ultrapassar a barreira de reação e formar os produtos. Nós sempre assumimos que o valor do fator de frequência $A$ de $\approx 6,93 \times 10^{+13} \mathrm{~s}^{-1}[91,92]$. Este valor é sugerido como sendo razoável para reações de quimissorção, como sugerido no capítulo 25 da referência [164].

Utilizamos a equação A.2 para estimar a temperatura para qual os produtos podem ser formados, dada uma energia de ativação $\mathrm{E}_{a}$. Neste caso, assumimos que $\mathrm{k}(\mathrm{T})=1$. 


\section{Bibliografia}

[1] R. L. McCreery e A. J. Bergren. Adv. Mater. 21, 4303 (2009).

[2] G. F. Cerofolini e E. Romano. Appl. Phys. A 91, 181 (2008).

[3] D. K. Aswal, S. Lenfant, D. Guerin, J. V. Yakhmi e D. Vuillaume. Anal. Chim. Acta 568, 84 (2006).

[4] S. A. DiBenedetto, A. Facchetti, M. A. Ratner e T. J. Marks. Adv. Mater. 21, 1407 (2009).

[5] D. J. Michalak, S. R. Amy, D. Aureau, M. Dai, A. EstẤlève e Y. J. Chabal. Nature Materials 9, 266 (2010).

[6] A. Ng, S. Ciampi, M. James, J. B. Harper e J. J. Gooding. Langmuir 25, 13934 (2009).

[7] A. Zeira, D. Chowdhury, S. Hoeppener, S. Liu, J. Berson, S. R. Cohennd R. Maoz e J. Sagiv. Langmuir 25, 13984 (2009).

[8] D. Riedel, M-L. Bocquet, H. Lesnard, M. Lastapis, N. Lorente, P. Sonnet e G. Dujardin. J. Am. Chem. Soc. 131, 7344 (2009).

[9] H. Sano, T. Yaku, T. Ichii, K. Murase e H. Sugimura. J. Vac. Sci. Technol B 27, 858 (2009).

[10] M. Yang, D. Wouters, M. Giesbers, U. S. Schubert e H. Zuilhof. ACSNano 3, 2887 (2009). 
[11] J. C. Ho, R. Yerushalmi, Z. A. Jacobson, Z. Fan, R. L. Alley e A. Javey. Nature Materials 7, 62 (2008).

[12] S-Y. Ku, K-T. Wong e A. J. Bard. J. Am. Chem. Soc. 130, 2392 (2008).

[13] P. G. Piva, R. A. Wolkow e G. Kirczenow. Phys. Rev. Lett. 101, 106801 (2008).

[14] I. Magid, L. Burstein, O. Seitz, L. Segev, L. Kronik e Y. Rosenwaks. J. Phys. Chem. C 112, 7145 (2008).

[15] C. S. Cucinotta, A. Ruini, E. Molinari, C. A. Pignedoli, A. Catellani e M. J. Caldas. J. Phys. Chem. C 112, 10167 (2008).

[16] M. J. Caldas, A. Calzolari e C. S. Cucinotta. J. Appl. Phys. 101, 081719 (2007).

[17] J. Chai, D. Wang, X. Fan e J. M. Buriak. Nature Nanotech. 2, 500 (2007).

[18] R. Chen, H. Kim, P. C. McIntyre e S. F. Bent. Chem. Mater. 17, 536 (2005).

[19] G. F. Cerofolini, G. Galati, S. Reina, L. Renna, D. Jones e V. Palermo. Appl. Surf. Sci. 252, 602 (2005).

[20] M. Chandross, E. B. Webb III, M. J. Stevens, G. S. Grest e S. H. Garofalini. Phys. Rev. Lett. 93, 166103 (2004).

[21] S. F. Bent. Surf. Sci. 500, 879 (2002).

[22] A. Calzolari, A. Ruini, E. Molinari e M. J. Caldas. Phys. Rev. B 73, 125420 (2006).

[23] H. Mizuno e J. M. Buriak. J. Am. Chem. Soc. 130, 17656 (2008).

[24] H. Mizuno e J. M. Buriak. Appl. Mat. Interf. 1, 2711 (2009). 
[25] M. H. Park, Y. J. Jang, H. M. Sung-Suh e M. M. Sung. Langmuir 20, 2257 (2004).

[26] J. M. Buriak. Chem. Rev. 102, 1272 (2002).

[27] O. Seitz, M. Dai, F. S. Aguirre-Tostado, R. M. Wallace e Y. J. Chabal. J. Am. Chem. Soc. 131, 1859 (2009).

[28] M. Coll, L. H. Miller, L. J. Richter, D. R. Hines, O. D. Jurchescu, N. GergelHackett, C. A. Richter e C. A. Hacker. J. Am. Chem. Soc. 131, 12451 (2009).

[29] S. K. Gupta, S. P. Koiry, A. K. Chauhan, N. Padma, D.K. Aswal e J. V. Yakhmi. Appl. Surf. Sci. 256, 407 (2009).

[30] H. Asanuma, H. Noguchi, Y. Huang, K. Uosaki e H-Z. Yuand. J. Phys. Chem. C 113, 21139 (2009).

[31] E. Biavardi, M. Favazza, A. Motta, I. L. Fragalà, C. Massera, L. Prodi, M. Montalti, M. Melegari, G. G. Condorelli e E. Dalcanale. J. Am. Chem. Soc. 131, 7447 (2009).

[32] Y. Ito, A. A. Virkar, S. Mannsfeld, J. H. Oh, M. Toney, J. Locklin e Z. Bao. J. Am. Chem. Soc. 131, 9396 (2009).

[33] Y. Paska e H. Haick. Appl. Phys. Lett. 95, 233103 (2009).

[34] E. C. P. Smits, S. G. J. Mathijssen, P. A. van Hal, S. Setayesh, T. C. T. Geuns, K. A. H. A. Mutsaers, E. Cantatore, H. J. Wondergem, O. Werzer, R. Resel, M. Kemerink, S. Kirchmeyer, A. M. Muzafarov, S. A. Ponomarenko, B. de Boer, P. W. M. Blom e D. M. de Leeuw. Nature 455, 956 (2008).

[35] N. Gergel-Hackett, C. D. Zangmeister, C. A. Hacker, L. J. Richter, C. A. Richter, N. Gergel-Hackett, C. D. Zangmeister, C. A. Hacker, L. J. Richter e C. A. Richter. J. Am. Chem. Soc. 130, 4259 (2008). 
[36] T. Bocking, A. Salomon, D. Cahen e J. J. Gooding. Langmuir 23, 3236 (2007).

[37] O. Seitz, T. Bocking, A. Salomon, J. J. Gooding e D. Cahen. Langmuir 22, 6915 (2006).

[38] S. Bent. ACSNano 1, 10 (2007).

[39] K. Funato, N. Shirahata e Yoshiko Miura. Thin Sol. Films 518, 699 (2009).

[40] X. Zhang, S. Kumar, J. Chen e A. V. Teplyakov. Surf. Sci. 603, 2445 (2009).

[41] J. A. Martinez, N. Misra, Y. Wang, P. Stroeve, C. P. Grigoropoulos e A. Noy. Nano Lett. 9, 1121 (2009).

[42] A. Cattani-Scholz, D. Pedone, M. Dubey, S. Neppl, B. Nickel, P. Feulner, J. Schwartz, G. Abstreiter e M. Tornow. ACSNano 2, 1653 (2008).

[43] H. IM, X-J. HUANG, B. GU e Y-K. CHOI. Nature Nanotech. 2, 430 (2007).

[44] G. F. Cerofolini, C. Galati, S. Reina, L. Renna, N. Spinella e G. G. Condorelli. Phys. Rev. B 74, 235407 (2006).

[45] A. S. Baluch, N. P. Guisinger, R. Basu, E. T. Foley e M. C. Hersam. J. Vac. Sci. Technol A - Letters 22 (2004).

[46] M. Born e J. R. Oppenheimer. Adv. Phys. 84, 457 (1927).

[47] J. Kohanoff. Electronic Structure Calculations for Solids and Molecules - Theory and Computational Methods. Cambridge Universtiy Press, (2006).

[48] H. Hellmann. Einfuhrung in die quantumchemie. Deutsche, Liepzig, (1937).

[49] R. P. Feynman. Phys. Rev. 56, 340 (1939).

[50] L. H. Thomas. Proc. Camb. Phil. Soc. 23, 542 (1927).

[51] E. Fermi. Z. Phys. 48, 73 (1928). 
[52] J. D. M. Vianna, A. Fazzio e S. A. Canuto. Teoria Quântica de Moléculas e Sólidos. Editora Livraria da Física, (2004).

[53] P. Hohenberg e W. Kohn. Phys. Rev. B 136, 864 (1964).

[54] W. Kohn e L.J. Sham. Phys. Rev. A 140, 1133 (1965).

[55] R. M. Martin. Electronic Structure - Basic Theory and Practical Methods. Cambridge Universtiy Press, (2004).

[56] D. M. Ceperley e B. J. Alder. Phys. Rev. Lett. 45, 566 (1980).

[57] J. P. Perdew e A. Zunger. Phys. Rev. B 23, 5048 (1981).

[58] J. P. Perdew, K. Burke e M. Ernzerhorf. Phys. Rev. Lett. 77, 3865 (1996).

[59] J. P. Perdew e Y. Wang. Phys. Rev. B 45, 13244 (1992).

[60] H. J. Monkhorst e J. D. Pack. Phys. Rev. B 13, 5188 (1976).

[61] N. Troullier e J. L. Martins. Phys. Rev. B 43, 1993 (1991).

[62] A. M. Rappe, M. Rabe, E. Kaxiras e J. D. Joannopoulos. Phys. Rev. B 41, 1227 (1990).

[63] D. Vanderbilt. Phys. Rev. B 41, 7892 (1990).

[64] P. Giannozzi, S. Baroni, N. Bonini, M. Calandra, R. Car, C. Cavazzoni, D. Ceresoli, G. L. Chiarotti, M. Cococcioni, I. Dabo, A. Dal Corso, S. de Gironcoli, S. Fabris, G. Fratesi, R. Gebauer, U. Gerstmann, C. Gougoussis, A. Kokalj, M. Lazzeri, L. Martin-Samos, N. Marzari, F. Mauri, R. Mazzarello, S. Paolini, A. Pasquarello, L. Paulatto, C. Sbraccia, S. Scandolo, G. Sclauzero, A. P. Seitsonen, A. Smogunov, P. Umari e R. M. Wentzcovitch. J. Phys.: Condens. Matter 21, 395502 (2009). 
[65] G. Henkelman. Methods for Calculating Rates of Transitions with Application to Catalysis and Crystal Growth. Tese de doutoramento, Chemistry Departament of University of Washington - Graduate School, Washington, (2001).

[66] B. J. Berne, G. Ciccotti e D. F. Coker. Classical and Quantum Dynamics in Condensed Matter Phase Simulations. World Scientific Books, (1998).

[67] G. Henkelman, B. P. Uberuaga e H. Jósson. J. Chem. Phys. 113, 9901 (2000).

[68] G. Henkelman, G. Jóhannesson e H. Jósson. Progress on Theoretical Chemistry and Physics. Kluwer Academic, (2000).

[69] G. Henkelman e H. Jósson. J. Chem. Phys. 113, 9978 (2000).

[70] B. Santra, A. Michaelides, M. Fuchs, A. Tkatchenko, C. Filippi e M. SchefiňĆer. J. Chem. Phys. 129, 194111 (2008).

[71] G. Binnig, H. Rohrer, Ch. Gerber e E. Weibel. Appl. Phys. Lett. 40, 178 (1982).

[72] G. Binnig, H. Rohrer, Ch. Gerber e E. Weibel. Phys. Rev. Lett. 49, 57 (1982).

[73] G. Binnig e H. Rohrer. Surf. Sci. 126, 236 (1983).

[74] A. Zangwill. Physics At Surfaces. Cambridge University Press, (1990).

[75] J. Tersoff e D. R. Hamann. Phys. Rev. B 31, 805 (1985).

[76] J. Bardeen. Phys. Rev. Lett. 6, 57 (1961).

[77] G. P. Srivastava. Rep. Prog. Phys. 60, 561 (1997).

[78] P. Kruger e H. Pollmann. Phys. Rev. Lett. 74, 1155 (1995).

[79] R. A. Wolkow. Phys. Rev. Lett. 68, 2636 (1992).

[80] A. W. Munz, Ch. Ziegler e W. Gopel. Phys. Rev. Lett. 74, 2244 (1995). 
[81] R. J. Hamers, R. M. Tromp e J. E. Demuth. Phys. Rev. B 34, 5343 (1986).

[82] R. J. Hamers, Ph. Avouris e F. Bozso. Phys. Rev. Lett. 59, 207 (1987).

[83] R. J. Hamers, Ph. Avouris e F. Bozso. J. Vac. Sci. Technol A 6, 508 (1988).

[84] H. N. Waltenburg e J. T. Yates. Chem. Rev. 95, 1589 (1995).

[85] J. Yoshinobu. Prog. Surf. Sci. 77, 37 (2004).

[86] R. J. Hamers e Y. Wang. Chem. Rev. 96, 1261 (1996).

[87] R. Felici, I. K. Robinson, C. Ottaviani, P. Imperatori, P. Eng e P. Perfetti. Surf. Sci. 375, 55 (1997).

[88] T. Uozumi, Y. Tomiyoshi, N. Suehira, Y. Sugawara e S. Morita. Appl. Surf. Sci. 188, 279 (2002).

[89] T. Uda, H. Shigekawa, Y. Sugawara, S. Mizuno, H. Tochihara, Y. Yamashita, J. Yoshinobu, K. Nakatsuji, H. Kawai e F. Komori. Prog. Surf. Sci. 76, 147 (2004).

[90] R. Konecny e D. J. Doren. J. Chem. Phys. 106, 2426 (1997).

[91] J-H. Cho, K. S. Kim, S-H. Lee e M-H. Kang. Phys. Rev. B 61, 4503 (2000).

[92] R. D. Smardon e G. P. Srivastava. Surf. Sci. 584, 161 (2005).

[93] A. I. Shkrebtii, R. Di Felice, C. M. Bertoni e R. Del Sol. Phys. Rev. B 51, 11201 (1995).

[94] T. Tabata, T. Aruga e Y. Murata. Surf. Sci. Lett. 179 (1987).

[95] L. Andersohn e U. Kohler. Surf. Sci. 284, 77 (1993).

[96] A. J. Mayne, D. Riedel, G. Comtet e G. Dujardin. Prog. Surf. Sci. 81, 1 (2006). 
[97] Y. J. Chabal e K. Raghavachari. Phys. Rev. Lett. 54, 1055 (1985).

[98] J. J. Boland. Phys. Rev. Lett. 65, 3325 (1990).

[99] J. J. Boland. Phys. Rev. Lett. 67, 1539 (1991).

[100] J. J. Boland. Surf. Sci. 261, 17 (1991).

[101] J. J. Boland. Adv. Phys. 42, 129 (1993).

[102] V. A. Burrows, Y. J. Chabal, G. S. Higashi, K. Raghavachari e S. B. Christman. Appl. Phys. Lett. 53, 998 (1988).

[103] G. S. Higashi, Y. J. Chabal, G. W. Trucks e K. Raghavachari. Appl. Phys. Lett. 56, 656 (1990).

[104] Y. J. Chabal. Physica B 170, 447 (1991).

[105] P. Dumas, Y. J. Chabal e P. Jakob. Surf. Sci. 269, 867 (1992).

[106] J. E. Northrup. Phys. Rev. B 44, 1419 (1991).

[107] Y. Wang, M. J. Bronikowski e R. J. Hamers. J. Vac. Sci. Technol A 12, 2051 (1994).

[108] J. P. Perdew e Y. Wang. Phys. Rev. B 33, R8800 (1986).

[109] M. Takahasi, S. Nakatani, Y. Ito, T. Takahashi, X. W. Zhang e M. Ando. Surf. Sci. 338, 846 (1995).

[110] E. L. Bullock, R. Gunnella, L. Patthey, T. Abukawa, S. Kono, C. R. Natoli e L. O. Johansson. Phys. Rev. Lett. 74, 2756 (1995).

[111] S. J. Jenkins e G. P. Srivastava. J. Phys.: Condens. Matter 8, 6641 (1996).

[112] A. selloni, A. Vittadini e M. Casarin. Phys. Rev. B 52, 5885 (1995).

[113] T. Uchiyama e M. Tsukada. Phys. Rev. B 55, 9356 (1997). 
[114] J. Ciston, L. D. Marks, R. Feidenhans'l, O. Bunk, G. Falkenberg e E. M. Lauridsen. Phys. Rev. B 74, 085101 (2006).

[115] E. M. Lauridsen, J. Baker, M. Nielsen, R. Feidenhans'l, G. Falkenberg, O. Bunk, J. H. Zeysing e R. L. Johnson. Surf. Sci. 453, 18 (2000).

[116] B. Sandfort, A. Mazur e J. Pollmann. Phys. Rev. B 54, 8605 (1996).

[117] S. Pflanz, R. Buchtler e W. Moritz. Phys. Rev. B 54 (1996).

[118] G. Ranga Rao, Z-H Wang, H. Watanabe, M. Aoyagi e T. Urisu. Surf. Sci. 570, 178 (2004).

[119] Z-H Wang, T. Urisu, S. Nanbu, J. Maki, G. Ranga Rao, M. Aoyagi, H. Watanabe e K. Ooi. Phys. Rev. B 69, 045309 (2004).

[120] G. Ranga Rao. Bull. Mater. Sci. 27, 497 (2004).

[121] Z-H. Wang, T. Urisu, H. Watanabe, K. Ooi, G. Ranga Rao S. Nanbu, J. Maki e M. Aoyagi. Surf. Sci. 575, 330 (2005).

[122] E. A. Irene. J. Electrochem. Soc. 125, 1708 (1978).

[123] A. Hemeryck, A. J. Mayne, N. Richard, A. Estève, Y. J. Chabal, G. Dujardin e G. Comtet. J. Chem. Phys. 126, 114707 (2007).

[124] Y. J. Chabal. Phys. Rev. B 29, 3677 (1984).

[125] K. Raghavachari, Y. J. Chabal e L. M. Struck. Chem. Phys. Lett. 252, 230 (1996).

[126] L. M. Struck, J. Eng. Jr., B. E. Bent, G. W. Flynn, Y. J. Chabal, S. B. Christman. E. E. Chaban, K. Raghavachari, G. P. Willians, K. Radermacher e S. Mantl. Surf. Sci. 380, 444 (1997). 
[127] M. K. Weldon, K. T. Queeney, A. B. Gurevich, B. B. Stefanov, Y. J. Chabal e K. Raghavachari. J. Chem. Phys. 113, 2440 (2000).

[128] M. K. Weldon, B. B. Stefanov, K. Raghavachari e Y. J. Chabal. Phys. Rev. Lett. 79, 2851 (1997).

[129] B. B. Stefanov, A. B. Gurevich, M. K. Weldon, K. Raghavachari e Y. J. Chabal. Phys. Rev. Lett. 81, 3908 (1998).

[130] K. T. Queeney, M. K. Weldon, Y. J. Chabal e K. Raghavachari. J. Chem. Phys. 119, 2307 (2003).

[131] B. R. Trenhaile, A. Agrawal e J. H. Weaver. Appl. Phys. Lett. 89, 151917 (2006).

[132] S.-Y. Yu, H. Kim e J.Y. Koo. Phys. Rev. Lett. 100, 036107 (2008).

[133] M. Z. Hossain, Y. Yamashita, K. Mukai e J. Yoshinobu. Phys. Rev. B 67, 153307 (2003).

[134] B. B. Stefanov e K. Raghavachari. Surf. Sci. Lett. 389, 1159 (1997).

[135] B. B. Stefanov e K. Raghavachari. Appl. Phys. Lett. 73, 824 (1998).

[136] K. Seino e W. G. Schmidt. Surf. Sci. 571, 157 (2004).

[137] H. Watanabe, S. Nanbu, Z-H Wang e M. Aoyagi. Chem. Phys. Lett. 424, 133 (2006).

[138] A. Estéve, Y. J. Chabal, M. Weldon, K. T. Queeney e M. D. Rouhani. J. Appl. Phys. 90, 6000 (2001).

[139] S. Okano e A. Oshiyama. Surf. Sci. 554, 272 (2004).

[140] O. Warschkow, S. R. Schofield, N. A. Marks, M. W. Radny, P. V. Smith e D.R.McKenzie. Phys. Rev. B 77, 201305 (2008). 
[141] R. Lelis-Sousa e M. J. Caldas. AIP Conference Proceedings 1199, 9 (2009).

[142] K. Akagi, H. S. Kato, M. Kawai e S. Tsuneyuki. Surf. Sci. 587, 34 (2005).

[143] H. Watanabe, S. Nanbu, Z-H Wang, J. Maki, T. Urisu, M. Aoyagi e K. Ooi. Chem. Phys. Lett. 383, 523 (2004).

[144] A. K. Rappé e W. A. Goddard III. J. Phys. Chem. 95, 3358 (1991).

[145] A. K. Rappé, C. J. Casewit, K. S. Colwell, W. A. Goddard III e W. M. Skiff. J. Am. Chem. Soc. 114, 10024 (1992).

[146] M. J. Hwang, T. P. Stockfish e A. T. Hagler. J. Am. Chem. Soc. 116, 2515 (1994).

[147] N. A. Lima e M. J.Caldas. Phys. Rev. B 72, 033109 (2005).

[148] R. J. Baierle e M. J. Caldas. Int. J. of Mod. Phys. B 13, 2733.

[149] Y. J.Chabal, K. Raghavachari, X. Zhang e E. Garfunkel. Phys. Rev. B 66, 161315 (2002).

[150] T. Uchiyama e M. Tsukada. Surf. Sci. 313, 17 (1994).

[151] R. J. Hamers e U. K. Kohler. J. Vac. Sci. Technol A 7, 2854 (1989).

[152] D. B. Skliar e B. G. Willis. J. Phys. Chem. C 112, 9434 (2008).

[153] Y. Terada, B-K. Choi, S. Heike, M. Fujimori e T. Hashizume. Jpn. J. Appl. Phys. 42, 4739 (2003).

[154] K. Ohmori, H. Ikeda, H. Iwano, S. Zaima e Y. Yasuda. Appl. Surf. Sci. 117 (1997).

[155] H. Ikeda, K. Hotta, T. Yamada, S. Zaima e Y. Yasuda. J. Appl. Phys. 77, 5125 (1995). 
[156] H. Ikeda, K. Hotta, S. Furuta, S. Zaima e Y. Yasuda. Appl. Surf. Sci. 104 (1996).

[157] T. Miura, M. Niwano, D. Shoji e N. Miyamoto. J. Appl. Phys. 79, 4373 (1996).

[158] T. Takahagi, A. Ishitani, H. Kuroda, Y. Nagasawa, H. Ito e S. Wakao. J. Appl. Phys. 68, 2187 (1990).

[159] M. J. Caldas, R. J. Baierle, R. B. Capaz e E. Artacho. Physica B 308, 329 (2001).

[160] T. Uchiyama e M. Tsukada. Phys. Rev. B 55, 9356 (1997).

[161] J. T. Arantes, R. H. Miwa e T. M. Schmidt. Phys. Rev. B 70, 235321 (2004).

[162] Y. Miyamoto. Phys. Rev. B 46, 12473 (1992).

[163] A. Hemeryck, N. Richard, A. Estève e M. D-Rouhani. Surf. Sci. 601, 2339 (2007).

[164] P. Atkins e J. de Paula. Atkin's Physical Chemistry - 8th Edition. Oxford University Press, (2006). 